\title{
Stimulation of renal adrenergic mechanisms as a model for the development of hypertension
}

Citation for published version (APA):

Kleinjans, J. C. S. (1983). Stimulation of renal adrenergic mechanisms as a model for the development of hypertension. [Doctoral Thesis, Maastricht University]. Rijksuniversiteit Limburg. https://doi.org/10.26481/dis.19831021jk

Document status and date:

Published: 01/01/1983

DOI:

10.26481/dis.19831021jk

Document Version:

Publisher's PDF, also known as Version of record

\section{Please check the document version of this publication:}

- A submitted manuscript is the version of the article upon submission and before peer-review. There can be important differences between the submitted version and the official published version of record.

People interested in the research are advised to contact the author for the final version of the publication, or visit the DOI to the publisher's website.

- The final author version and the galley proof are versions of the publication after peer review.

- The final published version features the final layout of the paper including the volume, issue and page numbers.

Link to publication

\footnotetext{
General rights rights.

- You may freely distribute the URL identifying the publication in the public portal. please follow below link for the End User Agreement:

www.umlib.nl/taverne-license

Take down policy

If you believe that this document breaches copyright please contact us at:

repository@maastrichtuniversity.nl

providing details and we will investigate your claim.
}

Copyright and moral rights for the publications made accessible in the public portal are retained by the authors and/or other copyright owners and it is a condition of accessing publications that users recognise and abide by the legal requirements associated with these

- Users may download and print one copy of any publication from the public portal for the purpose of private study or research.

- You may not further distribute the material or use it for any profit-making activity or commercial gain

If the publication is distributed under the terms of Article $25 \mathrm{fa}$ of the Dutch Copyright Act, indicated by the "Taverne" license above, 
STIMULATION OF RENAL ADRENERGIC MECHANISMS AS A MODEL FOR THE DEVELOPMENT OF HYPERTENSION 
Omslag: Henk Thijssen, Meerssen. Typografie en druk: BV Leiter-Nypels, Maastricht 


\section{STIMULATION OF RENAL ADRENERGIC MECHANISMS AS A MODEL FOR THE DEVELOPMENT OF HYPERTENSION}

\section{PROEFSCHRIFT}

ter verkrijging van de graad van doctor in de geneeskunde aan de Rijksuniversiteit Limburg te Maastricht op gezag van de rector magnificus prof. dr. H.C. Hemker, volgens besluit van het College van Dekanen in het openbaar te verdedigen op vrijdag 21 oktober 1983 , 's middags om 16.00 uur, in de Aula van de Universiteit

\section{DOOR}

Joseph Catharina Stephanus Kleinjans

geboren te Sittard. 
Promotor: Prof. dr. H.A.J. Struyker Boudier

Referenten: Prof. dr. F.I.M. Bonke

Prof. dr. O. Heidenreich

Prof. dr. K.H. Rahn

Financial support by Squibb, Rijswijk, The Netherlands, and by the Netherlands Heart Foundation for the publication of this thesis is gratefully acknowledged. 


\section{DANKWOORD}

Het mag verondersteld worden dat men langzamerhand bekend is met het feit dat het verwaardigen van een proefschrift geenszins een individuele prestatie is. De komende pagina's leggen dan ook getuigenis af van de werkzaamheden op het dierexperimenteel laboratorium van de kapaciteitsgroep Farmakologie gedurende de afgelopen vier jaar, gezien door het vergrootglas van de auteur.

Ik dank iedereen die een aktieve bijdrage heeft geleverd bij het tot stand brengen van dit proefschrift en ik breng mijn waardering uit jegens de medewerkers van de kapaciteitsgroep Farmakologie voor de kollegiale sfeer waarbinnen dit heeft kunnen plaatsvinden. 



\section{CONTENTS}

1. Renal control of arterial blood pressure - an introduction 15 $\begin{array}{ll}\text { 1.1 Renal autoregulation } & 16\end{array}$

1.1.1 Autoregulation of renal blood flow 16

1.1.2 Autoregulation of glomerular filtration rate 17

1.1.3 Autoregulation of tubular reabsorption rate 18

1.2 Neurohumoral control of renal function 20

$\begin{array}{ll}1.2 .1 & \text { Influences of renal nerves } \\ 1.20\end{array}$

1.2.2 The renin-angiotensin system 23

1.2.3 The renal prostaglandin system 25

1.2.4 Other hormonal systems 27

1.3 Renal function in hypertension 29

1.3.1 The cascade theory of whole body autoregulation 29

1.3.2 Kidney function and experimental models of hypertension 30

1.3.3 Renal nerve activity and experimental hypertension 33

1.4 Chronic intrarenal infusion of noradrenaline -

a new hypertension model $\quad 34$

1.5 The present thesis. $\quad 36$

2. Chronic local infusion into the renal artery of unrestrained rats 39

2.1 introduction 39

2.2 Methods $\quad 39$

2.2.1 Construction of the catheters $\quad 39$

2.2.2 Animals 40

2.2.3 Catheter implantation $\quad 40$

2.2.4 Evaluation of renal function 42

2.2.5 Composition of experimental groups 42

2.3 Results $\quad 44$

2.4 Discussion 44

3. Blood pressure response to chronic low-dose intrarenal noradrenaline infusion in conscious rats $\quad 47$

$\begin{array}{ll}3.1 \text { Intraduction } & 47\end{array}$

3.2 Methods 48

3.3 Results 49

3.4 Discussion $\quad 52$ 
4. Determination of whole bode clearance and apparent release rate of noradrenaline during chronic noradrenaline infusion

$\begin{array}{ll}4.1 \text { Introduction } & 57\end{array}$

4.2 Methods 58

4.3 Results $\quad 59$

4.4 Discussion 59

5. Plasma renin activity measurements and effects of captopril during noradrenaline-induced hypertension

63

5.1 Introduction 63

5.2 Methods 63

5.2.1 Plasma renin activity measurements 63

5.2.2 Chronic captopril administration 64

5.3 Results 65

5.3.1 PRA measurements 65

5.3.2 Effect of converting enzyme blockade on NA-induced hypertension 65

5.4 Discussion

6. Renal function during acute and chronic intrarenal noradrenaline infusion: exclusion of acute renal failure

6.1 Introduction $\quad 75$

6.2 Methods 76

6.2.1 Acute effects of intrarenal NA infusion on renal blood flow 76

6.2.2 Chronic effects of intrarenal and intravenous NA infusion on renal function $\quad 77$

$\begin{array}{ll}6.3 \text { Results } & 78\end{array}$

6.3.1 Acute effects of intrarenal NA infusion on renal function 78

6.3.2 Chronic effects of intrarenal and intravenous NA infusion on renal function 78

6.4 Discussion

7. Acute and chronic effects of intrarenal noradrenaline infusion on central hemodynamics

$\begin{array}{ll}7.1 \text { Introduction } & 87\end{array}$

7.2 Methods 88

7.2.1 Acute hemodynamic measurements 88

7.2.2 Long-range hemodynamic measurements 89

$\begin{array}{ll}7.3 \text { Results } & 89\end{array}$

7.3.1 Acute effects of NA on central hemodynamics 89

7.3.2 Chronic effects of NA on central hemodynamics 92

7.4 Discussion 
8. Body fluid and salt load as function of intake and output during chronic intrarenal infusion of noradrenaline

8.1 Introduction

8.2 Methods

8.3 Results

8.4 Discussion

9. General discussion and conclusions

Appendix: Arterial pressure variability during hypertension induced by chronic intravenous infusion of noradrenaline

A. 1 Introduction

A.2 Methods

A.3 Results

A.4 Discussion

References 



\section{PROLOGUE}

Science reflects the human necessity of thinking. Consequently, it possesses an intrinsic warrant. Science qualifies itself by its methodology: the ideology by which knowledge can develop in a justified manner.

The classic empiric view of Bacon and Hume - and of their twentieth. century alternatives of the Wiener Kreis - bases knowledge on elementary observations. The obvious methodology is the step-like scheme of perceiving, reasoning, perceiving, etc. The hypothesis of the foundation of knowledge on elementary observations implies that postulations can be verified by means of the empiric and logic activity.

Popper (Objective knowledge, 1972) challenges the primary of observation on the arguments that scientists do not gather sensory experiences randomly but that they are guided by certain notions or presumptions; secondly, that scientists are restricted in their observations and that the verification of a postulation can therefore never be based on an infinite number of empiric activities; and thirdly, that various theoretical terms as 'receptor', 'energy', and 'neurohumoral factor' hardly refer to sensory perception. Popper states that scientific theories must enable criticism, never can be verified but only falsified. Acceptation of a falsificator implies rejection of a theory and new concepts have to be formed.

His last statement is that the empiric activity is a function of the knowledge which is already possessed. Observations are mediated by a variety of presumptions, theories and knowledge (for instance about the used measuring instruments) altogether forming the epistemological field of knowledge. This implies that both verification and falsification are theory-dependent procedures.

If it is accepted that observations are a function of the epistemological field, two alternatives can be considered at the moment when a certain fact is not in conformity with a theory: the theory may be rejected, or when the theory is attractive because of its explanation for a greater variety of phenomena, an ad hoc hypothesis may be formulated which for instance makes the fact lesser compelling. Eventually, as Lakatos describes (Proofs and refutations, 1976), such a theory can be protected by a shield of ad hoc hypotheses. The methodology of Popper does not explain why a theory is sustained despite of numerous refutations.

The solution to this problem is that a scientific discipline which is a population of concepts, develops within an ecological niche, as Toulmin calls it (Human Understanding, 1972). This ecological niche is determined by intrinsic factors, thus the scientific methodology, and extrinsic factors which are imposed by the economic, social and cultural context.

For instance, the Cartesian progress of objectivation of life, which gave way 
to the study of living as well as dead matter dominated by the law of nature, was an epistemological rupture not restricted only to science but inspired by the whole of occidental culture which replaced hierarchical analogy by analysis, as Foucault shows (Les mots ef les choses, 1966).

And it is the impact of the ecological niche of a population of investigators which selects between the methodological alternatives of refuting a theory or supporting it with the help of ad hoc hypotheses. Only those concepts which comply with both the intrinsic and extrinsic terms, are accepted to evaluate a theory.

This implies that the changes in the way scientists regard nature, which Kuhn calls the scientific revolutions (The structure of scientific revolutions, 1962) appear not that drastic when also the extrinsic factors which determine the ecological niche are taken into account. This also implies the possiblity that the selection criteria which choose between conceptions are not intrinsic to the scientific discipline and therefore not independent. Since the selection criteria are a function of the social context which gradually changes, they have to be adapted constantly.

The establishment of the selection criteria at a given point of time is controlled by the hierarchy within the population of investigators. This hierarchical supervision does not necessarilly ly with a subgroup of internationally recognized investigators who possess the power to judge and select. In the view of Foucault, power is not demonstrable. Invisibility has been granted to power by focussing the attention on the less powerful, who become objects of power. Power deals with relations, more or less organized, more or less coordinated (Surveillir et punir, 1975). The strategics of power can be visualized by studying its techniques on the level of the smallest mechanisms e.g. the acceptance or refutation of a concept. The way wich a concept traverses through the scientific discipline may be of more interest than the concept itself.

In hypertension research, Guyton's systems analysis approach based on the earlier concepts of Borst to explain long-term arterial pressure regulation has been widely acknowledged. The theory of development and maintenance of chronic hypertension is based on two concepts: in the first place, it situates the origin of hypertension within the kidney by stating that an initial shift of the renal function curve which relates arterial pressure to urine output, to higher levels of arterial pressure, is necessary in order to sustain chronic hypertension; in the second place, that this shift of the renal function curve leads to a state of hypervolemia and increased cardiac output which elevates vascular resistance reflexively by means of the autoregulation mechanism. For detalled discussion of this hypertension theory is referred to the General Introduction. In recent years, it has been indicated in various animal hypertension models which primarily interfere with renal function that there exists no hypervolemic stage in the development of hypertension. However, the theory has not been rejected.

This thesis sets out to evaluate the Borst-Guyton theory with regard to its 
two concepts. In the following chapters, it will be shown that hypertension may originate within the kidney. However, it will be proven that hypertension can be induced by initial changes in renal function without any volume dependency. The experiments leading to this conclusions, were undertaken in full recognition of the demands intrinsic to the scientific discipline, as will be shown in the next chapters. However, the scope of this thesis on longer term may be that it enables us to follow its course through the epistemological field and thereby, to envisage the strategics of science once more. 


\section{RENAL CONTROL OF ARTERIAL BLOOD PRESSURE - AN INTRODUCTION}

The fundamental role of renal function in arterial blood pressure regulation has been acknowledged over the years. Selkurt (1951) observed in anesthetized dogs that if arterial pressure is raised acutely by $29 \%$ while renal blood flow and glomerular filtration rate do not change, output of urine increases markedly by $65 \%$; and conversely, when arterial pressure is reduced, water and salt excretion is decreased by the kidney. As indication of the impact of this so-called pressure-diuresis phenomenon: when arterial pressure is elevated acutely by expanding the blood volume in decapitated dogs from normotensive values of $100 \mathrm{mmHg}$ to $200 \mathrm{mmHg}$, output of water and electrolytes increases 12-fold (Guyton et al, 1981a). Furthermore, it has been shown that sodium intake up to 8 times normal for weeks in men does not elevate arterial pressure while the sodium output from the kidneys increases steeply (Guyton et al, 1980). Increasing the sodium intake 10 times above normal elevates arterial pressure only by 17 $\mathrm{mmHg}$ and is also associated with tremendous increase of urinary salt excretion (Murray et al, 1978). Loss of fluid and salt and thereby decrease of extracellular fluid volume declines arterial blood pressure and this is maintained until arterial blood pressure has returned to its original level (Borst and Borst-De Geus, 1963; Guyton et al, 1974; Struyker Boudier and Rahn, 1979). This feature of the renal hydraulic mechanism is called "infinite gain" which differentiates it from other blood pressure regulating systems, e.g. the baroreceptor control mechanism which has a finite gain possibly due to its adaptation to changed pressure within seconds (Eckberg, 1977) to days (Guyton et al, 1981b) and may sustain blood pressure at its deviant level.

The pressure level at which the renal hydraulic mechanism controls arterial pressure may be influenced by a variety of factors, intrinsic or extrinsic to the kidney. Urine output is determined by the difference between glomerular filtration rate and tubular reabsorption rate. Any factor which influences the relationship between arterial blood pressure and glomerular filtration rate, or arterial blood pressure and tubular reabsorption rate can affect the pressure control level of the renal function curve relating arterial pressure to urine output (Guyton et al, 1974).

Such factors are for instance neurohumoral agents as catecholamines, angiotensin II, aldosterone, antidiuretic hormone and prostaglandines; they are discussed below in their specific role of changing renal function primarily and leading to chronic hypertension eventually. These substances, however, add their actions to a regulation mechanism which is intrinsic to the kidney and known as renal autoregulation. 


\subsection{Penal autoregulation}

Under normal conditions, renal blood flow, glomerular filtration rate and tubular sodium reabsorption rate are kept remarkably constant, despite of variations in mean arterial pressure thanks to a phenomenon which is called "renal autoregulation".

\subsubsection{Autoregulation of renal blood flow}

Constancy of renal blood flow is maintained by adaptations in renal vascular resistance to changes in renal perfusion pressure; autoregulation of renal blood flow is, in principle, independent of neurohumoral factors and an intrinsic characteristic of the renal vascular bed. Various mechanisms have been proposed to explain this autoregulation capacity (Stein, 1976; Renkin and Gilmore, 1976) but nowadays the myogenic theory of autoregulation of renal blood flow has been accepted (Folkow, 1982). This theory was originally formulated by Bayliss (1902) who postulated vasodilatation of the hind limb of dog and cat in response to decreased perfusion pressure, in order to restore blood flow, which has been considered to be a general feature of vascular tissue since. It is hypothesized that a decrease in the transmural pressure gradient occurring when intravascular pressure decreases and extravascular pressure remains constant " will lead to a decrease in wall tension and to vasodilatation. This theory finds support by the observation that autoregulation is decreased during intrarenal infusion of papaverine or procaine which agents paralyze smooth muscle (Baer et al, 1970; Stein, 1976).

Myogenic autoregulation should be regarded as superimposed on the tubuloglomerular feadback mechanism within the macula densa (Folkow, 1982). It is suggested that changes in renal blood flow, and consequently changes in glomerular filtration rate (see below), alter the distal tubular load of sodium chloride which is sensored by the macula densa region lying in close association with this tubular segment (Fig. 1.1). Then, the macula densa triggers the juxtaglomerular apparatus to adapt the release of renin, and thereby the synthesis of angiotensin II which is capable of potent vasoconstriction. However, there is considerable controversy concerning the way by which the macula densa is stimulated by sodium chloride. Thurau (1974) applying single nephron microperfusion techniques reported increases of renin activity in the juxtaglomerular apparatus when sodium chloride concentration in the distal tubule was elevated. He proposed a mechanism whereby increase in renal blood flow, leading to increase in \#ubular sodium chlloride load, is counteracted by intrarenally synthetized angiotensin II which is supposed to exert its main vasoconstrictory action on the afferent renal arteriolae and to reduce renal blood flow.

This view has been challenged by Davis and Freeman (1976) and Nakane et al (1980) in favor of evidence that it is rather a decrease in distal tubular sodium chloride concentration which stimulates renin release. Furthermore, intra- 
renal angiotensin $\|$ formation is found to be increased in rats fed on a sodiumdeficient diet (Mendelsohn, 1979). Lastly, angiotensin Il seems to control glomerular filtration rate via efferent arteriolar constriction rather than through changes in afferent vascular tone (Hall et al, 1976; Baer and McGiff, 1980). Another objection is that in Thurau's view decreased renal perfusion pressure would lead to decreased renin release while in fact the contrary has been reported (Guyton, 1976; Hall et al, 1976; Abe et al, 1976b).

\subsubsection{Autoregulation of glomerullar filtration rate}

It is generally accepted that autoregulation of glomerular filtration rate is a part of autoregulation of renal blood flow (Brenner et al "1976). Glomerular filtration is promoted by the capillary hydrostatic pressure and opposed by the hydrostatic pressure in Bowman's capsule as well as by capillary blood oncotic pressure. In dogs, the capillary hydrostatic pressure is the primary driving force for glomerular filtration (Youngberg et al, 1977); increasing the plasma oncotic pressure hardly decreases the glomerular filtration rate (Hall and Guyton, 1976). In Munich-Wistar rats, the only rat strain with superficial glomeruli and therefore easily accessible for micropuncture studies, renal blood oncotic pressure appears to be the main determinant of glomerular filtration rate: a filtration equilibrium is obtained when the hydrostatic pressure gradient equals the opposive oncotic pressure gradient (Brenner et al, 1976). This difference between rats

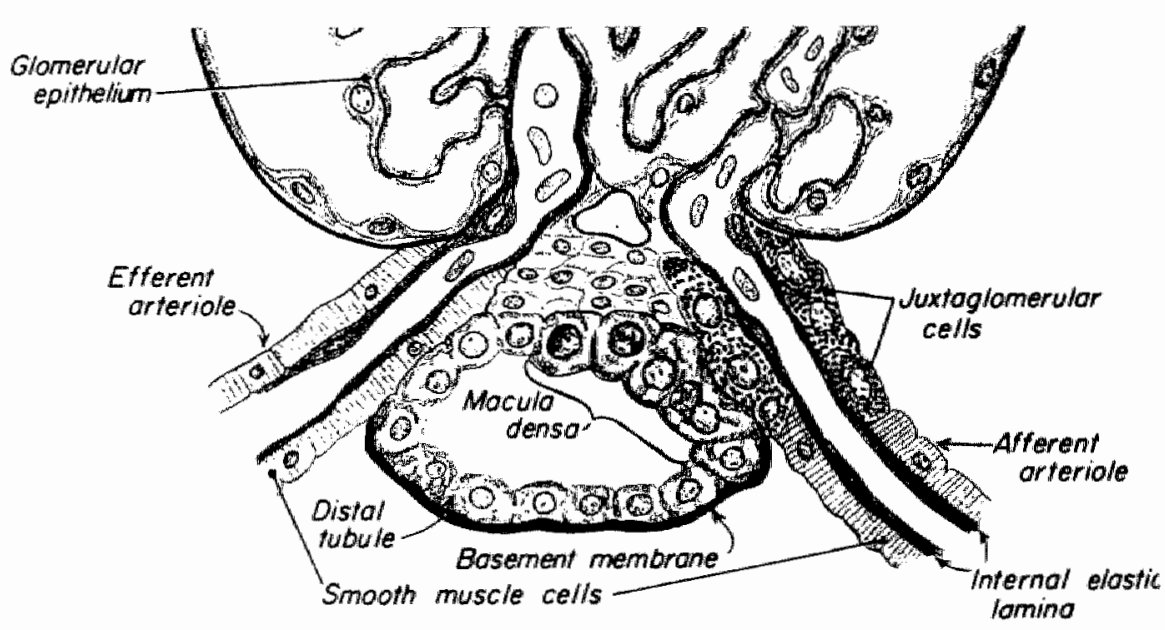

Figure 1.1

Schematic drawing of the juxtaglomerullair apparatus illustrating the close contact between the distal tubule, the macula densa and the juxtaglomerular cells.

From: Guyton AC: Textbook of medical physiology (1976). 
and dogs in dependency of glomerular filtration on plasma oncotic pressure is caused by the far greater permeability to water of the glomerular membrane of rats.

However, though autoregulation of renal blood flow is defined to be independent of vasoactive substances such as noradrenaline or angiotensin II (Stein, 1976. Hall et al, 1977a; Abe et al, 1976a) autoregulation of glomerular filtration rate does require an operational renin-angiotensin system (Hall et al, $1977 \mathrm{~b}$; 1981). In this respect, the term "autoregulation" is not quite correct. In sodium-depleted dogs with activated angiotensin II synthesis, reduction of the renal artery pressure by means of abdominal aorta clamping does not affect glomerular filtration rate except when formation of angiotensin II is inhibited by application of the converting enzyme blocker captopril. While calculated afferent arteriolar resistance declines during aortic constriction, keeping renal blood flow constant also during captopril administration, efferent resistance decreases after blockade of angiotensin II synthesis. Secondary infusions of angiotensin II restore glomerular filtration rate and efferent arteriolar resistance. Furthermore, in anesthetized rats which are infused with noradrenaline close to the renal artery, maintenance of the glomerular filtration rate despite of the reductions of renal blood flow, is dependent on the intactness of the renin-angiotensin system (Arundell and Johns, 1982). Therefore, it is concluded that angiotensin II controls glomerular filtration rate via regulation of efferent arteriolar resistance.

\subsubsection{Autoregulation of tubular reabsorption rate}

Adaptation of tubular reabsorption processes to changes in glomerular filtration rate is essential for constant volume and composition of body fluids. Except for the distal convoluted tubular segments and the collecting ducts which are directed by humoral agents such as antidiuretic hormone and aldosterone, intrinsic adaptation to variations in glomerular filtration seems to be general feature of tubular epithelium.

At the proximal tubule level a considerable constancy of fractional reabsorption is abserved implying that increases in glomerular filtration rate correlate with increases in tubular reabsorption rate; a phenomenon which is generally referred to as glomerulotubular balance.

Several mechanisms have been proposed to provide an explanation for this observation. In the first place, it has been postulated that tubular transmembrane transport is a function of the plasma oncotic pressure in the peritubular capillaries; when for instance, glomerular filtration rate increases and renal plasma flow is held constant, peritubular plasma protein concentration increases which facilitates tubular water and sodium reabsorption via paracellular pathways (De Wardener, 1978) (see also Fig. 1.2). Much evidence in favor of this hypothesis has been gathered in experiments in which changes in peritubular oncotic pressure were prevented during variations in glomerular filtration rate and glomerulotubular balance appeared to be blunted (Jacobson and Seldin, 
1977). However, there are some methodological difficulties concerning microperfusion techniques in the peritubular capillaries which prevent a clear view on the relevance of the tubular transmembrane oncotic gradient in relation to the glomenulotubular balance (De Wardener, 1978).

In the second place, it has been suggested that, possibly in addition to peritubular oncotic pressure, hydrostatic pressure plays a role in promixal tubular reabsorption since it has been shown that effects on urinary sodium excretion caused by changes in arterial blood pressure are independent of glomerular filtration rate. Small hydrostatic gradients with the pressure higher in the peritubular capillary exert a pronounced inhibition of sodium reabsorption (De Wardener, 1978).

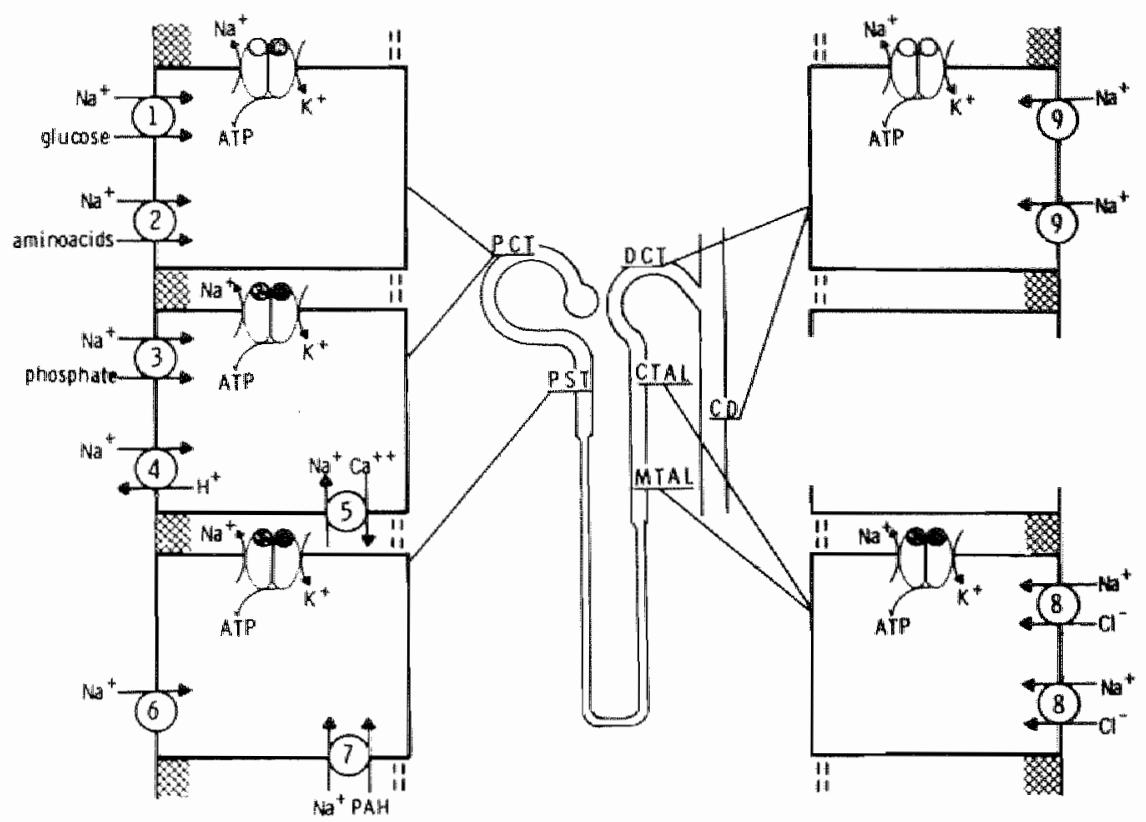

Figure 1.2

Survey of various models of transtubular Na* transport.

Na-K pump couples ATP hydrolysis to active $\mathrm{Na}^{*}$ transport from cytoplasma to extracellular fluid and creates electrochemical $\mathrm{Na}^{*}$ gradients from extracellular fluid to cytoplasma. Carriers mediating Na* coupled active transport of solutes are placed in numerical order. In proximal convolutted tubules (PCT), 1-5 have been identified in isolated membrane vesicles. In proximal straight tubules (PST), 6 and 7 are hypothetical. Primary active $\mathrm{Na}^{*}$ transport and secondary active $\mathrm{Cl}^{-1}$ transport (8) are hypothesized to occur in medullary (MTAL) and cortical (CTAL) thick ascending limbs of Henle. Furthermore, $\mathrm{Na}^{+}$may be actively reabsorbed in distal convoluted tubules (DCT) and collecting ducts (CD) (9).

From: Jörgensen PL: Physiol Rev 60: 864-917, 1980. 
The third hypothesis is that intratubular mechanisms are responsible for the glomerulotubular balance. One view is that proximal tubullar reabsorption could depend on facilitated transport mechanisms following Michaelis-Menten kinetics whereby the concentration of the substance influences the transport rate of that substance; for a solute with declining concentration along the nephron a rise in glomerular filtration rate would increase substrate concentrations and thereby transmembrane transport (Kiil, 1982). However, intratubular flow rate dependency of proximal tubular processes has not been established yet (Jacobson and Seldin, 1977; Häberle et al, 1981; Kiil, 1982). If the tubular filtrate contains substances which control their own reabsorption via changes in their tubular concentration, this implies that variations in glomerular filtration could be secondary, since changes in tubular reabsorption will lead to changes in the intraluminar hydrostatic pressure and therefore, influence the hydrostatic gradient over the glomerular membrane (Leyssac, 1976; De Wardener, 1978).

Lastly, in the loop of Henle and in the distal tubular reabsorption of sodium chloride is directly dependent of the rate of sodium chloride delivery which results in a constancy of fractional reabsorption rate (De Wardener, 1978; Folkow, 1982).

\subsection{Neurohumoral control of renal function}

\subsubsection{Influences of renal nerves}

The kidney is richly innervated as anatomical studies over the past decade have shown. Applying flluorescence and electron microscope techniques, the existence of adrenergic nerve endings have been established in the wall of both afferent and efferent renal arterioles in rats and monkeys (Stein, 1976; Barajas, 1978). Furthermore, existence of adrenergic nerve terminals in close association with basement membranes of proximal and distal tubules has been confirmed in rats and monkeys (Barajas, 1978) as well as in dogs (DiBona, 1977) after earlier disagreement due to non-specific staining techniques (Kim et al, 1980).

Cholinergic innervation of the renal cortex indicated by histochemically verified acetylcholinesterase presence parallels that observed with catecholamine fluorescence except that nerve terminals at the tubular level have not been defined so clearly (Stein, 1976; Barajas, 1978). Whether or not this particular staining technique reveals actual existence of cholinergic neurones remains unsolverd since it is possible that adrenergic nerves contain acetylcholinesterase (Barajas, 1978); furthermore, renal denervation abolishes adrenergic, but not cholinergic staining (Stein, 1976).

Beside morphological, also physiological evidence for adrenergic innervation of the kidney and sympathetic control of renal function has been brought up.

Electrical stimulation of efferent renal nerves in anesthetized dogs and rats produces an acute fall in renal blood flow due to renal vasoconstriction (Kottke 
et all, 1945; Hermansson et al, 1981). Single nephron glomerular filtration rate tends to decrease (Hermansson et al, 1981). The same results are obtained in conscious dogs although decreases in renal blood flow and glomerular fittration rate are not maintained over the whole stimulation period (Block et al, 1952).

Activation of the renal adrenergic nerve system produces vasoconstriction in the kidney via stimulation of postsynaptic alpha-receptors (Katholi et al, 1977; Insel and Snavely, 1981). It is discussed whether these postsynaptic alphaadrenoceptors are of the alpha $a_{1}$ - or alpha ${ }_{2}$-subtype (Ruffolo et al, 1981; Starke and Docherty, 1982) but rat arterial tissue probably contains both (Drew and Whiting, 1979; McGrath, 1982), each stimulated by the sympathetic neurotransmitter noradrenaline.

The release of noradrenaline by the sympathetic nerve endings is modified by presynaptically located receptors which are influenced by a variety of circulating endogenous substances. Inhibition occurs by noradrenaline via alpha $a_{2}$-adrenoceptors (Timmermans and Van Zwieten, 1982), by dopamine (Starke, 1981) or acetylcholine (Robie, 1979), and prostaglandines (Starke, 1981). Facilitation of adrenergic transmitter release may be produced via activation of beta ${ }_{2}$-adrenoceptors (Starke and Snavely, 1981) and by angiotensin II (Zimmerman, 1978). All these possible interactions have to be considered in evaluation of the role of the sympathetic nervous system in renal hemodynamics. However, since renal denervation does not influence renal blood flow or glomerular filtration rate (Stein, 1976; Rogenes and Gottschalk, 1982; Pelayo et al, 1983), it is assumed that under normal conditions renal hemodynamic parameters are controlled primarily by the renal autoregulation (Stein, 1976) and that renal nerves are involved in stressful or even pathological changes in renal function as for instance hypertension.

The observation that acute renal denervation in anesthetized animals induces decreases in reabsorption of water and sodium at the proximal tubule level, only partially compensated by autoregulatory increases in distal tubular transmembrane transport (BelloReus et al, 1975; Colindres and Gottschalk, 1978) points at possible neurogenic control of tubular reabsorption, especially since effects on urine output appear to be direct and not secondary to changes in renal hemodynamics (Colindres and Gottschalk, 1978) or peritubular oncotic and hydrostatic pressure (Pelayo et al, 1983).

However, acute renal denervation also increases urinary excretion and in chronically denervated animals, at least when conscious, there is no difference in diuresis and natriuresis between intact and denervated kidneys (Lifschitz, 1978; Gottschalk, 1979). Furthermore, possible contribution of the renin-angiotensin or prostaglandin mechanisms imposed on effects of renal denervation has not been evaluated.

Clear insight into the control of efferent renal nerves on tubular reabsorption of water and salt comes from electrical and chemical stimulation of intrarenal adrenergic systems. Low-level electrical stimulation of renal nerves in anesthe- 
tized rats which does not affect renal blood flow or glomerular filltration rate, decreases urinary flow and sodium excretion via increases in reabsorption at the proximal tubular level (DiBona, 1977; Colindres and Gottschalk, 1978) as well as in Henle's loop (DiBona and Sawin, 1982). Possible interference by the reninangiotensin system or prostaglandins could be excluded (Gottschalk, 1979).

Application of noradrenaline to the perfusate of isolated rat kidneys increases sodium reabsorption when perfusion pressure is held constant, without affecting urinary flow or fractional potassium excretion suggesting direct action on sodium reabsorption rate (Besarab et al, 1977). In isolated proximal tubules of the rat rather high concentrations of noradrenaline are able to stimulate fluid reabsorption when applied from the peritubular, but not from the luminal side (Bello-Reus, 1980; Chan, 1980).

These findings suggest that noradrenaline exerts its action on the renal $\mathrm{Na}^{+}-\mathrm{K}^{+}$ATPase located on the proximal tubular basement membranes (see Fig. 1.2) by increasing active transport of sodium. However, effects on active reabsorption of anions as $\mathrm{HCO}_{3}^{-}$on the proximal level $(\mathrm{Kiil}, 1982)$ and $\mathrm{Cl}^{-}$on the distal level (De Wardener, 1978) as well as on permeability to water or on sodium transport in the distal tubule (Besarab et al, 1977) cannot be excluded.

The increases in sodium reabsorption after stimulation of intrarenal adrenergic mechanisms have been reported to be inhibited by means of alphaadrenoceptor blockade with phenoxybenzamine (Gill and Casper, 1971; Zambraski et al, 1976; Chan, 1980). Possibly, adrenoceptors influencing tubular reabsorption of sodium and fluids are of the alpha ${ }_{2}$-subtype (Young and Kuhar, 1980). However, also beta-adrenoceptors, maybe of the beta ${ }_{1}$-subtype (Gavendo et al, 1980) have been associated with the effects of noradrenaline on sodium and water reabsorption in the proximal tubule (Besarab et al, 1977; Bello-Reus, $1980 ;$ Smits, 1980). Application of alpha- or beta-agonists have not defined the nature of the adrenoceptor involved yet (Blendis et al, 1972; Kim et al, 1980; Insel and Snavely, 1981).

Clearly, a very important feature of the renal adrenergic nerve system is its close functional relationship with several intrarenally operating humoral mechanisms; this role of the efferent renal nerves will be discussed later in this Introduction.

Afferent nerve signals have been demonstrated to be generated within the kidney. Afferent nerves do not influence renal hemodynamics and tubular reabsorption directly but they contribute as sensoric input to reflex loops mediated by the central nervous system (Calaresu and Ciriello, 1981) which may modify renal function via efferent renal nerves or via circulatory changes (Colindres et al, 1980). Both hypertensive and hypotensive effects of electricall stimulation of afferent renal nerves have been reported (Moss, 1982) whereas increases in sympathetic discharge frequency occur reflexively in both ipsilateral and contralateral efferent renal nerves (Calaresu et al, 1978).

Two classes of receptors which can activate afferent nerves leaving the kid- 
ney have been identified: the mechanoreceptors and the chemoreceptors. Renal mechanoreceptors are triggered by increases in renal arterial or venous pressure (Moss, 1982). Renal chemoreceptors have been subclassified using direct nerve activity recording techniques in types $\mathrm{R} 1$ and $\mathrm{R} 2$ (Recordati et al, 1981a). R1 receptors have no resting activity and are stimulated after complete renal ischemia whereas $\mathrm{R} 2$ receptors show electrical discharges under basic conditions and respond to backflow of urine into the renal pelvis. Especially high concentrations of potassium when present in renal pelvis perfusion solutions are able of triggering $\mathrm{R} 2$ chemoreceptors.

Furthermore, the frequency of afferent renal nerve signals is increased by adenosine (Recordati et al, 1977; Katholi et al, 1983) which is produced during renal ischemia. Also bradykinin has been reported to elicit cardiovascular responses attributed to activation of renal afferent nerves (Smits and Brody, 1983).

\subsubsection{The renin-angiotensin system}

Renin is synthesized, stored and released by the juxtaglomerular apparatus in the kidney. Upon its appearance in plasma it acts on its substrate angiotensino. gen, an alpha ${ }_{2}$-globuline, to produce the decapeptide angiotensin I which is converted enzymatically into the octapeptide angiotensin II mainly when passing through the pulmonary vascular bed. However, as already mentioned, also intrarenal formation of angiotensin II is possible (Thurau, 1974; Mendelsohn, 1979).

Angiotensin II is the most potent endogenous arterial vasoconstrictor; its action on renal arteriolae in autoregulation of glomerular filtration rate and its function in the tubuloglomerular feedback loop have been discussed above. Furthermore, it exerts a positive inotropic effect on cardiac muscle (Goodfriend and Peach, 1977). There is some controversy regarding the question whether the octapeptide influences sinoaortic baroreceptor function (Hatton et al, 1981; Coleman et al, 1981) but its functional interaction with the sympathetic nervous system is well established (Zimmerman, 1978; Recordati et al, $1981 \mathrm{~b}$; Hatton et al, 1982).

A possibly important feature of the intrarenal action of angiotensin II could be its effect on tubular reabsorption processes. Intraluminar application of unphysiologically high concentrations of angiotensin II decreases sodium reabsorption rate at the proximal and distal tubule level (Thurau, 1974) bult smaller concentrations are able to block fluid reabsorption when microperfused at the peritubular side (Leyssac, 1976). Lastly, angiotensin II stimulates the zona glomerulosa of the adrenal cortex to secrete the mineralocorticoid aldosterone, which enthances renal excretion of potassium and inhibits excretion of sodium by its interference with distal tubular reabsorption. The angiotensin IIaldosterone axis established the renin-angiotensin system as a link between the nephron and the adrenal cortex (Young and McCaa, 1980) and confirms its dominant role in body salt homeostasis. 
In evaluating the renin-angiotensin system in relation to its capacity to regulate renal function, determining factors are the several modes by which renin is released from the juxtaglomerular apparatus.

Well-known triggers for renin release are decreases in renal perfusion pressure and renal blood flow (Guyton, 1976; Peart, 1977). Strangely, this release mechanism is only functional when renall arteriolar autoregulation is operational (Abe et al, 1976a). After intrarenal application of papaverine, known to block autoregulation, renin secretion after acute hemorrhage is no longer observed (Davis and Freeman, 1976). The actual stimulus for release of renin might be a decrease of intraluminar arteriolar pressure at the level of the juxtaglomerular apparatus decreasing the transmural pressure gradient or a primary decrease in transmural pressure gradient causing renal wasodilatation, which possibly activates an intrarenal baroreceptor reflex loop. Intrarenal baroreceptors are believed to be located at the preglomerular site and they could be stimulated by arterial pressure reduction, renal artery obstruction and preglomerular vasoconstriction (Folkow "1982).

Secondly, activation of the tubuloglomerular feedback at the site of the macula densa will lead to secretion of renin, as is discussed above.

Furthermore, renin release is under direct or indirect control of several intrarenally operating humoral factors as for instance, angiotensin II (Torretti, 1982) or aldosterone, which perhaps exerts its influence via the tubular salt balance (Folkow, 1982), both inhibiting secretion of renin.

In the fourth place, release of renin is under sympathetic control, as is widely recognized. Renal sympathetic nerve terminals contact the juxtaglomerular apparatus (Davis and Freeman, 1976; Folkow, 1982). Low-level electrical renal efferent nerve stimulation which does not affect renal hemodynamics, increases renin secretion in dogs and cats (Osborn et al, 1980; Holdaas et al, 1981; Ammons et al, 1982). Blockade of beta-adrenergic receptors, in specific beta, -receptors, by means of intrarenally applied atenolol or metoprolol (Osborn et al, 1980; Holdaas et al, 1981) abolishes the increases in renin secretion rate after renal nerve stimulation. Intrarenal infusion of the beta-agonist isoprenaline raises renin release which is inhibited again by beta-receptor blockade (Krausz et al, 1980).

However, not only stimulation of beta-adrenoceptor interferes with renin secretion by the juxtaglomerular apparatus. Since alpha-adrenoceptors are located in the preglomerular arteriolae, this subtype of adrenoceptors may influence renin release by mediation of the intrarenal baroreflex mechanism. Whether stimulation of alpha-adrenoceptors decreases or increases renin secretion, remains controversial (Torretti, 1982); furthermore, it is suggested that there exists a direct alpha $a_{4}$-receptor mediated inhibitory action on the juxtaglomerular apparatus (Pettinger et al, 1976; Reid et al, 1978) or an indirect inhibition by means of blockade of noradrenaline release via presynaptically located alpha $_{2}$-receptors (Reid et al, 1978). 
It has been given some consideration that stimulation of afferent renal nerves may increase reflexively renin release from the contralateral kidney. This hypothesis, however, is not supported by experimental evidence (Calaresu et al. 1975).

As may be clear from presented observations, the renal adrenergic nerve system is closely related to the renin-angiotensin system, even to such extent that it has been argumented that renin release which is caused by non-neural stimuli e.g. decrease in renal perfusion pressure, is supported by increase of efferent renal nerve activity (Thames and DiBona, 1979).

\subsubsection{The renal prostaglandin system}

The initial enthusiasm for postulating a role of prostaglandins as circulating arteriolar vasodilators and therefore as important regulators of cardiovascular function, has been diminished by experimental evidence that under homeostatic conditions effects of prostaglandins on hemodynamics are not significant (Folkow, 1982). However, their influence on renal function is clearly recognized, as complicated as it is due to the vague difference between direct actions of various prostaglandins and their interference with other humoral agents affecting kidney blood flow and tubular water and salt reabsorption.

Intrarenal infusion of $\mathrm{PGE}_{2}, \mathrm{PGI}_{2}$ or the prostaglandin precursor arachidonic acid in anesthetized dogs results in increases in renal blood flow and renal vasodilatation (Anderson et al, 1976; Heinemann and Lee, 1976; Gerber and Nies, 1981) mainly in efferent arteriolae (Folkow, 1982), suggesting a role in angiotensin II mediated autoregulation of glomerular filtration rate. Earlier reports on rats indicated that $P G E_{2}$ causes renal vasoconstriction, contrary to dogs, while $\mathrm{PGl}_{2}$ induces vasodilatation (Gerber and Nies, 1981). However, it has been shown recently that intra-aortic or intrarenal infusion of $P G E_{2}$ in low doses in anesthetized rats increases renal blood flow and lowers arterial pressure (Haylor and Towers, 1982; Jackson et al, 1982). Administration of prostaglandin synthesis inhibitors as indomethacin decreases renal blood flow in unconscious dogs (Anderson et al, 1976; Gerber and Nies, 1981), while effects on glomerular filtration rate are contradictory (Olsen et al, 1976; Feigen et al, 1976). No clear description of the role of prostaglandins in renal hemodynamics could be obtained when dogs were conscious (Gerber and Nies, 1981).

Autoregulation of renal blood flow appears to be independent of inhibition of prostaglandin activity in dogs (Anderson et al, 1976) and rats (Finn and Arendshorst, 1976) indicating that under normal conditions, prostaglandins do not contribute to renal hemodynamics.

A second intrarenal action of the prostaglandin system is on sodium and water excretion. This is based on the observation that there is an inverse relationship between sodium intake and urinary $P G E_{2}$ excretion in rats, possibly mediated by angiotensin II or catecholamines (Tobian and O'Donnell, 1976). Furthermore, indomethacin induces reductions in urinary sodium excretion (Brater, 
1979; Haylor and Lote, 1980). The localization of prostaglandin synthesis in the renal medulla suggests a main action on medullary excretory functions e.g. vasopressin-independent water permeability in collecting tubules, medullary blood flow and transmembrane sodiumchloride transport.

$\mathrm{PGE}_{2}$ decreases the facilitation of water permeability by vasopressin (Folkow, 1982) but its concrete action is not fully understood (Stokes, 1981). Furthermore, prostaglandins increase medullary blood flow in dogs via an unknown mechanism (Anderson et al, 1976. Stokes, 1981) which may result in a decrease in peritubular osmotic pressure thereby reducing water reabsorption. In isolated medullary tubules of the rabbit, a not clearly established inhibition by $P G E_{2}$ on chloride transport in the thick ascending part of Henle's loop and on sodium transport in the collecting tubule has been reported (Stokes, 1981). Applying micropuncture techniques in rat kidneys, it has been confirmed by use of prostaglandin inhibitors that chloride reabsorption in the ascending distal tubule is decreased by prostaglandins (Higashihara et al, 1979).

A third main action by which prostaglandins control renal function, is modulation of renin release. In non-filtering dog kidineys with eliminated adrenergic control, infusion of arachidonic acid increases renal venous renin activity (Data et al, 1978). This effect is blocked by indomethacin. Application of prostaglandins $P G I_{2}$ and $P G E_{2}$ in the same experimental model also increases renin activity (Gerber et al, 1979). In man, intravenous infusion of $\mathrm{PGI}_{2}$ increases plasma renin activity (Patrono et al, 1982). Indomethacin blocks the increases in renin secretion after reduction of renal perfusion pressure within the autoregulation range in dogs, suggesting interference of prostaglandins with the intrarenal baroreceptor (Data et al, 1978; Blackshear et al, 1979). In conscious rats, indomethacin decreases urinary excretion of $P G E_{2}$ and plasma renin activity. Furthermore, indomethacin inhibits stimulation of renin release by beta-adrenoceptor agonists, arachidonic acid and vasodilatory agents (Suzuki et al, 1981).

As already indicated by the fact that sympathetic influence on renal function has to be excluded in order to evaluate contributions of the prostaglandin system to the release of renin, there is a close functional relationship between prostaglandins, renal adrenergic nerve activity and the renin-angiotensin mechanism. Renal nerve stimulation or intrarenal infusion of noradrenaline and adrenaline, as well as angiotensin II enhance renal prostaglandins synthesis in dogs (Baer and McGiff, 1980; Gerber and Nies, 1981). Indomethacin inhibits the slow return in renal blood flow to control levels after the initial decreases induced by these vasopressor stimuli (Satoh et al, 1981); furthermore, it increases the renal vascular response to exogenous angiotensin II and catecholamines but not to renal nerve stimulation (Finn and Arendshorst, 1976; Zambraski and DiBona, 1979). In the last place, prostaglandins mediate the increase of renin release after renal nerve stimulation via interference with alpha- or betaadrenoceptors (Kopp et al, 1981 vs. Campbell et all, 1979).

It would appear from these interactions that prostaglandins on the one 
hand and angiotensin || and renal catecholamines on the other hand counterbalance each other's influence on renal blood flow and especially glomerular filtration rate, resulting in a delicate neurohumoral system for renal hemodynamic control. However, this point of view should be regarded as an experimental framework and not as a definite mechanism since several other humoral agents influence renal function.

\subsubsection{Other hormonal systems}

In fact, a variety of hormones is involved in renal function regulation. Thyroid hormones, calcitonin, insulin, glucagon, progesterone, prolactin (Katz and Lindheimer, 1977) as well as histamine (Campbell and ltskovitz, 1976) and dopamine (Greven and Klein, 1977) can somehow influence renal hemodynamics and tubular reabsorption processes. Furthermore, as already mentioned, metabolites as adenosine can behave as intrarenally active hormones (Oswald et al, 1982; Katholi et al, 1983). Discussing all these endogenous substances in detail, is beyond the scope of this thesis. However, there are some humoral systems which deserve particular attention since they have been related in specific to renall function in the last years.

In the first place, the renall kallikrein-kinin system located in the distal tubules (Carretero and Scicli, 1980) has found to be related to the renin-angiotensin and the renal prostaglandin systems. Plasma kallikrein releases kallidin from the substrate kininogen; kallidin in turn is converted into bradykinin by an aminopeptidlase. Bradykinin is inactivated by kininase $\| I$ which in fact is the angiotensin I converting enzyme and forms the biochemical link between the reninangiotensin and the kallikrein-kinin system. Furthermore, there are three physiological ways by which kallikrein release is modulated via the renin-angiotensin system: both angiotensin $\|$ and aldosterone stimulate kallikrein synthesis and rellease. Kallikrein release is also stimulated by prostaglandins the synthesis of which is increased by angiotensin II (Levinsky, 1979; Carretero and Scicli, 1980). Reversely, kallikrein activates renin and stimulates prostaglandin release by the kidney; since prostaglandins stimulate renin release, the kallikrein-kinin system activates the renin-angiotensin systems indirectly (Levinsky, 1979; Schachter, 1980). In evaluating the interdependency of these three intrarenally operating humoral systems, the prostaglandins seem to play a pivotal role.

Kallidin and bradykinin are potent vasodilators (Folkow, 1982; Carretero and Scicli, 1980) and particularly by increasing renal blood flow in the renal medullary regio, they increase excretion of water probably by decreasing the peritubular osmotic pressure, and - secondarily to increases in urine volume - they will stimulate sodium excretion (Mills and Ward, 1975; Carretero and Scicli, 1980); direct actions on the distal tubule transport processes however cannot be excluded. Obviously kinins may produce diuresis and natriuresis via stimulation of prostaglandin release and thereby vasopressin actions on tubular reabsorption (Levinsky, 1979; Carretero and Scicli, 1980). 
As mentioned before, vasopressin or antidiuretic hormone is a humoral substance fundamentally involved in kidney excretory function; it increases permeability of water and therefore water reabsorption at the levels of the distal tubule and collecting duct, where in fact permeability of water is rate limiting to transmembrane transport, contrary to the proximal tubule.

Recently, much attention has been focussed on an endogenous sodium excretion stimulating substance. It appears in the circulation after blood volume expansion (De Wardener, 1978), which is best demonstrated in an experiment in which a donor rat is crosscirculated with a recipient assay rat. During blood volume expansion in the donor rat, urinary sodium excretion increases in the recipient assay rat. Plasma from a volume-expanded rat causes natriuresis when infused in another rat (De Wardener and Clarkson, 1982). This natriuretic hormone is an quabain-like inhibitor of renal $\mathrm{Na}^{+}-\mathrm{K}^{+}$ATPase (De Wardener and Clarkson, 1982; Folkow, 1982) which is possibly released by the central nervous system e.g. the upper brain stem-hypothalamus since natriuresis was not obtained in isolated kildney perfused with blood from a decapitated volume-expanded dog (Kaloyanides et al, 1977). Furthermore, lesions in the preoptic-hypothalamic periventricular region of rats reduce the natriuresis after volume expansion by eliminating the natriuretic hormone-like activity in plasma (Bealer et al, 1983).

The possible trigger for release of natriuretic hormone from the brain could be increase in right atrial pressure stimulating a reflex loop which also affects renal neurogenic activity (Linden, 1979), via afferent nerve fibers from the heart, as may be the case for another sodium excretion mediating substance, the atrial natriuretic factor. Injection of atrial homogenate produces natriuresis and diuresis in the rat (DeBold et al, 1981). This atrial natriuretic factor has been located in atrial myocytes of rat, rabbit, dog, baboon, and man (Trippodo et al, 1983). The molecular weight of the atrial natriuretic factor, probably a polypeptide which does not inhibit renal medullary $\mathrm{Na}^{+}-\mathrm{K}^{+}$ATPase, is about 4000 while the natriuretic hormone has a molecullar weight smaller than 1000 (Thibault et al, 1983).

Lastly, two hormone-like lipids have been extracted from the renal medulla of rabbits: the antihypertensive neutral and polar renomedullary lipids (Muirhead, 1980). Both decrease arterial blood pressure, but the polar lipid increases heart rate and renal nerve activity while the neutral lipid reduces heart rate and renal nerve activity (Muirhead et al, 1983).

In general, the kidneys appear to be the source as well as the target of a variety of neurohormonal substances. They provide a still not fully explored but rapidly developing experimental field which calls for distinct demarcations. In order to evaluate disturbances in renal function related to for instance chronic hypertensive conditions, one has chosen to determine a finite number of renal hemodynamic and neurohumoral factors creating an experimental matrix based on methodological considerations, rather than on the acknowledgement of the epistemological context. 


\subsection{Renal function in hypertension}

\subsubsection{The cascade theory of whole body autoregulation}

Since the renal hydraulic system which counterbalances changes in arterial pressure beyond its pressure control level by large alterations in urinary water and sodium excretion, is characterized by its infinite gain it is axiomatic that a shift in pressure setpoint of the renal function curve to higher arterial pressure values is elementary in order to sustain the hypertensive state. Should this shift not occur, elevations in arterial pressure would be reduced by continuous increases in sodium and water excretion so that normal pressure levels are even. tually obtained.

This shift in renal function curve sets the primary role of the kidney in hypertension disease as indicated by Borst and Borst-De Geus (1963) and elaborated by Guyton and co-workers (1974, 1977, 1980).

As a consequence of the shift in the renal function curve in hypertension, balance of sodium and water intake vs. excretion is obtained at the elevated arterial pressure level initially under slightly hypervolemic conditions.

This will be demonstrated firstly by increases in the extracellular fluid volume and in blood volume, which starts the cascade effect: increases in blood volume will raise central venous pressure and right atrial pressure. This will increase cardiac performance (according to Frank-Starling's law) and therefore cardiac output. Since arterial pressure is regarded to be the product of cardiac output and total peripheral resistance, increase in cardiac output will elevate arterial pressure, but only slightly.

Increases in cardiac output will raise blood flow and oxygen supply to the organs. This induces a rise in tissue resistance to higher flow via autoregulatory mechanisms, as originally formulated by Borst and Borst-De Geus (1963) and described previously in discussing renal autoregulation. Increase in overall blood flow will lead to elevation in total peripheral resistance via the concept of whole body autoregulation (Guyton, 1976, 1977; Liard, 1979). Although increases in arterial pressure will be initially blunted by baroreceptor mediated vasodilatation, this neurogenic reflexes will adapt gradually to the elevated blood pressure and pressure is allowed to raise further via increases in total peripheral resistance. Normalization of organ blood flow by increase of organ resistance will reduce cardiac output to control levels. Furthermore, renal loss of water and salt will decrease body fluid volume and thereby, cardiac output.

Liard $(1978,1979)$ has evaluated the possibility that a primary increase in cardiac output elevates total peripheral resistance via whole body autoregulation and therefore causes hypertension. Intracoronary administration of the betaadrenoceptor agonist dobutamine increases cardiac performance and cardiac output. Hypertension develops and cardiac output decreases to control indicating - secondarily to increases in arterial pressure - an adjustment in renal function, possibly caused by prolonged exposure of the kidney to increased per- 
fusion pressure which involves a large scale of intrarenal neurohormonal factors (Knox and Haas, 1982).

The dominance of the kidney in the induction of hypertension has led to the development of various animal hypertension models which primarily alter renal function. It is discussed in the next section to what extent hypertension in this animal models is associated with cascade-like elevations in vascular resistance secondary to an initial volume-retaining phase.

\subsubsection{Kidney function and experimental models of hypertension}

In humans suffering from essential hypertension, renal vascular resistance has found to be increased in quite an early phase (Hollenberg et al, 1978). A former postulation is that in essential hypertension elevated body load of sodium is maintained at normal levels of sodium intake which may point to deficiency in renal sodium excretion (Borst and Borst-De Geus, 1963). Furthermore, in spontaneously hypertensive rats, an in-bred strain which is genetically predisposed to develop high blood pressure and which is generally regarded as an experimental animal model for the chronic hypertensive condition in humans, there are also indications for early renal dysfunction.

When kidneys from hypertensive rats are implanted into normotensive animals the recipient rats become hypertensive; implantation of kidneys from normotensive rats reduces blood pressure of spontaneously hypertensive rats (Bianchi et al, 1974). Renal vascular resistance is increased in a very early stage of hypertension (Evenwel, 1982) mainly due to preglomerular vasoconstriction (Arendhorst and Beierwaltes, 1979a). Furthermore, renal perfusion pressure has to be increased relatively more in spontaneously hypertensive rats in order to excrete a certain amount of salt and water (Arendhorst and Beierwaltes, $1979 \mathrm{~b}$ ). A shift of the renal function curve to higher arterial pressure levels has been established in spontaneously hypertensive rats (Norman et al, 1978) and plasma volume appears to be increased in very young animals (Evenwel, 1982). In the Milan hypertensive rat strain, glomerular filtration is reduced and plasma volume increased compared with normotensive controls, at weaning age. These differences disappear in adult animals but at this age the hypertensive animals appear to have a smaller number of glomeruli (Bianchi et al ${ }_{y}$ 1979). Renal dysfunction is also associated with another form of genetic hypertension, the Dahl salt-susceptible rat (Rapp, 1982).

Obviously, it has been suggested that a primary interference with renal function can induce and maintain hypertension. Over the years, several animal hypertension models have been developed applying physiological or pharmacological technology, which somehow influence the relation between arterial pressure and glomerular filtration rate, or between arterial pressure and tubular reabsorption, resulting in a fundamental change in urine output as function of arterial pressure and a shift of the renal function curve to higher pressure levels.

When kidney mass in dogs is reduced by almost $70 \%$ and the animals are 
chronically salt-loaded, hypertension develops exactly as predicted by the cascade model (Coleman and Guyton, 1969). Due to the severe decline in excretory capacity, 5 -times normal intake of sait is able to increase body fluid volume by $30 \%$ and cardiac output by $40 \%$ within two days. Secondarily to changes in cardiac output total peripheral resistance increases over a 14-day period to approximately $40 \%$ above control levels. Arterial pressure is elevated by $20 \%$ after 2 days and maintained at a level $45 \%$ above normal (Guyton et al, 1980).

Secondly, extrarenal compression of renal parenchyma by wrapping the kidney in cellophane or silk according to Page or by applying a figure-of-eight ligature with a silk thread according to Grollman, also indwces sustained hypertension after contralateral nephrectomy. However, hypertension is associated with increases in total peripheral resistance from the onset. Although under normal conditions cardiac output is increased in the initial phase of hypertension in rabbits, elevations in total peripheral resistance also occur when the animals are held on a sodium-restricted diet and no volume retention is possible (Korner, 1980).

Artificial constriction of the renal artery by clamping has been introduced by Goldblatt as an animal hypertension model. There are two basic principles: with and without contralateral nephrectomy (one-kidney, one-clip vs. two-kidney, one-clip), both leading to hypertension in rabbits and rats; two-kidney, one-clip dogs usually fail to sustain elevated pressure chronicially (Carretero and Romero, 1977).

After 30 days of clamping the renal artery in one-kidney rabbits, total body water as well as extracellular fluid volume, but not plasma volume appear to be increased (Kurz et al, 1981). A positive sodium balance has found to occur in one-kidney, one-clip rats (Carretero and Romero, 1977), associated with an increase in cardiac output (Freeman et al, 1982) and a shift of the renal function curve to higher levels of arterial pressure (Norman et al, 1978).

Plasma renin activity is only increased in the early phase (Kurz et al, 1982; Freeman et al, 1982); chronic infusion of angiotensin I converting enzyme inhibitors in the rat prevents increases in arterial pressure until the 8th day after clipping (Freeman et al, 1979). The one-kidney, one-clip Goldblatt model seems to be renin-angiotensin dependent in its developmental phase and volumedependent in its established phase. However, hypertension also develops in one-kidney, one-clip dogs and rats which are fed on a sodium-deficient diet and plasma volume does not increase (Freeman et al, 1982).

The situation in two-kidney, one-clip animalls is more complicated. Body fluid volume and cardiac output may be increased in the very early phase (Carretero and Romero, 1977. Liard, 1979) but sodium balance and blood volume tend to be normal or negative in the later phase (Carretero and Romero, 1977; Liard, 1979) although also an increase in blood volume has been reported (Albertini et al, 1979).

Application of converting enzyme inhibitors prevents the onset of hyperten- 
sion over the complete clipping period (Freeman et al, 1979) suggesting a fundamental sustenance by the renin-angiotensin system in this hypertension model.

One-kidney, one-clip animals vs. two-kidney, one-clip animals differ in the functional contribution by various hormonal systems. Inhibition of prostaglandin synthesis by indomethacin increases blood pressure and decreases renal blood flow and plasma renin activity in one-kidney, one-clip rabbits, but affected only renin activity negatively in two-kidney, one-clip rabbits (Romero and Strong. 1979).

In one-kidney, one-clip rats, urinary kallikrein activity decreases more rapidly than in two-kidney, one-clip rats during the development of hypertension (Albertini et al, 1979).

Furthermore, the Goldblatt two-kidney as well as the one-kidney models are characterized by release of Muirhead's antihypertensive lipids from the renal medulla upon declipping (Muirhead et al "1980; Göthberg et al, 1982).

Also, chronic administration of desoxycorticosterone (DOCA), a saltretaining hormone of the adrenal cortex, in combination with simultaneous saltloading has been widely used as a rather pharmacological tool for induction of hypertension (Grollman, 1975). Hypertension develops after 1 to 2 weeks and is always preceded by increases in plasma and blood volume (Villamil et $a l_{\text {. }}$ 1982).

Lastly, stimulation of the renin-angiotensin-aldosterone axis by chronic intravenous infusion of angiotensin $\| 1$ or aldosterone has been tried in order to induce hypertension. Angiotensin $\mid 1$ when chronically infused via the jugular vein of rabbits and dogs causes immediate plasma concentration-dependent increases in arterial pressure which are maintained throughout the infusion period $(\mathrm{Yu}$ and Dickinson, 1971; Bean et al, 1978). Cardiac output is decreased so that hypertension is related to elevated total peripheral resistance (Young et al, 1980). Renal blood flow decreases but glomerular filtration rate remains unaffected (Hall et al, 1978). Angiotensin II infusion stimulates aldosterone secretion (Hall et al, 1978; Bean et al, 1979) but sodium retention occurs also when aldosterone levels have returned to normal (Hall et al, 1978; Young et al, 1980; Guyton et al, 1981).

It is postulated that during chronic intravenous angiotensin II infusion sodium balance is achieved at higher arterial pressure levels.

Chronic subcutaneous infusion of aldosterone in rats increases arterial blood pressure dose-dependently (Gorwitz and Jones, 1982). Chronic intravenous aldosterone infusion in dogs raises blood pressure while cardiac output stays within normal range (Lohmeier et al, 1978; Pan and Young, 1982). Blood volume and body water and salt load remain increased throughout the aldosterone application period (Pan and Young, 1982). Also during chronic aldosterone infusion fundamental changes in renal function, possibly on the tubular level, seem to result in a shift of body fluid and salt homeostasis to higher arterial pressure levels. 


\subsubsection{Renal nerve activity and experimental hypertension}

Whether or not hypertension is caused and maintained by sympathetic hyperactivity, has been discussed widely over the years, inspired as it became by the methodological progress of the radioenzymatic catecholamine assay (Goldstein, 1981).

Recently, cardiovascular research has given increased attention to the role of renal afferent and efferent nerves in kidney function as described previously in section 1.2.1. The consideration that renal adrenergic hyperactivity may induce a shift in the renal function curve by changing renal hemodynamics and tubular reabsorption processes, and thereby sustains hypertension, has initiated the evaluation of renal nerve activity in various animal hypertension models.

Direct electrical recording of splanchnic nerve activity has shown higher sympathetic discharge frequencies to the kidney in anesthelized and conscious spontaneously hypertensive rats (Iriuchijima, 1973; Judy et al, 1976; Thorén and Ricksten, 1979) although these results also have been contradicted (Francisco et al, 1981).

Surgical denervation of the kidneys retards the development of genetic hypertension (Liard, 1976; Kline et al, 1978; Diz et al, 1982). Renal tissue levels of noradrenaline are decreased after denervation during the period of delay (Kline et al, 1980; Cuche and Liard, 1981) but the renin-angiotensin and the kallikrein-kinin system in the kidneys of spontaneously hypertensive rats are left unaffected (Säynăvälammi et al, 1982).

Renal denervation has also been found to inhibit the development of DOCA-salt hypertension. When arterial pressure did raise eventually, it went along with increases in renal noradrenaline content indicating reinnervation (Katholi et al, 1980).

Furthermore, renal denervation reduces the severity of hypertension caused by clipping the renal artery or placing a figure-of-eight thread around the kidney in uninephrectomized rats (Katholi et al, 1981). Also in the two-kidney, one-clip model renal denervation of the clipped kidney lowers increased blood pressure as well as ellevated plasma noradrenaline levels to normal values without influencing renin activity (Katholi et al, 1982).

Renal denervation reduces the noradrenaline content in the hypothalamus of normotensive and one-kidney, one-clip hypertensive rats (Calaresu an Ciriel10, 1981; Winternitz et al, 1982) which indicates disturbances in central nerwous system mediated neurogenic reflex loops. Since clipping of the renal artery in two-kidney rats increases plasma noradrenaline concentrations, while uncilpping as well as renal denervation decreases plasma noradrenaline levels again, it has been suggested that clipping interferes with renal afferent tone resulting in hypertension correlated with sympathetic hyperactivity; surgical denervation interrupts renal afferent input and is supposed to diminish sympathetic hyperactivity (Katholi et al, 1982).

Lastly, renal denervation is effective in retarding the development of coarctatio aortae hypertension (Whitlow et al, 1982). 
These data show clearly the contribution of the renal nerve system to experimental hypertension.

Reversely, it has been attempted to produce increases in arterial blood pressure by stimulating sympathetic nerve activity or more specifically efferent renal nerve activity. Chronic electrical splanchnic nerve stimulation in conscious dogs increases arterial pressure throughout the stimulation period; renal plasma flow and glomerular filtration tend to increase or stay within control range (Kubicek et al, 1952).

In anesthetized cats, acute splanchnic nerve stimulation causes hypertension associated with normal peripherall resistance and increased cardiac output before adrenalectomy and normal cardiac output as well as venous and arterial vasoconstriction after adrenalectomy, indicating the necessity of adrenal catecholamines in order to increase cardiac output (Greenway and Innes, 1980). Indirectly induced baroreceptor-mediated sympathetic hyperactivity causes renal vasoconstriction while renal blood flow is normal (Fink and Bryan, 1980).

Since splanchnic nerve stimulation may affect renal function indirectly by production of vasoconstriction in the complete splanchnic bed, electrical renal nerve stimulation has been applied in order to exclude this aspecificity. Acute renal nerve stimulation in anesthetized dogs produces frequency-dependent decreases in renal blood flow and increases in renal vascular resistance; furthermore, the concentration of noradrenaline in renal venous plasma increases (Kottke et al, 1945; Carriere et al, 1980; Oliver et al, 1980). Arterial blood pressure is normal (Kottke et al, 1945) or slightly ellevated (Oliver et al, 1980).

Changes in intrarenal humoral mechanisms, primary via neurogenic activation or secondary via effects of nerve stimulation on renal hemodynamics have not been investigated yet.

Lastly, chronic electrical stimulation of renal nerves produces hypertension, maintained over the stimulation period (Kottke et al, 1945). However, data on renal function during long-term experimentally stimulated renal nerve activity are not available.

\subsection{Chronic intrarenal infusion of noradrenaline - a new hypertension model}

In hypertension research, increases in plasma noradrenaline concentration are considered as indices of overall sympathetic hyperactivity. Ever since the postulation that essential hypertension in man is a disease of neurogenic origin, one has determined plasma noradrenaline levels in order to evaluate the activity of the sympathetic nervous system. The controversy whether or not plasma noradrenaline concentrations are elevated in essential hypertension, is reviewed extensively elsewhere (Goldstein, 1981).

The intriguing point is that upon intravenous infusion of noradrenaline in normotensive man, one has to raise plasma noradrenaline levels far beyond the 
values observed in essential hypertension in order to obtain the same increases in arterilal blood pressure (Silverberg et al, 1978; Vlachakis, 1979; BerettaPiccoli el al, 1980).

Certainly, it could be argued that in hypertensive conditions, sensitivity of vascular adrenoceptors to circulating noradrenaline might have been increased. This may be the case but determination of vascular responsiveness to elevations in plasma noradrenaline levels in hypertensive and normotensive man has not revealed any indication for a drastical increase in adrenoceptor sensitivity in essential hypertension (Vlachakis, 1979; Beretta-Piccoli, 1980).

Secondly, since it is thypothesized that rather small cumulations in plasma noradrenaline concentrations are caused by spillover of noradrenaline from the synaptic cleft, due to increased release of the neurotransmitter by synaptic nerve terminals, intravenous noradrenaline infusion may have to raise plasma levels steeply in order to increase noradrenaline load of the synaptic cleft efficiently. However, electrical stimulation of overall sympathetic activity in normotensive pithed rats does not result in small elevations but in large increments of plasma noradrenaline concentrations which are 10-fold higher than measured levels in spontaneously hypertensive rats (Yamaguchi and Kopin, 1979).

After these considerations, it seems attractive to postulate that it is rather the specificity of sympathetic hyperactivity, directed towards the kidney which alters renal function and induces a kidney-mediated form of hypertension; the relatively small rises in plasma noradrenaline concentrations during hypertension may result from increased renal venous outflow of noradrenaline.

Alternatively, one coull propose a model whereby renal efferent nerve hyperactivity stimulates renin release directly or indirectly. Increases in plasma renin activity raise circulating levels of angiotensin II which facilitates noradrenaline release from sympathetic nerve endings by its presynaptic action. Furthermore, the possibility remains that sympathetically induced changes in renal hemodynamics in turn stimulate renal afferent nerves and via the centrally mediated reflex loops elevate overall sympathetic activity and plasma noradrenaline levels.

In order to test the hypothesis that an increase of the discharge frequency of sympathetic nerves, specifically directed towards the kidney, induces and maintains hypertension, a new experimental animal model had to be developed. Because of the obvious methodological difficulties of chronic electrophysiological stimulation of renal efferent nerves in unanesthetized animals, a different approach was chosen: chronic increases in renal nerve discharge frequencles are simulated by means of continuous intrarenal infusion of the sympathetic neurotransmitter noradrenaline.

Long-term intrarenal infusion of noradrenaline has been performed in con* scious dogs (Katholi et al, 1977; Cowley and Lohmeier, 1979). An infusion rate of $17 \mu \mathrm{g}$ noradrenaline $\mathrm{kg}^{-1} . \mathrm{hr}^{-1}$ induces sustained hypertension characterized by immediately decreased renall blood flow, increased plasma renin activity and 
positive sodium balance associated with a shift of the renal function curve to higher pressure levels. Cardiac output measured however only in the late phase of noradrenaline infusion appears to be decreased so that hypertension is related to elevations in total peripheral resistance by that time. Only one dosis of noradrenaline has been applied intrarenally, elevating plasma noradrenaline levels 2-fold, which may indicate that hypertension is caused by increases in circulating noradrenaline concentrations with possible contributions of circulating angiotensin $\| 1$ and augmented adrenoceptor responsiveness by changes in electrolyte balance. However, no information of acute effects on central hemodynamics or body fluid volume is available.

\subsection{The present thesis}

Graded activation of renal adrenergic systems over a certain period of time is the appropriate way to test the hypothesis that hypertension is induced and sustained by specific hyperactivity of efferent renal adrenergic nerves.

Evaluation of the effects of varying infusion rates of intrarenally administered noradrenaline in relation with measurements of plasma noradrenaline levels provides the opportunity to determine the action of noradrenaline restricthed to the kidney. Application of sophisticated technology which enables acute and chronic measurements of renal and centrall hemodynamic parameters in conscious animals such small as the rat, may assess the accurateness of the predictions of Guyton and co-workers that an inital shift of the renal function curve assumably induced by intrarenal infusion of noradrenaline, causes hypertension via volume expansion and subsequently - by means of whole body autoregulation - via elevations in total peripheral resistance.

Therefore, the aim of this thesis is to determine the acute and chronic cardiovascular effects of intrarenal application of several doses of noradrenaline in conscious rats.

Because of the small diameter, catheterization of the renal artery in rats is not possible without interrupting blood supply to the kidney and causing renal infarction. Therefore, an alternative technique for long-term intrarenal drug administration had to be developed (chapter 2).

In chapter 3, pressor responses to intrarenal infusion of several doses of noradrenaline will be related to changes in plasma noradrenaline concentrations and compared to results obtained during intravenous noradrenaline infusion. The fate of noradrenaline administered via these two infusion routes will be discussed in chapter 4 . In chapter 5 , the contribution of the reninangiotensin system will be examined. Special attention has to be paid to effects of acute and chronic intrarenal infusion of noradrenaline on renal function and on central hemodynamics. Changes in body fluid and salt homeostasis will be determined (chapters 6,7 and 8 ). 
Finally, in the general discussion acute and chronic effects of intrarenal noradrenaline infusion will be evaluated within the framework of the respective hypotheses concerning adrenergic modulation of renal function in relation to hypertension. 


\section{CHRONIC LOCAL INFUSION INTO THE RENAL ARTERY OF UNRESTRAINED RATS*}

\subsection{Introduction}

As discussed in the introductory chapter, the kidney plays a crucial role in the development and maintenance of hypertension. Local administration of substances into the kidney or its blood supply may provide a tool for further elucidation of this aspect of renal function. This type of experiment is mostly conducted in large animals like dogs and sheep, because in these animals a catheter may be placed in the renal artery without a very great disturbance of renal blood flow.

Both Beuzeville (1968) and Fine et al (1974) have described methods for renal artery catheterization in rats. Both methods do, however, involve introduction of a catheter into the lumen of a renal artery. This, by itself, may be a cause for hypertension (Davis, 1977). Furthermore, using that approach in preliminary experiments, we have frequently encountered problems like gross renal damages. Therefore, a technique has been developed which allows long-term access to the renal artery and which does not require any disturbance of the renal blood flow.

This chapter describes the technique and the evaluation of long-term efffects of the catheter on blood pressure and renal function.

\subsection{Methods}

\subsubsection{Construction of the catheters}

Catheters were constructed of a $15 \mathrm{~cm}$ piece of PE 10 tubing (Clay Adams, Parsippany, $\mathrm{NJ}$ ). The tip of the catheter had been stretched over a hot soldering iron to reduce its outer diameter to approximately $0.2 \mathrm{~mm}$. An inner diameter of $0.1 \mathrm{~mm}$ was maintained by the previous introduction of a steel wire of that diameter. The stretched tip was cutt to a length of approximately $1 \mathrm{~cm}$. A $1 \mathrm{~cm}$ piece of PE 50 tubing (Clay Adams, Parsippany, $N$ J) was heat-sealed to the other end of the catheter and a $4-5 \mathrm{~cm}$ piece of 602-155 silastic tubing (Dow Corning, Midland, MI) was slipped over it. Two silk ties (2-0) provided secure attachment of the silastic to the polyethylene tubing.

* based on: Smits JFM, Kasbergen CM, Van Essen H, Kleinjans JC and Struyker Boudier HAJ: Chronic local infusion into the renal artery of unrestrained rats. Am $₫$ Physiol 244: H304-H307, 1983. 


\subsubsection{Animals}

Male Wistar rats, weighing 250-350 grams, were purchased from CPBITNO Zeist, The Netherlands. They had free access to standard lab food and tap water throughout the experiments.

To prevent the non-cannulated kidney from obscuring any effect of the method on renal function, a unilateral (left) nephrectomy was performed under light ether anesthesia through a flank incision 4-5 weeks before the actual catheter implantation. Special care was taken to leave the adrenal gland and its blood supply intact.

\subsubsection{Catheter implantation}

For the implantation of the renal catheters, animals were lightly anesthetized with ether. The abdominal cavity was opened through a ventral midline incision and the intestines were kept in gauzes, wetted with $0.9 \% \mathrm{NaCl}$.

The liver was slightly retracted upwards and the right renal artery was localized. The inferior suprarenal artery ascending towards the adrenal gland originates from the renal artery at the right side of the rats as illustrated in Fig. 2.1, on the contrary to the left side where the suprarenal artery emerges directly from the abdominal aorta. The suprarenal artery was carefully freed from connective tissue over a length of 6-8 $\mathrm{mm}$, starting at the bifurcation of the renal and suprarenal arteries. Three silk ties (6-0) were passed under the vessel. The tie proximal to the renal artery was used for retraction of the artery only. The ligature distal to the renal artery was pushed up as far as possible and tied into a firm knot, whereas the middle ligature was tied loosely around the vessel for later fixation of the catheter. The suprarenal artery was slightly retracted at the two outer ties and a small hole was cut in it. The catheter was slipped in, the ligature proximal to the renal artery preventing insertion of the catheter tip into the lumen of the renal artery. The catheter was secured to the vessel and the silk ties were released. Patency was checked by drawing blood into the saline-filled catheter and immediately flushing it back. Intrarenal infusion had now become feasible by means of transportation of substances to the kidney via the renal blood flow.

If the catheters were to be used for chronic experiments, they were guided to the neck and attached to an Alzet TM osmotic minipump (ALZA corporation, Palo Alto, $\mathrm{Ca}$; model 2001, shown in Fig. 2.2) which had been primed in saline at $37^{\circ} \mathrm{C}$ for 4 hours before implantation. The pumps were filled with normal saline, which was pumped out at a rate of $0.90 \pm 0.02 \mu \mathrm{l}$. hr ${ }^{-1}$ (mean \pm S.D.), as found in in vitro calibrations. No heparin was added. The Alzet pumps were inserted subcutaneously between the shoulder blades.

For drug infusions, the pump may be replaced after some time with a drugcontaining minipump. In the present study, only saline was infused in order to measure possible artefacts resulting from this type of catheterization. Pumps were replaced after 2 days of infusion and if necessary, again 7 days later. This was done under light ether anesthesia. 


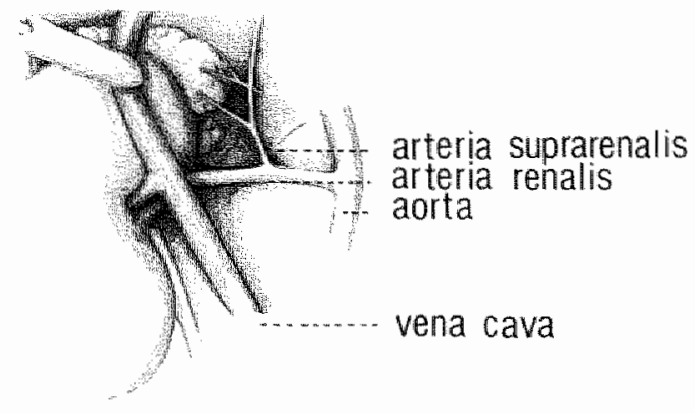

Figure 2.1

Drawing indicating the normal position of the right suprarenal artery in Wistar rats. The catheter is introduced $6-8 \mathrm{~mm}$ distal to the origin of the suprarenal artery from the renal antery. For clarity, the vena cava which was overlying the suprarenal artery, was retracted with a cotton-tip.
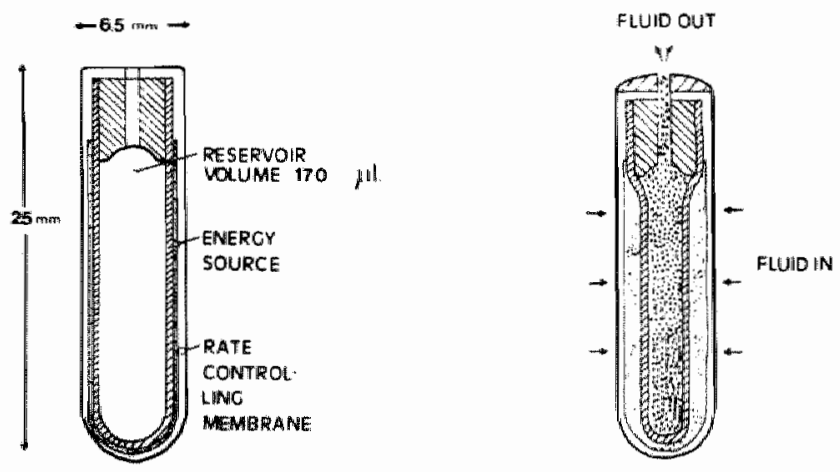

Figure 2.2

Schematic drawing of the working principle of the Alzet TM osmotic minipump, type 2001. 


\subsubsection{Evaluation of renal function}

Renal function was evaluated in conscious rats by measuring clearances of ${ }^{51} \mathrm{Cr}$-EDTA and ${ }^{125}$-PAH as estimates for glomerular filtration rate (GFR) and effective renal plasma flow (ERPF). Clearances were obtained according to standard pharmacokinetic methods (Smits ef al, 1982).

Briefly, the animals were equipped under ether anesthesia with a PE 10 femoral artery catheter and a silastic jugular vein catheter the day before measurements were done. One day later, blood pressure was measured according to the protocol described in section 3.2. After that, an i.v. bolus injection of $10 \mu \mathrm{Ci}$ ${ }^{51} \mathrm{Cr}$-EDTA (CJ 13P, The Radiochemical Centre, Amersham, England) was given and exactly 2 min later, a $100 \mu l$ arterial blood sample was obtained. Again, 2 min later $10 \mu \mathrm{Ci}{ }^{125} \mathrm{I}-\mathrm{PAH}$ (IM $315 \mathrm{P}$, The Radiochemical Centre) was given i. $v$. and repeated $100 \mu \mathrm{l}$ arterial blood samples were taken at $2,5,10,15$, $20,30,45,60$, and $90 \mathrm{~min}$ after the last injection. The exact times of blood sampling were carefully noted. Each blood sample was replaced by an equal amount of fresh donor blood obtained from litter mates. Concentrations of both ${ }^{51} \mathrm{Cr}$ EDTA and ${ }^{125}$ I-PAH in plasma were determined in a Packard scintillation counter. In each sample, overlap between channels was corrected for by internal standardization.

The data were fitted to a two-compartment open model according to:

$$
\mathrm{C}(\mathrm{t})=\mathrm{Ae}-\alpha \mathrm{t}+\mathrm{Be}-\beta \mathrm{t}
$$

The area under the plasma concentration time curve (AUC) was calculated by using the trapezium rule where $C(t=0)$ was $(A+B)$ and extrapolation to infinity was performed by dividing the last concentration on the curve by $\beta$.

Clearance was then calculated by:

Clearance $=$ Dose injected/Auc.

Clearance of ${ }^{51} \mathrm{Cr}$-EDTA was taken as a measure for GFR, whereas clearance of ${ }^{125} \mathrm{I}$.PAH was taken as ERPF. Both were calculated as absolute values as well as normalized for kidney weight, which was determined at the end of the experiment. No corrections for incomplete extraction or extrarenal clearance were made in the present study.

\subsubsection{Composition of experimental groups}

Blood pressure and renal hemodynamics were measured in 5 groups of animals. One group had 2 intact kidneys (group $I ; n=10$ ). In group $I_{\text {, }}$ animals had been subjected to a left unilateral nephrectomy 5 weeks before measurements, but no i.r. catheter was implanted (in = 9). In groups III, IV and V, left uninephrectomized animals were infused I.r. with saline. Durations of the infusions were respectively 2 days $(n=8$ ), 6 days (i.e. 4 days after replacement of the first pump; $n=9$ ) and 14 days (i.e. 12 days after replacement of the first pump; $n=8)$. 
At the end of the clearance experiments, animals were sacrificed with an i.v. overdose of pentobarbital and correct placement of the catheters was checked by macroscopic inspection. Data are presented as means \pm S.E.M. Groups were compared using Student's t-test for unpaired observations.

\subsection{Results}

Table 2.1 shows the results of measurements of parameters relevant to kidney function in untreated animals, left uninephrectomized animals and uninephrectomized rats at various phases of intrarenal saline infusion.

No significant aberrations in MAP in the experimental groups were observed when compared with untreated animals.

In rats, uninephrectomized 5 weeks previously, absolute levels of GFR and ERPF were clearly lower than in untreated rats. Catheterization of the right suprarenal artery of uninephrectomized rats and subsequently intrarenal saline infusion did not alter GFR and ERPF over the 14-day infusion period when compared with data in non-cannulated uninephrectomized animals.

When GFR and EPRF were normalized for right kidney weight, the same values for kidney function parameters were obtained in untreated rats, uninephrectomized rats and uninephrectomized rats receiving saline intrarenally.

The filtration fraction data indicated that neither uninephrectomy nor insertion of a catheter into the suprarenal artery on the contralateral site, interfered with renal function.

\subsection{Discussion}

The method described above provides a simple and reliable tool for obtaining access to the renal artery in rats. It has been used in acute and in chronic experiments for periods up to 14 days. For chronic infusions, it has now been used in more than 400 rats. Unlike methods described before (Beuzeville, 1968; Fine el al, 1974) it does not imply insertion of a catheter into the lumen of a renal artery.

The success ratio for the method is very high. In approximately $5 \%$ of the animals, it is impossible to use the right suprarenal artery as an access to the renal artery, because it originates from the ascending aorta. On the left side of the animals, this is always the case. Aithough preliminary observations in Sprague-Dawley rats indicate that in the latter strain the right suprarenal artery also originates from the ascending aorta in most animals, it should be regarded as a rare phenomenon in Wistar rats.

Although no anti-coagulants were used in the infusion solutions, clotting of the catheter occurred in only 4 out of the 48 rats that were used in this particular experiment. In all cases, this occurred during the tirst two days of infusion. At 
that time the minipumps were replaced by drug-containing pumps. Clotting as well as any other obstruction is evident immediately from balloon-like swelling of the sillastic part of the catheter system. The absence of clotting probably results from the implication of an Alzet osmotic minipump in the infusion system, providing a continuous flush. Although the pumping rate of the type 2001 pump is only $1 \mu \mathrm{l}$. $\mathrm{hr}^{-1}$, this results in a calculated flow velocity of an approximately 2 $\mathrm{mm} \cdot \mathrm{min}^{-4}$ in the $0.1 \mathrm{~mm}$ tip of the catheter, thus preventing any blood from entering it. In the present study, the effects of implantation of the catheter on renal function has been investigated in 44 rats. In order to prevent any possible compensation of a decreased renal function in the cannulated kidney by the contralateral kidney, the left kidney had been removed 5 weeks before the implantation of the catheter. Preliminary studies indicated that by that time the weight of the remaining kidney did not increase further. In the present study, hypertrophy was evident from the fact that in the uninephrectomized group, kidney weight was between 65 and $85 \%$ of the total kidney weight of the two-kidney group. At the time of the unilaterall nephrectomy, extreme care was taken to leave the left adrenal and its blood supply intact. Because insertion of the catheter implies interruption of the blood supply to the right adrenal it is essential that the left adrenal is functioning. In none of the animals studied so far any sign for adrenal insufficiency has been observed. In fact, by macroscopic view, left adrenal hypertrophy indicated by its enlarged size, was found in most of the rats.

Blood pressure in all groups of animals, measured intra-arterially before clearance measurements, was normal. This may be regarded as a gross indication for a normal renal function, since renal artery obstruction will result in hypertension (Davis, 1977). In the present study, direct evidence has been obtained for a normal renal function from the values for plasma clearances of ${ }^{51} \mathrm{Cr}$-EDTA and ${ }^{125}$ I.PAH, which are used as indications for respectively GFR and ERPF.

As compared to the two-kidney control group, all other groups had a slightly reduced GFR and ERPF when expressed as absolute values. However, if parameters were normalized for totall kidney weight, no differences whatsoever were observed. Furthermore, comparison of GFR and ERPF in cannulated groups and the group which was only subjected to a unilateral nephrectomy indicate that implantation of the catheter system per se did not have any effects on renal function. Also, in all groups filtration fractions were comparable.

The present study shows that it is possible to gain chronic access to the renal circulation of unrestrained rats for periods up to at least 14 days using the methods described here. There is no reason to assume that the 14-day period in this study is a maximum, since all catheter systems remained patent until termination of the animals. The fact that the catheter is not within the lumen of the renal artery is a major advantage over previously described methods (Beuzeville, 1968; Fine et al, 1974) which in our hands led to renal infarctions and hypertension. Furthermore, the latter infusion systems were only tested for periods up to $48-81$ hours (Fine et al, 1974). 
In summary, chronic catheterization of the suprarenal artery has proven to provide a reliable tool for long-term intrarenal infusions of drugs. The present study indicates that this catheterization method does not interfere with renal function. Effects of a substance, intrarenally applied via the suprarenal artery, are therefore produced directly by the drug itself. 


\section{BLOOD PRESSURE RESPONSE TO CHRONIC LOW-DOSE INTRARENAL NORADRENALINE INFUSION IN CONSCIOUS RATS*}

\subsection{Introduction}

The major conclusion of Guyton's systems analysis approach to blood pressure control is the acknowledgement of the dominance of renal function in chronic blood pressure regulation (Guyton et al, 1974). Chronic hypertension is stated to result from a shift of the renal function curve representing the steady-state relationship between mean arterial pressure (MAP) and urine output, to higher MAP levels. This adjustment in pressure control level at which excretion of water and salt is enhanced by even small increases in MAP, is present in spontaneously hypertensive rats (Norman et al, 1978).

It has been suggested in section 1.3.3 that an increased sympathetic activity towards the kidney could initiate or maintain hypertension by influencing renal function and preventing pressure diuresis and natriuresis. Directly and indirectly induced sympathetic hyperactivity towards the kidney causes renal vasoconstriction (Kubicek et al, 1953; Fink and Bryan, 1980). Additional neurogenic influences on renin release (Zanchetti et al, 1976) and renal tubular sodium reabsorption have been reviewed (DiBona et al, 1977). Direct recording of renal nerve activity shows increases in sympathetic discharge frequency towards the kidney in spontaneously hypertensive rats (Iriuchijima, 1975; Judy et al, 1976) and renal denervation delays the onset of genetic hypertension (Liard ${ }^{1977}$ ) and experimental renovascular hypertension in rats (Winternitz and Oparil, 1982). Furthermore, increased renal adrenergic activity as induced by chronic intrarenal infusion of noradrenaline causes hypertension in dogs (Katholi et al, 1977; Cowley and Lohmeier, 1979). However, effects of renal noradrenaline application at varying infusion rates in relation to increases in overall plasma noradrenaline concentrations were not studied.

Intrarenal infusion in conscious rats has not been achieved. In this chapter, the method for intrarenal infusion in unrestrained rats as described in chapter 2 is applied and the effects of a 5-day intravenous and intrarenal infusion of several doses of noradrenaline (NA) on MAP and plasma NA concentrations will be compared.

\footnotetext{
* based on: Kleinjans JCS, Smits.JFM and Struyker-Boudier HAJ: Chronic intrarenal infusion of low doses of noradrenaline produces hypertension in rats. In: Hypertension Mechanisms (eds WM Rascher, D Clough and DJ Ganten), Schattawer Verlag, Stuttgart, W. Germany, 1982, pp 490-494.

Kleinjans JCS, Simits JFM, Kasbergen CM, Vervoort-Peters HTM and StruykerBoudier HAJ: Blood pressure responses to chronic low-dase intrarenal noradrenallne infusion in conscious rats. Clin Sici 65: 111-116, 1983.
} 


\subsection{Methods}

102 male Wistar rats varying in weight from 292 to $425 \mathrm{~g}$ were used. Four weeks after removal of the left kidney, the animals were prepared under ether anesthesia for chronic infusion as follows: in 59 rats, the right suprarenal artery was cannulated with a stretched PE 10 catheter (volume $12 \mu l$ ) as described in section 2.2. In 43 rats, a silastic catheter (volume $17 \mu \mathrm{l}$ ) was inserted into the right jugular vein for intravenous infusion. Catheters for intrarenal and intravenous infusion were flushed with saline $(0.9 \% \mathrm{NaCl})$ from a subcutaneously implanted $\mathrm{Alzet}$ TM osmotic minipump. Furthermore, both groups of animals were provided with a PE 10 catheter into the fermoral artery for arterial pressure measurements and blood sampling.

After this surgery, the animals were allowed to recover for 2 days. They were housed individually and had free access to food and water. Arterial pressure was recorded under unrestrained conditions daily between 14.00 and 17.00 hours using a Strain Gauge transducer (CP01; Central Technology Company, Inglewood, $\mathrm{Ca}$ ) and a Grass 7D Polygraph. Arterial pressure data were sampled after A-D conversion by a Minc RT-11 minicomputer every 15 seconds during the last hour of each recording session; average arterial pressure (MAP) was calculated. Only rats with interdaily differences during the 2-day control period less than 10\% were used for infusion studies.

After this control period, saline minipumps were replaced under light ether anesthesia by pumps containing either saline or NA solutions in such concentrations that rates of infusion of NA of $4 \mu \mathrm{g} \cdot \mathrm{kg}^{-1} \cdot \mathrm{hr}^{-1}, 12 \mu \mathrm{g} \cdot \mathrm{kg}^{-1} \cdot \mathrm{hr}^{-1}$ " and 36 $\mu \mathrm{g} \cdot \mathrm{kg}^{-1}, \mathrm{hr}^{-4}$ were obtained.

Previously, chemical stability of NA in the pumps was tested. A $5 \mathrm{mg}$ per $\mathrm{ml}$ solution of NA ( $(-)$-arterenol bitartrate, Sigma, USA) in $0.9 \% \mathrm{NaCl}$ was prepared to which $1 \mathrm{mg}$ per $\mathrm{ml}$ ascorbic acid was added in order to prevent oxidation of NA. Two minipumps were filled with this solution and kept at $30-36^{\circ} \mathrm{C}$. The fluid released was analyzed daily for NA according to Holman et al (1976). These analyses indicated that more than $95 \%$ of the substance released daily is pure NA.

MAP was determined on five consecutive days. $0.5 \mathrm{ml}$ blood samples were taken from the animals in the experimental cage on control day as well as on the first and fourth day after starting the infusions and were analyzed for NA concentrations by means of a radioenzymatic assay (Peuler and Johnson, 1977). Plasma NA levels during intrarenal and intravenous infusion of three doses of NA were plotted against corresponding blood pressures; log concentrationeffect curves were fitted using an analyzing computer routine based on log-logit curve fitting as described by De Lean et al (1978), running on a digital Minc 11 minicomputer. Goodness of fit was evaluated on the basis of Chi-square statistics. Further data were analyzed statistically by means of non-parametric oneway analysis of variance for response curves (Zerbe, 1979) or a Student's t-test for unpaired values. 


\subsection{Results}

Chronic intrarenal NA infusion caused at all doses of NA increases in MAP which were statistically significant after 5 days of infusions as compared to levels of MAP during intrarenal saline infusions (Student's t-test; for $p$ values, see figures). Control levels of MAP varied between 94 and $126 \mathrm{mmHg}$ with a mean of $112 \pm 1 \mathrm{mmHg}$ (mean $\pm S E M$ ) and stayed within this range during saline infusion ( $\mathrm{n}=13$ ). Five days of intrarenal infusion of $4 \mu \mathrm{g} \mathrm{NA} \cdot \mathrm{kg}^{-1} \cdot \mathrm{hr}^{-1}(\mathrm{n}=14)$ increased MAP to $120 \pm 4 \mathrm{mmHg} ; 12 \mu \mathrm{g} \mathrm{kg}^{-1} \cdot \mathrm{hr}^{-1}(\mathrm{n}=7)$ elevated MAP to 131 $\pm 3 \mathrm{mmHg}$, and $36 \mu \mathrm{g} \cdot \mathrm{kg}^{-1} \cdot \mathrm{hr}^{-1}(\mathrm{n}=15)$ brought MAP up to even $150 \pm 3$ $\mathrm{mmHg}$ (fig. 3.1a).

Before starting intravenous infusions, MAP varied between 99 and 130 $\mathrm{mmHg}$ with a mean of $111 \pm 2 \mathrm{mmHg}$; MAP stayed at control levels during sallne infusion $(n=9)$. Intravenous application of $4 \mu \mathrm{g} \mathrm{NA} \cdot \mathrm{kg}^{-1} \cdot \mathrm{hr}^{-1}(\mathrm{n}=8)$ for 5 days did not cause significant changes in MAP. Increases in MAP during intravenous infusion of $12 \mu \mathrm{g} \mathrm{kg}^{-1} \cdot \mathrm{hr}^{-1}(\mathrm{n}=10)$ gained significance at day 5 when MAP reached levels of $121 \pm 3 \mathrm{mmHg}$. Intravenously applied doses of 36 $\mu \mathrm{g} \cdot \mathrm{kg}^{-1} \cdot \mathrm{hr}^{-1}(\mathrm{n}=12)$ increased MAP significantly up to $140 \pm 4 \mathrm{mmHg}$ on day 5 (fig. 3.1b). Fig. 3.2 summarizes the difference in MAP evaluated by means of an analysis of variance during chronic intrarenal vs. intravenous infusion of saline and three doses of noradrenaline. While there is no difference in MAP during saline infusion at both routes, intrarenal NA infusion produced significant greater increases in MAP compared to intravenous application at each dose for the complete infusion perïod.

Control pllasma NA levels before starting intrarenal infusions were $0.52 \pm$ $0.01 \mathrm{ng} \cdot \mathrm{ml}^{-1}$ and NA concentrations did not change during salline infusion when compared by means of a Student's ttest. Intrarenall infusion of each dose of NA raised plasma NA concentrations slowly but significantly on day 4 (Fig. 3.3). Intrarenal infusion of $4 \mu \mathrm{g} \mathrm{NA} \cdot \mathrm{kg}^{-1} \cdot \mathrm{hr}^{-1}$ resulted in plasma NA levels of $1.65 \pm$ $0.40 \mathrm{ng} \cdot \mathrm{ml}^{-1}$. At doses of $12 \mu \mathrm{g} \mathrm{NA} \cdot \mathrm{kg}^{-1} \cdot \mathrm{hr}^{-1}$ plasma NA concentrations of 3.00 $\pm 0.60 \mathrm{ng} \cdot \mathrm{ml}-1$ and at doses of $36 \mu \mathrm{g} \mathrm{NA} \cdot \mathrm{kg}^{-1} \cdot \mathrm{hr}^{-1}$, plasma NA levels of even $7.33 \pm 1.77 \mathrm{ng} \cdot \mathrm{ml}^{-1}$ were obtained.

On the day of starting intravenous infusions, plasma NA concentrations were $0.56 \pm 0.01 \mathrm{ng} \cdot \mathrm{ml}^{-1}$ "NA levels did not change significantly during chronic intravenous infusion of either saline or NA at doses of $4 \mu \mathrm{g} \cdot \mathrm{kg}^{-1} \cdot \mathrm{hr}^{-1}$. Doses of $12 \mu \mathrm{g} \mathrm{NA} \cdot \mathrm{kg}^{-1} \cdot \mathrm{hr}^{-1}$ raised plasma NA levels significantly to $1.61 \pm 0.21 \mathrm{ng} \cdot \mathrm{ml}^{-1}$ and doses of $36 \mu \mathrm{g} \mathrm{NA} \cdot \mathrm{kg}^{-1} \cdot \mathrm{hr}^{-1}$ to $3.63 \pm 0.28 \mathrm{ng} \cdot \mathrm{ml}^{-1}$ on day 4 .

The role of the systemic elevations of plasma NA was further analyzed by plotting plasma NA concentrations during intrarenal and intravenous NA infusion against corresponding blood pressures and fitting sigmoid log concentrationeffect curves (fig. 3.4). Goodness of fit was evaluated applying the sum of square residues principle. The relationship between plasma NA concentrations and MAPs during intrarenal and intravenous NA infusion appeared to be described 


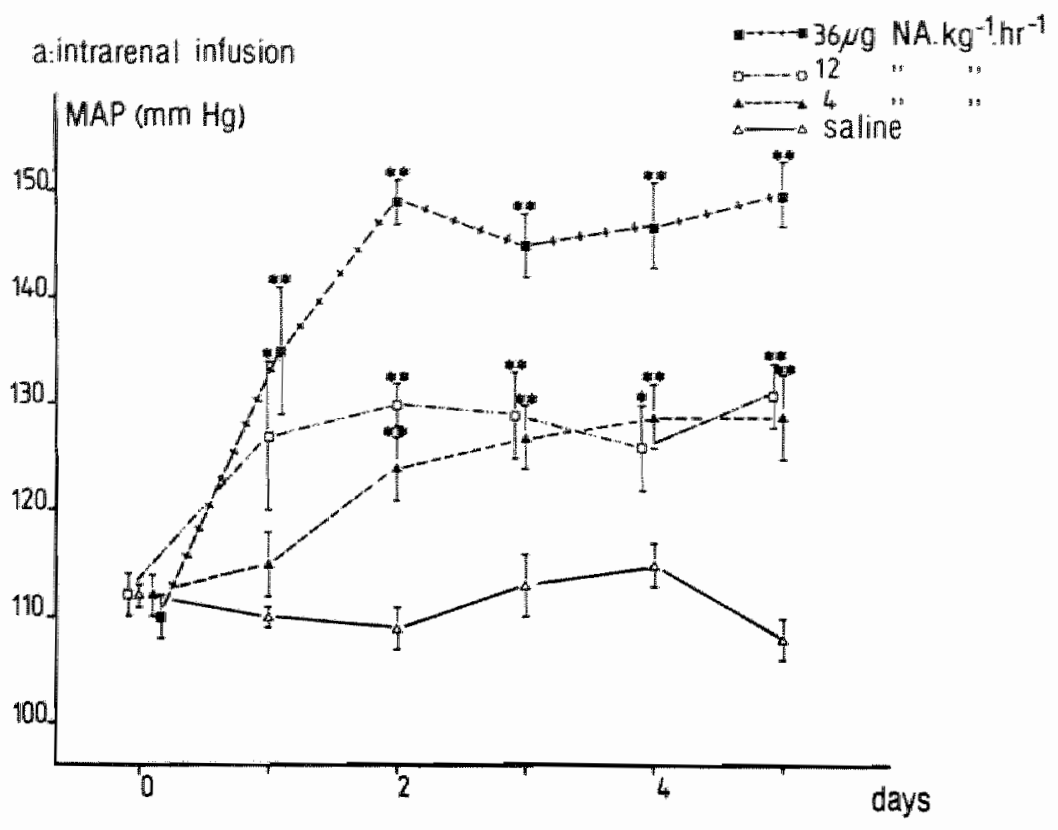

bintravenous infusion

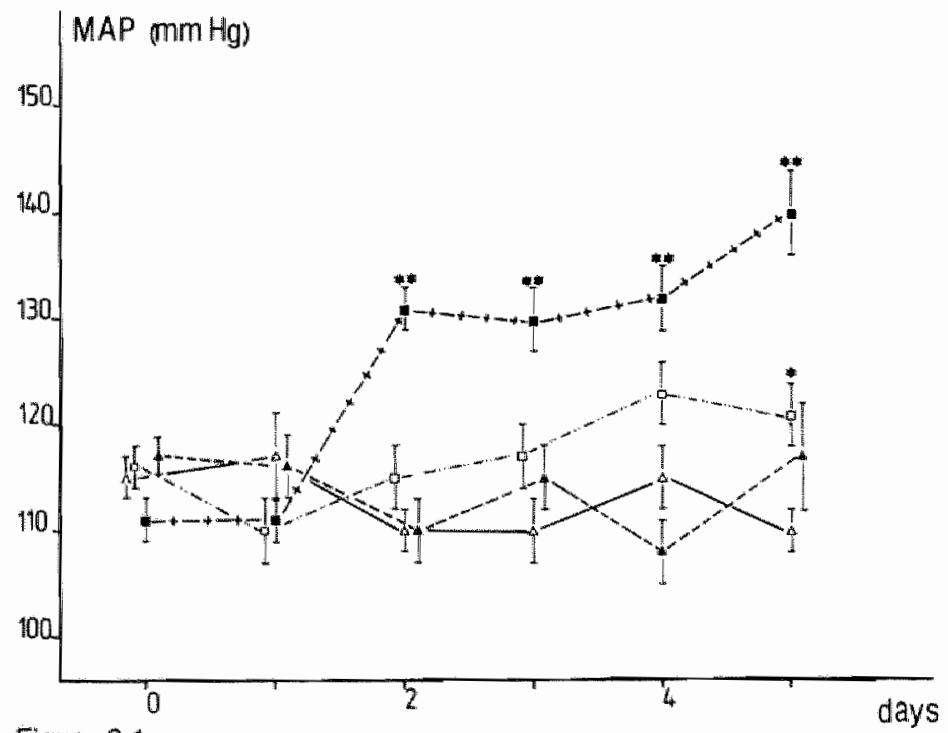

Figure 3.1

Effects on MAP during intrarenal (a) and intravenous (b) infusion of three doses of noradrenaline as compared with saline.

" $p<0.05 ; "$ " $p<0.005$ (Student's t-test). 


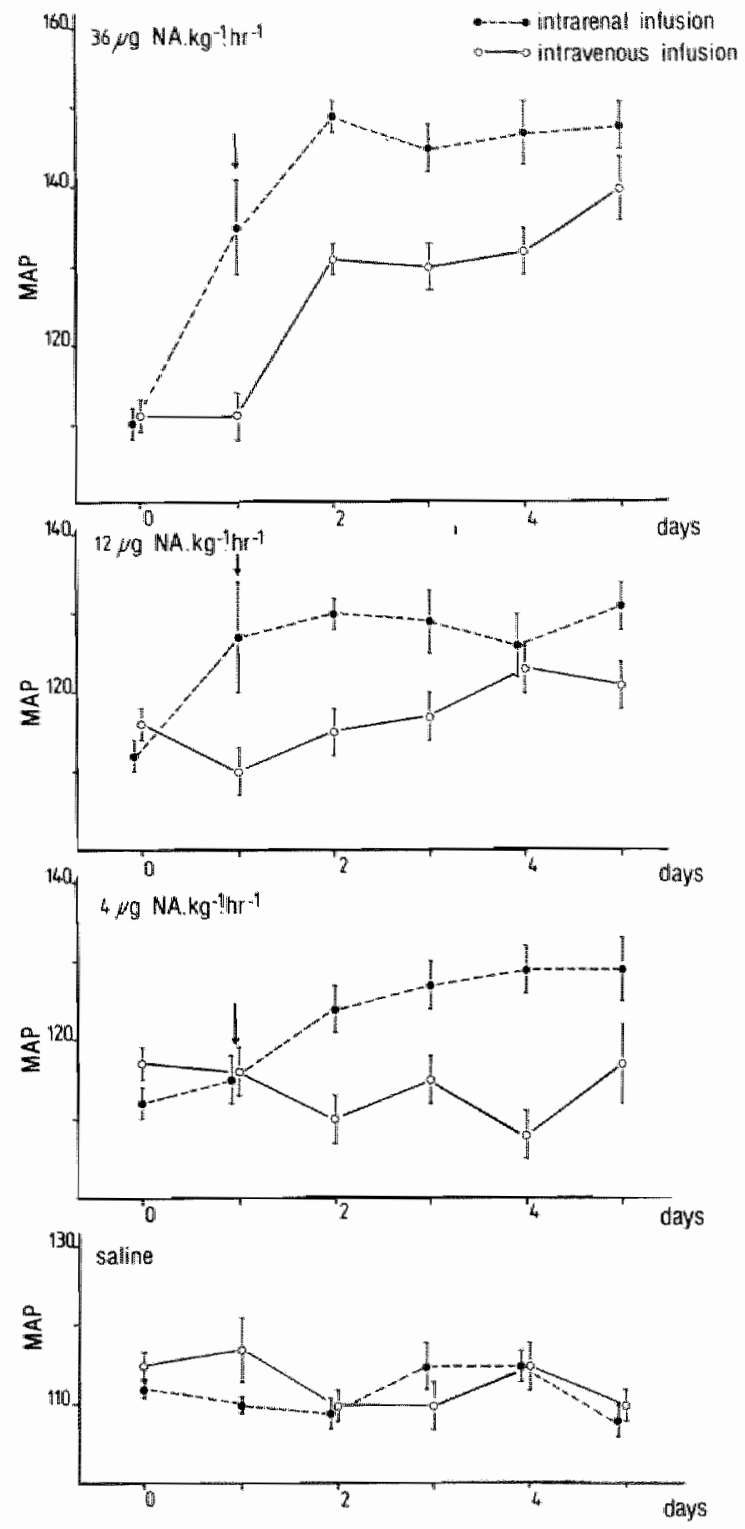

Figure 3.2

Differences in MAP during whole periods of intrarenal and intravenous infusion of three doses of noradrenaline and saline.

Arrows indicate first appearance of significant differences. $p<0.01$ (analysis of variance). 
well enowgh $\left(X^{2}{ }_{i r}=28.62<X^{2} p=0.05\right.$, when $v=40 ; X^{2}$ iv $=36.61<X^{2} p$ $=0.05$. when $v=56$ ) by presented log concentration-effect curves indicating an increased responsiveness of MAP to elevation of plasma NA concentrations during intrarenal NA infusion vs. intravenous NA.

\subsection{Discussion}

These experiments showed that renal adrenergic hyperactivity in uninephrectomized conscious rats as caused by chronic intrarenal infusion of NA induced sustained hypertension at doses which were non-effective when infused intravenously. Doses of noradrenaline which elevated MAP when given intravenously caused even greater increases in MAP when given intrarenally. These findings support the hypothesis that a renal neurogenic factor e.g. intrarenal noradrenergic activity, is involved in the development and maintenance of experimental hypertension in rats (Liard, 1977; Winternitz and Oparil, 1982) and essential hypertension in men (Hollenberg et al, 1978).

Intravenous infusion of NA at doses between 12 and $40 \mu \mathrm{g} \cdot \mathrm{kg}^{-1} \cdot \mathrm{hr}^{-1}$ has been reported to elicit pressor responses in conscious rabbits (DeSwiet and Dickinson, 1969), rats (Yamori et al, 1980), dogs (Johnson et al, 1979; CasalsStenzel et al, 1982), and men (Silverberg et al, 1978; Beretta-Piccoli et al, 1980), probably by stimulating vascular alpha-adrenoceptors (Yamori et al, 1980). In general, intravenous NA infusion had to raise plasma NA levels to $1.6 \mathrm{ng} \cdot \mathrm{m}^{-11}$ (3.2 on the logarithmic scale of Fig. 3.4) or higher in order to produce hypertension.

Considerably lower doses of NA when infused intrarenally in conscious one-kidney dogs, increase blood pressure (Johnson et al, 1979); furthermore, chronic intrarenal NA infusion at a rate of $17 \mu \mathrm{g} \cdot \mathrm{kg}^{-1} \cdot \mathrm{hr}^{-1}$ causes a sustained elevation in MAP of approximately $25 \mathrm{mmHg}$ while intravenous infusion of the same dose resulted in either transient (Katholi et al ${ }^{1977)}$ ) or sustained but significantly smaller increases in blood pressure (Cowley and Lohmeier, 1979). However, plasma NA levels during intrarenal and intravenous infusion appear to be the same at day 1 in the study in which plasma concentrations were actually measured (Katholl et al, 1979).

We found higher increases in plasma NA concentrations during intrarenal NA infusion, especially on day 4 (fig. 3.3) which means that at least part of the observed higher MAP during intrarenal NA administration may be attributed to higher plasma NA concentrations.

Either differences in modulation of the endogenous NA release mechanism or relatively more decreased NA clearance can account for higher plasma NA levels during intrarenal infusion. Circulating NA is mainly cleared by reuptake in sympathetic nerve endings (uptake1) (Iversen, 1973) and blood flow to richly innervated organs could determine NA clearance. Higher plasma levels of NA during intrarenal NA infusion could be caused by differences in blood flow distri- 
bution towards clearing organs. However, blood flow distribution data during chronic intrarenal NA infusion in the dog or in the rat are not yet available.

Furthermore, both glomerular filtration and tubular secretion contribute to the renal clearance of unbound NA (Silva et al, 1979). It is assumable that the concentration of unbound NA in the kidney is much higher during intrarenal than during intravenous NA infusion. The possibility exists that a decrease in glomerular filtration rate as observed during intrarenal infusion of NA in dogs (Cowley and Lohmeier, 1979) results in a rather steep decrease in renal NA clearance which explains the higher plasma NA levels.

Finally, an alternative explanation for the higher elevations in plasma NA concentration during intrarenal NA infusion could be a relatively more activated sympathetic nerve system due to stimulation of renal afferent nerves as is proposed by Winternitz and Oparil (1982), in order to elucidate the role of the sympathetic nerve system during established Goldblatt hypertension. Catecholamines have been suggested to stimulate afferent nerve tracts via modulation of arterial chemoreceptors (Mills and Smith, 198i3).
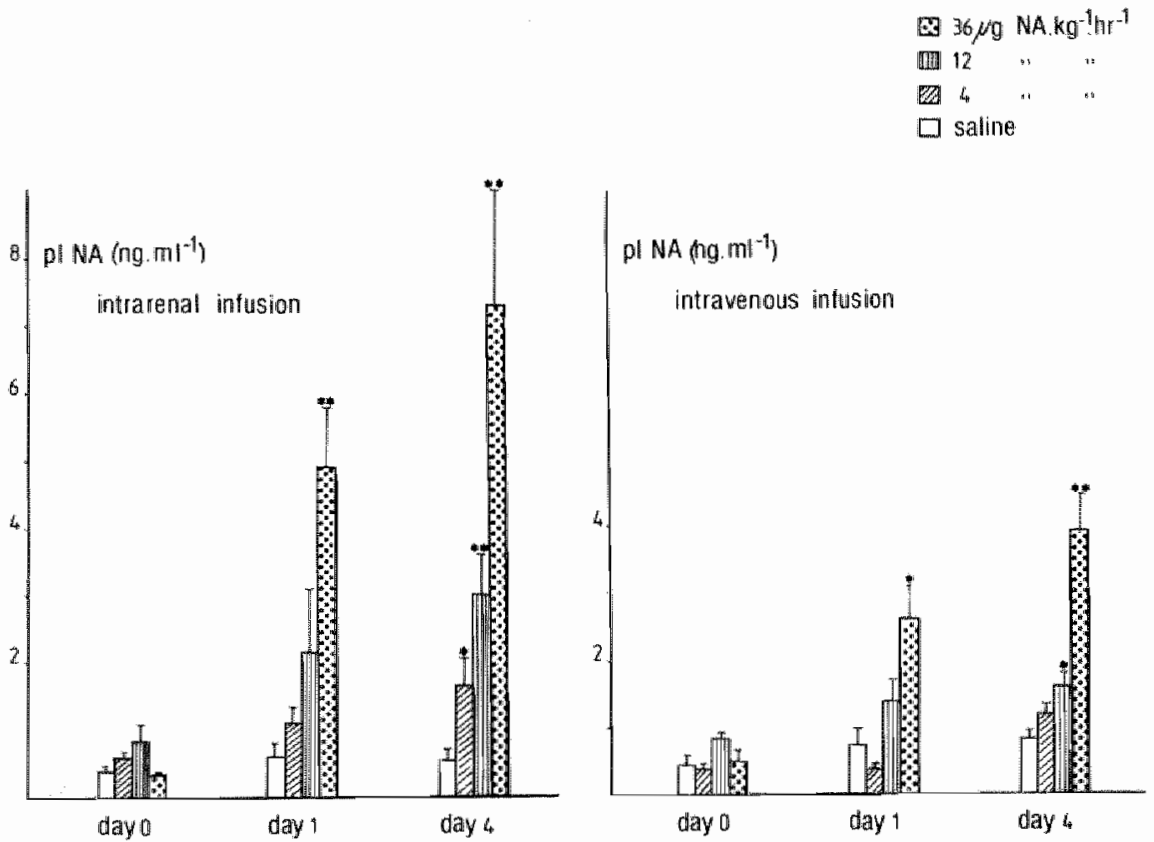

Figure 3.3

Plasma noradrenaline concentrations during intrarenal and intravenous infusion of three doses of noradrenaline and saline.

"p<0.05; "p<0.005 (Student's t-test). 
The experiments described in this chapter indicate that intrarenal infusion of doses as low as $4 \mu 9 \mathrm{NA} . \mathrm{kg}^{-1} \cdot \mathrm{hr}^{-1}$ causes hypertension without abvious increases in circulating plasma NA levels after $24 \mathrm{hr}$ of infusion. Hypothesized increased responsiveness of MAP to elevating plasma NA levels during intrarenal infusion of three doses of NA was confirmed by plotting plasma NA concentrations against corresponding MAPs and fitting log concentration-effect curves. The lack of plasma NA data lying on the flat upper part of the concentrationeffect curve during intravenous NA infusion does not necessarily lead to misinterpretation since the log-logit curve fitting computer model is able to correct for this problem (De Lean et al, 1978). It appears that the log concentration-effect curve is shifted to the left during intrarenal NA infusion. vs. intravenous infusion, indicating that any elevation of plasma NA levels above approximately 1.40 ng. $\mathrm{ml}^{-1}$ (3.1 on the logarithmic scale of Fig. 3.4) caused by intrarenal NA infusion induces higher levels of MAP compared to effects on MAP during intravenous infusion. This extra pressor effect during intrarenal NA infusion could be explained by increased sensitivity of vascular NA receptors. This is possibly

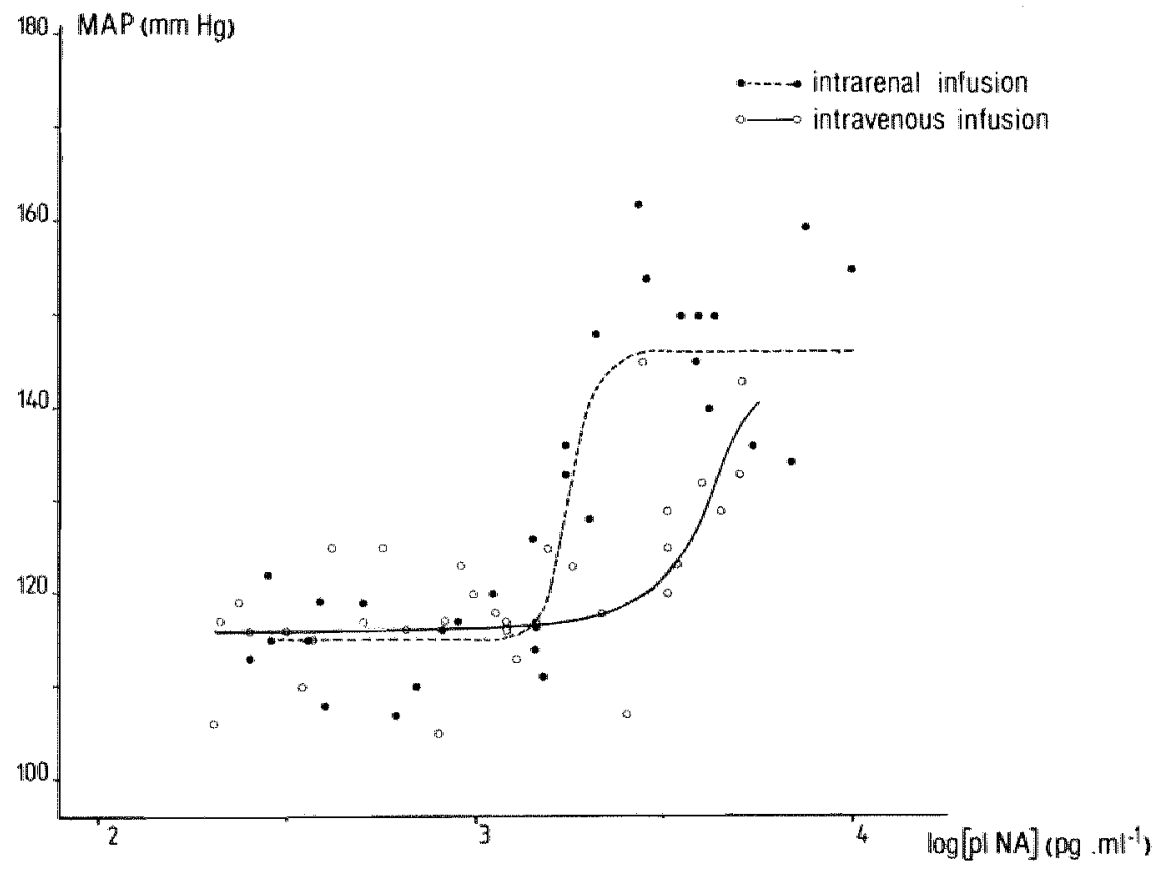

Figure 3.4

Comparison of $\log$ concentration-response curves during intrarenal and intravenous infusion of noradrenaline. 
caused by varied modulation of electrolyte balance, e.g. on the level of tubular sodium reabsorption (DiBona et al, 1977) which has been shown to mediate NA receptor sensitivity in the dog (Cowley and Lohmeier, 1979).

However, another explanation could be triggering of an additional intrarenally located pressor mechanism. Obviously, activation of the renin-angiotensin system is suggested. Increased plasma renin activity (PRA) during intrarenal NA infusion in the dog has been reported (Cowley and Lohmeier, 1979 "Ayers et al 1981). Chronic increases in PRA elevate circulating angiotensin Ill levels which in turn results in hypertension by the direct pressor effects (Bean et al ${ }^{1978)}$. Furthermore, angiotensï II facilitates NA release by adrenergic nerve endings (Zimmerman, 1978). Increased formation of angiotensin during intrarenal NA infusion in conscious rats may contribute to elevations in arterial pressure by the direct vasoactive action of the octapeptide and the presynaptic stimulation of NA release.

In the last place, intrarenal NA administration probably interferes with renal function primarily, causing renal vasoconstriction, renin secretion and changes in tubular reabsorption. The relatively higher renal load of NA during intrarenal infusion compared with intravenous infusion, especially at the low infusion rate of $4 \mu \mathrm{g} \mathrm{NA} \cdot \mathrm{kg}^{-1} \cdot \mathrm{hr}^{-1}$ may lead to retention of fluid and salt by the kidney, increasing extracellular fluid volume and plasma volume. This, in turn, will result in elevations of MAP according to the cascade theory of whole body autoregulation as described in section 1.3.1 which are superimposed on the higher MAP levels during intrarenal NA infusion, due to more increased plasma NA concentrations.

The strategy for further characterization of cardiovascular effects during stimulation of renal adrenergic mechanisms may be obvious from the various ad hoc hypotheses proposed in this chapter, to explain the pressor response observed during chronic intrarenal NA infusion. The following chapters are aimed at an analysis of each of these hypotheses.

In chapter 4 , it will be investigated whether the relatively higher plasma concentrations of NA during intrarenal infusion are to be attributed to a decrease in whole body clearance of NA, due to effects on central and renal hemodynamic parameters of the drug itself, or alternatively to an increase in endogem nous NA release. By means of infusion of ${ }^{3} \mathrm{H}-\mathrm{NA}$ along with unlabelled NA via the osmotic minipumps, the contribution of exogenously administered NA to overall plasma concentrations will be established.

Chapter 5 will evaluate changes in the renin-angiotensin system under the influence of intrarenal and intravenous NA infusion. Angiotensin II formation will be blocked chronically by means of the intraperitoneally administered converting enzyme inhibitor captopril, along with the long-term NA infusion. Determinations of MAP and plasma NA levels will reveal whether the support of circulating angiotensin II to NA-induced hypertension is direct or indirect via facilitation of NA release. 
In chapter 6, renal function will be studied during acute as well as during chronic intrarenal NA infusion in order to evaluate the primacy of renal vasoconstriction to increases in MAP. Furthermore, pathological conditions to the kidney, resulting from NAmediated ischemic insult, will be excluded.

Chapter 7 contains the hemodynamic characterization of acute and chronic cardiovascular effects of intrarenal and intravenous NA infusion.

Chapters 7 and 8 will analyze the hypothesis of the cascade-like development of NA-induced hypertension. In chapter 8 , body laad of fluid and salt will be determined during chronic intrarenal and intravenous NA infusion and related to intake as well as excretion of water, sodium and potassium.

Finally, chapter 9 will integrate the effects of long-term activation of the renal adrenergic mechanisms on cardiovascular parameters within the concept of changes in renal function related to sustained hypertension as described in the General Introduction. 


\section{DETERMINATION OF WHOLE BODY CLEARANCE AND APPARENT RELEASE RATE OF NORADRENALINE DURING CHRONIC NORADRENALINE INFUSION}

\subsection{Introduction}

In the previous chapter, it was described that the relatively higher pressor response to chronic intrarenall infusion of noradrenaline (NA) compared with intravenous application of the same doses of NA had in part to be attributed to achieved higher plasma concentrations of NA. Especially, on the 4th day of NA infusion, the difference in increases in plasma NA levels produced by intrarenal respectively intravenous NA administration was very obvious.

The first explanation for this observation might be that during intrarenal NA infusion, for some reason, the whole body clearance of NA has decreased relatively. The half-life of NA in plasma is very short (Ferreira and Vane, 1967) and it is mainly cleared by peripheral vascular beds. NA is taken up by richly sympathetically innervated tissues as the heart, the spleen, the lungs, the adrenal glands, and to a lesser extent, the kidneys (Whitby et al, 1961). Both neuronal (uptake ( $_{1}$ ) and extraneuronal (uptak $\theta_{2}$ ) reuptake processes account for the tissue binding of circulating NA (Lightman and Iversen, 1969; Iversen, 1973; Bell and Kushinsky, 1978); after blockade of uptake, by desmethylimipramine and uptake $_{2}$ by normetanephrine in rats, the half-life of NA is prolonged from 1.5 to 6.3 minutes (Benedict et al, 1978).

Also metabolic clearance contributes considerably to the disappearance of NA from plasma (Gitlow et al, 1981). Furthermore, non-protein bound NA is cleared by the kidney via glomerular filtration (Silva et al, 1979) as well as via active tubular secretion (Silva et al. 1979; Willis et al ${ }_{\text {1 }}$ 1980; Ball et al ${ }_{n} 1982$ ). Decreases in renal blood flow and glomerular filtration rate as produced by chronic intrarenal infusion of NA in conscious dogs (Cowley and Lohmeier, 1979) may affect renal clearance of NA.

The second explanation for the relatively steeper rises of plasma NA concentration during intrarenal NA infusion could be that the overall sympathetic activity monitored by plasma NA levels (De Champlain, 1978; Micalizzi and Pals, 1979; Wallin et al, 1981) was increased. The trigger for this sympathetic hyperactivity could be the stimulation of renal afferent nerves directly or indirectly by intrarenal effects of NA. Changes of renal afferent nerve activity has been proposed to mediate in the plasma NA levels elevations in Goldblatt hypertensive rats (Winternitz and Oparil, 1982).

In this chapter, a method for estimating the rate of entry of NA into plasma (NA apparent release rate) and clearance of NA as developed by Esler et al (1979) and modified for use in chronically NA-infused rats, was applied.

Although this method does not provide an index for the amount of NA which 
was produced endogenously and which was released from the osmotic minipumps, the determination of NA clearance and NA apparent release rate may elucidate to what extent changes in these parameters were responsible for the observed differences in plasma NA concentrations during chronic intrarenal and intravenous $N A$ infusion.

\subsection{Methods}

6 Rats were cannulated under ether anesthesia with a catheter into the right suprarenal artery for chronic intrarenal infusion; in 8 rats, a catheter was inserted into the right jugular vein for intravenous infusion as described in section 3.2 . Furthermore, the animals were provided with a catheter into the left femoral artery for blood sampling. Osmotic minipumps containing saline and $7-{ }^{3} \mathrm{H}-\mathrm{NA}$ (NET-377, New England Nuclear, specific activity 1-5 Cl/mmol, more than $95 \%$ pure ${ }^{3} \mathrm{H}$-NA) stabilized with a $1 \mathrm{mg} / \mathrm{ml}$ ascorbic acid were subcutaneously implanted and connected to the suprarenal artery or jugular vein catheter.

The rats were infused with saline and $7-3 \mathrm{H}-\mathrm{NA}$ at a dose of approximately $185.000 \mathrm{cpm} . \mathrm{hr}^{-1}$ for 2 days. On the second day, blood samples of $1.5 \mathrm{ml}$ were taken for determination of basal levels of plasma NA clearance and apparent release rate. After that, the saline minipumps were changed under light ether anesthesia by pumps containing, again, $7{ }^{3} \mathrm{H}-\mathrm{NA}$ as well as unlabelled NA in such concentrations that intrarenal and intravenous infusion rates of 185.000 $\mathrm{cpm}{ }^{3} \mathrm{H}-\mathrm{NA} \cdot \mathrm{hr}^{-1}$ and $36 \mu \mathrm{g} \mathrm{NA} \cdot \mathrm{kg}^{-1} \cdot \mathrm{hr}^{-1}$ (13 $\left.\mu \mathrm{g} \mathrm{NA} \cdot \mathrm{hr}^{-1}\right)$ were obtained. Blood samples were taken on the 1 st and 4 th day of chronic NA infusion, immediately cooled and centrifugated. The red blood cells resuspended in $1 \mathrm{ml} 0.9 \% \mathrm{CaCl}$ were resubstituted and plasma was assayed for ${ }^{3} \mathrm{H}-\mathrm{NA}$ and unlabelled NA as follows: to $400 \mu \mathrm{l}$ plasma was added $4 \mathrm{ml}$ Tris- $\mathrm{HCl}$ buffer, $\mathrm{pH}=8.6$, and $200 \mathrm{mg}$ aluminia (W 200, ICN Pharma) activated according to Anton and Sayre (1962). Standard procedures for determination of tritiated NA in plasma were applied (Esler et al, 1979; Majewski et al, 1982). ${ }^{3} \mathrm{H}-\mathrm{NA}$ was eluted by vortexing with 800 $\mu l 1 \mathrm{M} \mathrm{HCl}$. Pilot studies indicated that $1 \mathrm{M} \mathrm{HCl}$ recovers ${ }^{3} \mathrm{H}-\mathrm{NA}$ from the aluminia by $100 \%$ after correction for measuring errors.

The remaining plasma was assayed for unlabelled NA according to the ra* dioenzymatic method of Peuler and Johnson (1977) as described in section 3.2. Pillot experiments $(n=4)$ during which plasma was incubated without the presence of COMT, showed that tritiated metabolites of ${ }^{3} \mathrm{H}$-NA possibly occurring in plasma did not interfere with the radioenzymatic NA assay beyond the background level of radioactivity.

The specific activity of ${ }^{3} \mathrm{H}-\mathrm{NA}$ in plasma was then calculated. Whole body clearance and apparent release rate into plasma of NA were calculated using the following equations (Esler et al, 1979): 
NA apparent release rate $=$ $\left(\mu \mathrm{g} \cdot h r^{-1}\right)$

${ }^{3} \mathrm{H}-\mathrm{NA}$ infusion rate $\left(\mathrm{cpm} \cdot \mathrm{hr}^{-1}\right)$

specific activity of ${ }^{3} \mathrm{H}-\mathrm{NA}$ in plasma $\left(\mathrm{cpm} \cdot \mu \mathrm{g}^{-1}\right)$

Data are expressed as mean \pm S.E.M. and were statistically analyzed by means of a Student's t-test for unpaired values.

\subsection{Results}

Values of whole body clearance and apparent release rate of NA during a control period followed by 5 days of continuous intravenous or intrarenal infusion of $36 \mu \mathrm{g} \mathrm{NA} \cdot \mathrm{kg}^{-1} \cdot \mathrm{hr}^{-1}$, are given in Table 4.1 .

Before starting the intrarenal NA infusion "plasma NA concentrations were $0.64 \pm 0.14 \mathrm{ng}^{-1} \mathrm{ml}^{-1}$ and the intrarenally applied infusion rate of $36 \mu \mathrm{g}$ NA. $\mathrm{kg}^{-1} \cdot \mathrm{hr}^{-1}$ produced significant increases to $7.44 \pm 1.62 \mathrm{ng} \mathrm{NA} \cdot \mathrm{ml}^{-1}$ on day 4. Intravenous infusion of the same dose of NA raised plasma NA leveis from $0.66 \pm 0.15 \mathrm{ng} \cdot \mathrm{ml}^{-11}$ significantly to $4.77 \pm 1.04 \mathrm{ng} \cdot \mathrm{ml}^{-1}$. On the 4 th day of intrarenal NA infusion, plasma NA levels were increased by $56 \%$ above the concentrations obtained by intravenous infusion of the same dose of NA. These data are comparable with the results on changes in plasma NA levels in the previous study described in chapter 3 (see Fig. 3.3). The calculated NA clearance on control day during intrarenal infusion of ${ }^{3} \mathrm{H}-\mathrm{NA}$ was $3.52 \pm 1.51 \mathrm{l} . \mathrm{hr}^{-1}$ which was insignificantly higher than the $2.23 \pm 0.54 \mathrm{I} \mathrm{hr}^{-1}$ found during intravenous ${ }^{3} \mathrm{H}$ NA application. During 4 days of intravenous NA infusion, the clearance of NA was within control range. On the 4th day of intrarenal NA application, the NA clearance was decreased by $66 \%$ which was significantly lower than values obtained during intravenous NA infusion.

The apparent rate of entry of NA into plasma under normal conditions was approximately $1.5 \mu \mathrm{g} \cdot \mathrm{hr}^{-1}$. During chronic intrarenal NA infusion, the NA apparent release rate increased steeply to levels of $9.01 \pm 4.06 \mu \mathrm{g} \cdot \mathrm{hr}^{-1}$ insignificantly higher than values of $4.481 .07 \mu \mathrm{g} \cdot \mathrm{hr}^{-1}$ found on the $1 \mathrm{st}$ day of intravenous NA application. The apparent release rate of NA was equal in the later phase of intrarenall and intravenous NA infusion.

\subsection{Discussion}

This chapter presents preliminary observations on the mechanism responsible for the observed differences in plasma NA concentration increases during longterm intrarenal and intravenous NA infusion. The rather large interindividual va- 


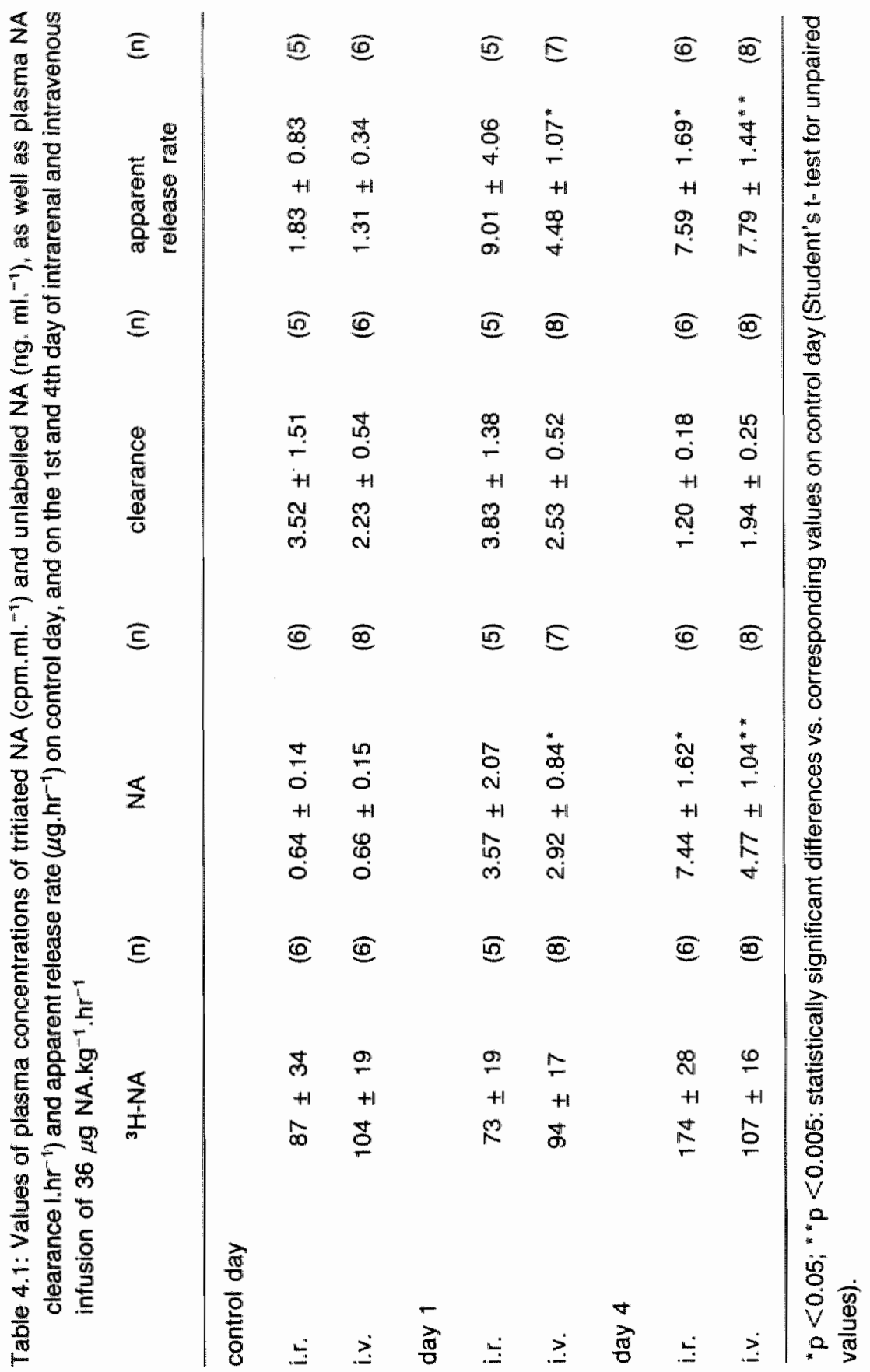


riations and the small groups of animals in the present study prevent definite conclusions but interesting observations on whole body clearance of NA and the NA apparent release rate, a relative index for the rate of entry of NA into plasma, have been made.

It is shown that whole body clearance of NA in rats under control conditions is 2.2-3.5 $1 . \mathrm{hr}^{-1}$ dependent on the infusion route and thereby an the differences in extraction ratio of NA by the heart vs. the kidney. These levels are deviant from values of total systemic clearance of NA obtained via alternative methods in rabbits (approximately $4.4 \mathrm{l} . \mathrm{kg}^{-1} \cdot \mathrm{hr}^{-1}$ ) (Brown et al, 1979; Majewski et al 1982) and men (approximately $3.5 \mathrm{I} . \mathrm{kg}^{-1} \cdot \mathrm{hr}^{-1}$ ) (Silverberg et al, 1978; Esler et $\mathrm{al}_{,}$1979). The high values in the rat are probably due to species differences; furthermore, it has to be recognized that in generall, the more reliable method for measurement of NA clearance is obviously by means of determination of plasma disappearance curvves of NA after rapid bolus injections of ${ }^{3} \mathrm{H}-\mathrm{NA}$ which in practice will be difficult because of the short half-life of NA.

NA clearance remained unaltered during chronic intravenous NA infusion but steeply decreased on the 4 th day of intrarenal NA application. Since neuronal uptake of NA (Iversen, 1973) as well as active tubular secretion (Silva et al. 1979; Willis et al, 1980) are probably concentration-dependent processes, it is suggested by the data of the present study that chronic intrarenal NA infusion eventually saturated the renal extraction mechanism of NA. Furthermore, impairment of the glomerular filtration rate as actually induced on the 4th day of long-term intrarenal but not intravenous infusion of $36 \mu \mathrm{g} \mathrm{NA} . \mathrm{kg}^{-1} . \mathrm{hr}^{-1}$ as shown in chapter 6 , might additionally or alternatively reduce the urinary excretion of NA (Masuyama et al, 1979; Ball et al, 1982).

It is concluded that decreased whole body clearance of NA specifically during intrarenal NA infusion accounted for the relatively higher plasma NA concentrations on the 4th but not on the 1st day of NA application.

Under normal conditions, the apparent release rate of NA was $1.5 \mu \mathrm{g} . \mathrm{hr}^{-1}$ which was equal to values obtained in rabbits if normalized for body weight (Majewski et al, 1982) but considerably higher than in men (Esler et al, 1979).

On the ist day of chronic intrarenal NA infusion, the rate by which NA entered into plasma was increased to a substantially higher level than during intravenous NA application, but this infusion route-dependent discrepancy in the increases of the NA apparent release rate had disappeared by the 4th day of chronic NA infusion. Since whole body clearance of NA had not changed on the 1 st day of NA application as compared with control values during intrarenal and intravenous infusion of ${ }^{3} \mathrm{H}-\mathbb{N A}$ combined with saline, it is concluded that the release of endogenously produced NA was elevated specifically on the 1st day of intrarenal infusion of $36 \mu \mathrm{g} \mathrm{NA} . \mathrm{kg}^{-1} \cdot \mathrm{hr}^{-1}$ although it is acknowledged that the applied method does not allow distinct discrimination between exogenously and endogenously released NA. The differences in plasma NA concentration in the initial phase of intrarenal and intravenous NA infusion are thus likely due to in- 
creased spillover of NA from the synaptic clefts of sympathetic nerves induced via renal adrenergic hyperactivity.

This elevated activity of the sympathetic nervous system on the 1st day of intrarenal NA infusion was possibly triggered by changes in discharge frequencies of renal afferent nerves. Stimulation of afferent nerves originating from the kidney has been suggested to account for the observed high plasma NA levels in Goldblatt hypertensive rats (Katholi et al, 1982).

Since renal ischemia has been found to increase discharge frequencies in renal afferent nerves (Recordati et al, 1981a) and intrarenal NA infusion decreases renal blood flow (Katholi et al, 1977; Cowley and Lohmeier, 1979; see also chapter 6), NA might modify renal afferent nerve activity indirectly by changing renal hemodynamics. Furthermore, NA has been shown to stimulate afferent nerves directly via chemoreceptors (Mills and Smith, 1983). The fact that the NA apparent release rate was equal on the 4th day of intrarenal and intravenous NA infusion might indicate that by that time the increases in overall sympathetic activity were no longer dependent on the route of NA administration.

Lastly, it could be argued that the actually measured plasma concentrations of unlabelled NA during intravenous and intrarenal NA infusion were considerably lower than calculations based on infusion rate and clearance data would have predicted.

Under-estimation of the NA clearance by the applied method remains possible due to the isotope effect with regard to neuronal uptake and metabolic degradation (Trendelenburg et al, 1983). Furthermore, NA is conjugated by the enzyme phenolsulfotransferase instantly upon its appearance into plasma (Kuchel et al, 1982). If the aluminium oxide also extracted conjugated ${ }^{3} \mathrm{H}-\mathrm{NA}$ from plasma, under-estimation of whole body clerarance of NA might have been the consequence. In summary, the higher plasma NA concentrations produced by intrarenal NA infusion, compared with intravenous application of the same doses of NA, are to be attributed initially to specifically increased endogenous NA release indicating overall sympathetic hyperactivity possibly caused by renal afferent nerve stimulation and to decreased whole body clearance of NA in the established stage of hypertension. 


\section{PLASMA RENIN ACTIVITY MEASUREMENTS AND EFFECTS OF CAPTOPRIL DURING NORADRENALINE-INDUCED HYPERTENSION}

\subsection{Introduction}

Activation of the renin-angiotensin system is likely to occur during intrarenal noradrenaline infusion in conscious rats. As reviewed in section 1.2.2, release of renin by the juxtaglomerular apparatus in the kidney is under direct control of renal sympathetic nerves. Low-level electrical stimulation of efferent renal nerves in dogs and cats increases renin secretion without affecting renal hemodynamic parameters (Osborn et al, 1980; Holdaas et al, 1981; Ammons et al, 1982). Intrarenal infusion of noradrenaline (NA), increasing the local neurotransmitter concentration sharply, stimulates plasma renin activity in conscious dogs (Katholi et al, 1977; Cowley and Lohmeier, 1979; Ayers et al, 1981).

Intravenous NA infusion also increases plasma renin activity in dogs (Katholi et al, 1977; Anderson et al, 1981), rats (Arundell and Johns, 1982), and men (Vlachakis, 1979; Beretta-Piccoli et all, 1980), maybe by increasing noradrenaline delivery to the kidney or by reducing glomerular filtration rate as observed in dogs (Cowley and Lohmeier, 1979. However, there still exists considerable discrepancy with regard to the response of renin rellease to intrarenal and intravenous infusion of NA.

Relatively higher renin release, and therefore increased levels of the circulating vasoactive peptide angiotensin II, may account for the additional pressor response in rats to chronic intrarenal NA infusion as described in chapter 3 . Furthermore, angiotensin II could contribute to observed higher plasma levels of NA during intrarenal infusion compared with intravenous infusion, by means of presynaptic stimulation of NA release from sympathetic nerve endings (Zimmerman, 1978).

In the present chapter, activation of the renin-angiotensin system during chronic intrarenal and intravenous NA infusion was determined directly by measuring plasma renin activity (PRA), as well as indirectly by measuring effects after inhibition of angiotensin II formation by means of long-term intraperitoneal administration of the converting enzyme blocker captopril: differences in blood pressure responses to intrarenal and intravenous NA infusion with and without captopril were determined and changes in blood pressure were related to increases in plasma NA concentrations.

\subsection{Methods}

\subsubsection{Plasma renin activity measurements}

33 Uninephrectomized rats were prepared under ether anesthesia for 
chronic intrarenal and intravenous infusion as described in section 3.2. Furthermore, they were provided with a catheter into the right femoral artery for blood sampling. After 2 days of saline infusion, osmotic minipumps were replaced under light ether anesthesia by pumps containing either saline or NA solutions, stabilized with $1 \mathrm{mg} / \mathrm{ml}$ ascorbic acid, so that saline or NA at infusion rates of 4 and $36 \mu \mathrm{g} \cdot \mathrm{kg}^{-1} \cdot \mathrm{hr}^{-1}$, was administered intrarenally. Only the $36 \mu \mathrm{g}$ NA. $\mathrm{kg}^{-1} \cdot \mathrm{hr}^{-1}$ was infused intravenously.

Blood samples of $1.0 \mathrm{ml}$ were taken without disturbing the animals which stayed in their home cages, on contral day and on the 1st and 4th day of chronic infusion of saline or NA.

Plasma was assayed for renin activity using a standard radioimmunological method (Sealey et al, 1972). In short, $25 \mu$ plasma was incubated at $37^{\circ} \mathrm{C}$ for 3 hours in the presence of $0.3 \mathrm{mg} / \mathrm{ml}$ dimercaptopropanol and $0.9 \mathrm{mg} / \mathrm{ml}$ quinoline $\left(\mathrm{pH}\right.$ was 5.5). Blank incubation was done at $0^{\circ} \mathrm{C}$ in order to correct for present angiotensin I. Angiotensin I was extracted from the incubation mixtures by means of a Dowex-WX4 ion-exchange resin. After washing with ammonium acetate $\mathrm{pH}=5,10 \%$ acetic acid and water, angiotensin I was eluted with ammonia $\mathrm{pH}=10$, and diethylamine. For correction of losses of angiotensin I during purification of plasma, ${ }^{125}$-angiotensin I (NEX-101, New England Nuclear) was added as tracer.

Radioimmunological assay was carried out by means of a commercial antiserum (NEA-022A, New England Nuclear) and ${ }_{125}$-angiotensin $\mid$ as radioligand. Free antiserum was bounded to active carbon. PRA was determined as ng of angiotensin I synthesized per mil plasma per hour.

The intraassay variation was $7 \%$. Data are expressed as mean \pm S.E.M. and statistical significances of differences were evaluated by means of a StUdent's t-test for unpaired values comparing effects of NA with saline.

\subsubsection{Chronic captopril administration}

40 Rats were provided under ether anesthesia with a femoral artery catheter and a chronic intrarenal or intravenous infusion catheter, perfused with saline from a subcutaneously implanted osmotic minipump. Furthermore, an osmotic minipump containing the converting enzyme blocker captopril (SQ 14.225 Squibb, Princeton, USA) in such concentrations that an infusion rate of $400 \mu \mathrm{g} \cdot \mathrm{kg}^{-1} \cdot \mathrm{hr}^{-1}$ was obtained, was implanted into the abdominal cavity. This chronic intraperitoneal infusion of captopril has been reported to attenuate the pressor response to a range of doses of angiotensin I 4-6-fold dependent on the duration of captopril infusion (Freeman et al, 1979; Millar et al, 1980) and has been used since to block angiotensin II synthesis on a long-term basis (also: Clappison et al, 1980; Seymour et al, 1980).

After a 2-day control period, saline-containing minipumps were replaced under light ether anesthesia by pumps filled with saline or NA solutions so that intrarenal infusion of saline or 4 and $36 \mu \mathrm{g} \mathrm{NA} \cdot \mathrm{kg}^{-1} \cdot \mathrm{hr}^{-1}$ was accomplished. Only 
the $36 \mu \mathrm{g} \cdot \mathrm{kg}^{-1} \cdot \mathrm{hr}^{-1}$ infusion rate was applied intravenously. NA was stabilized by means of ascorbic acid.

MAP was measured on control day and on 5 consecutive days of NA infusion according to the protocol described in section 3.2. Blood samples for determination of NA concentrations in plasma were taken from the femoral artery catheter on control day and on the 1st and 4th day of NA infusion.

As in chapter 3, plasma NA concentrations found during intrarenal NA infusion were plotted against corresponding MAPs and log concentration-effect curves fitted according to De Lean et al (1978). Goodness of fit was determined following the sum of square residues principle.

Elevations in MAP and plasma NA concentrations during combined infusion of NA and captopril were compared with data during intrarenal infusion of saline together with intraperitoneally administered captopril, applying the Student's t-test for unpaired values for statistical analysis.

Differences in MAP and plasma NA levels during intrarenal infusion of saline or NA and intravenous NA infusion with and without (in fact data from chapter 3) captopril treatment, were evaluated by means of non-parametric one-way analysis of variance (Zerbe ${ }_{n}$ 1979).

\subsection{Results}

\subsubsection{PRA measurements}

PRA on control day before starting the chronic saline or NA infusions averaged $1.65 \pm 0.12 \mathrm{ng}$ Angl.ml-1.hr-1 with a range from 0.90 to $3.49 \mathrm{ng} \mathrm{Angl.ml-1.hr-1}$ and stayed within this range during intrarenal saline infusion (Table 5.1). In the later stage of intrarenal infusion of both 4 and $36 \mu \mathrm{g} \mathrm{NA} \cdot \mathrm{kg}^{-1} . \mathrm{hr}^{-1}$, PRA was increased to approximately $2.20 \mathrm{ng} \mathrm{Angl.} \mathrm{ml}^{-1} \cdot \mathrm{hr}^{-1}$ " although statistical significance in these elevations of PRA compared with saline data was only obtained during intrarenal infusion of $4 \mu \mathrm{g} \mathrm{NA} . \mathrm{kg}^{-1} \cdot \mathrm{hr}^{-1}$.

During intravenous infusion of $36 \mu \mathrm{g} \cdot \mathrm{kg}^{-1} \cdot \mathrm{hr}^{-1}$ of NA, PRA increased to levels of $2.92 \pm 0.48 \mathrm{ng} \mathrm{Angl} . \mathrm{ml}^{-1} \cdot \mathrm{hr}^{-1}$ on day 4 , which was statistically significant when compared with PRA levels during intrarenal saline infusion.

\subsubsection{Effect of converting enzyme blockade on NA-induced hypertension} MAP of animals equipped with intraperitoneally placed osmotic minipumps and chronically infused with $400 \mu \mathrm{g} \cdot \mathrm{kg}^{-1} \cdot \mathrm{hr}^{-1}$ of captoprill, ranged from 88 to 118 $\mathrm{mmHg}$ before starting intrarenal infusion of saline or NA and intravenous infusion of NA; MAP stayed within this range during long-term intrarenal infusion of saline (fig. 5.1). During intrarenal NA infusion at the $4 \mu \mathrm{g} \cdot \mathrm{kg}^{-1} \cdot \mathrm{hr}^{-1}$ infusion rate combined with i.p. administration of captopril, MAP increased to $115 \pm 8 \mathrm{mmHg}$ on day 5 ; statistically significant differences with saline data were found only at day 4 . Intrarenal infusion of $36 \mu \mathrm{g} \mathrm{NA} . \mathrm{kg}^{-1} \cdot \mathrm{hr}^{-4}$ during i.p. captopril administration caused immediate significant increases in MAP up to $135 \pm 5 \mathrm{mmHg}$ on day 5 . 


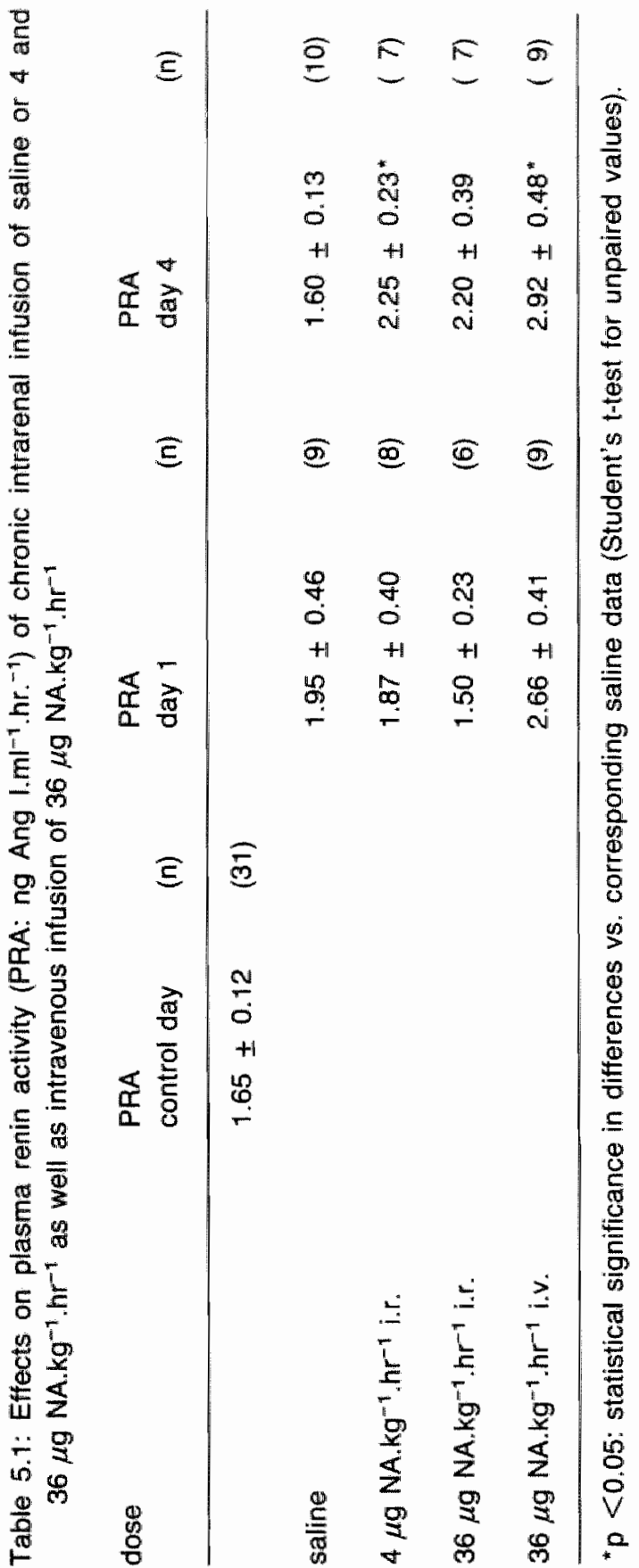


When the $36 \mu \mathrm{kg}-1 \mathrm{hr}-1$ infusion rate of NA was applied via the jugular vein during chronic converting enzyme inhibition, MAP rose significantly $60 m$ day 2, to thal tevels of $121 \pm 6 \mathrm{mmHg}$.

When increases in MAP induced by intrarenal and intravenous NA intusion during angiotensin 1 converting enzyme blockade were compared with MAP levels in non-captopril treated rats (data described in chapter 3), it was immediateIy evident that captopil inhibited significanty the pressor responses to 36 $\mu \mathrm{g} \cdot \mathrm{kg}^{-1} \mathrm{hr}^{-1}$ of NA intused both via the inrarenal and intravenous route fanalysis of variance; Fig. 5.2). Except for day 1 , differences in increases of MAP were approximately $15 \mathrm{mmHg}$.

Although pressure levels during captopril application remained lower at intrarenal infusion of $4 \mu \mathrm{g} \cdot \mathrm{kg}^{-1} \cdot \mathrm{hr}^{-1}$ of $\mathrm{NA}$ and of saline, no statistical significance in differences was obtained over the whole intusion period (analysis of variance). Captopril was able to block increases in MAP only during the intitial phase of intrarenal intusion of $4 \mu \mathrm{g} \mathrm{NA} \cdot \mathrm{kg}^{-1} \cdot \mathrm{hr}^{-1}$.

Plasma NA concentrations before starting the intrarenal infusions when captopril had been administered intraperitoneally for 2 days, were $0.80 \pm 0.13$ ng. $\mathrm{m}^{-\frac{1}{2}}$ which was significantly higher than control levels of plasma NA without

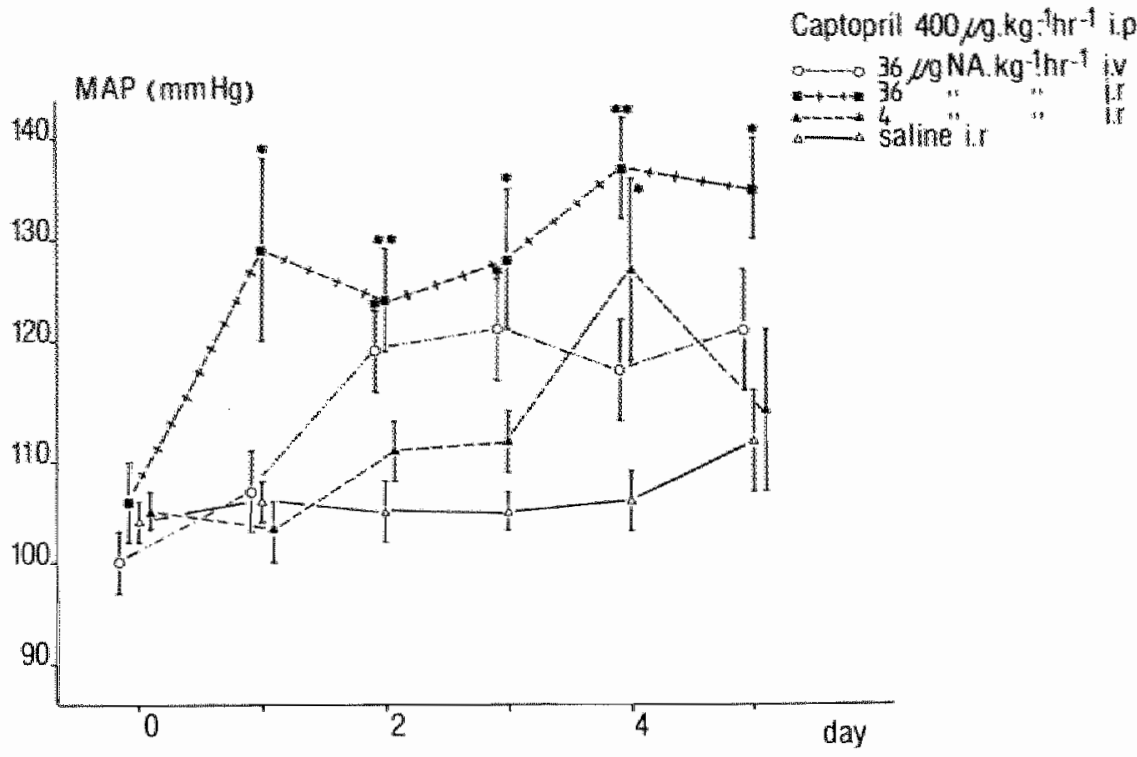

Figure 5.1

Effect of parallel intraperitoneal application of captopril or MAP responding to intrarenal infiusion of saline or two doses of NA, as well as intravenous infusion of NA.

" $p<0.05 ; "$ " $p<0.005$ indicate statistically significant differences vs. corresponding saline data (Student's t-test for unpaired values). 
captopril application which were $0.52 \pm 0.01 \mathrm{ng} \cdot \mathrm{ml}^{-1}$ (unpaired t-test; fig. $5.3 \mathrm{a}$ vs. fig. 5.3b). During intrarenall infusion of saline combined with captopril, plasma NA levels decreased again so that on the 4th day of saline intusion no longer a significant effect of captopril on plasma NA levels was observed.

During intrarenal infusion of 4 and $36 \mu \mathrm{g} \cdot \mathrm{kg}^{-1} \cdot \mathrm{hr}^{-1}$ of NA, plasma NA levels did not rise that much in the presence of the converting enzyme blocker as observed without captopril, although no statistical significance in the differences was obtained. On day 4 , intraperitoneal infusion of captopril had reduced the increases of plasma NA levels by $0.40 \mathrm{ng} \cdot \mathrm{ml}^{-1}$ at the $4 \mu \mathrm{g} \cdot \mathrm{kg}^{-1} \cdot \mathrm{hr}^{-1}$ infusion rate and by $3.47 \mathrm{ng} \cdot \mathrm{ml}^{-1}$ at the $36 \mu \mathrm{g} \cdot \mathrm{kg}^{-1} \cdot \mathrm{hr}^{-1}$ infusion rate of $\mathrm{NA}$.

Also before starting the intravenous. NA infusion, plasma NA concentrations were significantly higher in the presence of captopril: $1.40 \pm 0.24$ vs. 0.56 $\pm 0.01 \mathrm{ng} \cdot \mathrm{ml}^{-1}$. On the $1 \mathrm{st}$ day of intravenous infusion of $36 \mu \mathrm{g} \cdot \mathrm{kg}^{-1} \cdot \mathrm{hr}^{-1}$ of NA captopril treatment diminished the elevations of plasma NA levels insignificantly by $1.17 \mathrm{ng}^{-\mathrm{ml}^{-1}}$. On the 4 th day of intravenous NA infusion "plasma NA levels were equal with and without intraperitoneal captoprill infusion.

Furthermore, effects of intraperitoneal captopril infusion on the relationship between MAP and plasma NA concentrations during chronic intrarenal NA infusion were evaluated. The sigmoid log concentration-effect curve presented in fig. 5.4 appeared to be a reliable representation of these relations $\left(X^{2}\right.$ ir $=58.9$ $<X^{2} p=0.05$ when $v=47$ ). Captopril treatment shifted the log concentrationeffect curve obtained by intrarenal NA infusion down and slightly to the right. No concentration-effect curve was determined for the relation between plasma NA levels and MAP during intravenous NA infusion because of the lack of sufficient data.

\subsection{Discussion}

In chapter 3 , the hypothesis has been formulated that relatively more increased circulating levels of angiotensin II may be responsible for both the higher plasma NA concentrations and the additional pressor response during chronic intrarenal NA infusion, compared with intravenous infusion of the sympathetic neurotransmitter.

The activity of the renin-angiotensin mechanism during intrarenal and intravenous NA infusion has been evaluated in the present study by measuring plasma renin activity (PRA) and by administering the converting enzyme inhibitor captoprill intraperitoneally along with the long-term NA infusions.

Chronic intrarenal infusion of 4 and $36 \mu \mathrm{g} \mathrm{NA} \cdot \mathrm{kg}^{-1} \cdot \mathrm{hr}^{-1}$ increased PRA slowly and significantly by $38 \%$ on day 4 . Intravenous infusion of $36 \mu \mathrm{g}$ NA. $\mathrm{kg}^{-1} \cdot \mathrm{hr}^{-1}$ even increased PRA by $83 \%$. This difference might be due to the fact that during intrarenal NA infusion, the relatively high load of NA in the kidney interfered with both beta-adrenergic receptors which mediate the stimulation of renin release (Weinberger et al, 1975) and alpha-adrenergic 

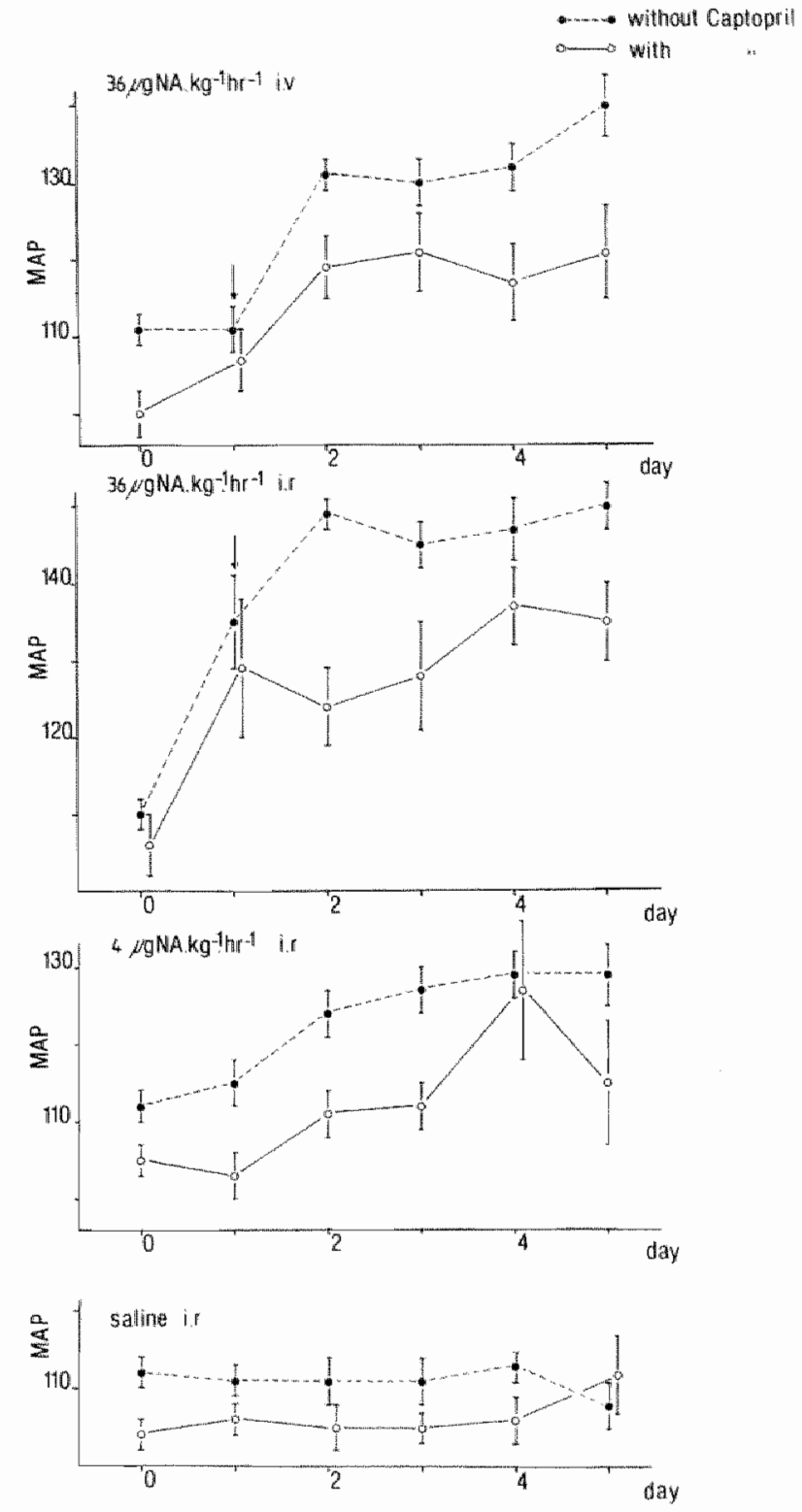

Figure 5.2

Comparison of effects on MAP of intrarenal infusion af saline or two doses of INA as well as intravenous infusion of NA with and without captopril treatment. Arrow indicates appearance of statistically significant differences (analysis of variance). 
receptors which possibly mediate the inhibition of renin release (Pettinger et al, 1976). During intravenous NA infusion, the intrarenal NA concentration may have been relatively low so that only beta-receptor stimulation occurred.

Effects on increases of PRA during intravenous and intrarenal NA infusion in various species are not consistent in literature. In men, intravenous infusion of NA at pressor doses does not affect PRA (Vlachakis, 1979) or increases PRA by $44 \%$ (Beretta-Piccoli et al, 1980). In conscious dogs, intravenous infusion of approximately $17 \mu \mathrm{g} \mathrm{NA} . \mathrm{kg}^{-1} \cdot \mathrm{hr}^{-1}$ has been reported, not to affect PRA (Cowley and Lohmeier, 1979), to increase PRA 3-fold transiently (Katholi et al, 1977) or even, to reduce PRA (Casals-Stenzel ef al, 1982). Higher infusion rates, elevating plasma NA concentrations 14-fold, increase PRA 2-fold (CasalsStenzel et al, 1982). In conscious rats, long-term intravenous infusion of $36 \mu \mathrm{g}$ NA. $\mathrm{kg}^{-1} \cdot \mathrm{hr}^{-1}$ which increases plasma NA levels 6- to 8-fold as is shown in chapter 3, significantly increased PRA after 4 days of infusion.

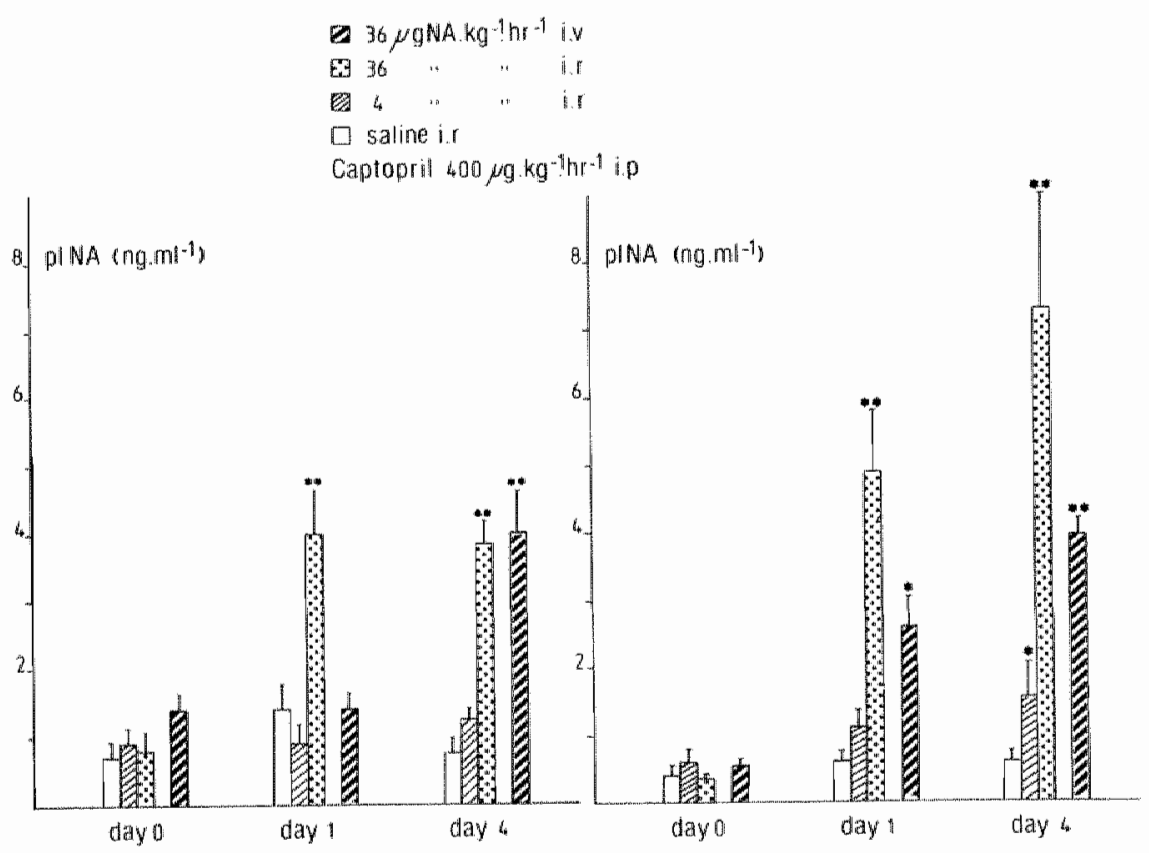

Flgure 5.3

Comparison of effects on plasma NA concentrations of intrarenal infusion of saline or two doses of NA as well as intravenous NA infusion with (left) and without (right) captopril treatment..

" $p<0.05 ; * p<0.005$ indicate statistically significent differences vs. day-0 levels (Student's t-test for unpaired values). 
Intrarenal infusion of approximately $17 \mu \mathrm{g} \mathrm{NA} \cdot \mathrm{kg}^{-1} \cdot \mathrm{hr}^{-1}$ in conscious dogs stimulates PRA (Katholi et al, 1977; Cowley and Lohmeier, 1979), initially maybe via non-adrenergic mechanisms since PRA increases cannot be blunted by alpha- or beta-adrenoceptor blockers (Ayers et al, 1981). In anesthetized rats, intra-arterial infusion of NA close to the renal artery during $30 \mathrm{~min}$ increases PRA (Arundell and Johns, 1982). In the study described in this chapter, intrarenal infusion of 4 and $36 \mu \mathrm{g} \mathrm{NA} \cdot \mathrm{kg}^{-1} \cdot \mathrm{hr}^{-1}$ both increase PRA significantly when compared with saline infusion.

Johnson et al (1979) have found that intrarenal infusion of $7.5 \mu \mathrm{g}$ $\mathrm{NA} . \mathrm{kg}^{-1} \cdot \mathrm{hr}^{-1}$ in conscious dogs does not raise PRA while intravenous application of the same dosis increases PRA by $50 \%$. Adrenaline appears to be even more effective to elevate PRA when infused intravenously but not intrarenally. These authors therefore suggest the mediation of renin release by an extrarenal beta-receptor.

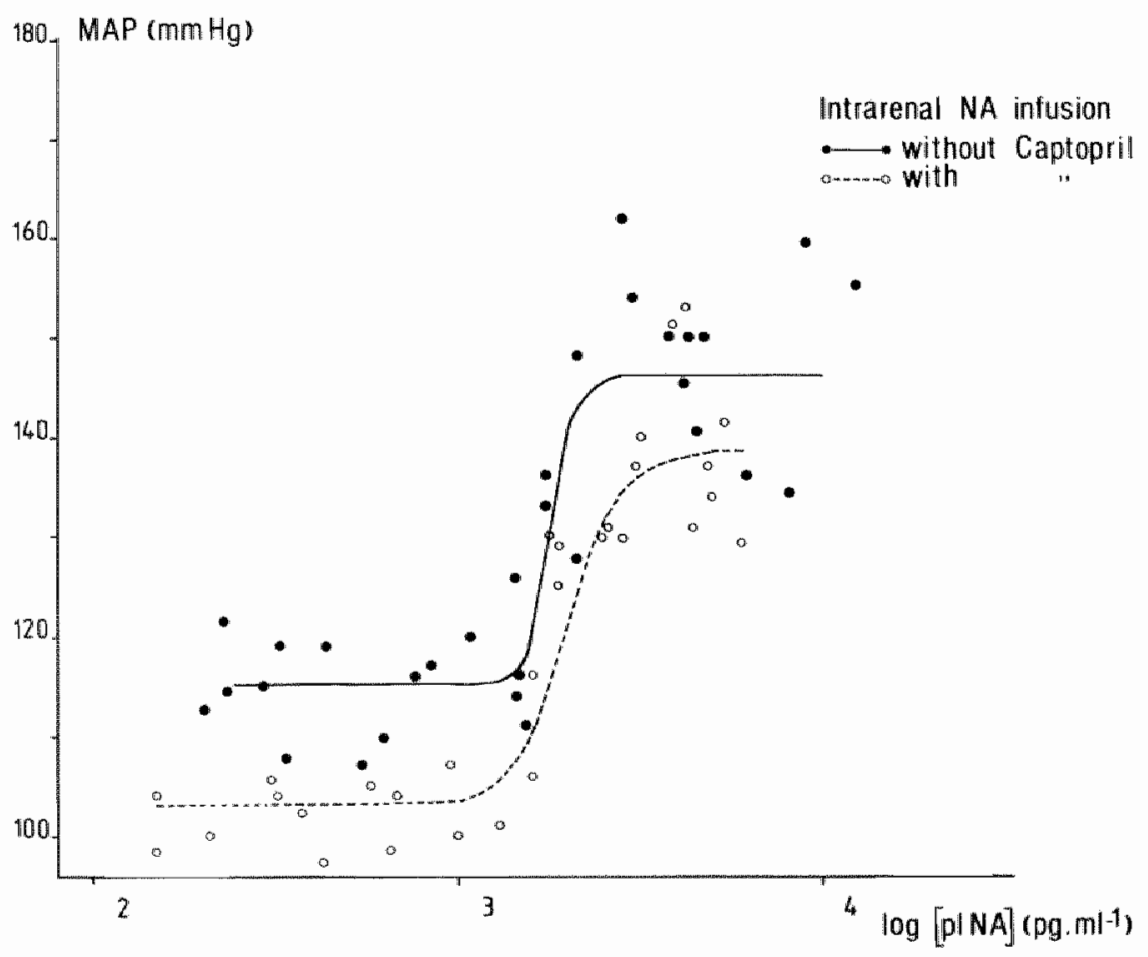

Figure 5.4

Comparison of log concentration-effect curves during chronic intrarenal NA infusion with and without parallel captopril application. 
Since angiotensin $I$ is capable of inhibiting renin release, PRA measurements do not necessarily reflect the functional contribution of the reninangiotensin system to NA-induced hypertension. Clearer insight may come from the captopril infusion studies. Intraperitoneal infusion of the converting enzyme blocker captopril in a dose of $400 \mu \mathrm{g} \cdot \mathrm{kg}^{-1} \cdot \mathrm{hr}^{-1}$ has been reported to decrease the pressor response to angiotensin 1 . The ratio of doses required to increase arterial pressure by $10 \mathrm{mmHg}$ in captopril-treated vs. control rats after 5 days of infusion was 4.6 (Millar et $a l, 1980$ ). This infusion rate of captopril lowered arterial pressure after 2 days in intrarenally saline infused Wistar rats as shown in this study, as well as in normotensive Sprague-Dawley rats (Millar et al, 1980) but over the whole period of intrarenal saline infusion, effects of captopril on MAP were not significant.

Captopril did not prevent hypertension to occur during chronic intrarenal and intravenous infusion of $36 \mu \mathrm{g} \mathrm{NA} . \mathrm{kg}^{-1} \cdot \mathrm{hr}^{-1}$, but elevations in MAP were approximately $15 \mathrm{mmHg}$ below MAP levels obtained without captopril treatment. During combined infusion of captopril and $4 \mu \mathrm{g} \mathrm{NA} \cdot \mathrm{kg}^{-1} \cdot \mathrm{hr}^{-1}$ intrarenally, this difference of $15 \mathrm{mmHg}$ in pressor response even resulted in absence of hypertension except for day 4.

Plasma NA concentrations during the control period before starting the NA infusions were higher in captopril-treated rats, consistent with findings in strokeprone spontaneously hypertensive rats (Lai et al, 1981) and hypertensive men (Campell et al, 1982). This was probably caused by neurogenic activation reflexively to the observed decreases in MAP after 2 days.

Since plasma NA concentrations increased to a lesser degree with intraperitoneally administered captopril during intrarenal infusion of, especially, $36 \mu \mathrm{g} \mathrm{NA} \cdot \mathrm{kg}^{-1} \cdot \mathrm{hr}^{-1}$, antihypertensive effects of captopril in this animal model could be attributed to lowering of the plasma NA levels produced by intrarenal NA infusion. It is unlikely that renal NA clearance (Silva et al, 1979) was increased because of the fact that converting enzyme blockade has been reported, not to affect or even reduce glomerular filtration rate in dogs and rats (Johns, 1979; Clappison et al, 1980; Arundell and Johns, 1982).

However, release of renin was stimulated similarly by intravenous and intrarenal infusion of $36 \mu \mathrm{g} \mathrm{NA} . \mathrm{kg}^{-1} \cdot \mathrm{hr}^{-1}$ and therefore circulating levels of angiotensin II were probably equal as also indicated by the observation that captopril lowered MAP by $15 \mathrm{mmHg}$ both during intravenous and during intrarenal application of this infusion rate. This implies that captopril treatment should have reduced plasma NA levels via inhibition of presynaptic facilitation of NA release by angiotensin II (Zimmerman, 1978) not only during intrarenal NA infusion but also during intravenous NA infusion. However, this did not occur.

An explanation for the plasma NA lowering effect of captopril, specifically during intrarenal NA infusion, may be that the differences in plasma NA levels during intrarenal vs. intravenous infusion of NA resulted from overall sympathetic hyperactivity caused by afferent renal nerve stimulation only during intrarenal 
NA infusion as has been suggested in chapter 3. Although plasma angiotensin Il levels were probably the same during intrarenal and intravenous NA infusion, the NA release stimulating effect of angiotensin $\|$ and thereby the inhibitory effect of captopril might be only evident during intrarenal NA infusion.

Intraperitoneal infusion of captopril shifted the log plasma NA concentration vs. MAP curve during intrarenal NA infusion down and slightly to the right. If stimulation of angiotensin II synthesis was exclusively responsible for the additional pressor response during intrarenal NA infusion as described in chapter 3, application of the converting enzyme blacker would have shifted the log concentration to the level obtained during intravenous NA infusion Comparing figs. 3.4 and 5.4, this appeared not to be the case; since PRA was equally increased during intravenous and intrarenal infusion of $36 \mu \mathrm{g}$ NA. $\mathrm{kg}^{-1} \cdot \mathrm{hr}^{-1}$, it is concluded that angiotensin II contributed to hypertension induced by both intravenous and intrarenal infusion of NA equally by its direct pressor response.

Furthermore, since it is known that captopril treatment attenuates the vascular response to NA (Antonaccio and Kerwin, 1981; Imai et al, 1982), blood pressure lowering effects of converting enzyme inhibition during intrarenal and intravenous NA infusion may also be attributed to equal decreases in vascular adrenoceptor sensitivity.

Since captopril inhibits formation of angiotensin II by blocking the converting enzyme which is identical to kininase $\|$, blood pressure lowering effects of captopril during NA infusion could be due to accumulation of bradykinin, especially because urinary bradykinin excretion increases after intravenous captopril application in anesthetized dogs (Clappison et al, 198). However, it has been shown in conscious rats that bradykinin is not responsible for the antihypertensive action of captopril since original blood pressure levels can be fully restored by administration of angiotensin II (Textor et al, 1981).

In summary, in conscious rats made hypertensive by chronic stimulation of intrarenal adrenergic mechanisms, the renin-angiotensin system is activated but does not sustain the extra pressor effect by the direct vasopressor action of angiotensin II. The octapeptide contributes to the blood pressure elevations mainly by its indirect potentation of overall sympathetic activity. 


\section{RENAL FUNCTION DURING ACUTE AND CHRONIC INTRARENAL NORADRENALINE INFUSION: EXCLUSION OF ACUTE RENAL FAILURE*}

\subsection{Introduction}

Chronic hypertension is presumed only to persist by means of a shift of the renal function curve representing the steady-state relationship between arterial pressure and urine output, to higher pressure levels. Any factor influencing (a) renal wascular resistance, (b) glomerular filtration rate, and (c) fubular sodium and water reabsorption can induce this shift of the renal function curve (Guyton, 1974).

Neurogenic factors may alter renal function. Electrical stimulation of efferent renal nerves in anesthetized dogs and rats decreases renal blood flow and produces renal vasoconstriction (Kottke et al, 1945; Hermansson et al, 1981) while glomerular filtration rate tends to decrease (Hermansson et al, 1981). In conscious dogs, the same results have been obtained although the reductions in renal blood flow and glomerular filtration rate are not maintained over the whole stimulation period (Block et al, 1952).

Furthermore, low-level electrical stimulation of renal nerves which does not influence renal hemodynamics, increases the secretion of renin in cats and dogs (Osborn et al, 1980; Holdaas et al, 1981. Ammons et al, 1982) and therefore stimulates the synthesis of angiotensin II. Angiotensin II may influence renal blood flow via its overall pressor action and increase glomerular filtration rate by constricting the renal efferent arteriolae (Hall et al, $1977 \mathrm{~b}, 1981$ ).

Activation of renal adrenergic receptor by means of intrarenal application of noradrenaline (NA) has been found to increase renal perfusion pressure in isolated rat kidneys (Besarab et al, 1977). Long-term infusion of NA into the renal artery of conscious dogs decreases renal blood flow. Glomerular filtration rate is unaffected (Katholi et al, 1977) or reduced (Cowley and Lohmeier, 1979). From these data, it is obvious that chronic intrarenal NA infusion in conscious rats may produce changes in renal hemodynamics which could lead to a shift of the renal function curve to high levels of arterial pressure. Hypertension during intrarenal NA infusion is possibly characterized by elevations in vascular resistance as a reflex to increase in cardiac output caused by volume retention after this shift of the renal function curve (Guyton, 1977). This could offer an explanation for the additional pressor response superimposed on the direct vasopressor action of NA during intrarenal NA infusion as described in chapter 3 . In the

"based on: Kleinjans JCS, Smits JFM, Kasbergen CM, Van Essen $H$ and StruykerBoudier HAd: Evaluation of renal function during long-term intrarenal norepinephrine infusion in conscious rats. Renal Physiol, in press, 1983. 
present study, acute and chronic effects of intrarenal NA infusion on renal blood flow and glomerular filtration rate were determined in order to test the hypothesis that activation of renal adrenoceptors primarily changes renal function. In the following chapters 7 and 8 , the consequences for central hemodynamics and body fluid and salt homeostasis will be evaluated.

Secondly, intrarenal infusion of high doses of NA in anesthetized dogs and rats has been developed as a model for human acute renal failure (Cromin et al, 1978a, 1978b; Taguma et $\mathrm{al}_{*}, 1980^{\text {; Conger et }} \mathrm{al}_{,}$1981). Acute renal failure induces pulmonary edema and cardiac failure, often associated with hypertension due to severe hypervolemia. This implies that during intrarenal NA infusion, hypertension may develop not as a direct result of stimulation of renal adrenergic mechanism but as a side-effect of induced renal ischemia. Chronic intrarenal infusion of NA, especially at the infusion rate of $36 \mu \mathrm{g} \cdot \mathrm{kg}^{-1} \cdot \mathrm{hr}^{-1}$ may cause pathological conditions in the kidney. Therefore, in this study the possibility of the accurrence of acute renal insufficiency was evaluated and it was also investigated whether the NA-induced changes in renal hemodynamics were reversible.

\subsection{Methods}

\subsubsection{Acute effects of intrarenal NA infusion on renal blood flow}

Because of the bulkiness of the electromagnetic flowprobes determinations of renal blood flow by this measuring device cannot be achieved in conscious rats. The pulsed Doppler technique which has been developed at the Department of Pharmacology, University of lowa, and introduced in our laboratory recently, provides the possibility for acute measurements of changes in regional blood flow. The method has been described extensively elsewhere (Haywood et al, 1981). In this set of experiments, 5 uninephrectomized rats were provided under pentobarbital anesthesia with a Doppler flowprobe around the right renal artery. This probe consists of a $1-\mathrm{mm}$ diameter piezoelectric crystal that emits a 20-MHz signal and receives the reflected sound waves from passing blood cells. The crystall was embedided in epoxy and placed in a Silastic cuff which was constructed to hold the crystal at a $45^{\circ}$ angle to the blood vessel. Wires were guided subcutaneously to an ultraminiature receptable attached to the skull. The Doppler frequency shift which is a function of the velocity of the blood cells and therefore provides a relative parameter of the blood flow through the renal artery was measured by a $545 \mathrm{C}-3$ directional pulsed Doppler flowmeter and recorded on a Schwarzer polygraph. This surgical procedure involved furthermore the implantation of a catheter into the suprarenal artery.

After 4 days for recovery, the rats were cannulated under ether anesthesia with a catheter into the left femoral artery for measurements of arterial pressure. The next day, the animals were prepared for measurements of renal blood flow during intrarenal NA infusion. Catheters and wires were protected by means of a light steel spring. After an equilibration period of 1 hour, the suprarenal artery 
catheter was filled with the particular NA solution. Then, baseline values of mean arterial pressure (MAP), renal blood flow (RBF), and calculated renal vascular resistance (RVR) were determined over a 20-minute control period. After that, NA was infused intrarenally by means of a Precidor infusion pump (pumping rate $100 \mu(\mathrm{hr})$ during 2 hours. MAP, RBF and RVR were averaged over 15-minute periods and effects of intrarenal NA infusion were expressed as percentile changes of control levels. Firstly, the dose of $4 \mu \mathrm{g} \mathrm{NA} \mathrm{kg}^{-1} \cdot \mathrm{hr}^{-1}$ was ap-

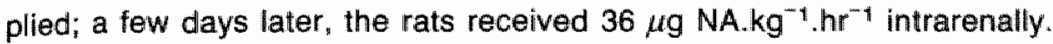

Data are expressed as mean \pm S.E.M. and were analyzed by means of a Student's t-test for paired values.

\subsubsection{Chronic effects of intrarenal and intravenous NA infusion on renal function}

For intrarenal infusion, the right suprarenal artery was cannulated under ether anesthesia in 75 uninephrectomized rats. For intravenous infusion, a catheter was inserted into the right jugular vein of 16 rats. All animals were provided with a catheter into the left femoral artery for measurements of MAP and for blood sampling, and with a catheter into the left femoral vein for intravenous injections. Saline-containing osmotic minipumps were connected to the suprarenal artery or jugular vein catheter and the animals were given a control period of 2 days. For chronic NA infusions, the saline minipumps were replaced under ether anesthesia by pumps containing NA solutions in such concentrations that intrarenal infusion rates of 4 and $36 \mu \mathrm{g} \mathrm{NA} \mathrm{kg}^{-1} \cdot \mathrm{hr}^{-1}$ were obtained. Only the $36 \mu \mathrm{g}$ NA. $\mathrm{kg}^{-1} \cdot \mathrm{hr}^{-1}$ dose was applied intravenously. Intrarenal NA infusion was stopped after 5 days by disconnecting, again under light ether anesthesia, the osmotic minipumps.

MAP was determined as described in section 3.2 before starting the renal function experiments. Effective renal plasma flow (ERPF) and glomerular filtration rate (GFR) were measured as plasma clearance of ${ }^{125} \mathrm{I}$-para amino hippuric acid (PAH) and of ${ }^{51} \mathrm{Cr}$-EDTA respectively according to experimental procedures already described in section 2.2. RVR was calculated as resistance to renal plasma flow. All data were normalized for right kidney weight. 11 Experimental groups were created: ERPF and GFR as well as MAP were measured in groups of rats on control day $(n=9)$, on the 1st and 4th day of intravenous infusion of $36 \mu \mathrm{g} \mathrm{NA} \cdot \mathrm{kg}^{-1} \cdot \mathrm{hr}^{-1}(\mathrm{n}=7$, respectively $\mathrm{n}=9)$, on the 1st and 4 th day of intrarenal infusion of $4 \mu \mathrm{g} \mathrm{NA} \cdot \mathrm{kg}^{-1} \cdot \mathrm{hr}^{-1} \quad(n=10$, respectively $\mathrm{n}=10)$, and $36 \mu \mathrm{g}$ NA. $\mathrm{kg}^{-1} \cdot \mathrm{hr}^{-1}(\mathrm{n}=8$, respectively $\mathrm{n}=9)$. Furthermore, in additionall groups of rats on the 1st and 4 th day after terminating the intrarenal infusion of $4(n=7$, respectively $n=7)$ and $36 \mu \mathrm{g} \mathrm{NA} \cdot \mathrm{kg}^{-1} \cdot \mathrm{hr}^{-1}(\mathrm{n}=10$, respectively $\mathrm{n}=6)$.

Data are expressed as mean \pm S.E.M. and were analyzed by means of a Student's t-test for unpaired values. 


\section{6..3. Pesults}

\subsubsection{Acute effects of intrarenall NA infusion on renal function}

Acute intrarenal infusion of $4 \mu \mathrm{g} \mathrm{NA} . \mathrm{kg}^{-1} \cdot \mathrm{hr}^{\mathrm{m}} 1$ increased MAP significantly by 10\% (Fig. 6.1a) and produced a transient significant decrease in RBF with a minimum of $13 \%$ below starting levels after 1 hour of infusion (Fig. 6.1b). In the second hour of NA infusion, RBF returned to control levels again. RVR increased transiently with a maximum of $30 \%$ above starting values. After 2 hours of intrarenal infusion of $4 \mu \mathrm{g} \mathrm{NA} . \mathrm{kg}^{-1} . \mathrm{hr}^{-11}$, RVR was still elevated by approximately $5 \%$ although no statistial significance was obtained (Fig. 6.1C). Intrarenal infusion of $36 \mu \mathrm{g} \mathrm{NA} . \mathrm{kg}^{-1}$. hr ${ }^{-1}$ increased MAP significantly by $25 \%$ after 15 minutes (Fig. 6.1 a). RBF was decreased to a minimum of $34 \%$ below control (Fig. 6. 1b). In the second hour, RBF rose again but stayed significantly reduced by $15 \%$. RVR increased steeply by $50-60 \%$ at this infusion rate with a maximum of $92 \%$ after $45 \mathrm{~min}$ (Fig. 6.1c). Thereafter a slight return of RVR to $50 \%$ above control values which evidently was a statistically significant difference, was observed.

\subsubsection{Chronic effects of intrarenal and intravenous NA infusion on renal function}

Effects of chronic intrarenal infusion of 4 and $36 \mu \mathrm{g} \mathrm{NA} \cdot \mathrm{kg}^{-1} \cdot \mathrm{hr}^{-1}$ and intravenous infusion of $36 \mu \mathrm{g} \mathrm{NA} . \mathrm{kg}^{-1} . \mathrm{hr}^{-1}$ on MAP are summarized in Table 6.1. While MAP stayed within control range on the first day of NA administration, MAP had increased insignificantly on the 4th day of intrarenal infusion of $4 \mu \mathrm{g}$ NA. $\mathrm{kg}^{-1} . \mathrm{hr}^{-1}$ and significantly during infusion of $36 \mu \mathrm{g} \mathrm{NA} . \mathrm{kg}^{-1} \cdot \mathrm{hr}^{-1}$ at both routes applied. After cessation of intrarenal NA infusion, MAP decreased to control levels.

GFA ranged from 0.76 to $1.30 \mathrm{ml} \cdot \mathrm{min}^{-1} \mathrm{~g}$ kidney weight ${ }^{-1}$ on control day (Fig. 6.2a) and stayed witin this range during intravenous infusion of $36 \mu \mathrm{g}$ NA. $\mathrm{kg}^{-1} \cdot \mathrm{hr}^{-1}$ and during intrarenal infusion of $4 \mu \mathrm{g} \mathrm{NA} \cdot \mathrm{kg}^{-1} \cdot \mathrm{hr}^{-1}$. A small insignificant decrease to $0.88 \pm 0.13 \mathrm{ml} \cdot \mathrm{min}^{-1} \cdot \mathrm{g} \mathrm{kw}^{-1}$ was observed on the 4 th day af

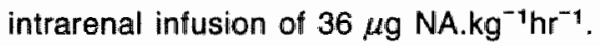

ERPF on control day varied between 2.36 and $4.84 \mathrm{ml} . \mathrm{min}^{-1} \mathrm{~g} \mathrm{kw}-1$ (Fig.

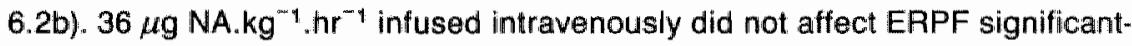
ly. ERPF during intrarenal infusion of $4 \mu \mathrm{g} \mathrm{NA} . \mathrm{kg}^{-1} \cdot \mathrm{hr}^{-1}$ decreased significantly $(p<0.005)$ to $2.78 \pm 0.27 \mathrm{mll}^{\mathrm{min}}{ }^{-1} \mathrm{~g} \mathrm{kw} \mathrm{kW}^{-1}$ at day $1_{\text {, }}$, but returned to control levels at day 4 , whereas ERPF stayed at this decreased level during the complete period of intrarenal infusion of $36 \mu \mathrm{g} \mathrm{NA} \cdot \mathrm{kg}^{-1} \cdot \mathrm{hr}^{-1}$.

Calculated filtration fraction (FF) did neither change during chronic intrarenal nor during intravenous NA infusion (Fig. 6.2c).

RVA on contral day was $29.8 \pm 3.5 \mathrm{mmHg} \cdot \mathrm{min} . \mathrm{g} \mathrm{kw} \cdot \mathrm{ml}^{-1}$ and an insignitilcant increase was observed during intravenous infusion of $36 \mu \mathrm{g} \mathrm{NA} \cdot \mathrm{kg}^{-1} . \mathrm{hr}^{-1}$ (Fig. 6.3). Intrarenal NA application at both infusion rates produced significant increases in RVR on the 1 st day. While RVR was only slightly elevated on the 
a
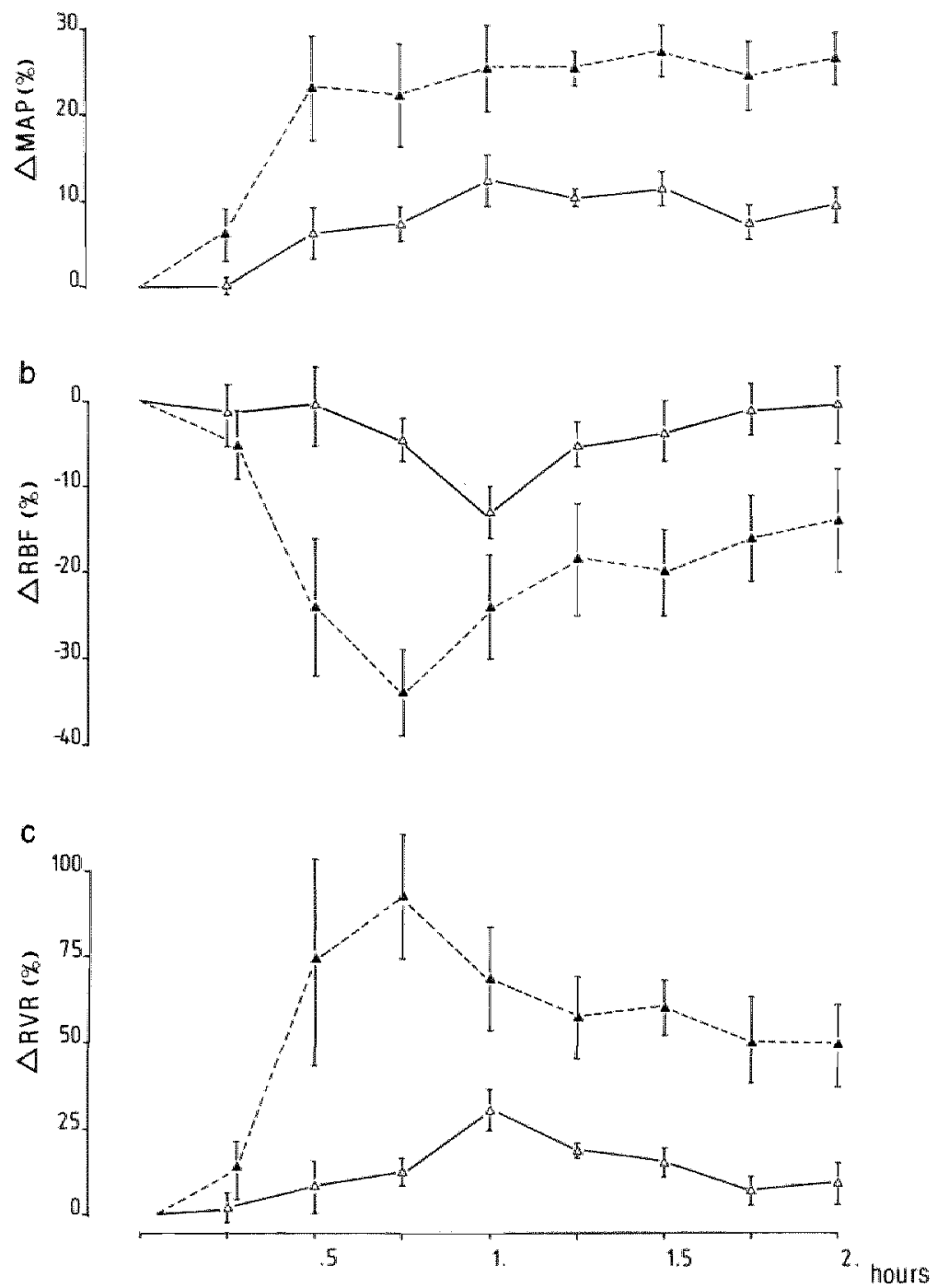

Figure 6.1

Percentual changes in mean arterial pressure (MAP), renal blood flow (RBF) and calculated renal vascular resistance of acute intrarenal infusion of two doses of $N A$. Results of statistical analysis are described in section 6.3 . 


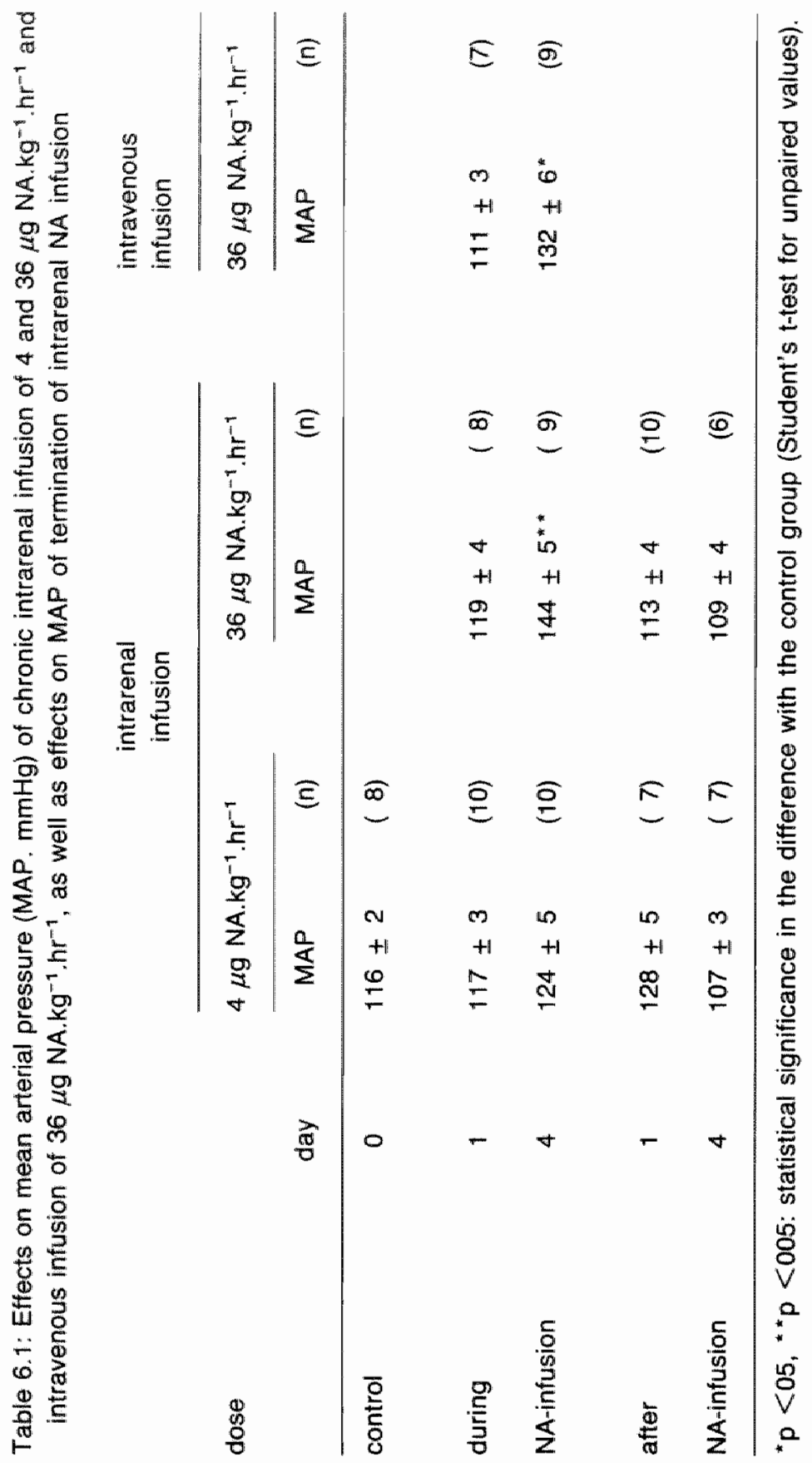



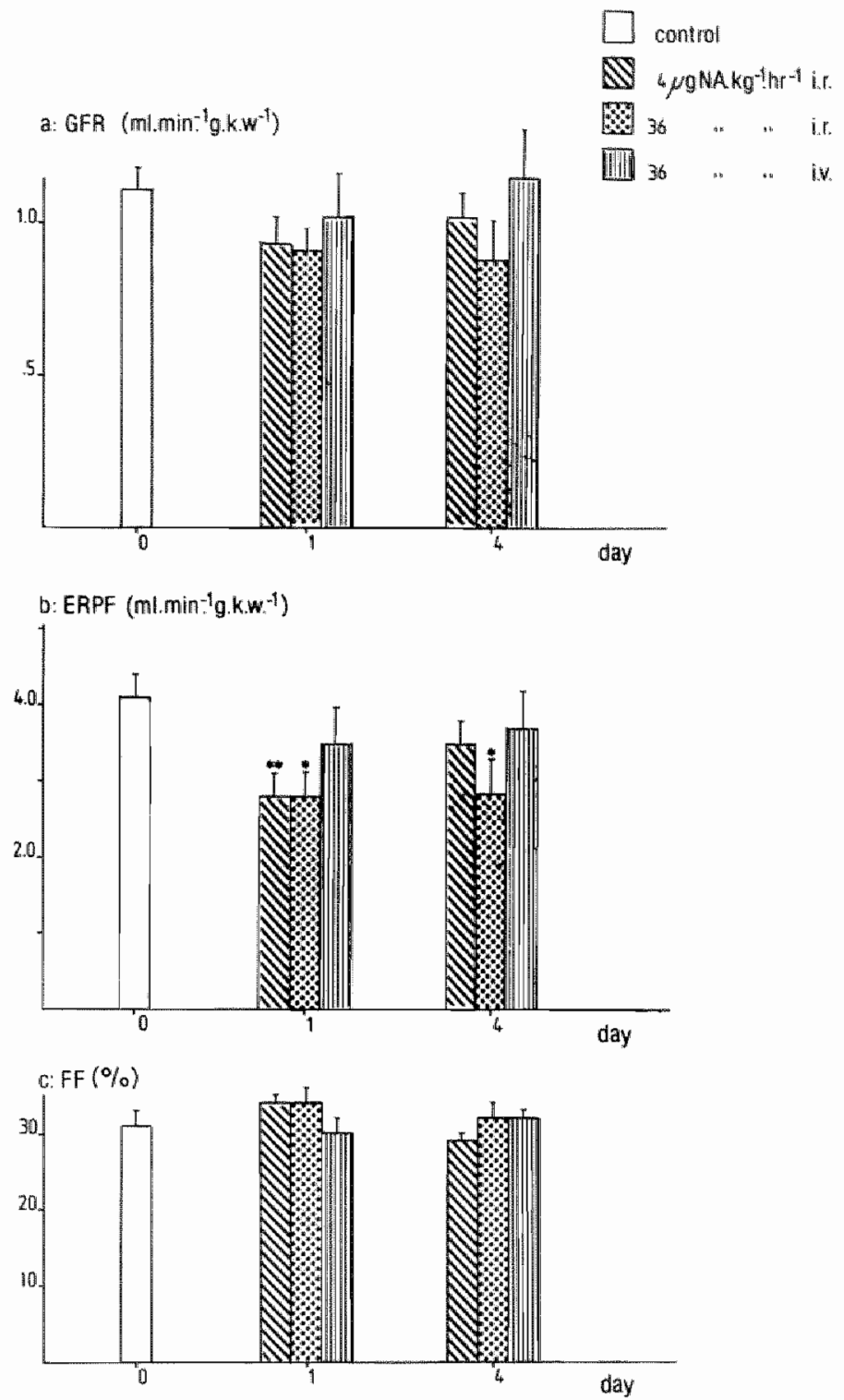

Figure 6.2

Effects of chronic intraremal infusion of 4 and $36 \mu \mathrm{g} \mathrm{NA} . \mathrm{kg}^{-1} \cdot \mathrm{hr}^{-1}$ as well as intravenous infusion of $36 \mu \mathrm{g} \mathrm{NA} \cdot \mathrm{kg}^{-1} \cdot \mathrm{hr}^{-1}$ on (a) glomerular filtration rate (GFR). (b) effective renal plasma flow (ERPF) and (c) filtration fraction (FF).

" $p<0.05 ; *{ }^{*} p<0.005$ indicate statistically significant diffierences vs, control values (Studentt's t-testt for unpaired values). 
4th day of intrarenal NA infusion of $4 \mu \mathrm{g} \cdot \mathrm{kg}^{-1} \cdot \mathrm{hr}^{-1}$, it had increased further to $66.0 \pm 13.0 \mathrm{mmHg} \cdot \mathrm{min}$. $\mathrm{g} \mathrm{kw} \cdot \mathrm{ml}^{-1}$ at the $36 \mu \mathrm{g} \cdot \mathrm{kg}^{-1} \cdot \mathrm{hr}^{-1}$.

After cessation of the intrarenal NA infusions by disconnecting the osmotic minipumps, GFA and ERPF did not differ significantly from control values (Figs. $6.4 a$ and b). In rats in which ERPF was significantly decreased during intrarenal infusion of $36 \mu \mathrm{g} \mathrm{NA} . \mathrm{kg}^{-1} \cdot \mathrm{hr}^{-1}$, it had returned to $92 \%$ of levels observed in the control group within $24 \mathrm{hr}$ after stopping the infusion.

\subsection{Discussion}

Intrarenal NA infusion in conscious rats produced immediate dose-dependent reductions in RBF and increases in RVR. During intrarenal infusion of $36 \mu \mathrm{g}$ NA. $\mathrm{kg}^{-1} \cdot \mathrm{hr}^{-1}$, decreases in RBF were maintained throughout the 5-day infusion period. Intrarenal infusion of $4 \mu \mathrm{g} \mathrm{NA} \cdot \mathrm{kg}^{-1} \cdot \mathrm{hr}^{-1}$ caused transient decreases in RBF; RBF decreased initially after starting the infusion, returned to normal in the second hour, was reduced again on the 1st day of application of this infusion rate and rose to levels slightly below normal in the later phase of the infusion period. It is possible that RBF was restored by the increasing MAP during intrarenal infusion of $4 \mu \mathrm{g} \mathrm{NA} . \mathrm{kg}^{-1}$. hrr ${ }^{-1}$ but not during intrarenal infusion of 36 $\mu \mathrm{g} \mathrm{NA} . \mathrm{kg}^{-1} \cdot \mathrm{hr}^{-1}$. Also RVR was ellevated over the whole infusion period of 36 $\mu \mathrm{g} \mathrm{NA} . \mathrm{kg}^{-1} \cdot \mathrm{hr}^{-1}$, peaking after 1 hour, decreasing somewhat on the 1st day of infusion and approaching levels of $70 \%$ above normal finally. During intrarenal infusion of $4 \mu \mathrm{g} \mathrm{NA} \cdot \mathrm{kg}^{-1} \cdot \mathrm{hr}^{-1}$ also a maximum in increases of RVR was

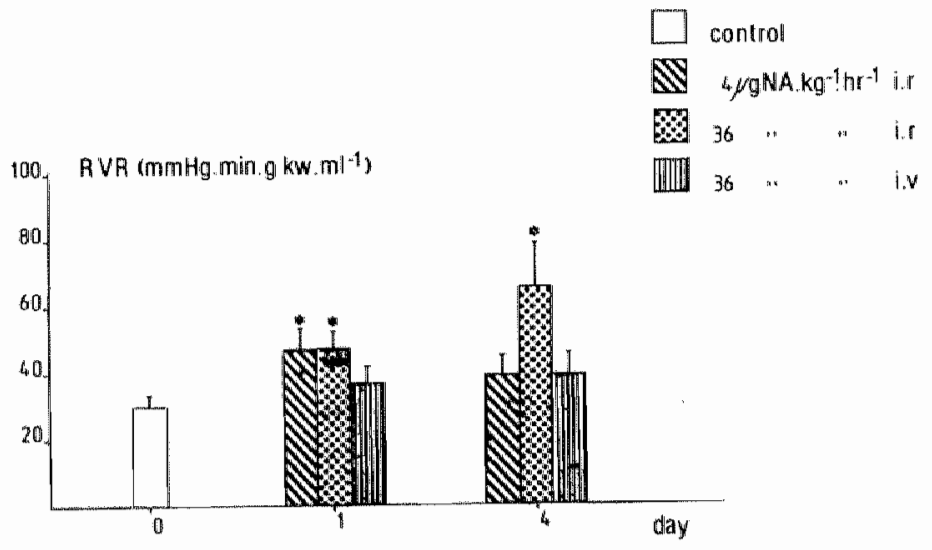

Figure 6.3

Effects of chronic intrarenal and intravenous. NA infusion on renal vascular resistanct (RVR).

" $p<0.05$ : statistically significant differences vs. control (Student's t-test for unpairec values). 
observed after 1 hour; then RVR decreased to almost control values but was again elevated on the 1st day of NA infusion. Finally, RVF had returned on day 4 to levels insignificantly elevated above control. The reductions in RVR after the initial increases were probably due to the renal autoregulation. However, the steep increases in RVR on longer term during intrarenal infusion of $36 \mu \mathrm{g}$ NA. $\mathrm{kg}^{-1} . \mathrm{hr}^{-1}$ could not be prevented. Since myogenic autoregulation is a rather fast operating mechanism (Stein, 1976), it may explain the reductions in RVR after the fast increase but it is not clear what caused the reductions in RVR to slightly elevated levels on the 4 th day of intrarenal infusion of $4 \mu \mathrm{g} \mathrm{NA} . \mathrm{kg}^{-\eta} . \mathrm{hr}^{-1}$. In conscious dogs, chronic electrical stimulation of renal nerves could also not maintain the reductions in RBF and GFR over the complete stimulation period (Block et al, 1952).

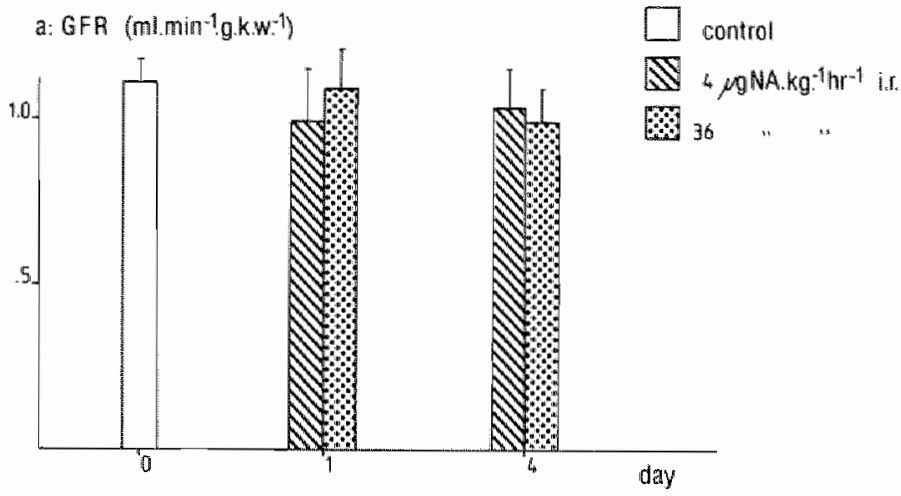

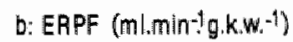

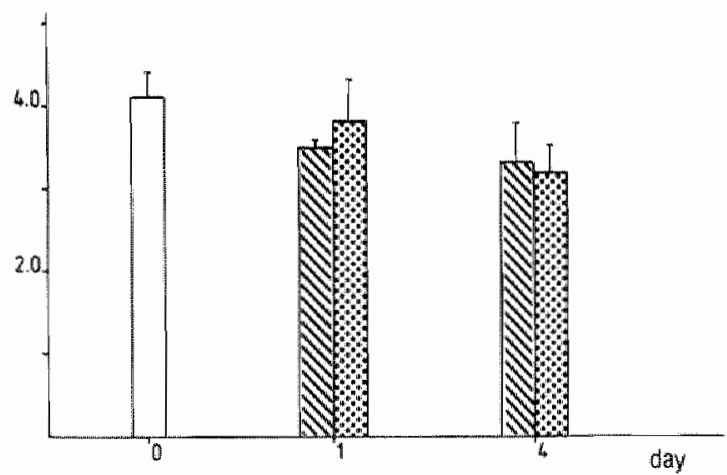

Figure 6.4

Recovery of (a) glomerular filtration rate (GFR) and (b) effective renal plasma flow (ERPF) after chronic intrarenal NA infusion. No significant differences vs. control data are observed. 
GFR was not affected in the present study: only a small insignificant decrease was observed on the 4th day of intrarenal infusion of $36 \mu \mathrm{g} \mathrm{NA} . \mathrm{kg}^{-1}$. hr ${ }^{-1}$.

The changes in renal function produced by intrarenal NA infusion were directly caused by renal adrenoceptor stimulation and were not secondary to increases in MAP: intravenous infusion of $36 \mu \mathrm{g} \mathrm{NA} \cdot \mathrm{kg}^{-1} . \mathrm{hr}^{-9}$ elevated MAP without influencing renal hemodynamics. Furthermore, when data on RVR during intrarenal NA infusion are related to data on total peripheral resistance presented in the next chapter, it may be obvious that increases in RVR preceded increases in total peripheral resistance at both doses of NA applied intrarenally.

During long-term intrarenal infusion of $17 \mu \mathrm{g} \mathrm{NA} \mathrm{kg}^{-1} \cdot \mathrm{hr}^{-1}$ in conscious dogs, RBF is also decreased after 1 hour of NA application (Katholi et al, 1977) and stays below starting values throughout the infusion period (Katholi et al, 1977; Cowley and Lohmeier, 1979). GFR is not changed (Katholi et al, 1977) or is decreased, dependent of sodium intake (Cowley and Lohmeier, 1979).

In anesthetized rats and dogs, however, acute intrarenal infusion of doses of 36-45 $\mu \mathrm{g} \mathrm{NA} \cdot \mathrm{kg}^{-1} \cdot \mathrm{hr}^{-1}$ produces steep decreases in RBF and GFR (Conger et al, 1981; Cronin et al, 1978b). Furthermore, after termination of the intrarenal NA infusion, RBF as well as GFR stay reduced for weeks (Cronin et al, 1978a).

Therefore, intrarenal NA infusion has been postulated as a model for human acute renal failure. During intrarenal NA infusion RBF and GFR decreases to practically undetectable levels (Cronin et al, 1978b; De Torrente et al, 1978). Sustenance of the reductions in GFR and RBF is associated with increases in intraluminar proximal tubule pressure (Burke et al, 1980; Conger et al, 1981) and with morphological changes in tubular epithelium (Cronin et al, 1978b; Taguma et al, 1980).

Severe pathological reductions in GFR and RBF have not been observed during intrarenal infusion of NA in conscious dogs (Katholi et al, 1977; Cowley and Lohmeier ${ }_{v} 1979$ ) and rats (the present study). After 4 days of intrarenal infusion of $36 \mu \mathrm{g} \mathrm{NA} . \mathrm{kg}^{-1} . \mathrm{hr}^{-1}$. GFR was still $89 \%$ of control levels in rats. A longterm decrease of at least $30 \%$ in ERPF seemed necessary in order to produce a reduction in GFR at all.

Duration of intraranal NA infuoion, a oruoial faotor in oxporimonto with anesthetized animals (Cronin et al 1978 a), played no important role in awake rats as indicated by the fact that GFR remained unaltered. Furthermore, after cessation of the NA infusion by disconnecting the osmotic minipumps, ERPF and GFR returned to control levels within 24 hours.

The elegance of the catheterization method applied in the present study which does not imply insertion of a catheter into the renal artery and therefore does not disturb renal blood flow, might also explain why acute renal failure does not occur during intrarenal infusion of NA in conscious rats.

Furthermore, it is speculated that activation of neurogenic reflexes via stimulation of renal afferent nerves is inhibited under pentobarbital anesthesia and neurogenic mediation in the mobilization of protective mechanisms has become 
impossible. Fo instance, autoregulation of GFA is dependent on angiotensin 1

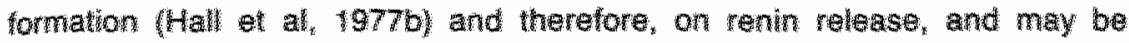
hampered in aneshetized animass with diminished sympathetic tone. Funthemore, release of endogenous vasodilators which could be stmutated by renal sympathetic nerves, might be inhibited due lo anesthesia. This coutd explan the absence of acute renal lature during chronic inusion of NA into the renal artery of conscious rats.

in summary, intrarenal NA infusion in the present hpertension model induces renal vasoconstriction which precedes the elevations of total peripherat resistance. No pathological conditions to the kidney are created. 



\section{ACUTE AND CHRONIC EFFECTS OF INTRARENAL NORADRENALINE INFUSION ON CENTRAL HEMODYNAMICS*}

\subsection{Introduction}

This chapter will deal with the possibility that the changes in renal function induced by stimulation of adrenergic mechanisms by means of intrarenal infusion of noradrenaline (NA) as described in chapter 6 , alter the steady-state relationship between arterial blood pressure and urine output. Renal vasoconstriction and decreased giomerular filtration rate may lead to decreases in urinary excretion of water and salt, thereby causing hypervolemia (Guyton, 1976; Norman et al, 1978). Additionally, the direct stimulating effect of NA on renal tubular reabsorption of water and sodium (Besarab et al, 1977; Bello-Reus, 1980) may increase extracellular fluid and plasma volume. Volume retention increases cardiac output by augmenting venous return, which implies that in the initial phase after shifting of the renal function curve the elevations in arterial blood pressure are associated with higher cardiac output. Increases in overall organ blood flow induces reflexively - by means of the autoregulation mechanism elevations of peripheral resistance so that in the established phase of hypertension increased arterial blood pressure is correlated to increased total peripheral resistance (Guyton, 1977; Liard, 1979).

These cascade-like ellevations in total peripheral resistance may be superimposed on the direct vasopressor actions of increases in plasma NA concentrations during chronic intrarenal NA infusion, offering an explanation for the observed additional pressor response caused by stimulation of renal adrenergic mechanisms as depicted in chapter 3 . Artificial activation of renal adrenergic mechanisms by means of electrical stimulation of splanchnic nerves in anesthetized cats increases cardiac output acutely (Greenway and Innes, 1980). Longterm intrarenal NA infusion in conscious dogs causes hypertension characterized by a positive sodium balance (Katholi et al, 1977; Cowley and Lohmeier, 1979). However, information on the acute and chronic effects of induced renal adrenergic hyperactivity in conscious animals, sampled on a rather continuous basis, is not available yet.

Therefore, in this chapter we measured central hemodynamics during acute and long-term intrarenal NA infusion in freely moving rats provided with an electromagnetic flowprobe for cardiac output determinations; the results of this study will be combined with data on renal function from chapter 6 and data on

"based on: Kleinjans JCS, Smits JFM, Van Essen H, Kasbergen CM and StruykerBoudier HAJ: Hemodynamic characterization of hypertensilon induced by chronic intrarenall infusion of norepinephrine in conscious rats. Hypertension, submitted for publication. 
body fluid and salt balance as will be described in chapter 8 in order to evaluate the hypothesis of volume-dependent developments of hypertension induced by intrarenal NA infusion.

\subsection{Methods}

\subsubsection{Acute hemodynamic measurements}

12 Uninephrectomized rats were instrumented under Nembutal anesthesia with an electromagnetic flowprobe (Skalar, The Netherlands) around the ascending aorta according to a surgical procedure standardized in our laboratory (Smits et al, 1982). The flowprobe gets incapsulated in connective tissue and after a week, long-term recording of cardiac output becomes feasible. After this recove$\mathrm{ry}_{\mathrm{t}}$ rats were provided under ether anesthesia with catheters into the right suprarenal artery for intrarenal infusion or into the right jugular vein for intravenous infusion. Furthermore, a catheter was inserted into the left femoral artery for determinations of mean arterial pressure (MAP).

After 2 days, the rats were prepared for acute hemodynamic measurements while staying in their home cages with free access to food and water. MAP was recorded by means of a Grass 7D-polygraph; a continuous flow of pyrogen-free saline $(0.5 \mathrm{ml} / \mathrm{hr})$ was maintained through the femoral artery catheter using a PVB F 100 continuous flush device and a Harvard 975 infusion pump. Cardiac output was monitored by means of a Skalar 600 electromagnetic blood flow meter and a Grass amplifier "and normalized for body weight (Cl).

Generally, continuous measurements of cardiac output over several hours cannot be performed without close observation and correction of possible variations of the blood flow zero levell, which are due to off-set fluctuations in the electromagnetic flowprobe. Therefore, a micropressor unit was constructed by the Electronic Department of the Universtiy of Limburg. This consists of an analog system which generates data of mean arterial pressure and mean cardiac output as well as heart rate and compensates for zero-level aberrations in the blood flow signal as indicated below, and of a digital system (6800-micro) wich digitizes and samples corrected analog data on a minute-to-minute basis. Thereupon, data are presented to a Minc RT-11 minicomputer for storage and further calculations. In the analog part of this measuring device, mean cardiac output containing the zero-level variations is calculated from the unfiltered flow signal. A peak detector determines the zero value of each flow complex. A sample-hold circuit combined with an integrator calculates the mean zero level over a 1-minute period which is subtracted from the earlier determined mean flow values, resulting in mean cardiac output compensated for off-set fluctuations.

Heart rate (HR), normalized stroke volume (SVI) and normalized total peripheral resistance (TPRI) are calculated from the MAP and $\mathrm{Cl}$ data, determined every minute and averaged from hour to hour.

Intrarenal infusions of 4 and $36 \mu \mathrm{g} \mathrm{NA} . \mathrm{kg}^{-1} \mathrm{hrr}^{-1}$ as well as intravenous 
infusions of $36 \mu \mathrm{g} \mathrm{NA} \cdot \mathrm{kg}^{-4} \cdot \mathrm{hr}^{-1}$ over a 22-hour periad were performed by means of a Precidor infusion pump (pumping rate: $100 \mu / \mathrm{hr}$ ). Catheters and wires were protected by a light steel spring and connected to a Tech Serv swivel system.

After a 1 -hour period for adaptation to the experimental circumstances" the suprarenal artery or jugular vein catheter were filled with the particular NA solutions and after a 20-minute control period for baseline determinations, the intrarenal or intravenous NA infusions were started.

Rats were used as their own control. Data are expressed as mean \pm S.E.M. and were analyzed by means of a Student's t-test for paired values.

\subsubsection{Long-range hemodynamic measurements}

37 Rats were provided with electromagnetic flowprobe as described above. Catheters were implanted into the left femoral artery for measurement of MAP. Furthermore, the rats were prepared for chronic intrarenal or intravenous infusion as described in section 3.2. Saline-containing osmotic minipumps were connected and central hemodynamics were determined over a 2-day control period.

MAP, HR and $\mathrm{Cl}$ were recorded on a Grass 7D-polygraph. $\mathrm{Cl}$ was preamplified via a Skalar 600 electromagnetic flowmeter. "HR was derived from the cardiac output signal using a Grass tachograph.

Analog data were digitally converted by a Minc RT-11 minicomputer and sampled every 15 seconds. TPRI and SVI were calculated. Measurements were performed between 14.00 and $17.00 \mathrm{hr}$ during 2-hour sessions, and mean values of the hemodynamic parameters over the last 45 minutes of the recording session were determined. After 2 days, saline infusing minipumps were replaced under light ether anesthesia by pumps containing either saline or NA solutions acidified by $1 \mathrm{mg} / \mathrm{ml}$ ascorbic acid so that intrarenal infusion of saline or NA in doses of 4 and $36 \mu \mathrm{g} \cdot \mathrm{kg}^{-1} \cdot \mathrm{hr}^{-1}$, as well as intravenous infusion of $36 \mu \mathrm{g}$ NA. $\mathrm{kg}^{-1} \cdot \mathrm{hr}^{-1}$ could be applied. Effects of 5-day intrarenal or intravenous NA infusion on central hemodynamics were daily determined and compared with data obtained during intrarenal saline infusion.

Statistical significance in the differences were calculated using a Student's t-test for unpaired values.

\subsection{Results}

\subsubsection{Acute effects of NA on central hemodynamics}

Control levels of MAP over a 20-minute period before starting the acute intrarenal infusion of $4 \mu \mathrm{g} \mathrm{NA} \cdot \mathrm{kg}^{-1} \cdot \mathrm{hr}^{-1}(\mathrm{n}=4)$ were $119 \pm 5 \mathrm{mmHg}$ (Fig. 7.1). No significant increases of MAP vs. control values were caused during the 22 hours of intrarenal infusion of this dose of NA except for the 4th hour when MAP reached levels of $128 \pm 1 \mathrm{mmHg}$. A transient significant fall in $\mathrm{Cl}$ below starting values of $32.8 \pm 4.1 \mathrm{ml} \cdot \mathrm{min}^{-1} .100 \mathrm{~g} \mathrm{bw}^{-1}$ was observed during the first 10 hours of NA infusion, with a minimum level of $26.6 \pm 3.5 \mathrm{ml} \cdot \mathrm{min}^{-1}$ in the 9 th hour. Decreases 

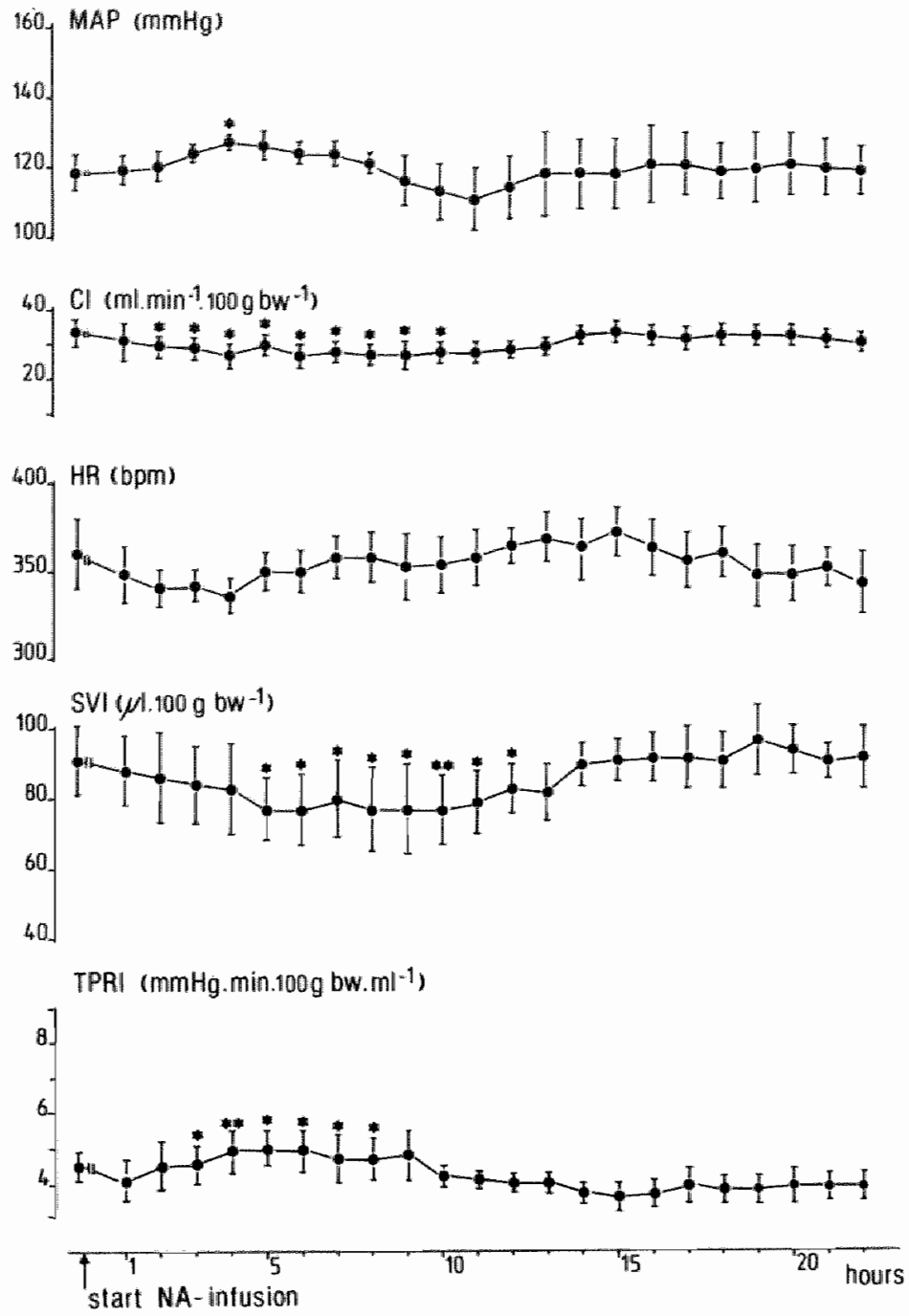

Figure 7.1

Effects on hemodynamic parameters of acute intrarenal infusion of $4 \mu \mathrm{g} \mathrm{NA} \cdot \mathrm{kg}^{-1}$. $\mathrm{hr}^{-1}$. For abbreviations, see text.

$" p<0.05 ; \cdots p<0.005$ : statistically significant differences vs. pre-infusion values (Student's t-test for paired values). 

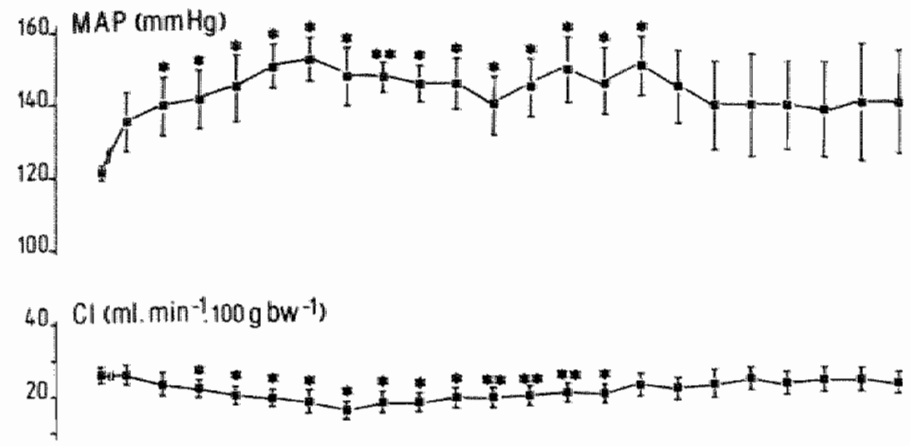

400, HR (bom)

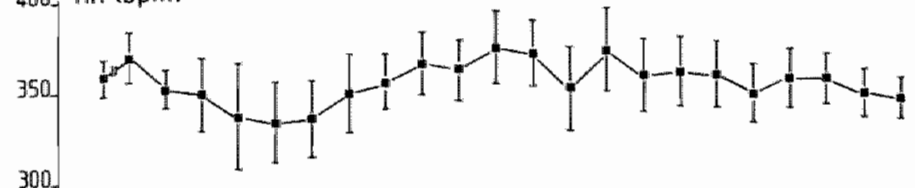

100. $\left.S V \mid(\mu) .100 \mathrm{~g}^{\mathrm{b} w} \mathrm{w}^{-1}\right)$
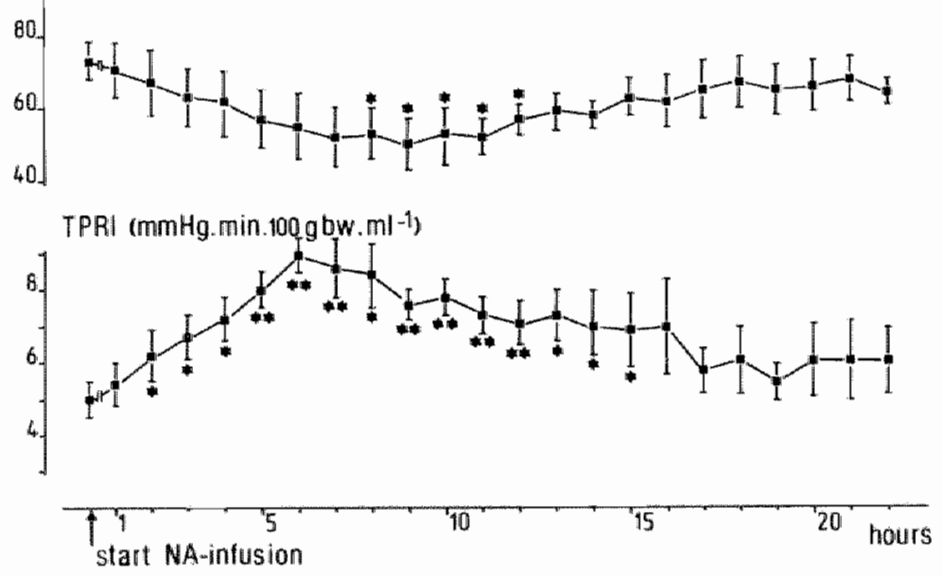

Figure 72

Effects on hemodynamic parameters of acute intrarenal infusion of $36 \mu \mathrm{g} \mathrm{NA} . \mathrm{kg}^{11} \cdot \mathrm{hr}^{-1}$. For abbreviations, see text.

"p <0.05; "p <0.005: statistically significant differences vs. pre-intusion levels (Student's t-test for paired values. 
in $\mathrm{Cl}$ were caused by decreases in SVI (minimum value $76.7 \pm 12.8 \mu \mathrm{l}$.100 g $b w^{-1}$ during the 9th hour) whereas no effects on HR were observed. Control values of TPAl were $3.9 \pm 0.6 \mathrm{mmHg} \cdot \mathrm{min} .100 \mathrm{~g} \mathrm{bw} \cdot \mathrm{ml}^{-1}$ and intrarenall infusion of $4 \mu \mathrm{g} \mathrm{NA} \cdot \mathrm{kg}^{-4} \cdot \mathrm{hr}^{-1}$ caused a transient significant increase to a maximum of $5.0 \pm 0.5 \mathrm{mmHg} \cdot \min .100 \mathrm{~g} \mathrm{bw} \cdot \mathrm{ml}^{-1}$. Both $\mathrm{Cll}$ and TPRl returned to control levels in the latter half of the 22-hour infusion period of $4 \mu \mathrm{g} \mathrm{NA} \cdot \mathrm{kg}^{-1} \cdot \mathrm{hr}^{-1}$.

Acute intrarenal infusion of $36 \mu \mathrm{g} \mathrm{NA} \cdot \mathrm{kg}^{-1} \cdot \mathrm{hr}^{-1}(\mathrm{n}=4)$ produced changes in hemodynamic parameters which were sustained throughout the 22-hour infusion period (Fig. 7.2). MAP was $122 \pm 1 \mathrm{mmHg}$ before starting the NA administration and rose immediately to levels of approximately $145 \mathrm{mmHg}$. Statistical significance of these increases vs. control values was obtained over the first 15 hours. After that, MAP decreased slightly but never reached initial levels. Basic values of $\mathrm{Cl}$ were $26.1 \pm 1.4 \mathrm{ml} \cdot \mathrm{min}^{-1} .100 \mathrm{~g} \mathrm{bw}^{-1}$ and intrarenal infusion of $36 \mu \mathrm{g} \mathrm{NA} . \mathrm{kg}^{-1} \cdot \mathrm{hr}^{-1}$ caused immediate decreases to a minimum of $16.1 \pm$ $1.6 \mathrm{ml} . \mathrm{min}^{\alpha 1} .100 \mathrm{~g} \mathrm{bw}^{-1}$ after 7 hours. Although a small increase was observed in the latter period of NA infusion, $\mathrm{Cl}$ stayed below starting levels for these 22 hours. Obvious decreases were seen again in SVI which reached a minimum of $49.6 \pm 6.9 \mu \mathrm{l} .100 \mathrm{~g} \mathrm{bw}^{-1}$ in the 9 th hour. No effects on HR were produced. TPRI was elevated immediately by intrarenal NA infusion of $36 \mu \mathrm{g} \cdot \mathrm{kg}^{-1} \cdot \mathrm{hr}^{-1}$. Starting at $5.1 \pm 0.4 \mathrm{mmHg} \cdot \min .100 \mathrm{~g} \mathrm{bw}^{-1} \mathrm{~m}^{-1}$, levels of $8.9 \pm 0.9$ $\mathrm{mmHg} \cdot \min .100 \mathrm{~g}$ bw. $\mathrm{ml}^{-1}$ were obtained in the 6 th hour. Statistically significant differences vs. control values in TPRI were gained over the same period as in MAP and $\mathrm{Cl}$. In the latter phase of NA infusion, TPRI decreased slightly but did not return to starting levels.

During 22 hours of intravenous infusion of $36 \mu \mathrm{g} \mathrm{NA} \cdot \mathrm{kg}^{-1} \cdot \mathrm{hr}^{-1}(\mathrm{n}=4$, data not shown), MAP rose occasionally by $40 \mathrm{mmHg}$ (see Appendix I). Cl was decreased over the complete infusion period with a minimum of $22 \%$ below starting levels after $8 \mathrm{hr}$. TPRI was constantly elevated with a maximum of $76 \%$ above control values in the 7 th and 8 th hour.

\subsubsection{Chronic effects of NA on central hemodynamics}

On the second day of the control period before starting the chronic NA infusions by connecting NA containing osmotic minipumps, MAP varied between 96 and $126 \mathrm{mmHg}$ (Fig. 7.3) and stayed in this range during chronic intrarenal infusion of saline $(n=9)$. Intrarenal infusion of $4 \mu \mathrm{g} \mathrm{NA} \cdot \mathrm{kg}^{-1} \cdot \mathrm{hr}^{-1}$ for 5 consecutive days $(n=9)$ raised MAP to $133 \pm 8 \mathrm{mmHg}$; increases were immediately significant when compared with saline data. When the $36 \mu \mathrm{g} \cdot \mathrm{kg}^{-1} \cdot \mathrm{hr}^{-1}$ infusion rate of NA was applied intrarenally $(n=10)$, increases in MAP up to $150 \pm 5 \mathrm{mmHg}$ on day 5 were produced; statistical significance of the pressor response was obtained over the complete infusion period. The same dose of NA intravenously infused $(n=9)$ induced relatively smaller increases in MAP though also significant from the second day; ultimate levels of MAP were $145 \pm 3 \mathrm{mHg}$.

Fig. 7.4 shows the effects on $\mathrm{Cl}$. Control values were between 19.6 and 


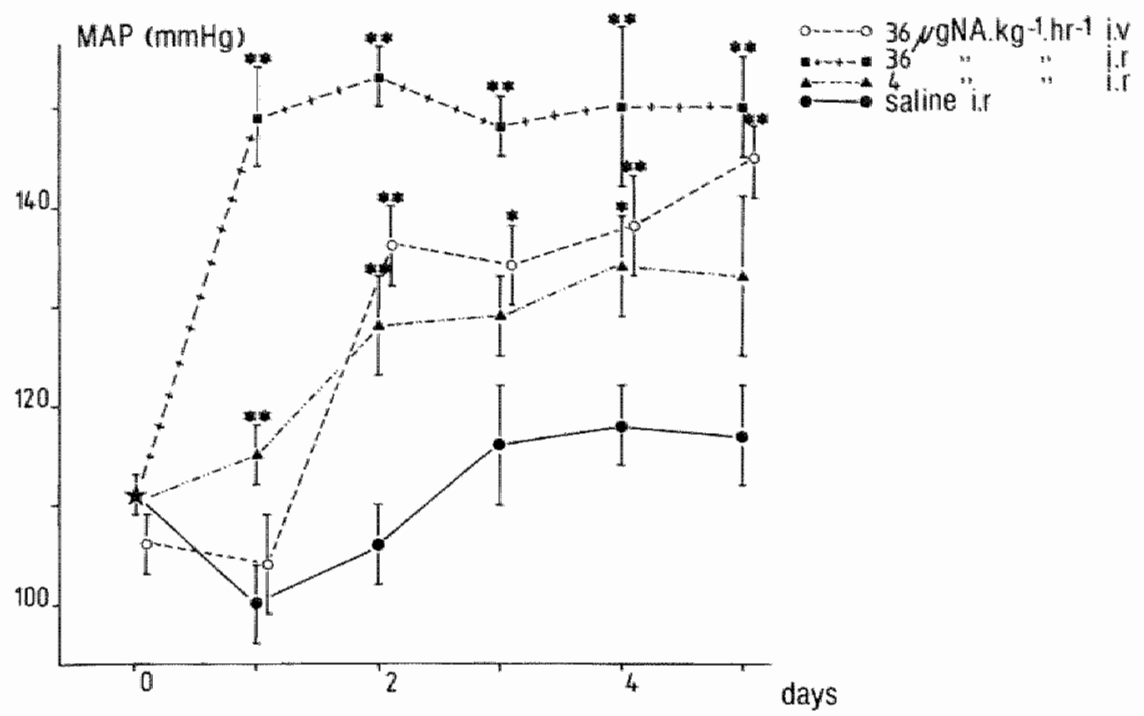

Figure 7.3

Changes in mean arterial pressure (MAP) caused by chronic intrarenal infusion of saline or twa dases of NA as well as intravenous infusion of one dose of NA.

"p <0.05; "p <0.005: statistically significant differences vs. corresponding saline data (Student's t-test for unpaired values).

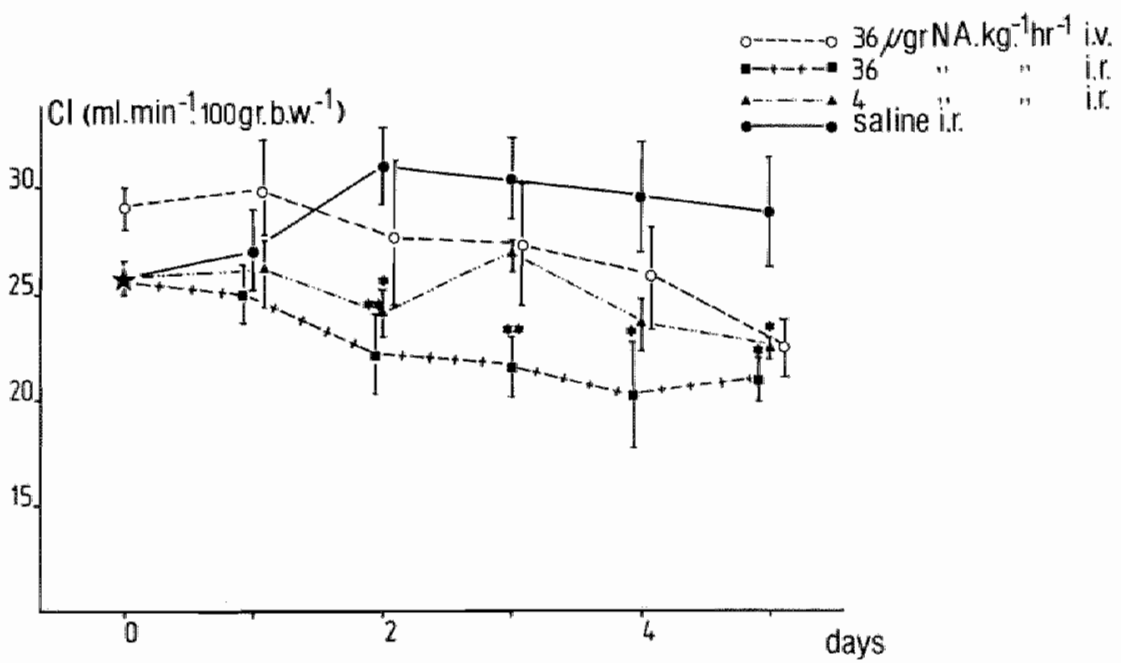

Figure 7.4

Changes in normalized cardiac output (CI) during chronic intrarenal and intravenous NA infusion statistically analyzed by cornpairing with corresponding intrarenally applied saline data.

"p<0.05; "p <0.005 (Student"s t-test for unpaired values). 


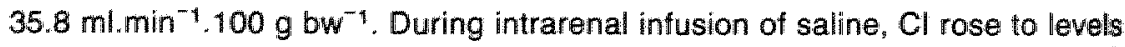
of $28.8 \pm 2.6 \mathrm{ml}^{-\mathrm{min}^{-1} .100 \mathrm{~g} \mathrm{bw}}{ }^{-1}$. Cl decreased significantly to approximately $22.0 \mathrm{ml} \mathrm{min}^{-1} .100 \mathrm{~g} \mathrm{bw}^{-1}$ during intrarenal infusion of both doses of NA; however, obvious decreases were obtained earlier in the infusion period of $36 \mu \mathrm{g}$ NA. $\mathrm{kg}^{-1} . \mathrm{hr}^{-1}$ although statistical significance was not reached. $\mathrm{Cl}$ decreased to the same extent on the 5th day of intravenous infusion of $36 \mu \mathrm{g} \mathrm{NA} \cdot \mathrm{kg}^{-1} . \mathrm{hr}^{-1}$.

Fig. 7.5 indicates that the decreases in $\mathrm{Cl}$ during chronic intrarenal NA infusion were associated with decreases in both determinants of $\mathrm{Cl}, \mathrm{HR}$ (Fig. 7.5a) and SVI (Fig. 7.5b). Although changes in HR were marginal, significant decreases in SVI parallelled significant decreases in Cl exactly. During intravenous NA infusion, HR rose slightly so that the low $\mathrm{Cl}$ levels on day 5 were caused exclusively by a relatively greater decrease in SVI.

Effects on TPRI are shown in Fig. 7.6. On control day, TPRI ranged be-

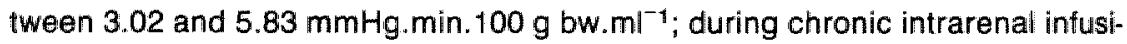
on of saline, TPRI decreased somewhat along with the increases of $\mathrm{Cl}$. Intrarenal infusion of $4 \mu \mathrm{g} \mathrm{NA} \cdot \mathrm{kg}^{-1} \cdot \mathrm{hr}^{-1}$ elevated TPRI significantly over the whole infusion period up to $5.95 \pm 0.45 \mathrm{mmHg} \cdot \mathrm{min} .100 \mathrm{~g} \mathrm{bw} \cdot \mathrm{ml}^{-1}$ on day 5 and the 36 $\mu \mathrm{g} \mathrm{NA} . \mathrm{kg}^{-1} . \mathrm{hr}^{-1}$ infusion rate produced immediately significant increases to final levels of $7.49 \pm 0.35 \mathrm{mmHg}$.min. $100 \mathrm{~g} \mathrm{bw} \cdot \mathrm{ml}^{-1}$. Intravenous infusion of $36 \mu \mathrm{g}$ NA. $\mathrm{kg}^{-1} \cdot \mathrm{hr}^{-1}$ raised TPRI significantly from day 2 to levels of 6.68 $\pm 0.39 \mathrm{mmHg} \cdot \mathrm{min} .100 \mathrm{~g} \mathrm{bw} \cdot \mathrm{ml}^{-1}$ on day 5 .

\subsection{Discussion}

In this study, it has been found that hypertension induced by either intrarenal or intravenous NA infusion is characterized by elevated total peripheral resistance at any stage of its development. Differences in pressor response to intrarenal vs. intravenous application of NA correlate well with differences in increa. ses of TPRI. No indication of volume retention hemodynamically manifested by increases in cardiac output, has been observed during NA infusion by either route. Cl decreased slowly and secondary to elevations of MAP, mostly by reductions in SVI probably caused by increases of cardiac afterload and activation of baroreflex mechanisms; application of $4 \mu \mathrm{g} \mathrm{NA} \cdot \mathrm{kg}^{-1} \cdot \mathrm{hr}^{-1}$ via the suprarenal artery caused acutely transient decreases in $\mathrm{Cl}$ and elevations in TPRI while MAP rose slightly but insignificantly. The infusion rate of $36 \mu \mathrm{g} \mathrm{NA} \cdot \mathrm{kg}^{-1} \cdot \mathrm{hr}^{-1}$ produced sustained decreases in $\mathrm{Cl}$ and increases in TPRI throughout the infusion period when applied intrarenally, and minor decreases in $\mathrm{Cl}$ when infused intravenously.

During chronic infusion of $N A$, measurements of hemodynamic parameters revealed that $\mathrm{Cl}$ also decreased secondary to elevations in MAP and TPRI, induced by intrarenal as well as intravenous NA application. The observed increases in $\mathrm{Cl}$ during intrarenal saline infusion were probably due to hypovolemia during the first days after laparotomy necessary for suprarenal artery catheterization. 

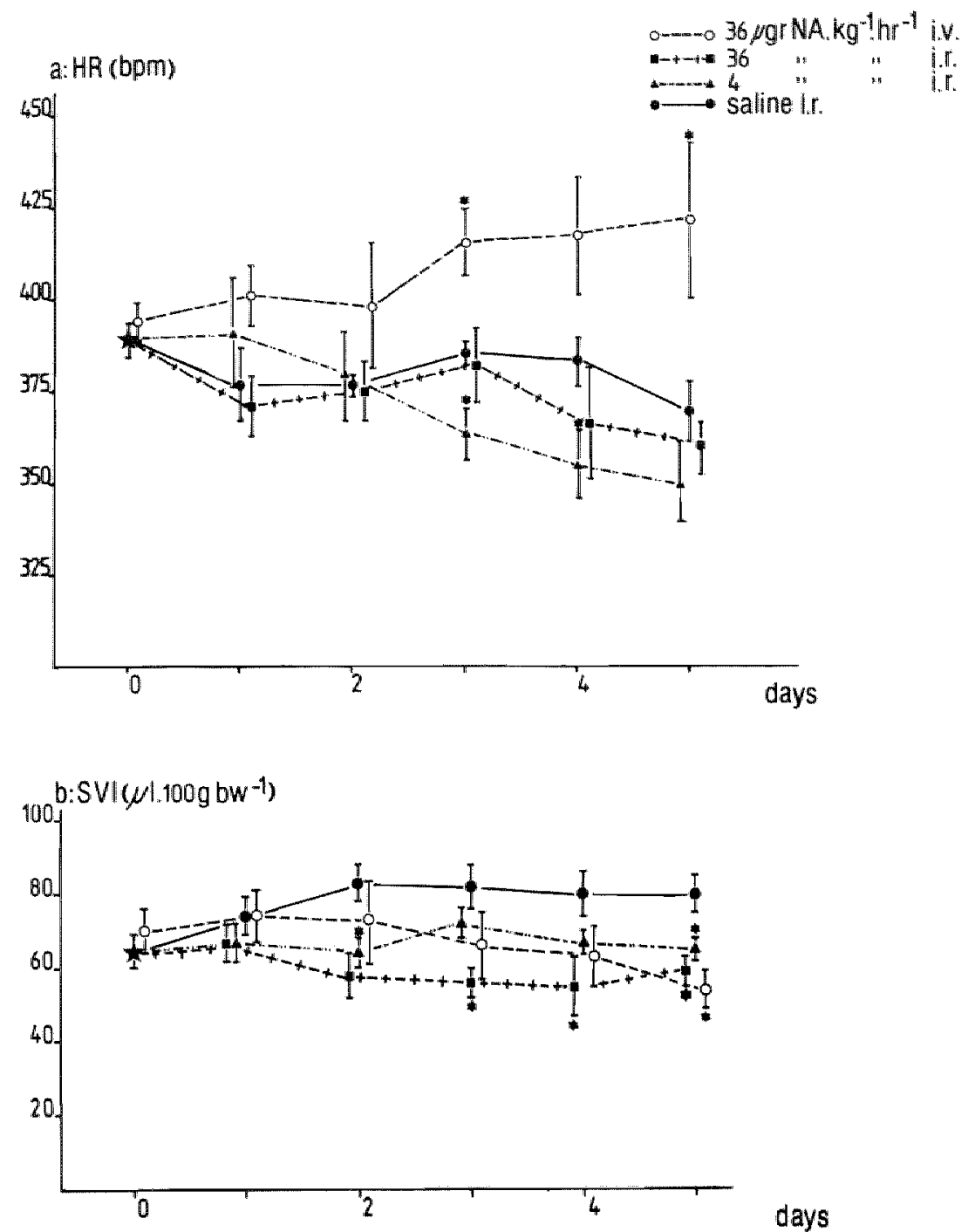

days

Figure 7.5

Effect on (a) heart rate (HA) and (b) normalized stroke volume (SVI) of chronic intrarenal and intravenous infusion of NA statistically analyzed by comparing with intrarenally applied saline data.

${ }^{*} p<0.05$ (Student's $t$-test for unpaired values). 
Therefore, values of hemodynamic parameters during 5 days of intrarenal and intravenous NA infusion were compared with corresponding data during chronic intrarenal infusion of saline.

TPRI was elevated significantly on the 1st day of intrarenal infusion of 4 and $36 \mu \mathrm{g} \mathrm{NA} \cdot \mathrm{kg}^{-1} . \mathrm{hr}^{-1}$ compared with saline data and on the 2 nd day of intravenous infusion of $36 \mu \mathrm{g} \mathrm{NA} . \mathrm{kg}^{-1} . \mathrm{hr}^{-1}$; the increases in TPRI were maintained over the complete infusion period.

Despite the initial renal vasoconstriction and the presumably high tubular and peritubular load of NA during intrarenal infusion of the neurotransmitter, increases in cardiac output did not precede hypertension in this animal model.

Long-term infusion of $17 \mu \mathrm{g} \mathrm{NA} \cdot \mathrm{kg}^{-1} \cdot \mathrm{hr}^{-1}$ into the renal artery of conscious dogs which raised MAP by $25 \mathrm{mmHg}$ has been reported to produce a positive sodium balance, even when plasma sodium concentrations are elevated stepwise (Katholi et al, 1977; Cowley and Lohmeier, 1979). However, cardiac output was only measured in the later phase of intrarenal NA infusion, by means of the dye-dilution technique, and appeared to be decreased (Katholi et al, 1977).

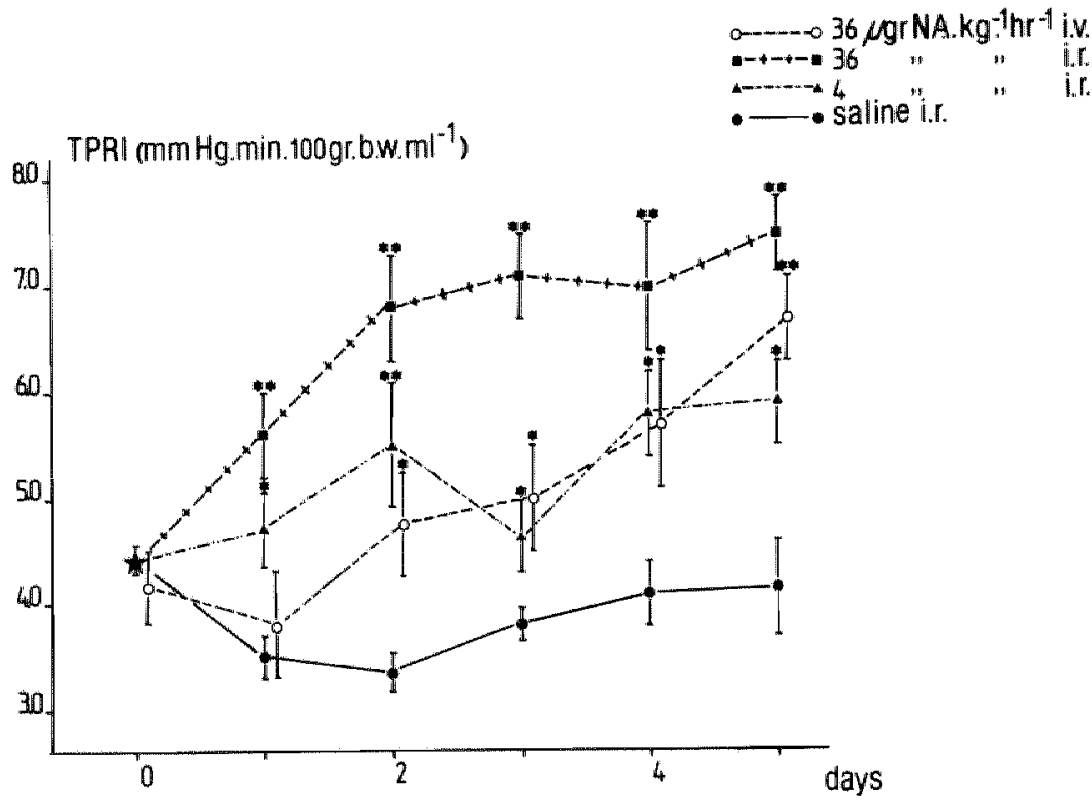

Figure 7.6

Effects on total peripheral resistance index (TPRI) of chronic intrarenal and intravenous NA infusion.

" $p<0.05$; " $p<0.005$ : statistically significant differences vs. corresponding intrarenally applied saline data (Student's t-test for unpaired values). 
Generally, elevation of renal vascular resistance does not necessarily lead to vollume retention and increased cardiac output. In one-kidney, one-clip rats

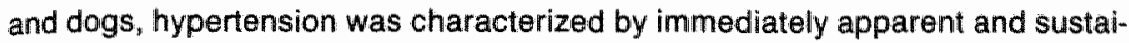
ned increases in total peripheral resistance; volume and cardiac output changes were not essential for the development of chronic hypertension (Korner, 1980). Elevation of MAP in another experimental renal hypertension model, bilateral cellophane wrapping in rabbits, was also due to increases in peripheral resistance from the earliest stage (Freeman et al, 1982). In fact, in only one animal hypertension model, reduction of renal mass combined with chronic excessive salt loading, renal dysfunction leads to cascade-like increases in total peripheral resistance exactly as predicted (Guyton et al, 1980).

An intriguing observation in the course of the experiments on hemodynamic characterization of effects of intrarenal NA application is that the infusion rate of $4 \mu \mathrm{g} \mathrm{NA} . \mathrm{kg}^{-1} . \mathrm{hr}^{-1}$ when applied intrarenally was effective to increase MAP (see also chapter 6) and TPRI within a few hours. Since this infusion rate during acute (preliminary experiments) and chronic (see chapter 3 ) intravenous administration was not able to elicit a vasopressor response and, furthermore, plasma NA levels were not increased until the 4th day of intrarenal infusion of this dose, the increases in vascular resistance were not the result of leakage of NA into the systemic circulation. It is therefore hypothesized that intrarenal NA infusion stimulated renal afferent nerves directly or indirectly.

Stimulation of the renorenal reflex loop (Recordati et al, 1981a) could lead to increases in overall sympathetic activity as is shown in two-kidney, one-clip Goldblatt rats (Katholi et al, 1982). During the acute phase of intrarenal infusion of $4 \mu \mathrm{g} \mathrm{NA} . \mathrm{kg}^{-1} . \mathrm{hr}^{-1}$ "this sympathetic hyperactivity does not necessarily have to be reflected by increases in plasma NA concentrations since spillover of the neurotransmitter from the synaptic cleft may be a rather slow process.

Alternatively, stimulation of renal afferent nerves may activate another unknown vasopresor mechanism, or reversely inhibit the synthesis and release of endogenous vasodilatory substances.

For further discussion on the evidence that hypertension caused by intrarenal or intravenous NA infusion is not volume-dependent at any developmental sitage, and suggestions concerning alternative mechanism which could explain the elevation in TPRI, see section 8.4 . 


\section{a. BODY FLUID AND SALT LOAD AS FUNCTION OF INTAKE AND OUTPUT DURING CHRONIC INTRARENAL INFUSION OF NORADRENALINE*}

\subsection{Introduction}

This chapter deals with further searches for evidence that longterm intrarenal infusion of noradrenaline in conscious rats causes water and sodium retention by the kidney thereby revealing volume dependency of the development of hypertension induced by activation of renal adrenergic mechanisms.

It is assumable that renal excretion of water and salt declines during intrarenal NA infusion. In the first place, decreases in renal blood flow as reported in chapter 6 may reduce glomerular filtration rate (Guyton, 1976). Secondly, lowlevel stimulation of renal efferent nerves which does not affect renal hemodynamics, has been found to decrease urinary excretion of water and sodium (DiBona, 1977; DiBona and Sawin, 1982). Furthermore, application of NA to isolated rat kidneys stimulates tubular sodium reabsorption if the renal perfusion pressure is held constant (Besarab et al, 1977) and rather unphysiological concentrations of NA increase water reabsorption in isolated rat tubules (Bello-Reus, 1980; Chan, 1980). In the third place, intrarenal NA infusion stimulates the reninangiotensin-aldosterone axis in dogs (Katholi et al, 1977; Cowley and Lohmeier, 1979 ; Ayers et al, 1981) and rats (see chapter 5); aldosterone increases sodium reabsorption by its direct tubular action.

In the present study, plasma volume as well as plasma sodium and potassium concentrations, related to intake and urinary excretion of water and salt, have been determined during chronic intrarenal NA infusion and compared with data obtained during intravenous NA infusion.

\subsection{Methods}

In uninephrectomized rats, the suprarenal artery was cannulated for chronic intrarenal infusion of saline or NA as described in section 3.2. As control for effects of systemically appearing NA, another group received a catheter into the jugular vein for intravenous infusion of NA. Catheters were perfused with saline from a subcutaneously implanted osmotic minipump over a 2-day control period. After that, the saline minipumps were replaced by saline or NA-containing pumps so that chronic intrarenal infusion of saline or 4 and $36 \mu \mathrm{g} \mathrm{NA} \cdot \mathrm{kg}^{-1} \cdot \mathrm{hr}^{-1}$ as well as intravenous infusion of $36 \mu \mathrm{g} \mathrm{NA} . \mathrm{kg}^{-1} \cdot \mathrm{hr}^{-1}$ became possible.

\footnotetext{
*based on: Kleinjans JCS, Smits JFM, Kasbergen CM and Struyker-Boudier HAJ: Body fluid and sait homeostasis during hypertension caused by chronic intrarenal norepinephrine infusion in conscious rats. J Hypert, in press, 1983.
} 
In 64 animals, a method for plasma volume determination in conscious freely moving rats was applied which has been developed in our laboratory recently (Evenwel, 1982). Beside the catheters for intrarenal and intravenous infusion of NA, catheters were inserted into the right femoral artery for blood sampling and into the right femoral vein for injection of 125 -albumin.

Plasma volume was measured as follows: after a rapid bollus injection of $5 \mu \mathrm{Ci}{ }^{125}$-albumin (Ire, The Netherlands), blood samples of $0.2 \mathrm{ml}$ were taken from the femoral artery catheter at $t=30,60$ and $90 \mathrm{~min}$. Donor blood was given as substitution for loss of red blood cells. Radioactivity in plasma was counted. Log concentration vs. time extrapolation to $t=0$ was applied and the plasma 125 -albumin concentration at time of injection was calculated. Plasma volume was determined by dividing the doses and the plasma concentration at $t=0$ of 125/-albumin and normalized for body weight (PVI).

PVI was measured on control day and on the 1st of intrarenal infusion of saline or NA and intravenous infusion of NA in one subgroup of rats as well as on control day and on the 4th day of saline or NA infusion in a second subgroup in order to avoid possible complications resulting from immunological reactions observed after three times repeated albumin administration. Before the second measurement of $P V I$, a blood sample was taken in order to correct for resting radioactivity in plasma.

Plasma concentrations of sodium and potassium were measured by means of a flame photometer in blood samples of 32 rats, collected in the course of the determination of plasma renin activity during intrarenal and intravenous NA infusion as described in chapter 5 .

A group of 23 rats were housed in metabolic cages with free access to food and water. After 4 days for habituation, ad libitum intake of food and water, as well as urine output were monitored daily during chronic intrarenal infusion of saline or NA and intravenous infusion of NA; cumulative water intake (WI) and urine output (UO) as well as cumulative intake and urinary excretion of sodium $\left(I_{\mathrm{Na}}+\right.$ vs. $\left.U_{\mathrm{Na}}+. V\right)$ and potassium $\left(\mathrm{I}_{K}+\right.$ ws. $\left.U_{K}+. V\right)$ were determined.

Data were statistically analyzed by means of a Student's t-test for unpaired values.

\subsection{Results}

Effects of chronic intrarenal infusion of 4 and $36 \mu \mathrm{g} \mathrm{NA}_{\mathrm{Ng}}{ }^{-1} \mathrm{hr}^{-1}$, and intrave-

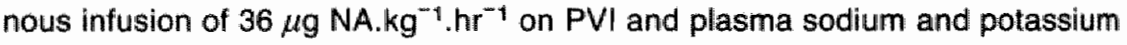
concentrations as compared with data obtained during intrarenal saline infusion are displayed in Table 8.1.

During 5 days of intrarenal saline infusion, PVI increased slowly from 4.1 \pm 0.1 to $5.5 \pm 0.1 \mathrm{ml}^{2} 100 \mathrm{~g} \mathrm{bw}^{-1}$ and both intrarenal and intravenous NA infusion produced significantly lower PVIs on the 4 th day of infusion.

Only during intrarenal infusion of $36 \mu \mathrm{g} \mathrm{NA} \cdot \mathrm{kg}^{-1} \cdot \mathrm{hr}^{-1}$, significant changes 


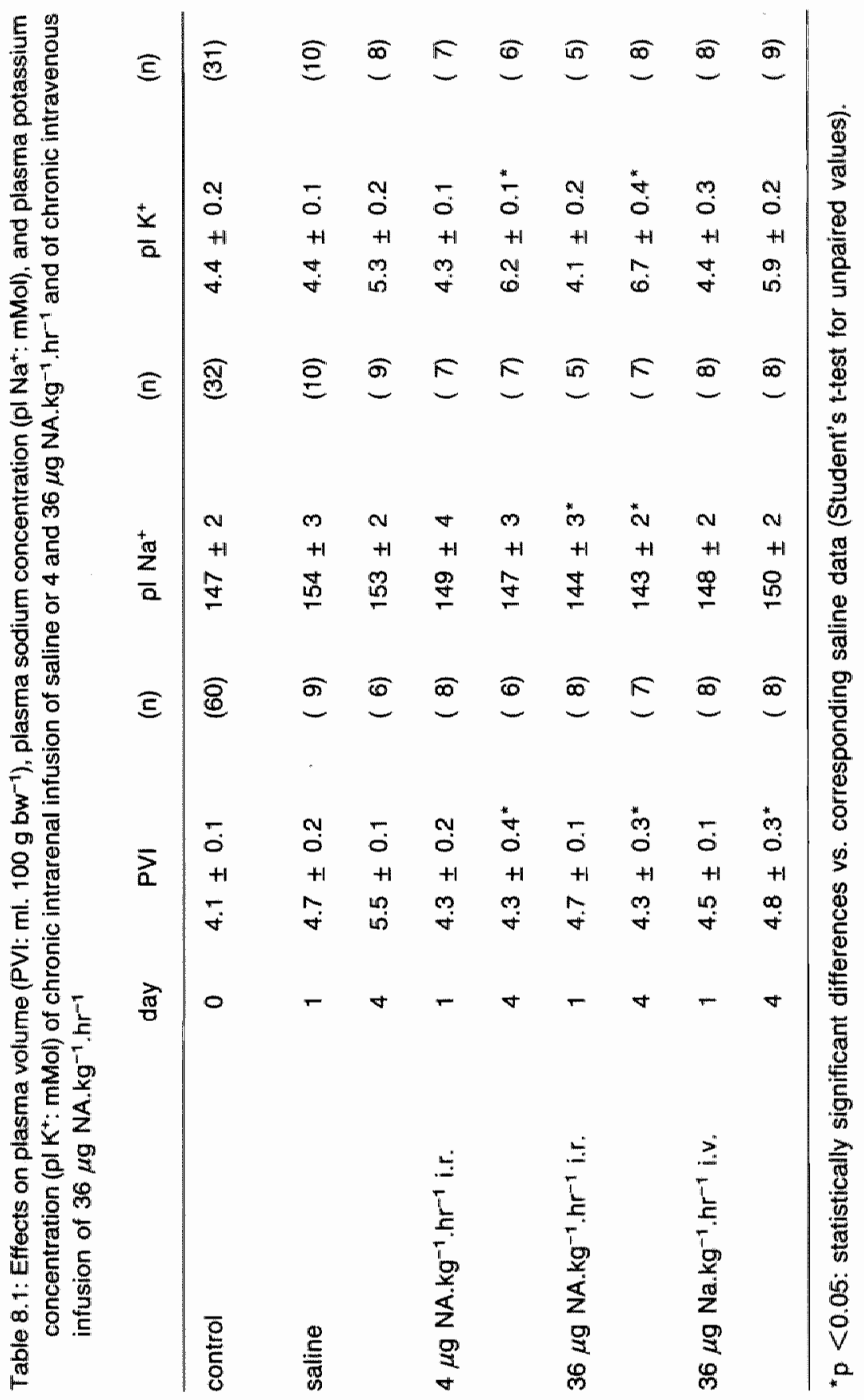


in plasma sodium concentration were obtained. The plasma sodium concentration was decreased by approximately $7 \%$ over the wholle infusion period.

On the contrary, intrarenal infusion of NA as well as intravenous infusion of NA were able to elevate plasma potassium concentration as compared to saline data. On the 4th day of intrarenal saline infusion, plasma potassium concentration was $5.3 \pm 0.2 \mathrm{mMol}$; intravenous infusion of $36 \mu \mathrm{g} \mathrm{NA} \mathrm{kg}^{-1} \cdot \mathrm{hr}^{-1}$ produced an insignificant increase of $11 \%$ while intrarenal infusion of 4 and $36, \mu \mathrm{g}$ NA. $\mathrm{kg}^{-1} \cdot \mathrm{hr}^{-1}$ raised plasma potassium concentration significantly by 17 and $26 \%$, respectively.

Decreases in PVI during intrarenal infusion of $4 \mu \mathrm{g} \mathrm{NA} \cdot \mathrm{kg}^{-1} . \mathrm{hr}^{-1}$ were related to significant increases in cumulative UO (fig. $8.1 \mathrm{~b}$ ) since cumulative WI was unchanged (fig. 8. 1a). However, changes in PVI during intrarenal application of the higher dose of NA were produced by decreases in cumulative WI since cumulative UO was normal. Furthermore, during intravenous infusion of $36 \mu \mathrm{g}$ NA. $\mathrm{kg}^{-1} \cdot \mathrm{hr}^{-1}$, cumulative UO was increased in the initial phase and cumulative WI was decreased during the latter part of the NA infusion period.

Decreases in plasma sodium concentration during intrarenal infusion of $36 \mu \mathrm{g} \mathrm{NA} \cdot \mathrm{kg}^{-1} \cdot \mathrm{hr}^{-1}$ appeared to be caused by steeply decreased cumulative $\mathrm{INa}_{\mathrm{Na}}$ over the complete infusion periad, which even surpassed the decline in cumulative $U_{\mathrm{Na}}+. V$ in the later phase of NA infusion (figs. 8.2a and 8.2b). During the complete period of chronic intrarenal as well as intravenous infusion of $N A, U_{K}+. V$ was decreased significantly (fig. $8.3 \mathrm{~b}$ ). Only during intrarenal infusion of $36 \mu \mathrm{g} \mathrm{NA} \cdot \mathrm{kg}^{-1} \cdot \mathrm{hr}^{-1}$, significant decreases in cumulative $\mathrm{I}_{\mathrm{K}}+$ were observed (fig. 8.3a).

\subsection{Discussion}

In this study, body fluid and salt homeostasis during chronic activation of renal adrenergic mechanisms was evaluated in order to find supporting evidence for the hypothesis formulated in section 3.4 that hypertension induced by long-term intrarenal NA infusion may be characterized by a volume-retaining phase.

However, no indication of increased body load of water and sodium could be obtained during hypertension caused by either intrarenal or intravenous infusion of NA. During intrarenal saline infusion, PVI increased somewhat confirming the suggestion that rats were hypovolemic at the point of starting the longterm intrarenal NA infusion (in order to correct for this loss of fluid during laparotomy, normal tap drinking water is replaced nowadays in our laboratory by a $5 \%$ glucose solution from which the rats tend to drink large quantities). Both during intrarenal and during intravenous infusion of NA, PV\| stayed significantly below the PVI values obtained during intrarenal saline infusion correlating well with the decreases in cardiac output during chronic NA infusion described in chapter 7 , suggesting that in the sustained phase of hypertension the decreased cardiac preload mainly reduced cardiac output. 


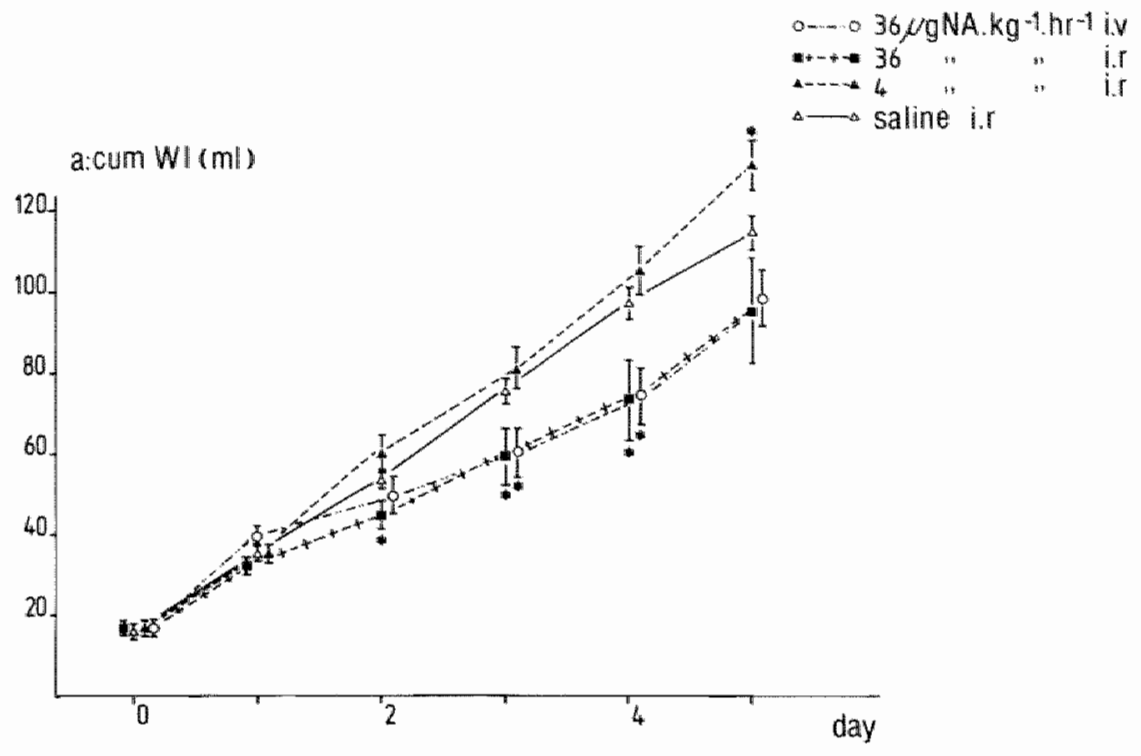

b:cum $100(\mathrm{ml})$

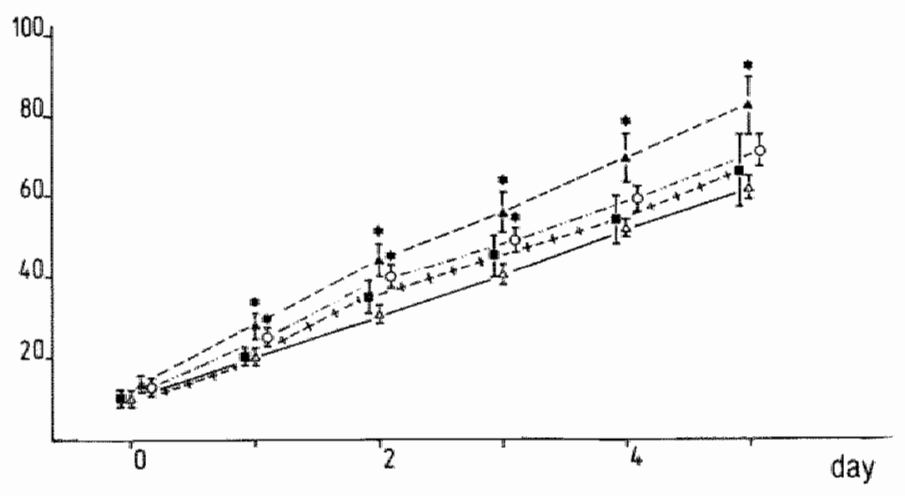

Filgure 8.1

Changes in cumulative (a) water intake (WI) and (b) urine output (UO) caused by intravenous and intrarenal NA infusion and statistically compared with corresponding intrarenally applied saline data.

" $p<0.05$ (Student's t-test for unpaired values). 


$$
\begin{aligned}
& \therefore \cdots 36 \mu \mathrm{gNA} . \mathrm{kg}^{-1} \mathrm{hr}^{-1} \mathrm{Hy} \\
& \text {-... } 36 \\
& \text { - }-4 \\
& \Delta \rightarrow \text { saline ir }
\end{aligned}
$$
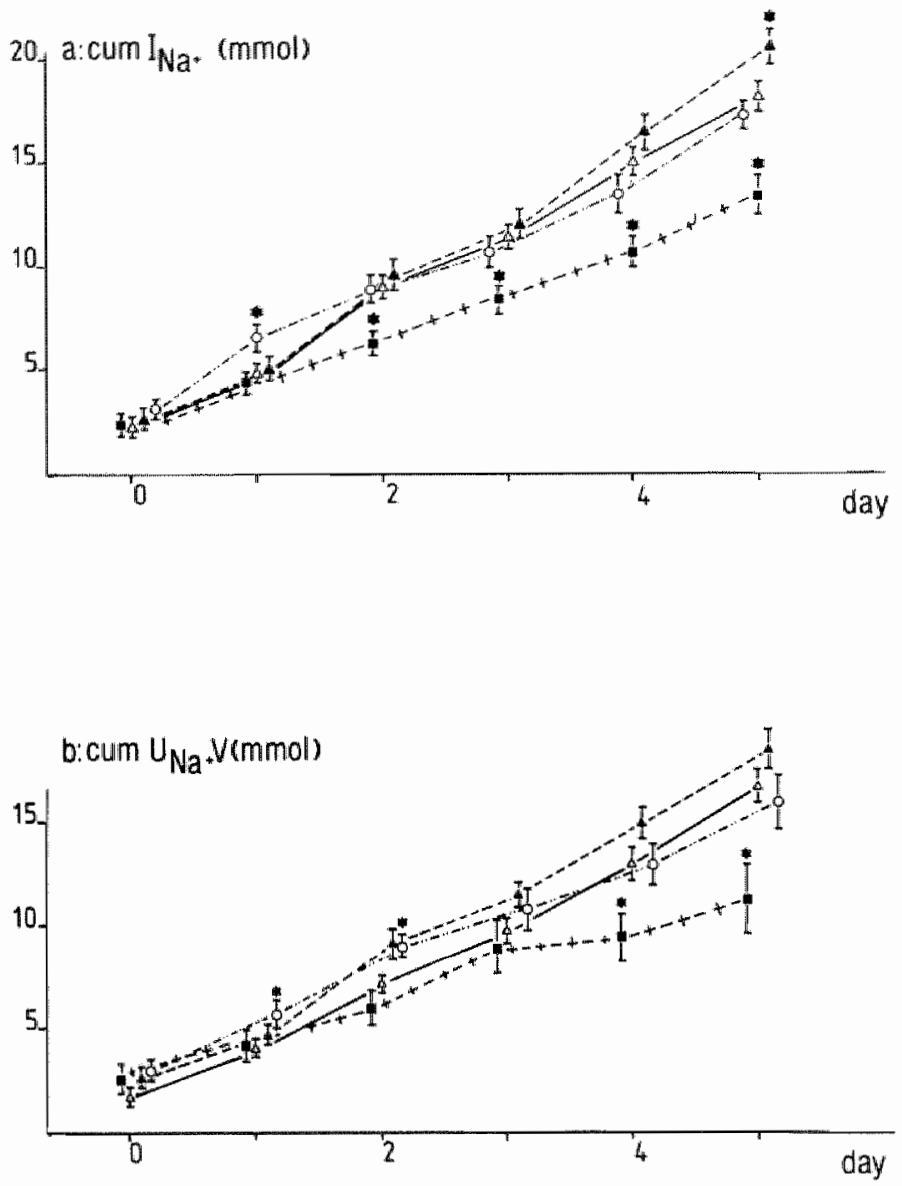

\section{Figure 8.2}

Changes in cumulative (a) intake of sodium and (b) urinary excretion of sodium caused by intravenous and intrarenal NA infusion and statistically compared with corresponding intrarenally applied saline data.

" $p<0.05$ (Student's t-test for unpaired values). 

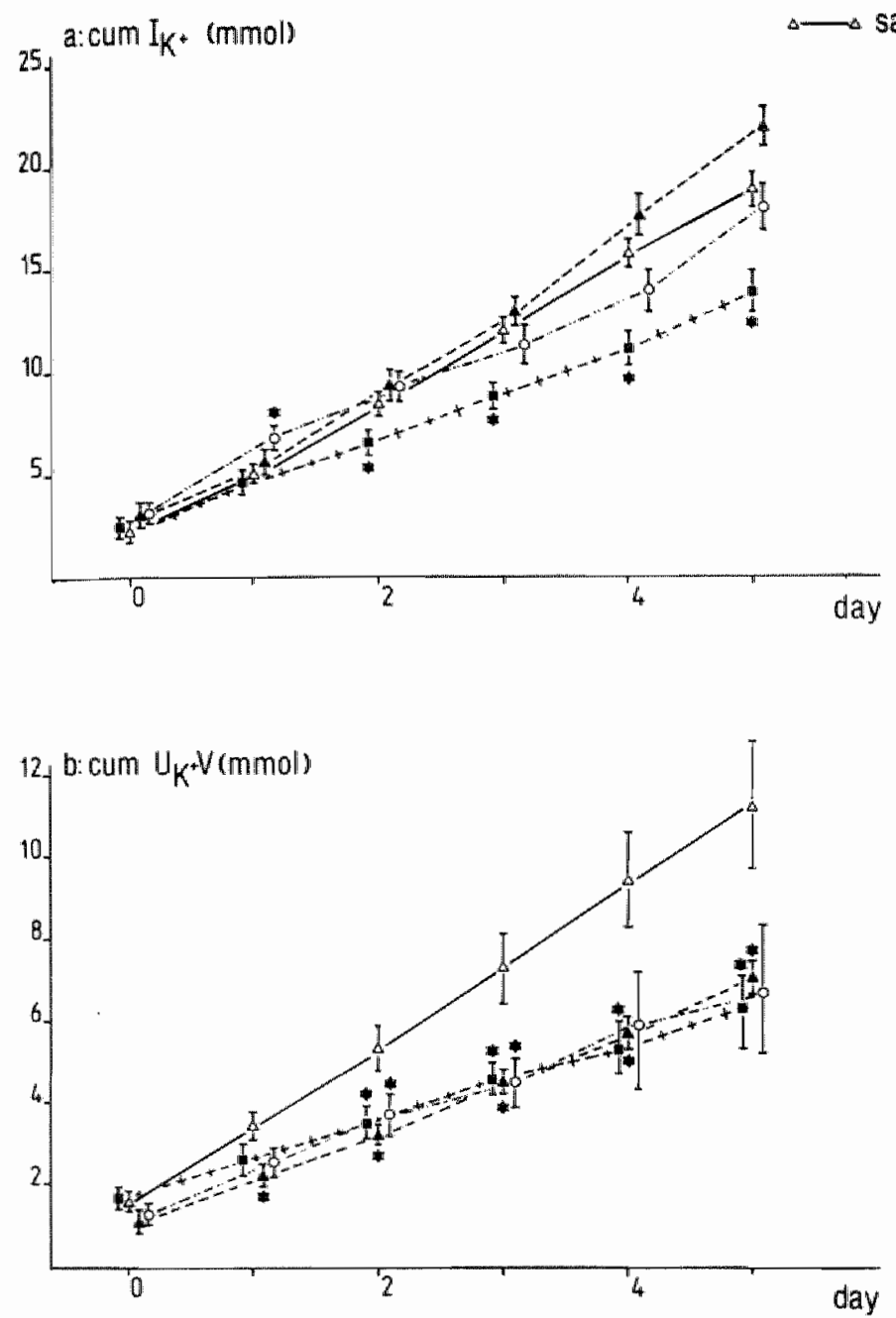

Figure 8.3

Changes in cumulative (a) intake of potassium and (b) urinary excretion of potassium caused by intravenous and intrarenal NA infusion and statistically compared with corresponding intrarenally applied saline data.

" $p<0.05$ (Student's t-test for unpaired values). 
However, the mechanism by which the lower PV/s were produced are appatrently not the same. Intrarenal infusion of $4 \mu \mathrm{g} \mathrm{NA} \cdot \mathrm{kg}^{-1} \cdot \mathrm{hr}^{-1}$ produced decreases in PVI by increasing the renal water excretion while $36 \mu \mathrm{g} \mathrm{NA} \mathrm{kg}^{-1} \cdot \mathrm{hr}^{-1}$ administered intrarenally reduced mainly the intake of water. Intravenous NA infusion influence initially urine output, but in the later phase also water intake.

Steep reductions in sodium intake were responsible for the decreases in plasma sodium concentrations during intrarenal NA infusion; the observed reduced urinary sodium excretion in the later phase of NA application seemed to be secondarily related to the decreased sodium intake and not to be caused by the direct tubular effects of the neurotransmitter as was expected conformably the renal nerve stimulation experiments (DiBona, 1977; DiBona and Sawin, 1982).

These data indicate that the hypothesis that intrarenal NA infusion leads to retention of water and sodium by the primary action of NA on renal function, is not verified, which may be subscribed by additional data on the tubular effects of NA: Besarab et al (1977) have shown that application of NA to the perfusate of isolated rat kidneys does not increase tubular sodium reabsorption when the renal perfusion pressure is allowed to raise under influence of the vasopressor actions of NA. Furthermore, unphysiologically high concentrations of NA have to be applied in order to stimulate water reabsorption in isolated rat proximal tubules (Bello-Reus, 1980).

Intrarenal infusion of $17 \mu \mathrm{g} \mathrm{NA.} \mathrm{kg}^{-1} \mathrm{hr}^{-1}$ in conscious dogs, however, produces a positive sodium balance (Katholi et al, 1977; Cowley and Lohmeier, 1979), while the renal function curve relating arterial pressure to urine output, was shifted to higher MAP levels (Cowley and Lohmeier, 1979). But these dogs were held on a fixed sodium diet while the rats in the present study, having free access to food and water, decreased their plasma sodium concentration mainly by reducing their sodium intake - in fact, by eating less. This points at changes in behavioral patterns resulting either from different sensoric input to the central nervous system possibly caused by the altered homeostatic conditions during chronic intrarenal NA infusion, or by the direct central action of NA itself which has been reported to elicit a central sympatho-inhibitory effect after intravenous administration at doses of $10-15 \mu \mathrm{g} \cdot \mathrm{kg}^{-1}$ in anesthetized cats (Sinha and Schmitt, 1974).

Summarizing the effects of chronic stimulation of renal adrenoceptors on central hemodynamics and body load of water and sodium, it is obvious that hypertension induced by chronic intrarenal NA infusion is characterized by immediate elevations in total peripheral resistance which are primary and not reflexive to increases in cardiac output. This implies that the additional pressor response during intrarenal NA infusion indicated by the shift of the log pllasma NA concentration vs. arterial pressure curve to lower plasma NA levels, as described in chapter 3 , was not caused by autoregulatory vasoconstriction after an initial hypervolemic phase. 
Therefore, despite of the primary change of renal function, this renal hypertension model is not volume-dependent.

Also in other animal hypertension models, which are supposed to interfere with renal function directly, the autoregulation theory of hypertension can not longer be upheld. Although in one-kidney, one-clip Goldblatt hypertensive rats, the pressure control level of the renal hydraulic system is shifted to higher levels of arterial pressure (Norman et al, 1978), and a positive sodium balance and increased cardiac output usually occurs in the established phase of hypertension (Carretero and Romero, 1977; Freeman et al, 1982), hypertension can develop in sodium-depleted one-kidney Goldblatt dogs which have no possibility of sodium and water retention, and is associated with immediately elevated total peripheral resistance and decreased cardiac output (Freemam el al, 1982).

Cellophane-wrapping of the remaining kidney in uninephrectomized rabbits has also been reported to cause hypertension correllated with initially higher cardiac output, but again during sodium depletion hypertension develops without increases in cardiac output but is entirely associated with elevated vascular resistance (Korner, 1980, 1982).

It is therefore concluded that hypertension experimentally induced by primary changes in renal function, is not generally characterized by a volumeretaining phase and that at this point the Borst-Guyton theory is not correct.

Since activation of the renin-angiotensin system nor whole body autoregulation accounts for the additional increase in total peripheral resistance during intrarenal NA infusion, alternative mechanisms have to be considered.

The most striking difference between effects of intrarenal and intravenous infusion of NA may be obtained from the present data on plasma potassium concentrations. Chronic infusion of 4 and $36 \mu \mathrm{g} \mathrm{NA} \cdot \mathrm{kg}^{-1} \cdot \mathrm{hr}^{-1}$ into the renal artery of conscious rats produced significant increases in plasma potassium concentrations after 4 days while intravenous infusion of $36 \mu \mathrm{g} \mathrm{NA} \cdot \mathrm{kg}^{-1} \cdot \mathrm{hr}^{-1}$ elevated plasma potassium concentration slightly and insignificantly. Increases in plasma potassium concentrations are mainly caused by decreased urinary excretion of potassium, although during intrarenal application of the higher infusion rate of NA also potassium intake was diminished. Since plasma potassium concentrations as well as urinary potassium excretion did not differ very much during intrarenal infusion of 4 and $36 \mu \mathrm{g} \mathrm{NA} \cdot \mathrm{kg}^{-1} \cdot \mathrm{hr}^{-1}$, the possibility remains that reductions of faecal potassium excretion compensated for decreases in potassium intake, associated with decreases in sodium intake during intrarenal infusion of $36 \mu \mathrm{g} \mathrm{NA} . \mathrm{kg}^{-1} . \mathrm{hr}^{-1}$.

Furthermore, it is clear that increases in plasma potassium concentrations are not related to decreases in plasma sodium concentrations, which excludes the possibility that potassium is reabsorbed by the kidney in exchange for sodium.

It has been reported recently that tubular NA handling is featured by active 
secretion of NA. Electrical stimulation of renal nerves in rabbits increases urinary NA excretion when compensated for changes in glomerular filtration rate (Lappe et al, 1982) and acute renal denervation decreases NA excretion in rats (Morgunov and Baines, 1981). Active secretion of NA is inhibited by cyanine 863 suggesting that tubular transmembrane exchange of NA is exerted via a cation exchange mechanism (Lappe et al, 1980). The steeply increased plasma potassium concentrations during intrarenal NA infusion could be explained by the fact that peritubular unbound NA which is highly concentrated during intrarenal infusion of 4 as well as $36 \mu \mathrm{g} \mathrm{NA} \cdot \mathrm{kg}^{-1} \cdot \mathrm{hr}^{-1}$ but assumably not during intravenous infusion of $36 \mu \mathrm{g} \mathrm{NA} \mathrm{kg}^{-1} . \mathrm{hr}^{-1}$, was actively exchanged for potassium.

However, an alternative mechanism may account for the increases in plasma potassium levels during intrarenal NA infusion (Heidenreich $O$, personal communication). The rat kidney contributes considerably to the storage of glucose. Adrenaline, but to a lesser extent also noradrenaline, is known to stimulate the intracellular gluconeogenesis, which appears to be associated with steep increases of the intracellular potassium concentration. The elevations of plasma potassium concentrations during chronic intrarenal NA application may be due to leakage of potassium from kidney cells parallel with a NA-stimulated gluconeogenesis. Measurements of plasma glucose levels may elucidate the relevance of this suggested mechanism.

In turn, these increased plasma potassium concentrations could result in exaggerated vascular tension since depolarization of arterial vascular muscle cells is facilitated by reducing the resting membrane potential (Hermsmeyer 1976) and arterial responsiveness to NA is increased (Casteels et al, 1977; Skang and Detar, 1981) by raising extracellular potassium concentrations. 


\section{GENERAL DISCUSSION AND CONCLUSIONS}

This thesis presents an experimental hypertension model in which efferent renal sympathetic nerve hyperactivity in conscious rats is simulated by means of intrarenal infusion of noradrenaline (NA). Specific stimulation of renal adrenergic mechanism may involve a rhapsody of cardiovascular responses many of which will be induced by secondary activation of neurohumoral systems supporting the initial effects of increased sympathetic tone within the kidney eventually leading to hypertension, as elucidated in the Generall Introduction.

Increased renal sympathetic nerve activity has been established to be associated with genetic hypertension by means of the technique of direct recordings of renal nervous discharge frequencies. Furthermore, it has been shown that elimination of the sympathetic innervation of the kidneys by surgical renal denervation at least retards the development of genetic hypertension and DOCA-salt hypertension. Also, renal denervation reduces the arterial pressure levels in Goldblatt hypertensive rats and in dogs with chronic coarctation hypertension.

The observation that changes in renal function are eminent in an early phase of essential hypertension in men and spontaneous hypertension in rats, supports the Borst-Guyton hypothesis that a primary alteration in renal function is a necessary condition for the development of sustained hypertension. Since urinary output of water and salt is inter alia a function of arterial pressure, a shift of the excretory capacity of the kidney to a level of higher arterial pressure may result in hypertension characterized by volume retention and - reflexively to increases in cardiac output - elevations in vascular resistance. Renal adrenergic hyperactivity may lead to changes in renal hemodynamics and tubular reabsorption processes adjusting the renal hydraulic system to increased levels of arterial pressure.

The relevance of renal adrenergic hyperactivity to the development of hypertension has been estalished by long-term infusion of NA into the renal artery of conscious dogs, which causes increase of arterial pressure associated with a positive sodium balance and a shift of the renal function curve to higher pressure levels. However, in these studies an infusion rate has been applied which does not restrict the action of NA to the kidney. Furthermore, no information on the time dependency of several processes associated with the development of hypertension has been obtained.

Therefore, in this thesis, cardiovascular responses to varying intrarenally applied doses of NA in conscious rats were determined. Recent advances in small animal laboratory technology make the rat suitable for measurements of systemic and regional hemodynamic parameters on a rather continuous scale 
so that in specific the precedence of changes in renal function, and subsequently of increases in cardiac output to the elevations of arterial pressure during intrarenal NA infusion could be evaluated in order to test the validity of the BorstGuyton hypothesis.

Because infusion into the renal artery of conscious rats has not been achieved yet, a method for chronic intrarenal infusion in freely moving rats had to be developed in the first place. Cannulation of the right inferior suprarenall ar: tery which originates from the right renal artery and ascends towards the adrenal gland, with the tip of the catheter manipulated towards the bifurcation with the renal artery, appeared to provide a reliable tool for gaining long-term access to the renal artery of rats as described in chapter 2 .

Applying this type of catheterization, NA was administered into the right kidney of normotensive uninephrectomized Wistar rats at infusion rates of 4,12 and $36 \mu \mathrm{g} . \mathrm{kg}^{-1} \cdot \mathrm{hr}^{-1}$ for 5 days by means of Alzet TM osmotic minipumps (chapter 3). All doses of NA were effective in elevating arterial pressure (MAP); furthermore, MAP increased further during intrarenal infusion of a particular dose of NA when compared with intravenous infusion via the jugular vein. Partly, this relatively augmented pressor response was attributed to achieve higher plasma NA concentrations during intrarenal NA infusion. However, by plotting log plasma NA concentration vs. MAP curves, it could be shown that any elevation of plama NA concentrations beyond approximately $1.40 \mathrm{ng} \cdot \mathrm{ml}^{-1}$ produced by intrarenal NA application caused considerably greater increase in MAP when compared with intravenous infusion. It was speculated that this additional pressor response during intrarenal NA infusion was caused by either increased sensitivity to circulating NA of adrenoceptors located in the vascular wall, or stimulation of a kidney-mediated pressor mechanism.

In chapter 4, it was investigated whether the relatively higher increases of plasma NA levels during intrarenal NA infusion were due to reduced whole body clearance of NA or to increased release of endogenously produced NA. By filling osmotic minipumps with NA solutions containing tracer amounts of tritiated NA, values of NA clearance and the rate of entry of NA into plasma during chronic intravenous and intrarenal infusion of $36 \mu \mathrm{g} \mathrm{NA} . \mathrm{kg}^{-1} \cdot \mathrm{hr}^{-1}$ could be calculated. The apparent release rate of NA was relatively more elevated on the 1st day of intrarenal NA infusion; since whole body clearance of NA was not changed on the Ist day of NA application compared with control levels, it was concluded that the endogenous production of NA was relatively more increased. This was inter. preted as a first indication that the overall activity of the sympathetic nervous system was increased during intrarenal NA infusion, possibly induced by intrarenal changes which modified renal afferent nerve tonus, conformable to find: ings on increased plama NA levels in Goldblatt hypertensive rats which also have been attributed to afferent renal nerve stimulation. On the 4 th day of NA infusion, the apparent release rate of NA was equal during intravenous and intrarenal NA application. By that time, the differences in plasma NA concentra- 
tions were related to decreased whole body clearance of NA during intrarenal NA infusion possibly caused by changes in renal function or saturation of renal NA clearance mechanisms.

In summary, the higher plasma NA concentrations during intrarenal NA infusion as compared with intravenous infusion were caused initially by the higher endogenous release of NA and secondarily by decreased whole body clearance.

Chapter 5 evaluates the contribution of the renin-angiontensin system to the elevated MAP during intrarenal and intravenous NA infusion in order to assess the nature of the pressor mechanism triggered by renal adrenergic hyperacitivity which possibly added its action to the direct pressure elevating effects of circulating NA. Intrarenal infusion of 4 and $36 \mu \mathrm{g} \mathrm{NA} \cdot \mathrm{kg}^{-1} \cdot \mathrm{hr}^{-1}$ as well as intravenous infusion of $36 \mu \mathrm{g} \mathrm{NA} . \mathrm{kg}^{-1} \cdot \mathrm{hr}^{-1}$ increased the plasma renin activi-

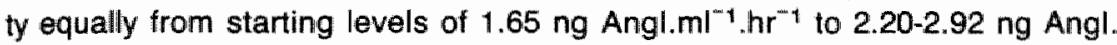
$\mathrm{ml}^{-1} \cdot \mathrm{hr}^{-1}$ on the 4th day of NA infusion probably via the direct stimulation of intrarenal, renin release mediating, beta-adrenoceptors. However, intrarenal NA might also counteract renin secretion via interference with renal alphaadrenergic receptors. Increases in renal vascular resistance were quite margi-

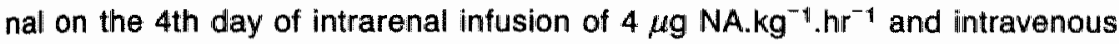
infusion of $36 \mu \mathrm{g} \mathrm{NA} \cdot \mathrm{kg}^{-1} \cdot \mathrm{hr}^{-1}$ (see chapter 6) which makes stimulation of renin release via intrarenal baroreceptors unlikely.

Secondly, inhibition of the angiotensin II synthesis by means of intraperitoneal infusion of the converting enzyme blocker captopril parallel with the chronic NA infusions was equally effective in lowering MAP during intravenous and intrarenal NA application. The mean decrease in MAP was approximately 15 $\mathrm{mmHg}$ indicating that during intrarenal infusion of 4 and $36 \mu \mathrm{g} \mathrm{NA} . \mathrm{kg}^{-1} \cdot \mathrm{hr}^{-1}$ and intravenous infusion of $36 \mu \mathrm{g} \mathrm{NA} . \mathrm{kg}^{-1} \cdot \mathrm{hr}^{-1}$ the synthesis of angiotensin II and thereby the vasopressor action of the octapeptide was equally stimulated as was already suggested by the plasma renin activity data.

Furthermore, during chronic intraperitoneal infusion of captopril, intrarenal but not intravenous NA application raised plasma NA concentrations to a lesser degree than without captopril treatment. On the 4th day of intrarenal infusion of $36 \mu \mathrm{g} \mathrm{NA} . \mathrm{kg}^{-1} \cdot \mathrm{hr}^{-1}$ combined with captopril plasma NA concentrations did not exceed levels obtained by intravenous infusion of the same dose of NA, with or without converting enzyme blockade. This observation was interpreted as the second indication of overall sympathetic hyperactivity specifically during intrarenal NA infusion via stimulation of renall afferent nerves. It is hypothesized that the presynaptic facilatory action on NA release of angiotensin II is necessary to elevate the plasma NA concentrations during intrarenal NA infusion as high as they did.

The renin-angiotensin system could not account for the additional pressor effect during intrarenal NA infusion because of its equal activation by intrarenal or intravenous application of pressor doses of NA. Therefore, it was investigated whether an initial change in renal function induced by stimulation of renal 
adrenergic mechanisms by means of intrarenal, but not intravenous NA infusion, might lead to increases of peripheral resistance according to the cascade-like model of development of hypertension as described in the General Introduction.

Renal blood flow appeared to decrease immediately in a dose-dependent manner during intrarenal NA infusion (chapter 6 ). The elevations of renal vascular resistance were directly caused by the intrarenal action of NA and were not secondary to increases in MAP since the intravenously applied pressor dose of $36 \mu \mathrm{g} \mathrm{NA} . \mathrm{kg}^{-1} \cdot \mathrm{hr}^{-1}$ did not alter renal function. The primacy of the effect on renall blood flow was furthermore assessed on the 1st day of intrarenal infusion of 4 $\mu \mathrm{g} \mathrm{NA} . \mathrm{kg}^{-1} . \mathrm{hr}^{-1}$ when renal vascular resistance was significantly increased at normotensive pressure levels. Glomerular filtration rate was reduced slightly on the 4 th day of intrarenal infusion of $36 \mu \mathrm{g} \mathrm{NA} . \mathrm{kg}^{-1} . \mathrm{hr}^{-1}$ which probably also contributed to the decreased NA clearance, described in chapter 4 . Severe renal dysfunction, however, was not observed.

Thereupon, in order to evaluate the predicted increases in cardiac output assumably caused by the volume-retaining action of NA within the kidney, acute and chronic effects on central hemodynamics of intrarenal vs. intravenous NA infusion were determined. However, a hyperkinetic stage in the development of hypertension either caused by intrarenal or by intravenous NA application could not be demonstrated. Elevations in MAP were associated with increases in total peripheral resistance and reductions in cardiac output from the onset (chapter 7). Furthermore, it was shown that intrarenal application of the low dose of $4 \mu \mathrm{gg}$ NA. $\mathrm{kg}^{-1} \cdot \mathrm{hr}^{-1}$ was able to elevate MAP already in the acute phase of administration. Since this infusion rate did not cause hypertension when applied intravenously, the immediate pressor response to intrarenal infusion of low doses of NA was taken as the third indication of the vasopressor effect of increasing the renal afferent nerve tonus. Because of the fact that on the 1st day of intrarenal infusion of $4 \mu \mathrm{g} \mathrm{NA} . \mathrm{kg}^{-1} \cdot \mathrm{hr}^{-1}$ plasma NA concentrations were not increased significantly yet as was described in chapter 3 , it cannot be excluded that stimulation of renal afferent nerves might involve another vasopressor neurohumoral mechanism than the sympathetic nervous system.

Further evidence that hypertension induced by long-term activation of renal adrenergic systems is not volume-dependent at any developmental phase, cumulated during studies on the body fluid and salt balance during chronic NA infusion as described in chapter 8 . Plasma volumes decreased parallelly with the reductions in cardiac output depicted in chapter 7 , not only by increased urine output but intriguingly also by reduced intake of water. Plasma sodium concentrations were unchanged or decreased only during intrarenal infusion of 36 $\mu \mathrm{g} \mathrm{NA} . \mathrm{kg}^{-1}, \mathrm{hr}^{-1}$ mainly by diminishing the sodium intake - in fact, by eating less.

Since total peripheral resistance increased immediately from the onset of NA-induced hypertension and furthermore since only reductions in body fluid and sodium load as well as in cardiac output were observed, the elevations of 
MAP during chronic intrarenal or intravenous NA infusion were not initiated by a primary hyperkinetic phase.

Also in alternative hypertension models in which renal function is modified primarily e.g. one-kidney, one-clip Goldblatt hypertension and hypertension caused by bilateral cellophane wrapping of the kidneys, increased cardiac output appears not to be a necessary prehypertensive condition. Therefore, the autoregulation theory of the development of hypertension which predicts cascade-like elevations in vascular resistance after an initial hypervolemic phase, has to be rejected.

However, this thesis acknowledges that the site of origin of hypertension may be situated within the kidney. The relevance of renal adrenergic hyperactivity in theorizing on the role of the kidneys in the development and sustenance of arterial hypertension may be obvious (Fig. 9.1).

The most striking differences between the discussed studies on the chronic intrarenall infusion of NA in conscious dogs and the experiments on rats presented in the previous chapters of this thesis, are the data on the plasma electrolyte concentrations. While sodium was retained specifically during intrarenal NA infusion in dogs, application of NA into the renal artery of rats did not change or even decreased plasma sodium concentrations. Since the dogs were held on a fixed sodium diet while the rats had free access to food and water and reduced mainly their sodium intake, this discrepancy within the experimental protocol might explain the differences in these highly significative data.

Furthermore, rats increased their plasma potassium concentrations by reducing the urinary excretion of potassium. It is suggested that NA interferes selectively with renal potassium retaining or releasing mechanisms. Subsequently, these elevations of plasma potassium concentrations might account for the increased peripheral resistance via sensitization of vascular adrenoceptors. Since plasma potassium concentrations were higher during intrarenal than during intravenous infusion of NA, relatively more increased vascular adrenoceptor sensitivity might explain the additional pressor response observed during intrarenal NA infusion. The obvious test of this hypothesis is to elevate plasma potassium concentrations without affecting body sodium load during chronic intravenous NA infusion which should increase MAP further.

Furthermore, at various moments it has already been hypothesized that intrarenal NA application could interfere with renal afferent nerve tonus, resulting in activation of vasopressor mechanisms. An experimental approach to investigate the contribution of renal afferent nerves to kidney-mediated hypertension could be to eliminate the sensoric input from the renal afferent nerves to the central nervous system specifically by dissecting the ipsilateral dorsal roots of the spinal segments $T 9$ to $L 1$ through which the renal afferent nerves have been found to enter the spinal chord (Ciriello et al, 1982; Lappe et al, 1982b).

Whether or not the effects of intrarenal NA infusion on renal afferent nerves were direct or indirect, is rather irrelevant; modification of renal afferent nerve 
activity provides a new concept not integrated within the Borst-Guyton theory concerning the role of the kidney in arterial pressure regulation and hypertens: on. The possession of a fastly operating neurogenic reflex loop by the kidney may provide an extrinsic control system of renal hemodynamics additional to the intrinsic autoregulation mechanism. Changes in ipsilateral renal function may be buffered by adaptation of the ipsilateral renal efferent nerve activity and fur. thermore, counteracted by the contralateral kidney, as a centrally mediated response to alterations in renal afferent nerve tonus, resulting in constancy of body excretory capacity. Specific features of this renal neurogenic reflex loop

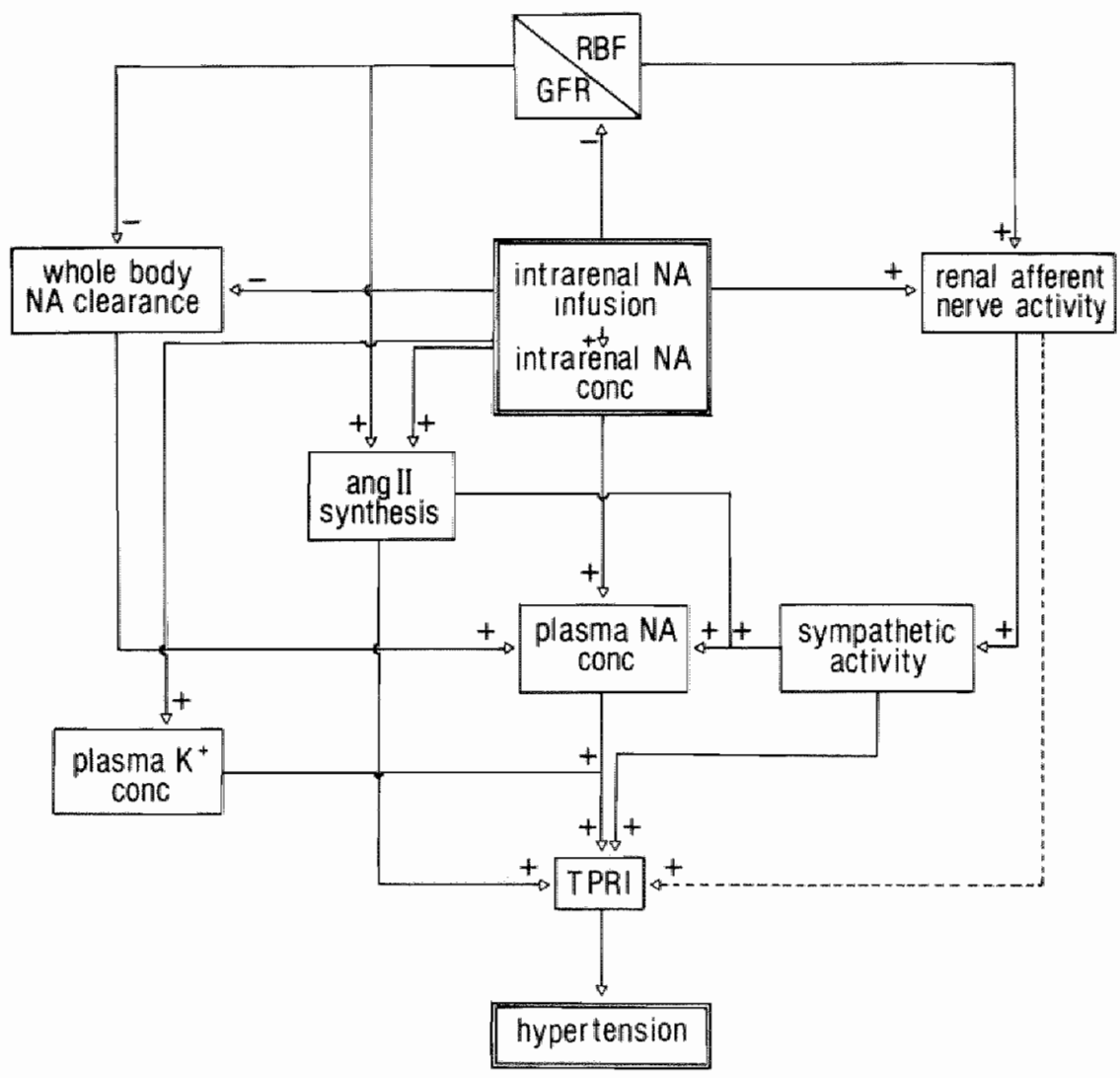

Figure 9.1

Schematic representation of suggested relations between events initiated by intrarenal infusion of noradrenaline as discussed in the present thesis. The interrupted line stands for putative mechanisms.

+ indicates increase;

- indicates decrease. 
as for instance receptor adaptation vs. infinite gain, have to be determined in order to abtain clear insight on the function of renal afferent nerves in long-term arterial pressure control. In this respect, the usefulness for future hypertension research of the presented experimental hypertension model may be asserted. 


\section{SUMMARY}

Essential hypertension in men has often been discussed to have a neurogenic origin. Earlier concepts concerned an increase in overall sympathetic activity to induce and maintain hypertension. However, recent developments in cardiovascular research show that specific elimination of the input of efferent sympathetic nerves to the kidney has a substantial blood pressure lowering effect in various animal hypertension models. This thesis aimed to reversely induce specific renal adrenergic hyperactivity in conscious normotensive rats in order to produce sustained hypertension. Chronically increased renal nerve discharge frequencies were simulated by means of long-term infusion of the sympathetic neurotransmitter noradrenaline (NA) into the renal artery of rats. In the General Introduction which deals with intrinsic and extrinsic features of renal control of arterial pressure, it is extensively discussed why hypertension is likely to occur during chronic activation of renal adrenergic mechanisms.

Since intrarenal infusion in unanesthetized rats has not been achieved yet, a method to gain long-term access to the renal artery had to be developed first. Cannulation of the right suprarenal artery which emerges from the right renal artery appears to provide a reliable tool for chronic intrarenal infusion of drugs in conscious rats (chapter 2).

In chapter 3 , it is shown that infusion of NA into the renal artery of uninephrectomized rats for 5 consecutive days causes dose-dependent increases in arterial pressure maintained throughout the infusion period. Intrarenal NA infusion raises arterial pressure to a higher level compared with intravenous infusion of NA at that particular dose. Partly these increased pressor responses to intrarenal NA application are due to achieved higher levels of NA. Furthermore, an additional kidney-mediated pressor mechanism is triggered during intrarenal NA infusion.

Chapter 4 deals with further investigations of mechanisms which could be responsible for the relatively higher increases in plasma NA concentrations during intrarenal NA infusion. It is shown that in the initial phase of NA application, the release of endogenously produced NA is relatively more increased during intrarenal NA infusion, reflecting overall sympathetic hyperactivity, but that during the established stage of hypertension the higher plasma NA levels are due to decreased whole body clearance of NA.

In the following chapters, it has been attempted to determine the nature of the additional pressor mechanism activated by intrarenal NA infusion.

Chapter 5 evaluates the contribution of the renin-angiotensin system. Measurements of plasma renin activity as well as intraperitoneal infusion of the converting enzyme blocker captopril during chronic NA application indicate that an- 
giotensin II raises arterial pressure additional to circulating NA to the same extent during intrarenal and intravenous NA infusion. Therefore, it is concluded that specific activation of the renin-angiotensin system during intrarenall NA infusion is not likely to account for the additional pressor mechanism.

Furthermore, in this chapter it is shown that angiotensin II possibly contri. butes to the elevated overall activity of the sympathetic nervous system during intrarenal but not during intravenous NA application by its presynaptic facilitation of NA release from sympathetic nerve endings.

The additional pressor response can also not be attributed to cascade-like elevations in total peripheral resistance reflexive to a hyperkinetic stage of hypertension. Although intrarenal NA infusion changes renal function primarily (chapter 6), expectingly leading to volume and sodium retention and to increases in cardiac output, total peripheral resistance increases immediately from the onset of hypertension induced by either intrarenal or intraveous NA infusion while cardiac output decreases slowly and secondarily to arteriall pressure elevations (chapter 7). Furthermore, in chapter 8 it is shown that also plasma volume and plasma sodium concentrations are reduced during intrarenally NA-induced hypertension indicating that no volume retention by the kidney occurs. Stimulation of renal adrenergic mechanisms leads to hypertension not characterized by a body fluid volume-dependent phase.

Obviously, alternative pressure elevating systems are involved in the development of renal experimental hypertension. With regard to the augmented vascular response during intrarenal NA infusion, two mechanisms increasing arterial pressure possibly additional to each other, may be of importance:

- specific stimulation of renal afferent nerves especially in the initial phase of intrarenal NA infusion may induce a pressor effect via stimulation of either the overall activity of the sympathetic nerve system or via an unknown pressor mechanism mediated by the central nervous system;

- specific increases in plasma potassium concentrations during intrarenal NA infusion may sensitize vascular wall adrenoceptors causing a more effective pressor effect of already elevated circulating NA levels. 


\section{SAMENVATTING}

Essentiële hypertensie is reeds eerder voorgesteld als een ziekte met een neurogene oorsprong. In voorafgaande jaren werd gedacht in termen van een toename van veeleer de algehele aktiviteit van het sympathisch zenuwstelsel die hypertensie zou veroorzaken en in stand houden.

Recente ontwikkelingen in het kardiovaskulair onderzoek tonen echter aan dat het uitsluitend elimineren van de sympathische innervatie van de nier reeds een duidelijke verlaging van de bloeddruk veroorzaakt in diverse diermodellen voor hypertensie. De opzet van dit proefschrift was om in wakkere normotensieve ratten de aktiviteit van het sympathische zenuwstelsel, specifiek in de nier, juist te doen toenemen met de bedoeling kontinue toename in de bloeddruk te veroorzaken.

Chronische stijgingen in de frekwentie van zenuwontladingen in de nier werden nagebootst met behulp van langdurige toediening van de sympathische neurotransmitter noradrenaline (NA) via de nierarterie van de rat. In de Algemene Inleiding die de intrinsieke en extrinsieke eigenschappen van de nier in het licht van de bloeddrukregulatie bespreekt, wordt uitgebreid aan de orde gesteld waarom het waarschijnlijk is dat de bloeddruk zal stijgen tijdens een chronische aktivatie van intrarenale adrenerge mechanismen.

Aangezien intrarenale infusie in niet-verdoofde ratten tot nu toe onmogelijk was, moest in de eerste plaats een methode ontwikkeld worden waarmee op langere termijn via de nierarterie geinfundeerd kan worden.

Het blijkt dat in de katheterisatie van de rechter arteria suprarenalis, die zich aftakt van de rechter nierarterie, een betrouwbare manier gevonden is om chronisch stoffen toe te dienen aan de nier van wakkere ratten (hoofdstuk 2).

In hoofdstuk 3 wordt aangetoond dat infusie van NA via de nierarterie van eén-nierige ratten tijdens 5 opeenvolgende dagen dosisafhankelijke stijgingen in de bloeddruk veroorzaakt, die gedurende de gehele periode van toediening in stand worden gehouden. Intrarenale infusie van NA produceert bloeddruknivo's die hoger zijn vergeleken met intraveneuze toediening van dezelfde dosis van NA. Deze sterkere reaktie van de bloeddruk tijdens de intrarenale toediening van NA is gedeeltelijk het gevolg van het feit dat hogere plasmakoncentraties van NA bereikt worden. Bovendien wordt tijdens de intrarenale infusie van NA een mechanisme geaktiveerd dat via de nier additioneel de bloeddruk verhoogt.

Verder onderzoek naar mechanismen die verantwoordelijk zouden kunnen zijn voor de sterkere stijgingen in de plasmakoncentraties van NA tijdens de intrarenale infusie van NA, wordt beschreven in hoofdstuk 4 . Het blijkt dat in de initiële fase van toediening van NA het verschijnen van endogeen NA in plasma 
relatief meer is toegenomen tijdens de intrarenale infusie van $N_{4}$, hetgeen op een algehele aktivering van het sympathisch zenuwstelsel wijst; wanneer de bloeddruk zich op het hogere nivo gestabiliseerd heeft, wordt de grotere stijging in de plasmakoncentraties van NA echter veroorzaakt door een afname van de totale lichaamsklaring van NA.

In de daaropvolgende hoofdstukken is een poging ondernomen om de aard van het additionele bloeddrukverhogende mechanisme dat door de intrarenale infusie van NA geaktiveerd wordt, te achterhalen.

In hoofdstuk 5 wordt de bijdrage van het renine-angiotensine systeem vastgesteld. Bepalingen van de aktiviteit van renine in plasma, alsmede intraperitoneale infusie van captopril dat de vorming van angiotensine II tegengaat, geven aan dat angiotensine II in dezelfde mate bijdraagt aan de drukstijgingen tijdens de intrarenale en intraveneuze infusies van NA als toevoeging aan het effekt van cirkulerend NA zelf. De konklusie ligt voor de hand dat het additionele bloeddrukverhogende mechanisme, in werking gesteld tijdens de intrarenale infusie van NA, waarschijnlijk niet synoniem is met de specifieke aktivering van het renine-angiotensine systeem.

Bovendien wordt in dit hoofdstuk aangetoond dat angiotensine II mede verantwoordelijk zou kunnen zijn voor de toegenomen algehele aktiviteit van het sympathisch zenuwstelsel tijdens de intrarenale, maar niet tijdens de intraveneuze toediening van NA in die zin dat angiotensine II via zijn presynaptische werking de afgifte van NA door de sympathische zenuwuiteinden bevordert.

Evenmin lijkt hel additionele bloeddrukverhogende effelkt toegeschreven te kunnen worden aan kaskade-achtige stijgingen in de totale lichaamsvaatweerstand als een reflex op een hyperkinetisch stadium in de hypertensie. Hoewel de intrarenale infusie van NA primair de nierfunktie beinvloedt (hoofdstuk 6), hetgeen volgens verwachting zou moeten leiden tot retentie van water en natrium en stiging in het hartminuutvolume, neemt de totale lichaamsvaatweerstand onmiddellijk toe, gepaard aan stijgingen in de bloeddruk en onafhankelijk van de omstandigheid dat hypertensie veroorzaakt wordt door intrarenale dan wel door intraveneuze infusie van NA. Het hartminuutvolume daalt langzaam en als reaktie op de toename in de bloeddruk (hoofdstuk 7). Bovendien wordt in hoofdstuk 8 aangetoond dat het plasmavolume en de plasmakoncentran tie van natrium eveneens afnemen tijdens hypertensie, geinduceerd door de intrarenale infusie van NA, hetgeen aangeeft dat er geen retentie van water in de nier plaatsvindt. Dit impliceert dat de hypertensie die veroorzaakt wordt door de langdurige stimulatie van renale adrenerge mechanismen, niet gekarakteriseerd wordt door afhankelijkheid van de volumebalans.

Er zijn duidelijk andere bloeddrukverhogende mechanismen betrokken bij de ontwikkeling van deze renale vorm van experimentele hypertensie. Twee systemen die elkaar wellicht ondersteunen in het doen toenemen van de bloeddruk, kunnen van belang zijn met betrekking tot het relatief grotere effekt op de vaatwand: 
- specifieke stimulatie van afferente zenuwbanen uit de nier, met name tijdens de beginfase van de intrarenale toediening van NA, zou een bloeddrukverhogende reaktie kunnen induceren, ofwel via toename van de algehele aktiviteit van het sympathisch zenuwstelsel ofwel via stimulatie van een onbekend systeem dat bloeddrukstijgingen veroorzaakt via het centrale zenuwstellsel;

- specifieke toename in de plasmakoncentratie van kalium tijdens de intrarenale infusie van NA zou de gevoeligheid van de in cle vaatwand gelegen adrenerge receptoren kunnen vergroten, hetgeen effektievere bloeddrukstijgingen door de toch al verhoogde plasmakoncentraties van NA tot gevolg zou kunnen hebben. 


\section{APPENDIX: ARTERIAL PRESSURE VARIABILITY DURING HIYPERTENSION INDUCED BY CHRONIC INTRAVENOUS INFUSION OF NORADRENALINE*}

\section{A.1. Introduction}

Standard laboratory procedures usually involve determinations of mean arterial pressure (MAP) by recording arterial pressure during 1 hour, sampling arterial pressure data with a certain frequency and averaging these values over the recording period thereby obtaining the MAP of that particular day (see section 3.2.). The variability in MAP as indicated by the standard deviation of MAP is generally not taken into account.

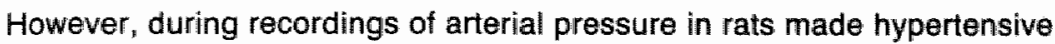
by chronic intravenous (and intrarenal) infusion of noradrenaline (NA), a pronounced instability of arterial pressure was observed (Fig. A.1).

In this appendix, an attempt is made to characterize this variability in arterial pressure in detail. In the first place, by evaluating the standard deviation (S.D.) of the MAP, averaged over a group of rats which were chronically infused intravenously with NA, information on the magnitude of the variability was obtained. Secondly, since it is possible that changes in variability of arterial pressure are dule to alteration of the amplitude of certain frequencles or to appearance of additional oscillations, spectral analysis was applied in order to determine the contribution of frequency bands to the variability of the arterial pressure signal. Furthermore it was attempted to find a physiological correlate of the variability in arterial pressure. The most important system in shortterm regulation of arterial pressure is the sino-aortic baroreflex mechanism which regulates changes in arterial pressure instantaneously and keeps fluctuations in arterial pressure within low range. Elimination of the baroreflex mechanism by means of afferent denervation or lesions of the central relay nucleus, the nucleus tractus solitarii, induces high variability in arterial pressure (Nathan and Reis, 1977; Norman et al, 1980; Cowley, 1981; Talman et al, 1980). It was therefore hypothesized that decreases in baroreflex sensitivity (BRS) are responsible for the varlability during NA-induced hypertension and the relation between BRS and arterial pressure variability during chronic intravenous NA infusion was investigated.

"based on: Kleinjans $J$, Kasbergen $C$, Vervoort-Peters $L$, Smits $J$ and Struykerm Boudier $\mathrm{H}$ : Chronic intravenous infulsion of noradrenaline produces labile hypertension in conscious rats. Life Scil 29: 509-514, 1981.

Kleinjans J, Muytjens A and Struyker-Boudier $\mathrm{H}$ : Variability in blood pressure during noradrenaline-induced hypertension in rats. Arch lint Physiol Biochem, in press, 1983. 


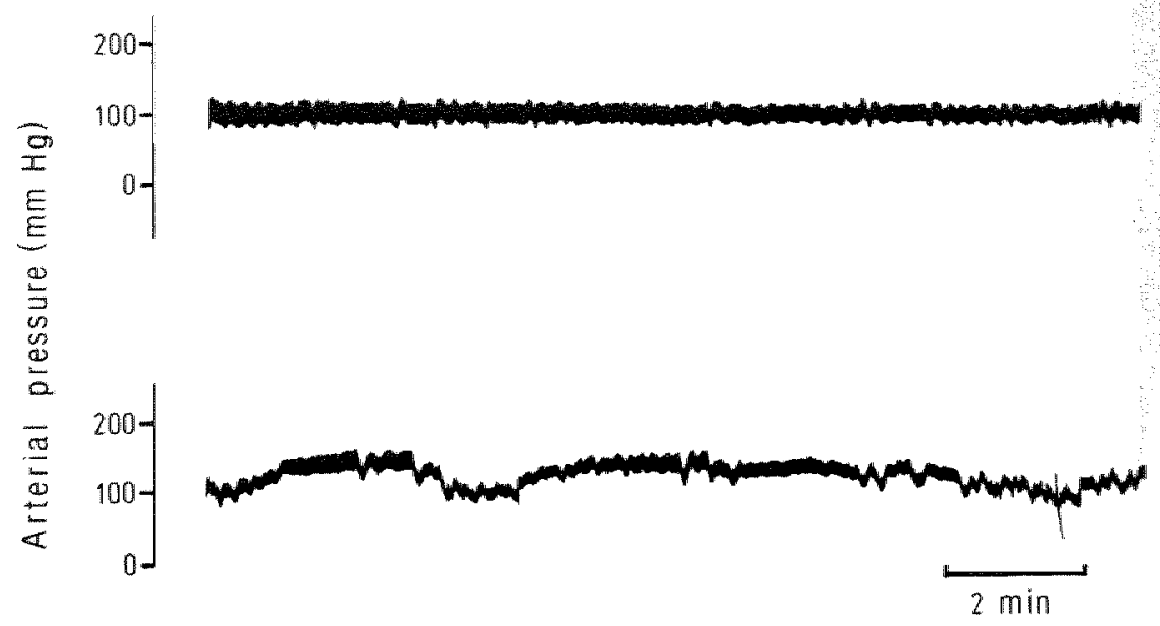

Figure: A.1

Arterial pressure registrations on the 4th day af intravenous infusion of saline (above) and $36 \mu \mathrm{g} \mathrm{NA} . \mathrm{kg}^{-1}$.hr-1 (below) indicating blood pressure variability during intravenous NA application.

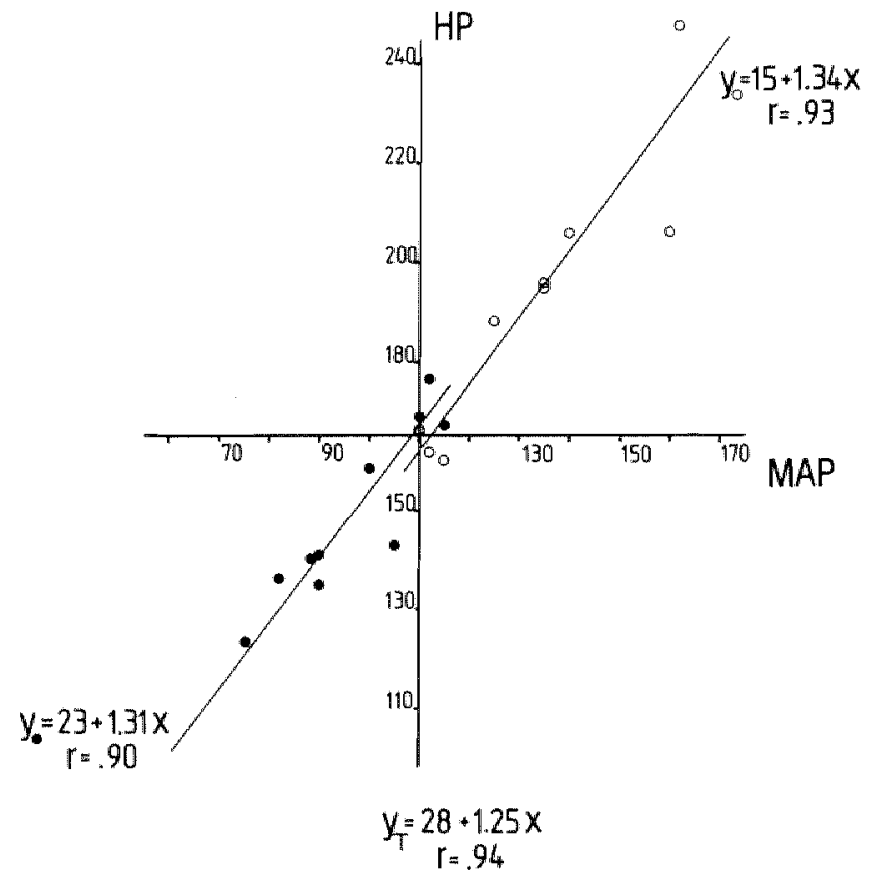

\section{Figure A.2}

Example of determination of baroreflex sensitivity by means of serial injections of phenylephrine and sodium nitroprusside. For further explanation, see section A.2. 


\section{A.2. Methods}

44 Rats were provided with a catheter into the femoral artery for measurements of arterial pressure and a catheter into the jugular vein for intravenous infusion. After a 2-day control period, osmotic minipumps were connected so that chronic intravenous infusion of saline or NA at doses of 12 and $36 \mu \mathrm{g} \cdot \mathrm{kg}^{-1} \cdot \mathrm{hr}^{-1}$ was maintained for 5 consecutive days. MAP was determined daily as described in section 3.2 and the S.D. was calculated. S.D.s were averaged over the subgroups receiving intravenous NA infusion to mean S.D. and compared with data abtained during saline infusion by means of a Student's t-test for unpaired values.

Spectral analysis of the analog variations in the arterial pressure registra-

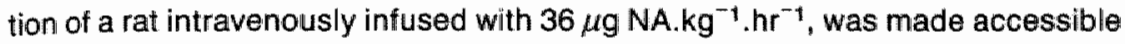
by the Department of Medical Information of the University of Limburg and performed as follows: analog arterial pressure measurements using a CTC CP 01 strain gauge and Grass equipment were registrated on control day and on 5 consecutive days of NA administration by means of a Hewlett and Packard 3960 in. strumentation recorder (cut-off frequency $100 \mathrm{~Hz}$ ), during 1 hour. Analog arterial pressure registrations were sampled (cut-off frequency $10 \mathrm{~Hz}$, sample frequency $30 \mathrm{~Hz}$ ) and power spectra of these arterial pressure time series were estimated applying Fast Fourier Transform by means of a IMSL routine (FTFPS) on a Vax computer. In order to increase accuracy, arterial pressure time series are divided in a number of consecutive segments of equal length; for calculation of mean power spectra, we used 96 segments of 1024 samples. Power spectra were normalized (total power equals 1).

In 20 rats, additionally provided with a catheter into the femoral vein "BRS was measured by means of serial injections of phenylephrine, elevating arterial pressure, and of sodium nitroprusiside, causing depressor effects (Mancia et al, 1980; Faris et al, 1980). Maximal change in heart rate (HR) induced by each change in arterial pressure was measured. Correlations between maximal changes in theart period $(\mathrm{HP}=1 / \mathrm{HR})$ and related maximal changes in arterial pressure were calculated using linear regression. Although values of BRS determined by serial phenylephrine injections were slightly higher than obtained by sodium nitroprusside, the differences were not statistically significant. Therefore, linear regression was applied to the complete set of correlations between heart rate and arterial pressure. Only significant correlations were used and the slope was taken as an index for BRS (For example, see Fig. A.2).

BRS was determined on control day, on the 1st and 5th day of intravenous infusion of $12 \mu \mathrm{g} \mathrm{NA} \cdot \mathrm{kg}^{-1} \cdot \mathrm{hr}^{-1}$ and on the 1st and 4 th day of infusion of $36 \mu \mathrm{g}$ NA. $\mathrm{kg}^{-1} \cdot \mathrm{hr}^{-1}$. Rats were used as their own control: data were analyzed by means of a Student's t-test for paired values. 


\section{A.3. Results}

Fig. A.3 shows the mean S.D. in MAP on control day and on 5 consecutive days of intravenous infusion of saline or NA in doses of 12 and $36 \mu \mathrm{g} \cdot \mathrm{kg}^{-1} \cdot \mathrm{hr}^{-1}$. Varia: bility in arterial pressure increased with the dose-dependent increases in MAP (Fig. 3.1.b). During intravenous infusion of $12 \mu \mathrm{g} \mathrm{NA} . \mathrm{kg}^{-1} . \mathrm{hr}^{-1}$, mean S.D. was approximately $10 \mathrm{mmHg}$ and during infusion of $36 \mu \mathrm{g} \mathrm{NA} \cdot \mathrm{kg}^{-1} \cdot \mathrm{hr}^{-1}$, even levels of $20 \mathrm{mmHg}$ were obtained.

Fig. A.4a shows the power spectrum of a rat's arterial pressure signal under normal conditions. Clear contributions of the following components were seen:

- between 5.0 and $7.0 \mathrm{~Hz}$, variations were attributed to $\mathrm{HR}$,

- between 1.5 and $2.5 \mathrm{~Hz}$, variations were possibly reflecting respiratory activity,

- smaller than $1.0 \mathrm{~Hz}$, variations were slow-wave components the physiological correlates of which are poorly understood.

Along with the intravenous infusion of $36 \mu \mathrm{g} \mathrm{NA} \cdot \mathrm{kg}^{-1} \cdot \mathrm{hr}^{-1}$, comparing Fig. A.5a with Fig. A.4a, HA contributions tended to spread over a wider frequency band $(3.0<F<7.5 \mathrm{~Hz})$ whereas low-frequency components with $F<0.05$, comparing Fig. A.5b with Fig. A.4b, tended to increase.

Table A.1 shows the effect of intravenous infusion of 12 and $36 \mu \mathrm{g}$ NA. $\mathrm{kg}^{-1} \cdot \mathrm{hr}^{-1}$ on BRS. While no changes in BRS were observed on the 1st day of NA infusion, both doses of NA decreased BRS significantly in the

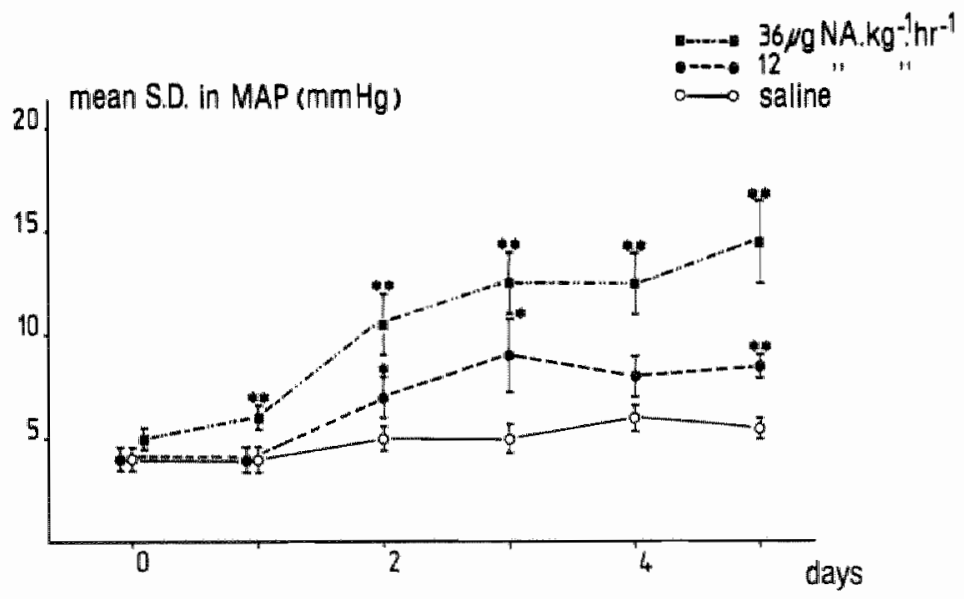

Figure A.3

Variability in arterial pressure during intravenous infusion of saline or two doses of NA. ${ }^{*} p<0.05_{i}{ }^{*} p<0.005$ indicate statistically significant differences vs. corresponding saline data (Student's t-test for unpaired values). 


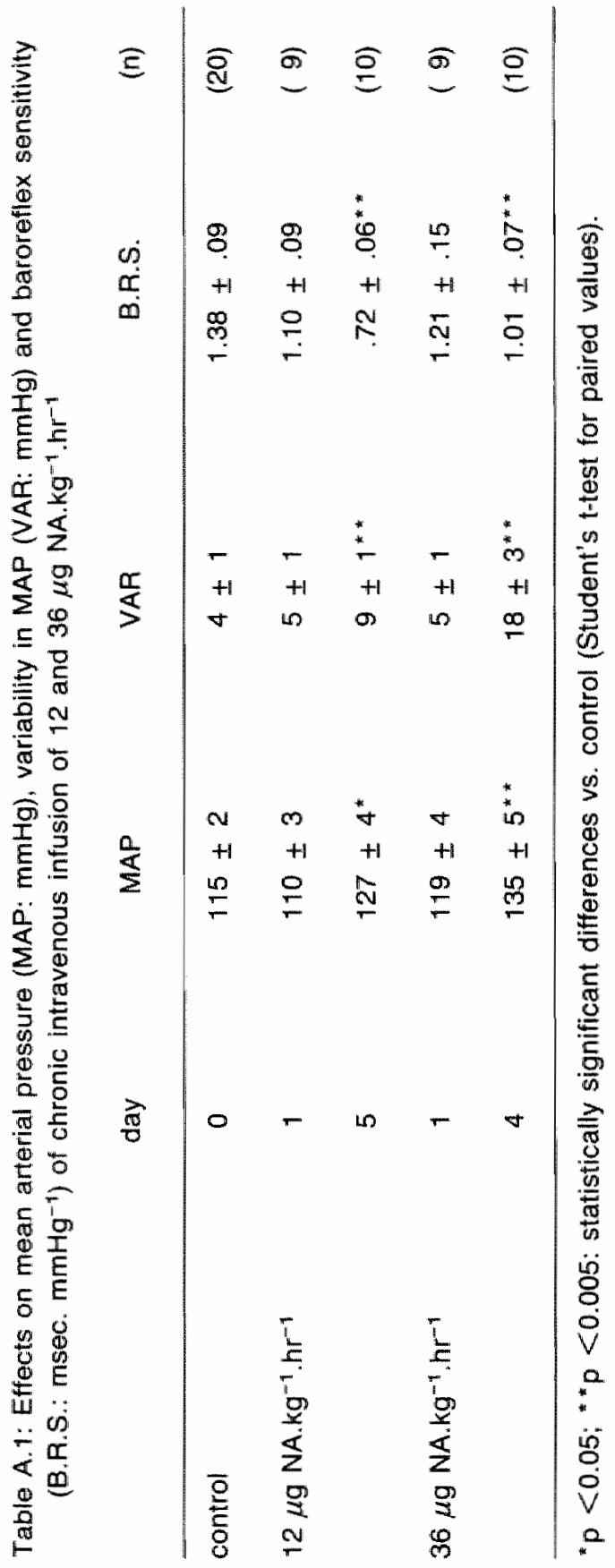


DAY O: MAP $118 \pm 4$
LOGP US F MOSLE.TT LW102A
$21-F E B-83$
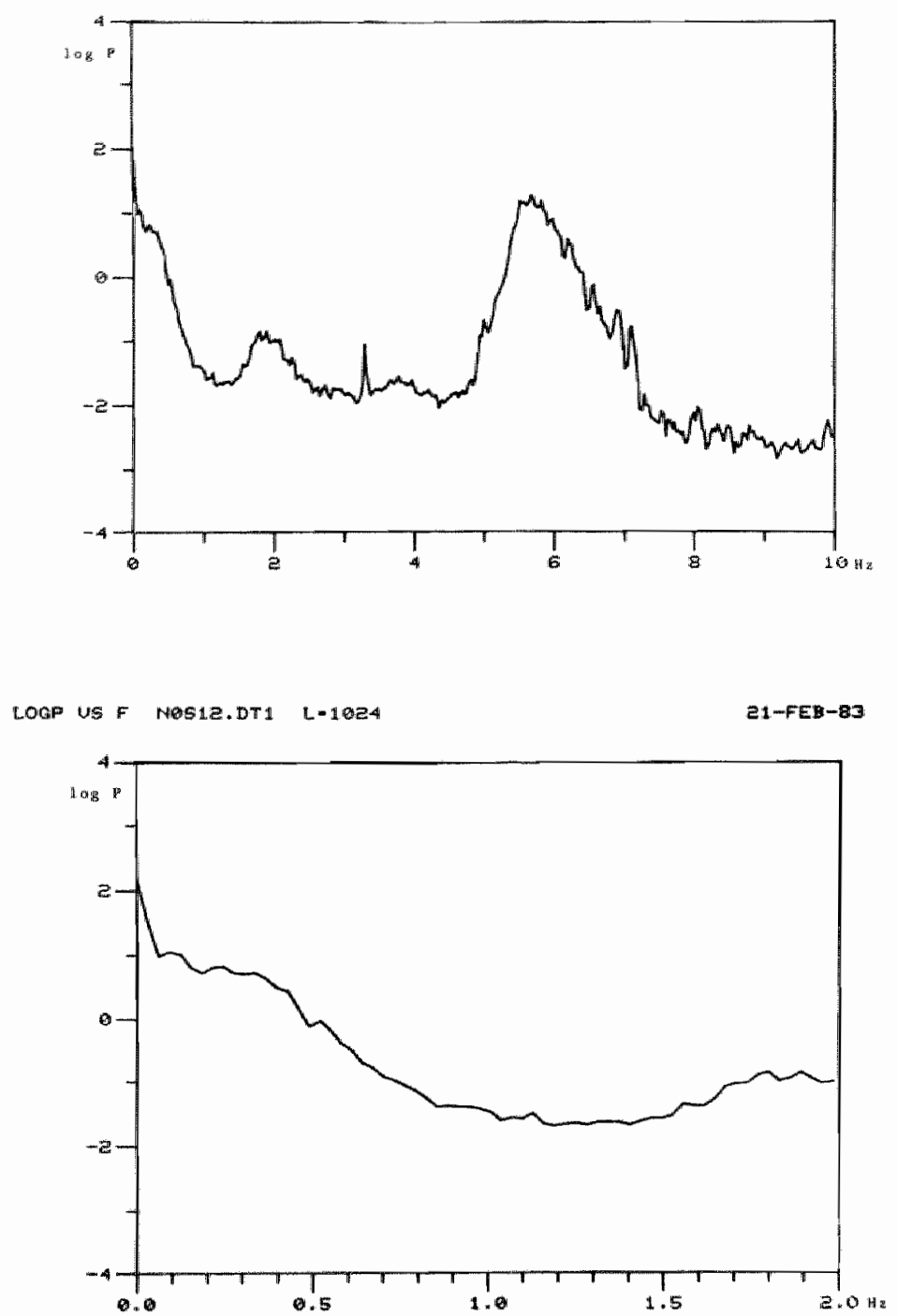

Figure A.4

a. Power spectrum of arterial pressure time series of a rat under control conditions.

b. Extended horizontal axis.

For further explanation, see text. 
DAY 4: MAP $121 \pm 19$

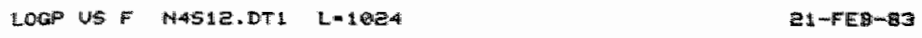

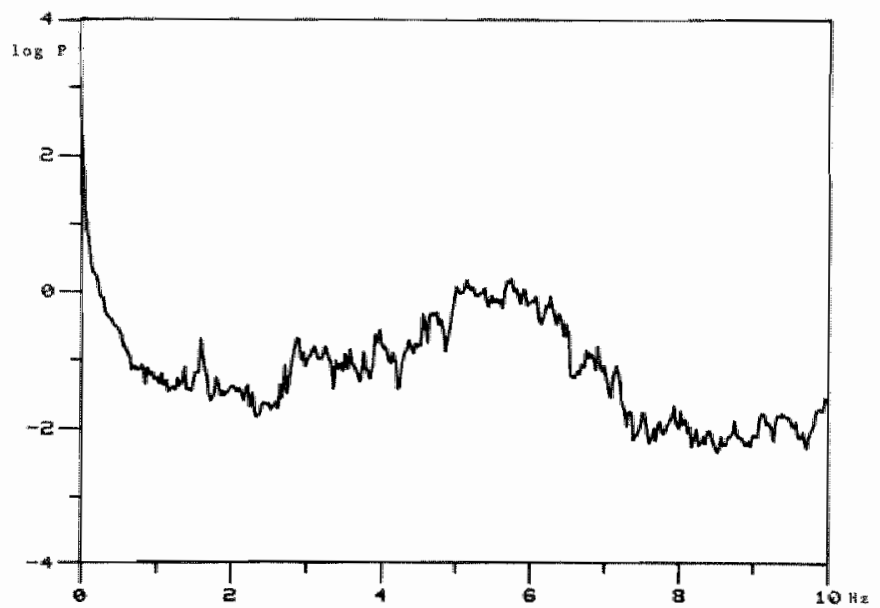

LOGP US F HAS1E.DTH L-1024 R1-FEB-BO

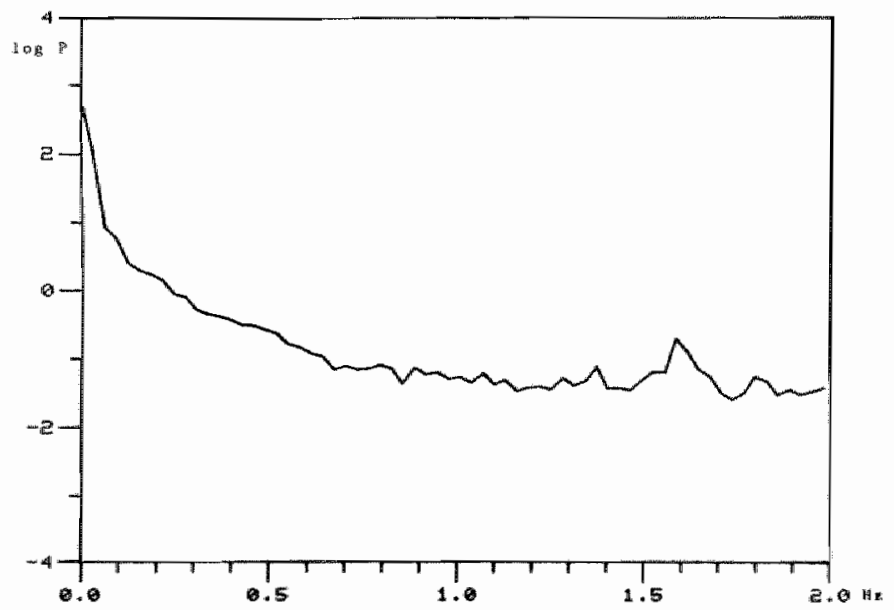

Figure A.5

a. Power spectrum of arterial pressure time series of a rat on the 4 th day of intravenous infusion of $36 \mu \mathrm{g}$ NA. $\mathrm{kg}^{-1} . \mathrm{hr}^{-1}$.

b. Extended horizontal axis.

For further explanation, see text. 
later phase of infusion. However, decreases in BRS were not parallel to MAP related increases in variability: arterial pressure variability was higher during infusion of $36 \mu \mathrm{g} \mathrm{NA} . \mathrm{kg}^{-4} \cdot \mathrm{hr}^{-1}$ compared with $12 \mu \mathrm{g} \mathrm{NA} \cdot \mathrm{kg}^{-1} \cdot \mathrm{hr}^{-1}$, but BRS was not further decreased.

\section{A.4. Discussion}

Several procedures were followed in order to characterize the increased variability of arterial pressure during chronic intravenous infusion of NA. The magnitude of the variability expressed as the S.D. of daily MAP values appeared to correlate with the height of MAP.

The nature of the variability determined by the contributions of various frequency components in the power spectrum of the arterial pressure time series, was associated with broadening of the heart rate components over a wider frequency band and with increasing of the contribution of slow-wave components.

Before more definite conclusions can be drawn on the participation of different frequency components in variability, a more extensive series of experiments needs to be performed.

In studies on hypertensive patients, S.D. in MAP determined over a 24-hour period is increased when compared with normotensive controls (Mancia et al, 1980). Significant positive correlations were found between variability and systolic arterial pressure but there seemed to exist no clear relation between variability and diastolic pressure (Littler et al, 1978; Clement et al, 1979; Watson et al, 1980). In spontaneously hypertensive rats, variability of arterial pressure is also increased at high pressure levels (Frohlich et al, 1972).

The importance of power spectrum analysis to obtain insight in cardiovascular control, has been acknowledged (Akselrod et al, 1981). The increase in the contribution of low-frequency components to arterial pressure variability induced by intravenous NA infusion may point at intermittent slow release of humoral agents which elicit a vasopressor response directly or indirectly. But it could be established by means of power spectrum analysis that the reninangiotensin system is not responsible for oscillations in arterial pressure of dogs fed on a chronically altered sodium level (Shimada and Marsh, 1979). However, the blockade of the renin-angiotensin system by converting enzyme inhibition increases the low-frequency heart rate fluctuations drastically in dogs on a normal diet (Akselrod et al, 1981). Fluctuations in heart rate may cause fluctuations in cardiac output and thereby in arterial pressure (Shimada and Marsh, 1979). During intravenous NA infusion, the release pattern of renin could be changed without necessarily influencing overall plasma renin activity (see chapter 5). Additional infusion of the converting enzyme inhibitor captopril, however, does nat affect the S.D. in MAP of the NA-infused rats.

Since elimination of the baroreflex mechanism by afferent denervation (Norman et $\mathrm{al}_{\text {" }}$ 1980; Cowley "1981) or lesion of the nucleus tractus solitarii 
(Nathan and Reis, 1977; Talman et al, 1980) induces high variability of arterial pressure, changed BRS has been associated with variability observed in hypertension. BRS has been shown to be decreased in hypertensive men (Simon et al, 1977) and spontaneously hypertensive rats (Struyker-Boudier et al, 1982). However, decreased BRS is correlated only weakly with arterial pressure variability in men (Mancia et al, 1980).

Decreased BRS is partly associated with increased arterial pressure variability during hypertension produced by chronic intravenous NA infusion as is shown in Table A.1. But during infusion of $36 \mu \mathrm{g} \mathrm{NA}$. $\mathrm{kg}^{-1} \cdot \mathrm{hr}^{-1}$, BRS was decreased to the same extent as during infusion of $12 \mu \mathrm{g} \mathrm{NA}^{\mathrm{kg}}{ }^{-1} . \mathrm{hr}^{-4}$, while variability of arterial pressure was substantially higher.

The decrease in BRS cannot be attributed to effects of NA itself on sino-aortic baroreceptors since NA is known to increase baroreceptor afferent nerve activity in isolated carotid sinus preparations (Tomomatsu and Nishi, 1981; Yao and Thorén, 1983) and therefore is not likely to cause inhibition of baroreceptors. Decreases in BRS may parallel the development of hypertension via the reduction of distensibility of blood vessels in which the baroreceptors are located, or secondarily as a result of functional alterations in the central nervous system.

Furthermore, in in-vitro aortic arch-aortic nerve preparations of normotensive rats, increases of extracellular potassium concentrations appear to decrease the barorefllex sensitivity (Andresen et al, 1979). The changes in electrolyte balance e.g. the small increases in extracellular potassium concentrations during intravenous NA infusion as described in chapter 8 , may decrease BRS.

It could be argued that the variability in arterial pressure was caused by variations in the minute-to-minute release rate of NA by the osmotic minipumps creating in fact an artificial pheochromocyloma (Mancia et al, 1979; Bravo et al, 1979). This would also imply that variability in heart rate was produced by this pulsatile release pattern of the osmotic minipumps because NA was infused via the jugular vein, approaching the heart as first target.

However, intravenous injection of the ganglion blocker chlorisondamine (5-7.5 mg. kg-1) abolishes the variability in heart rate but does not affect variability in arterial pressure despite of the fact that MAP was lowered by approximately $40 \mathrm{mmHg}$ indicating that the minipumps do not release NA in a pulsatile manner (Smits et al, 1983). Subsequent bolus injections of NA after ganglion blockade do increase heart rate so that it is concluded that the responsiveness of adrenoceptors remains unaltered by ganglion blockade.

Therefore, variability in arterial pressure during intravenous infusion of NA is not due to fluctuations in the release of NA by the osmotic minipumps. Variability is partly associated with decreased baroreflex sensitivity. Since ganglion blockade lowers MAP without affecting variability, the observed slow oscillations in arterial pressure are partly neither of neurogenic origin nor related to the height of arterial pressure, but seem to be an intrinsic feature of the peripheral vascular system responding to excessive amounts of NA. 
Abe $Y$, Kishimoto $T$ and Yamamoto $K$ : Effect of angiotensin II antagonist infusion on autoregulation of renal blood flow.

Am J Physiol 231: 1267-1271, $1976 a$.

Abe $Y$, Kishimoto $T$ and $Y a m a m o t o K$ : Relationship between renin secretion and renal autoregulation in the dogs.

Jpn Circ J 40: 935-943, 1976b.

Akselrod S, Gordon D, Ubel FA, Shannon DC, Barger AC and Cohen RJ: Power spectrum analysis of heart rate fluctuation: A quantitative probe of beat-to-beat cardiovascular control.

Science 213: 220-222, 1981.

Albertini $A$, Rosas $R$, Croxatto HR and Roblero $J$ : Kallikrein-kinin system in one- and twokidney Goldblatt hypertensive rats.

Clin Sci 56: 227-233, 1979.

Ammons WS, Koyama S and Manning JW: Neural and vascular interaction in renin response to graded renal nenve stimulation.

Am J Physiol 242: R552-R562, 1982.

Anderson AJ, Berl T, McDonald KM, Schrier RW: Prostaglandins: Effects on blood pressiure, renal blood flow, sodium and water excretion.

Kidney Int 10: 205-215, 1976.

Anderson WP, Korner PI and Selig SE: Mechanism involved in the renal responses to intravenous and renal artery infusions or noradrenalline in conscious dogs.

J Physiol 321: 21-32, 1981.

Andresen MC, Kuraoka S and Brown AM: Individual and combined actions of calcium, sodium, and potassium ions on baroreceptors in the rat.

Circ Res 45: 757-763, 1979.

Anton AH and Sayre DF: A study of the factors affecting the aluminum oxidetrihydroxyindole procedure for the analysis of catecholamines.

J Pharmacoll Exp Ther 138: 360-375, 1962.

Antonaccio $\mathrm{MJ}$ and Kerwin L: Evidence for prejunctional intribition of norepinephrine release by captopril in spontaneously hypertensive rats.

Eur J Pharmacol 68: 209-212, 1980.

Antonaccio MJ and Kerwin L: Pre-and postjunctional inhibition of vascular sympathetic function by captopril in SHR. Implication of vascular angiotensin III in hypertension and antihypertensive actions of captopril.

Hypertension 3 (suppl l): 54-62, 1981.

Arendshorst WJ and Beienwaltes WH: Henal and mephron hemodynamics in spontaneousily hypertensive rats.

Am J Physiol 236: F246-F251, 1979a.

Arendshorst WJ and Beierwaltes WH: Renal tubular reabsorption in spontaneously hypertensive rats.

Am J Physiol 237: F38-F47, 1979b. 
Arundell LA and Johns El: Effect of comerting enzyme inhibition on the renal hemodynamic responses to noradrenaline infusion in the rat.

Br J Pharmacol 75: 553-558, 1982.

Ayers CF, Katholi RE, Carey $\mathrm{AM}$, Yancey MR and Monton CL: Acute and chronic intrarenal alpha- and beta-adrenergic stimulation of renin release in the conscious dog.

Hypertension 3:615-621, 1981.

Baer, PG, Navar $L G$ and Guyton $A C$ : Renal autoregulation, filtration rate, and ellectrolyte excretion during vasodilatation.

Am J Physiol 219: 619-625, 1970.

Baer, PG and MCGiff JC: Hormonal systems and renal hemodynamics.

Ann Rew Physiol 42: 589-601, 1980.

Ball, SG, Gunn IG and Douglas IH: Renal handling of dopa, dopamine, norepinephrine, and epinephrine in the dog.

Am J Physiol 242: F56-F62, 1982.

Barajas L: Innervation of the renal cortex.

Fod Proc 37: 192-1201, 1978.

Bayliss WM: On the local reactions of the arterial wall to changes in internal pressure. $₫$ Physiol 28: 220, 1902.

Eealer SL, Haywood JA, Gruber KA, Buckalew Jr WM, Fink GD, Brody MJ and Johnson AK: Preoptic-hypothalamic periventricular lesions reduce natriuresis to volume expansion.

Am J Physiol 244: R51-R57, 1983.

Bean BL, Brown JJ, Casals-Stenzel J, Fraser R, Lever AF, Mortorn $\|_{\mathrm{J}}$, Petch B, Riegger AJG, Robertson Jl and Tree M: An altered relation between arterial pressure and plasma angiotensin II concentration resulting from prolonged infusion of angiotensin II.

Clin Sci Mol Med 55: 217s-220s; 1978.

Bean, BL, Brown JJ, Casals-Stenzel J,Fraser R, Lever AF, Millar JA, Morton Jل, Petch $B$, Riegger $\mathrm{AJ}$, Robertson $\mathrm{J}$ and Tree $\mathrm{M}$ : The relation of arterial pressure and plasma angiotensin II concentration. A change produced by prolonged infusion of angiotensin III in the conscious dog.

Circ Res 44: 452-458, 1979.

Bell $C$ and Kushinsky R: Involvement of uptake1, and uptake2 in terminating the cardiovascular activity of noradrenaline in normotensive and genetically hypertensive rats.

J Physiol: 283: 41-51, 1978.

Bello-fieus E, Colindres RE, Pastoriza-Munoz E, Mueller RA, Gottschalk CW: Effects of acute unilateral renal denervation in the rat.

J Clin Invest 56: 208-217, 1975.

Bello-Reus E: Effect of catecholamines on fluid reabsorption by the isolated proximal convoluted tubule.

Am J Physiol 238: F347-F352, 1980.

Bienedict $C R$, Fillemz $M$ and Stanford $C$. Changes in plasma noradrenaline concentration as a measure of release rate.

Bir J Pharmac 64: 305-309, 1978.

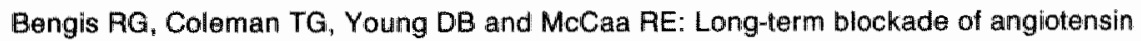
formation in various normotensive and hypertensive rat models using converting enzyme inhibitor (SQ 14,225).

Circ Res 43 (suppl l): 45-52, 1978. 
Beretta-Piccoli C. Weidmann $P$, Meier A, Grimm M, Keusch G and Gluck Z Effects of short-tem norepinephrine infusion on plasma catecholamines, renin and aldosterone in normal and hypertensive man.

Hypertension 2: 623-630, 1980 .

Besarab $A_{r}$ Silva $P$, Landsberg $L$ and Epstein $F H$ : Effect of catecholamines on tubular function in the isolated perfused rat kidney.

Am J Physiol 233: F39-F45, 1977.

Beuzeville C: Catheterization of renal artery in rats.

Proc Soc Exp Blol Med 129: 932-936, 1968.

Bianchi G, Fox U, DiFrancesco GF, Giovanetti AM and Pagetti D: Blood pressure changes produced by kidney crosstransplantation between spontaneously hypertensive rats and normotensive rats.

Clin Sci Mol Med 47: 435-438, 1974.

Blanchi G, Baer PG, Duzzi L, Fox U, Caravaggi AM, Möhring J and Cusii D: Kidney function studies in the Milan hypertensive strain of rats.

In: The kidney in arterial hypertension (eds: Bianchi $\mathrm{G}$ and Bazzato G). Bunge Scientific Publishers, Utrecht, 1979, pp 144-151.

Blackshear JL, Spielman WS Knox FG and Romero JiC: Dissociation of renin release and renal vasodilation by prostaglandin synthesis inhibitors.

Am J Physiol 237: F20-F24, 1979.

Blendis $L M_{4}$ Auld RB, Alexander EA and Levinsky NG: Effect of renal beta- and alphaadrenergilc stimulation on proximal sodium reabsorption in dogs.

Clin Sci 43: 569-576, 1972.

Block MA, Wakim KG and Mann FC: Renal function during stimulation of renal nerves. Am J Physial 169: 670-677, 1952.

Borst JG and Borst-De Geus A: Hypertension explained by Starling's theory of circulatory homeostasis.

The Lancet March 30: 677-682, 1963.

Brater DC: Effect of indomethacin on salt and water homeostasis.

Clin Pharmacol Ther 25: 322-330, 1979.

Bravo EL, Tarazi RC Gifford RW and Stewart AH: Circulatory and urinary catecholamines in pheochromocytoma.

New Engl J Med 301: 682, 1979.

Brenner BW, Deen WM and Robertson CR: Glomerular filtration.

In: The kidney (eds: Brenner BM and Rector FC). WB Saunders Company, Philadelphia, 1976, pp 251-271.

Brown M.M, Davies DS and Dallery CT: Quantitative analysis of noradrenaline clearance. Br J Pharmacol 67: 452P-453P, 1979.

Burke TJ, Cronin RE, Duchin KK, Pellerson LN and Schrier RW: Ischemia and tubule obstruction during acute renal failure in dogs: mannitol in protection.

Am J Physiol 238; F305-F314, 1980.

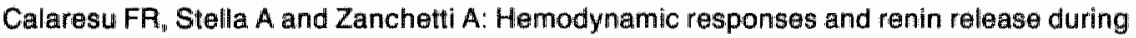
stimulation of afferent renal nerves in the cat.

$\downarrow$ Physilol 255: 687-700, 1976.

Calaresu FR, Kim P, Nakamura $H$ and Sato A: Electrophysiological characteristics of rem norenal reflexes in the cat.

J Physiol (Lond) 283: 141-154, 1978. 
Calaresu FA and Ciriello J: Altered concentration of catecholamines in the hypothalamusi of the rat after renal denervation.

Can J Physiol Pharmacol 59: 1274-1277, 1981.

Calaresu FR and Ciriello. J: Renal afferent nerves affect discharge rate of medulliary and hypothalamic single units in the cats.

$\checkmark$ Autonom Nerv Syst 3: $311-320,1981$.

Campbe\|\| WB and liskovitz HD: Effect of histamine and antihistamines on renal hemody namics and functions in the isolated perfused canine kidney.

JPharmacol Exp Ther 198: 661-667, 1976.

Campbell WB, Graham AB and Jackson EK: Role of renal prostaglandins in sympathet:cally mediated renin release in the rat.

$J$ Clin Invest 64: 448-456, 1979.

Campbell BC. Shepherd AN and Reid JL: Effects of the angiotensin converting enzyme inhibitor, captopril, in essential hypertension.

Br. Clin Pharmacol 13: 213, 1982.

Carretero $\mathrm{OA}$ and Romero JC: Production and characteristics of experimental hypertension in animals.

In: Hypertension (eds: Genest J, Koiw E and Kuchel O). McGraw-Hill Book Company, New York, 1977, pp 485-506.

Carretero $O A$ and Scicli $A G$ : The renal kallikrein-kinin system.

A.m J Physiol 238: F247-F255, 1980.

Carretero $O A$ and Scicli AG: Possible role of kinins in circulatory homeostasis.

Hypertension 3 (suppl 1): 4-12, 1981.

Carriere $S$ Cardinal $J$ and Le Grimellec $C$ : Influence of sodium intake on catecholamine releasie by angiotensin and renal merwe stimulation in dogs.

Caan J Physiol Pharmacol 58: 1092-1101, 1980.

Casals-Stenzel J, Tree M, Brown JJ, Fraser R, Lever AF, Millar JA, Morton JJ, Robertson JIS, Feid IL and Hamilton C: Prolonged infusion of norepinephirine in the conscilous dog: effects on blood pressure, heart rate, renin, angiotensin II, and aldosterone.

$J$ Cardiowasc Pharmacol 4 (suppl): $\$ 114-S 121,1982$.

Casteels $R$, Kitamura K, Huriyama $H$ and Suzuki $H$ : Excitation-contraction coupling in the smooth muscle cells of the rabbit main pulmonary artery.

J Physiol 271: 63-79, 1977.

Ciriello J, Calaresu FR and Recordat GM: Spinal cord projections of renal afferent fibers (ARN) in the rat.

Fed Proc 41: 1258 (abstr nr 5769), 1982.

Chan $\mathrm{YL}$ : The role of norepinephrime in the regulation of fluid absorption in the rat proximal tubule.

$\checkmark$ Pharmacol Exp Ther 215: 65-70, 1980.

Cllappison BH, Millar JA, Casley DJ, Anderson WP and Johnston Cl: Rienal, adrenal and vascular changes during inhibition of converting enzyme with captoprill.

Clin Exp Pharmacol Physiol 7: 493-498, 1980.

Cilement DL, Mussche IMM, Vanhoutte $G$ and Pannier $\mathrm{A}$ : Is blood pressure variabillity related to activity of the sympathetic system?

Clin Sci $57: 217 \mathrm{~s}-219 \mathrm{~s}_{\mathrm{s}}, 1979$.

Coleman TG and Guyton AC: Hypertension caused by salt loading in the dog. III. Onsel transients of cardiac output and other circulatory variables.

Circ Res 25: 152-160, 1969. 
Coleman TG, Salgado MCO, Bengïs RG, Davis Jr MH and Dent AC: Baroreceptor reflex in the rat after converting enzyme inhibition or angiotensin receptor blockade.

Clin Exp Pharmacol Physiol 8: 79-82, 1981.

Colindres RE and Gottschalk CW: Neural control of renal tubular sodium reabsorption inr the rat: single nephron analysis.

Fed Proc 37: 1218-1221, 1978.

Colindres RE, Spielman WS, Moss NG, Harrington WW and Gottschalk CW: Functional evidence for renorenall reflexes in the rat.

Am J Physiol 239: F265-F270, 1980.

Conger JD, Fobinette JB and Guggenheim S.J: Effect of acetylcholine on the early phase of reversible norepinephrine-induced acute renal failure.

Kidney Int 19: 399-409, 1981.

Cowley Jr AW and Lohmeier TE: Changes in renal vascular sensitivity and arterial pressure associated with sodium intake during long-term intrarenall norepinephrine infusion in dogs.

Hypertension 1: 549-558, 1979.

Cronin AE, Erickson AM, De Torrente A, McDonald KM and Schrier RW: Norepinephrineinduced aculte renal faiture: a reversible ischemic model of acute renal failure.

Kidney Int 14: 187-190, 1978.

Cronin AE, De Torrente A, Miller PD, Bulger RE, Burke TJ and Schrier RW: Pathogenic mechanism in early norepinephrine-induced acute renal failure: functional and histologicall correlates of protection.

Kidney Int 14: 115-125, 1978.

Cuche JL and Llard JF: Tissue catecholamines following renal denervation spontaneously hypertensive rats.

Experientia 37: 1089-1090, 1981.

Data JL, Gerber JG, Crump WJ, Frölich JC, Hollifield JW and Nies AS: The prostaglandin system. A role in canine baroreceptor control of renin release.

Circ Res 42: 454-458, 1978.

Davis JO: The pathogenesis of chronic renovascular hypertension.

Circ Res 40: 439-444, 1977.

DeBolld $A J$, Barenstein HB, Veress AT and Sonnenberg $H:$ A rapid and potent natruretic response to intravenous injection of atrial myocardial extract in rats.

Life Sci 28: 89, 1980.

DeChamplain $\mathrm{J}$ : The contribution of the sympathetic nervous system to arterial hypertension.

Can Physiol Pharmacol 56: 341-353, 1978.

Dejonge, $A_{4}$ Wilffert $B$, Kalkman HO, VanMeel CA. Thoolen MJMC, Timmermans PBMWM and VanZwieten PA: Captoprill impairs the vascular smooth muscle contraction mediated by postsynaptic alpha2-adrenoceptors in the pithed rat.

Euir J Pharmacol 74: 385-386, 1981.

DeLean A, Munson PJ and Rodbard D: Simultaneous analysis of families of sigmoidal curves: application to bioassay radioligand assay and physiological dose-rosponses curves. Am J Physiol 235: E97-E102, 1978.

DeSwiet $M$ and Dickinson $C J$ : The delayed pressor reposnse to small doses of intravenous noradrenaline in conscious rabbits.

J Physiol 205: 515-526, 1969. 
DeTorrente Miller PD, Cronin RE, Paulsen PE, Erickson AM and Schrier RW: Effects of furosemide and acetylcholine in norepinephrine-induced acute renal failure.

Am J Physiol 235: F131-F136, 1978.

Dewardener HE: The control of sodium excretion.

Am J Physiol 235: F163-F173, 1978.

DeWardener HE and Clarkson EM: The natriuretic hormone: recent developments.

Clin Sci 63: $415-420,1982$.

DiBona GF: Neurogenic regulation of renal tubular sodium reabsorption.

Am J Physiol 233: F73 F81, 1977.

DiBona GF and Sawin LL: Effect of renal nerve stimulation on $\mathrm{NaCl}$ and $\mathrm{H} 2 \mathrm{OO}$ transport in Henle's loop of the rat.

Am J Physiol 243: F576-F580, 1982.

Diz DI, Nasjletti A and Baeir PG: Renal denervation at weaning retards development of hypertension in New Zealand genetically hypertensive rats.

Hypertension 4: 361-368, 1982.

Drew GM and Whiting SB: Evidence for two distinct types of postsynaptic alphaadrenoceptor in vascular smooth muscle in vivo.

Br J Pharmac 67: 207-215, 1979.

Eckberg DL: Adaptation of the human carotid baroreceptor cardiac reflex.

J Physiol 269: 579-589, 1977.

Esler $M$, dackman $G$, Bobik $A$, Kelleher $D$. Jennings $G$, Leonard $P$, Skews $H$ and Korner $P$ : Determination of norepinephrine apparent release rate and clearance in humans.

Life Sci 25: 1461-1470, 1979.

Evenwel RT: The development of spontaneous hyperterision in rats.

Academic Thesis, Maastricht, 1982.

Faris 18 , lannos $\mathrm{J}$, Jamieson $\mathrm{GG}$ and Ludbrook $\mathrm{J}$ : Comparison of methods for eliciting the baroreceptor heart rate reflex in conscious rats.

Clin Exp Pharmacol Physiol 7: 281-291, 1980.

Feigen LP, Klainer E, Chapnick BM and Kadowitz PJ: The effect of indomethacin on renal function in pentobarbital-anesthetized dogs.

J Pharmacol Exp Ther 198: 457-463, 1976.

Ferreira SH and Vane JR: Half-lives of peptides and amines in the circulation.

Nature 215: $1237-1240,1967$.

Finne LG, Lee H, Goldsmith D, Weber H and Blautox MD: Effects of catheterization of renal artery on renal function in the rat.

$J$ Appl Physiol 37: 930-933, 1974.

Fink GD and Bryan WJ: Renal vascular resistance and reactivity in the neurogenic hypertensive rat.

Am J Physial 239: F474-F477, 1980.

Finn WF and Arendshorst WJ: Effect of prostaglandin synthetase inhibitors on renal blood flow in the rat.

Am J Physiol 231: 1541-1545, 1976.

Folkow B: Physiological aspects of primary hypertension.

Physial Rev 62: 347-504, 1982.

Francisco LL. Sawin LL and DiBona GF: Renal sympathetic nerve activity and the exaggerated natriuresis of the spontaneous hypertensive rat.

Hypertension 3: 134-1138, 1981. 
Freeman RH, Davis JO, Watkins BE, Stephens GA and DeForrest JM: Effects of continuous converting enzyme blockade on renovascular hypertension in the rat.

Am I Physiol 236: F21-F24, 1979.

Freeman $\mathrm{AH}$, Davis $\mathrm{JO}$ and Seymour AA: Volume and vasoconstriction in experimental renovascular hypertension.

Fed Proc 41: 2409-2414, 1982 .

Frohlich ED, Pffeffer M, Weiss AK and Brecher GA: Variability of arterial pressure in normotensive and spontaneously hypertensive rats.

Proc Soc Exp Biol Med 140: 145-148, 1972.

Garwitz ET and Jones AW: Aldosterone infusion into the rat and dosedependent changes in blood pressure and arterial ionic transport.

Hypentension 4: 374-381, 1982.

Gavendo S, Kapuler S, Serban I, laina A, Ben-David E, Eliahou H: Beta1-receptors in kidney tubular cell membrane in the rat.

Kidney Int 17: 764 770, 1980.

Gerber JG, Keller RT and Nies AS: Prostaglandins and renin release. The effect of PGI2, PGE2 and 13,14-dihydro PGE2 on the barareceptor mechanism of renin release in the dog.

Circ Res 44: 796-799, 1979.

Gerber JG and Nies AS: The role of prostaglandins in the control of renal hemodynamics. Min Electrol Metab 6: 27-34, 1981.

Gill Jr JA and Casper AGT: Depression of proximal tubular sodium reabsorption in the dog in response to renal beta-adrenergic stimulation by isoproterenol.

$\checkmark$ Cilin Invest 50 : $112-118,1971$.

Gill Jir $\Downarrow R$ : Neural control of renal tubular sodium reabsorption.

Nephron 23: 116-118, 1979.

Gitllow $S$, Dziedzic $S_{n}$ Dziedzic L and Roubein I: Metabolism of D, L-3Hnorepinephrine in essential hypertension.

Clin Exp Hypert 3: 897-918, 1981.

Goodfriend TL and Peach MJ: Specific functions of angiotensin I, II and III.

In: Hypertension (eds: Genest J, Koiw E and Kuchel O). McGraw-Hill Book Company, New York, 1977, pp 168-172.

Goldstein DS: Plasma norepinephrine in essential hypertension. A study of the studies. Hilypertension 3: 48-52, 1981 .

Göthberg $\mathrm{G}_{\|}$Lundin $\mathrm{S}$ and Folkow $\mathrm{B}$ : Acute vasodepressor effect in normotensive rats following extracorporal perfusion of the declipped kidney of two-kidney, onewclip hypertensive rats.

Hypertension 4 (suppl II): 101-105, 1982.

Gottschalk CW: Renal nerves and sodium excretion.

Ann Rev Physiol 41: 229-240, 1979.

Greenway CV and Innes IR: Effects of splanchnic nerve stimulation on cardiac preload, afterload and output in cats.

Circ Fes $46: 181 \cdot 189,1980$.

Greven $f$ and Klein $H$ : Effects of dopamine on whole kidney function and proximal transtubular volume fluxes in the rat.

Naunyn-Schmied Arch Pharmacol 296: 289-292, 1977. 
Grolman A: Experimental induction of hypertension.

In: Handbook of experimental pharmacology. XVI.3. Springer Verlag. New York, 1975 , pp $71-96$.

Cuyton AC, Coleman TG, Cowley لir AW, Manning J RD, Noman RA and Ferguson JD: A systems analysis approach to understanding long-range arterial blood pressure control and hypertension.

Circ Res 35: 159-176, 1974.

Guyton AC: Textbook of medical physiology. WB Saunders Company, Philadelphia, 1976.

Guyton $\mathrm{AC}$ : Personal views on the mechanism of hypertension.

In: Hypentension (eds: Genest $J_{1}$ Koiw E and Kuchel O). McGraw-Hill Book Compary, New York, 1977, pp 566-575.

Guyton AC, Coleman TG, Young DB, Lohmeier TE and DeClue JW: Salt balance and long-term blood pressure control. Ann Rev Med 31: 15-27, 1980.

Guyton AC, Hall JE, Lohmeler TE, Jacson TE and Manning Jr RD: The many roles of the kidney in arterial pressure control and hypertension.

Can J Physiol Pharmacol 59: 513-519, 1981a.

Guyton AC, Hall JE, Lohmeier TE Jackson TE and Kastner PR: Blood pressure regulation: basic concepts.

Fed Proc 40: 2252-2256, $1981 \mathrm{~b}$.

Häberle DA, Shigai TT, Maier G, Schiffl H and Davis JM: Dependency of proximal tubular fluid transport on the load of gllomerular tiltrate.

Kidney Int 20: 18-28, 1981.

Hall JE and Guyton $A C$ : Changes in renal hemodynamics and renin release caused by increased plasma oncotic pressure.

Am J Physiol 231: 1550-1556, 1976.

Hall JE Guyton $\mathrm{AC}$ and Cowley Jr AW: Dissociation of renal blood flow and filtration rate augoregulation by renin depletion.

A.m J Physiol 232: F215-F221, 1977a.

Hall JE, Guyton AC, Jackson TE, Coleman TG, Lohmeier TE and Trippodo NC: Control of glomerular filtration rate by renin-angiotensin system.

Am J Physiol 233: F366-F372, $1977 \mathrm{~b}$.

Hall JE, Guyton AC, Salgado HC, MCCaa RE and Balfe JW: Renal hemodynamics in acute and chronic angiotensin II hypertension.

Am J Physiol 235: F174-F179, 1978.

Hall JE, Coleman TG, Guyton AC, Kastner PA and Granger JP: Control of glomerullar filtration rate by circulating angiotensin II.

Am I Physiol 241: R190-R197, 1981.

Handler JS and Orloff $J$ : The mechanism of action of antidiuretic hormone.

In: Handbook of physiology, section 8: Renall physiology (eds; Orloff $\mathrm{J}$ and Berliner RW). American Physiological Society. Washington, 1973, pp 791-814.

Hatton $\mathrm{A}_{*}$ Clough D, Faulkner $K$, Conway J: Angiotensin-converting enzyme inhibitor resets baroreceptor reilexes in conscious dogs.

Hypertension 3: 676-681, $198 \%$.

Hatton R, Clough DP, Adigun A and Conway J: Functional interaction between angiotensin and sympathetic reflexes in cats.

Clin Sci $62: 51-56,1982$. 
Haylor $J$ and Lote $\mathrm{CJ}$ : Renal function in conscious rats after indomethacin. Evidence for a fubular action of endogenous prostaglandins.

J Physiol 298: 371-381, 1980.

Haylor $J$ and Towers $J$ : Renal vasodilator activity of prostaglandin $E_{2}$ in the rat anesthetized with pentobarbitone.

Br J Pharmacol 76: 131-137, 1982.

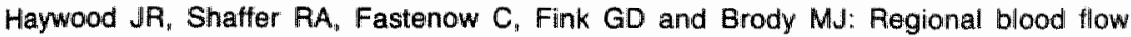
measurement with pulsed Doppler flowmeter in conscious rat.

Am J Physiol 241: H273-H278, 1981.

Heinemann $\mathrm{HO}$ and Lee JB: Prostaglandines and blood pressure control.

Am $ل$ Med 61: 681 695, 1976.

Hermansson $\mathrm{K}$, Larson $\mathrm{M}$, Kallskog $\mathrm{O}$ and Wolgast $\mathrm{M}$ : Influence of renal nerve activity on arteriolar resistance, ultrafiltration dynamics and fiud reabsorption.

Pflug Arch 389: 85-90, 1981.

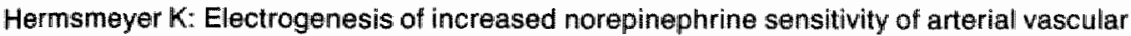
muscle in thypertension.

Circ Res 38: 362-367, 1976.

Higashihara E, Stokes JB, Kokko JP, Campbell WB and DuBose TD: Cortical and papillary micropuncture examination of chloride transport in segments of the rat kidney during inhibition of prostaglandin production.

$\mathrm{J}$ Clin Invest 64: 1277-1287, 1979.

Holdaas $H$, DiBona GF and Kiil F: Effect of low-levell renal nerve stimulation on renin release from nonfiltering kidneys.

Am J Physial 241: F156-F161, 1981.

Hollenberg NK, Borucki LJ and Adams DF: The renal vasculature in early hypertension: evidence for a pathogenic role.

Medicine 57: $167-178,1978$.

Holman RB, Angwin P and Barchas JD.

Neurosci 1: 147-152, 1976.

Imai $Y$, Abe K, Seino M, Haruyama T, Tajma J, Sato M, Goto T, Hiwatara M, Kasai $Y$, Yoshimaga $K$ and Sekino $H$ : Attenuation of pressor responses to norepinephrine and pitressin and potentiation of pressor response to angiotensin II by captopril in human subjects.

Hypertension 4: 444-451, 1982.

Insel PA and Snavely MD: Catecholamines and the kidney: receptors and renal function. Ann Rev Physiol 43: 625-636, 1981.

Iriuchijima J: Sympathetic discharge rate in spontaneously hypertensive rats. Jpn Heart J 14: 350-356, 1973.

Iversen LL: Catecholamine uptake processes.

Br Med Bull 29: 130-135, 1973.

Jackson EK, Heidemann HT, Branch AA and Gerkens JF: Low dose intrarenal infusions of PGE2, PGI2 and 6-keto-PGE1 vasodilate in the vivo rat kidney.

Circ Resi 51: 67, 1982.

Jacobson HR and Seldin DW: Proximal tubular reabsorption and its regulation.

Ann Rew Pharmacol Toxicol 17: 623-646, 1977. 
Johns Ed: Action of angiotensin I conwerting enzyme inhibitor on the control of renal function in the cal.

Clirt Sci 56: 365-371, 1979.

Johnson MD, Schier DN and Barger AC: Circulating catecholamines and control of plasma renin activity in conscious dogs.

Am J Physiol 236: H463-H470, 1979.

Jorgensen PL: Sodium and potassium ion pump in kidney tubules.

Physial Pev 60: 864-917, 1980.

Judy WV, Watanabe AM, Henry DP, Besch HR, Murphy WR and Hockel GM: Sympathetic nerve activity. Role in regulation of blood pressiure in the spontaneously hypertensive rat. Circ Res (Suppl II) 38: 21-29, 1976.

Kaloyanides $\mathrm{G}$, Cohem $L$ and DiBona GF: Failure of selected endocrine organ ablation to modify the natriuresis of blood volume expansion in the dog.

Clin Sei Mol Med 52: 351-356, 1977.

Katholi AE, Carey AM, Ayers CR, Vaughan ED, Yancey MR and Morton CL: Production of sustained hypertension by chronic intrarenal norepinephrine infusion in conscious dogs.

Circ Res (Suppl 1) 40: 118-126, 1977.

Katholi RE, Naftilan AJ and Oparil S: Importance of renal sympathetic tone in the development of DOCA-salt hypertension in the rat.

Hypertension 2: 266-273, 1980.

Katholi RE, Winternitz SR and Oparil S: Role of renall nerves in the pathogenesis of onekidney renal hypertension in the rat.

Hypertension 3: $404-409,1981$.

Katholi RE. Whitlow PL, Winternitz SF and Oparil S: Importance of the renail nerves in established two-kidney, one-clip Goldblatt hypertension.

Hypertension 4 (Suppl II): 166-174, 1982.

Katholi RE, Hageman GR, Whitlow PL and Woods WT: Hemodynamic and afferent renal merve responses to intrarrenal adenosine in the dog.

Hypertension 5 (Suppl 1):149-154, 1983.

Katz Al and Lindheimer MD* Actions of hormones on the kidney.

Ann Rev Physiol 39: 97-134, 1977.

Kiil F: Mechanism of glornerulotubular balance: the whole kidney approach.

Renal Physiol 5: 209-221, 1982.

Kim JK, Linas SL and Schrier RW: Catecholamines and sodium transport in the kidney. Pharmacol Fev 31: 169-178, 1980.

Kline RL, Kelton PM and Mercer PF: Effect of renal denervation on the developent of hypertension in spontaneously hypertensive rats.

Can J Physiol Pharmacol 56: 818-822, 1978.

Kline $\mathrm{R} L$, Stuart $\mathrm{PJ}$ and Mercer PF: Effect of renal denervation on arterial pressure and renal norepinephrine concentration in Wistarkyoto and spontaneously hypertensive rats. Can J Physiol Pharmacol 58: 1384-1388, 1980.

Knox FG and Haas JA: Factors influencing renal sodium reabsorption in volume expansion.

Rev Physiol Biochem Pharmacol 92: 76-113, 1982. 
Kopp U. Aurell M, Sjolander M and Aoblad $B$ : The role of prostaglandins in the alpha- and beta-adrenoceptor mediafed renin release response to graded renal neve stimulation. Pflügers Arch 391: $1-8,1981$

Korner Pl: The present status of the autoregulation theory of the pathogenesis of hypertension.

Clin Exp Pharmacol Physiol 7: 521-526, 1980

Korner Pl: Circulatory regulation in hypertension.

$\mathrm{Br} J$ Clin Pharmacol 13: 95-105, 1982.

Kottke $F \unlhd$. Kubicek WG and Visscher MB: The production of arterial hypertension by chronic renal artery-merve stimulation.

Am J Physiol 145: 38-47, 1945.

Krausz MM, Feuerstein $G$, Feuerstein $N$ and Gutman $Y$ : The role of the renin-angiotensin system in mediation of adrenal catecholamine secretion in the cat induced by intrarenall beta-adrenergic stimulation.

Circ Fes 47: 835-839, 1980.

Kubicek WG "Kottke FJ, Laker DJ and Visscher MB: Renal function during arterial hyperm tension produced by chronic splanchnic nerve stimulation in the dog.

Am J Physiol 174: 397-400, 1953.

Kuchel O, Buu NT, Hamet P, Larochelle P, Bourque $M$ and Genest J: Essential hypertension with low conjugated catecholamines imitates pheochromocytoma.

Hypertension 3: 347-355, 1981.

Kurz KD, Johnson A, Ichikawa S, Fowler Jr WL and Payne CG: Fluid volumes in onekioney 30-day renal artery stenosis rabbits.

Proc Soc Exp Biol Med $\| 68: 311-318,1981$.

Lai FM, Tanikella T, Herzlinger $H$, Thibault $L$ and Cervon $P$ : Effects of continuous angiotensin l-converting enzyme blockade on blood pressure, sympathetic activity and reninangiotensin system in strokeprone spontaneously hypertensive rats.

Life Sci 28: 1309, 1981.

Lappe RW, Henry DP and Willis LR: Mechanism of renal tubular secretion of norepinephrine in the rabit.

J Pharmacol Exp Ther 215: 443-449, 1980.

Lappe RW, Henry DP and Willis LR: Contribution of renal sympathetic merves to the urinary excretion of norepinepthrine.

Can J Physiol Pharmacol 60: 1067-1072, 1982.

Lappe RW, Webb RL, Boutelle $\mathrm{S}$ and Brody MJ: Identification of central projections of renal afferent nerves.

Fed Proc 41: $5770,1982$.

Levinsky NG: The renal kallikrein-kinin system.

Circ Res $44: 441-451,1979$

Leyssas PP: The renin angiotensin system and kidney function. A review of contributions to a new theory.

Acta Physilol Scand suppl 442: 3-52, 1976.

Liard JF: Renal denervation delays blood pressure increase in the spontaneously hypertensive rat.

Experientia 33: 339-340, 1977. 
Liard JF: Hypertension induced by prolonged intracoronary administration of dobutamine in conscious dogs.

Clin Sci Mol Med 54: $153-160,1978$.

Liard JF: Cardiogenic hypertension.

In: Intl Rev Physiol Cardiovascular Physiology III, vol. 18 (eds: Guyton AC and Young DB). Uniwersity Park Press, Baltimore, 1979, pp 317-355.

Lilschitz MD: Lack of a rolle for the renal nerves in renal sodium reabsorption in conscious dogs.

Clin Sci Mol Med 54: 567-572, 1978.

Lightman SL. and Iwersen LL: The role of uptake2 in the extraneuronal metabolism of catecholamines in the isolated rat heart.

Bir J Pharmacol 37: 638-649, 1969.

Linden RJ: Atrial reflexes and renal function.

Am J Cardiol 44: 879-883, 1979.

Littler WA, West MJ, Honour AJ and Sleight P. The variability of arterial pressure.

Am Heart J 95: 180-186, 1978

Lohmeier TE, Cowley Jr AW, DeClue JW and Guyton AC: Failure of chronic aldosterone infusion to increase arterial pressure in dogs with angiotensin-induced hypertension.

Circ Res 43: 381-390, 1978.

Majewski $H$. Hedler $L$ and Starke $K$ : The noradrenaline release rate in the anesthetized rabbit: facilitation by adrenaline.

Naunyn-Schmied Arch Pharmacol 321: 20-27, 1982.

Mancia G, Ferrari A, Gregorini L, Parati G, Pomidossi G and Zanchetti A: Prolonged intraarterial blood pressure recording in diagnosis of phaeochromocytoma.

The Lancet $\$ 193-1194,1979$.

Mancia $G$, Ferrari A, Gregorini L, Parati G, Pomidossi G, Bertinieri G, Grassi $G$ and Zanchetti A: Blood pressure variability in man: its relation to thigh blood pressure, age and baroreflex sensitivity.

Clin Sci 59: 401s-404s, 1980.

Masuyama $Y$, Nishimura T, Nishio I and Kuchii $M$ : Noradrenaline clearance in hypertensive patients with various degrees of renal function.

Clin Sci 57: 213s-215s, 1979.

MCGrath JC: Evidence for more than one type of postjunctional alpha-adrenoceptor.

Blochem. Pharmacol 31: 467-484, 1982.

Mendelsohn FAO: Evidence for the local occurrence of angiotensin II in rat kidney and its modulation by dietary sodium intake and converting enzyme blockade.

Clin Sol 57: 173-179, 1979.

Micalizzi ER and Pals DT: Evaluation of plasma norepinephrine as an index of sympathetic meuron function in the conscious, unrestrained rat.

Lite Sci 24: 2071-2076, 1979,

Millar JA ${ }$ Casey DJ and Johnston Cl: Adrenal angiotensin II receptors and vascular reactivity to angiotensin II in the rat during continuous inhibition of angiotensin converting enzylme.

Clin Sci 59: 65s-69s, 1980 .

Miller MJS and Scroop GC: Disappearance of angiotensin II and noradrenaline from the renal and femoral circulations of the dog.

Clin Sci 58: 29-35, 1980. 
Mills IH and Ward PE: The relationship between kallikrein and water excretion and the conditional relationship belween kallikrein and sodium excretion.

I Physiol 246: 695-707, 1975.

Mils $E$ and Smith PG: Catecholamine infusions can increase sympathetic nerve activity reflexly by stimulating anterial chemoreceptors.

Fed Proc 42: 895 (abstr ne 3531), 1983.

Norgunov $N$ and Baines $A D$ : Renal nerves and catecholamine excretion.

Am J Physiol 240: F75m881, 1981.

Moss NG: Renal function and renal afferent and efferent nerve activity.

Am J Physiol 243: F425-F433, 1982.

Muirhead EE: Antihypertensive functions of the kidney.

Hypertension 2: 444-464, 1980.

Muirhead EE, Folkow B, Byers LW, Desiderio DM, Thoren P, Göthberg G. Dow AW and Brooks B: Cardiovascular effects of antinypertensive polar and neutral renomedullary lipids.

Hypertension 5 (suppl 1): 112-118, 1983.

Müler $\mathrm{J}$ and Barajas. L: Electron microscopic and histochemical evidence for a tubular innervation in the renal contex of the monkey.

J Ultrastruct Res 41: 533-549, 1972 .

Murray RH, Luft FC, Bloch $R$ and Weyman AE: Blood pressure responses to extremes of sodium intake in normal man.

Proc Soc Exp Biol Med 159: 432-436, 1978.

Nakane $H$, Nakane $Y$, Corvol $P$ and Menard J: Sodium balance and renin regulation in rats: role of intrinsic renal mechanisms.

Kidney lnt 17: 607-614, 1980.

Nathan MA and Reis DJ: Chronic labile hypertension produced by lesions of the nucleus tractus solitarii in the cat.

Circ Res 40: 72-81, 1977.

Norman Jr RA, Enobakhare JA, DeClue JW, Douglas BH and Guyton AC: Arterial pressure-urinary output relationship in thypertensive rats.

Am J Physiol 234: R98-R103, 1978.

Norman Jir RA, Coleman TG and Dent AC: Pseudohypertension in sinoaortic denervated rats.

Clin Sci 59: 303s-306s, 1980.

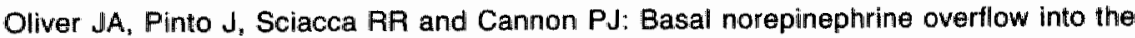
renal vein: effect of renal nerve stimulation.

Am J Physiol 239: F371-F377, 1980.

Olsen UB, Magnussen MP and Eilertsen E: Prostaglandins, a link between renal hydroen hemodynamic in dogs.

Acta Physiol Scand 97: 369-376, 1976.

Osborn JL, DiBona GF and Thames MD: Beta1-receptor mediation of renin secretion elicited by low-frequency renal nerve stimulation.

$J$ Pharmacol Exp Ther 216:265-269, 1981.

Osswald $\mathrm{H}_{3}$ Hermes $\mathrm{HH}$ and Nabakowski $\mathrm{G}$ : Role of adenosime in signal transmission of tubuloglomerullar feedback,

Kidmey Int 22 (suppl 12): 136-142, 1982

Pan YJ and Young DB: Experimental aldosterone hypertension in the dog.

Hypertension 4: 279-287, 1982. 
Patrono $\mathrm{C}$, Pugliese F, Ciabattoni G, PatrignaniP, Maseri A, Chierchia S, Peskar BA, Cinotil GA, Simonetti BM and Plerucci A: Evidence for a direct stimulatory effect of prostacycin on renin release in man.

J Clin Invest 69: $231 \cdot 239,1982$

Peart WS: The kidney as an endocrine organ.

The Lancet September 10 543-547, 1977.

Pelayo JC, Ziegler MG, Jose PA and Blantz RC: Renal denervation in the rat: analysis off glomerular and proximal tubular function.

Am J Physiol 244: F70-F77, 1983.

Pettinger WA, Keeton TK, Campbell WB and Harper DC: Evidence for a renal alphaadrenergic receptor inhibiting renin release.

Circ Res 38: 338-346, 1976.

Peuler JD and Johnson GA: Simultaneous single isotope radioenzymatic assay of plasma norepinephrine, epinephrine and dopamine.

Life Sci 21: 625-636, 1977.

Powis G: The binding of catecholamines to human serum proteins.

Med Pharmacol 24: 707-712, 1975.

Flapp JP: Dahl salt-susceptible and salt-resistant rats.

Hypertension 4: 753-763, 1982.

Recordati GM, Moss NG and Waselkov LE: Renal chemoreceptors.

Circulation 56 (suppl III): 247, 1977.

Recordati $G$, Genovesi S, Cerati D, DiCintio R and Gerometta P: Excitatory effect of converting enzyme unhibitors on efferent sympathetic postganglionic nerve activity to the kidney in the rat.

Clin Sci 61: 223s-225s, 1981a.

Recordati G, Moss NG, Genovesi S and Rogenes P: Renal chemoreceptors.

J Autonom Nerv System 3: 237-251, 1981b.

Fieid IA, Morris BJ and Ganong WF: The renin-angiotensin system.

Ann Rev Physiol 40: 377-410, 1978.

Renkin EM and Gilmore JP: Glomerular filtration.

In: Handbook of physiology, section 8: Renal physiology (eds: Orloff $J$ and Berliner PW). American Physiological Society, Washington, 1973, pp 185-248.

Robie NW: Presynaptic inhibition of canine renal adrenergic nerves by acelylcholine in vivo. Am J Physiol 237; H326-H331, 1979.

Rogenes PR and Gottschalk CW: Renal function in conscious rats with chronic unilateral renal denervation.

Am J Physiol 242: F14Q-F148, 1982.

Romero JC and Strong CG: The effect of Indomethacin blockade of prostaglandin synthesis on blood pressure of normal rabbits and rabbits with renovascular hypertension.

Circ Res 40: 35-40, 1977.

Ruffolo Jr FR, Waddell JE and Yaden EL: Postsynaptic alpha adrenergic receptor subtypes differentiated by yohimbine in tissues from the rat. Existence of alphaz-adrenergic receptors in rat aorta.

$J$ Pharmacol Exp Ther 217: 235-240, 1981.

Satoh $S_{\text {. Ohyama }} Y$ and Hayashi $M$ : Effects of renal nerve stimulation, norepinephine and angiotensin If on renal blood flow in relation to release of $P G$-like substances in anesthetized dogs.

Arch Int Pharmacodyn 254: 304-316, 1981. 
Sânävallammi P. Vaalasti A, Pyykonen ML. Ylitalo P and Vapaatalo H: The effect of renal sympathectomy on blood pressure and plasma renin activity in spontaneously hypertensive and normotensive rats.

Acla. Physiol Scand 115: 289-293, 1982.

Schachter M: Kallikreins (kininogenases). A group of serine proteases with bioregulatory actions.

Pharmacol Riev 31: 1-17, 1980.

Sealey $J E$, Gerten-Barnes $\mathrm{J}$ and Laragh $\mathrm{JH}$ : The renin system. Variations in man measured by radioimmunoassay or bicassay.

Kidney Int 1: $240,1972$.

Selkurt EE: Effect of pulse pressure and mean arterial pressure modification on renal hemodynamics and electrolyte and water excretion.

Circulation 4: 541-551, 195it.

Seymour AA, Davils JO, Freeman RH, DeForrest JM, Rowe BP, Stephens GA and Williams GM: Hypertension produced by sodium depletion and unilateral nephrectomy: a new experimental model.

Hypertension 2: 125-129, 11980 .

Schachter M: Kallikreins (kininogenases). A group of serine proteases with bioregulatory actions.

Pharmacol Rev 31: 1-17, 1980.

Sealey JE, Gerten-Banes $J$ and Laragh JH: The renin system. Variations in man measured by radioimmunoassay or bioassay.

Kidney Int 1: 240, 1972.

Selkurt EE: Effect of pulse pressure and mean arterial pressure modification on renal hemodynamics and electrolyte and water excretion.

Circulation 4: 541-551, 1951 .

Seymour AA, Davis $\mathrm{JO}$, Freeman RH, DeForrest JM, Rowe BP, Stephens GA and Williams GM: Hypertension produced by sodium depletion and unilateral nephrectomy: a new experimental model.

Hypertension 2: 125-129, 1980.

Shimada SG and Marsh DJ: Oscillations in mean arterial blood pressure in conscious dogs.

Circ Res 44: 692-700, 1979.

Silva P. Landsberg $L$ and Besarab A: Excretion and metabolism of catecholamines by the isolated perfused rat kidney.

$\mathrm{J}$ Clin Invest 64: 850-857, 1979.

Silverberg AB, Shah SD, Haumond MW and Cryer PE: Norepinephrine: hormone and neurotransmitter in man.

Am J Physiol 234: E252-E256, 1978.

Simon AC, Safar ME, Weiss YA, London GM and Milliez PL: Baroreflex sensitivity and cardiopulmonary blood volume in normotensive and hypertensive pallients.

Br Heart $\ 39$ : 799-B05, 1977.

Sinha JN and Schmilt H: Centrall sympatho-inhibitory effects of intracisternal and intravenous administration of moradrenaline in high doses.

Eur J Pharmacol 28: 217-221, 1974.

Skaug $N$ and Detar $R$ : Steady-state effects of extracellular potassium concentration on vascular smooth muscle reactivity.

Am J Physioll 241: H217-H223, 1981. 
Smits J: The antimypertensive effect of propranolol

Academic Thesis, Maastricht, 1980.

Smits JFM, Coleman TG, Smith TL, Kasbergen CM, VanEssen, $H$ and Struyker-Boudier HAJ: Antihypertensive effect of propranolol in conscious spontaneausly hypertensive rats: central hemodynamics, plasma wolume, and renal function during beta-blockade with propranololl.

$\Downarrow$ Cardiovasc Pharmacol 4: 903-914, 1982.

Smits IF and Brody MJ: Differential hemodynamic responses to intrarenally and intravenously infused bradykinin and adenosine in conscious rats.

Fed Proc 42: 4059, 1983.

Smits JFM, Kleinjans JC, Kasbergen CM and Struyker-Boudier HAJ: Lability of blood pressure during long-term intravenous infusion of norepinephrine in normottensive rats: contribution of the sympathetic nerwous system.

Proc 1st Eur Meeting on Hyperteinsion, Milan, 1983.

Starke K: Presynaptic receptors.

Ann Hev Pharmacol Toxicol 21: 7-30, 1981.

Starke $K$ and Dacherty JR: Types and functions of peripheral alpha-adrenoceptors.

$\mathrm{J}$ Cardiovasc Pharmacol 4: s3-s7, 1982.

Stein $J$ : The renal circulation.

In: The kidney (eds: Brenner BM and Rector FC). WB Saunders Company, Philadelphia, $1976, \mathrm{pp} 215-250$.

Stokes JB: Integrated actions of renal medullary prostaglandins in the control of watter excretion.

Am d Physiol 240: F471-F480, 1981.

Struyker-Boudier HAJ en Pahn $\mathrm{KH}$ : Systeemanalyse van de bloeddrukregulatie; het sympathische zenuwstelsel en hypertensie.

Ned Tijdschr Gieneeskd 123: 960-968, 1979.

Struyker-Boudier HAJ, Evenwel RT, Smits JFM and VanEssen H: Baroreflex sensitivity during the development of spontaneous hypertension in rats.

Clin Sci 62: 589-594, 1982.

Susic $H$ and Malik KU: Attenutation by arachidonic acid of the effect of vasoconstrictor stimuli in the canime kidney.

$J$ Pharmacol Exp Ther 219: 377-382, 1981.

Suzuki S, Franco-Saenz F, Tan SY and Mulrow PJ: Effects of indomethacin on plasma renin activity in the conscious rat.

Ami J Physiol 240: E286-E289, 1981.

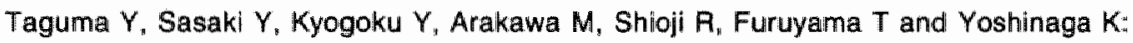
Morphological changes in an early phase of norepinephrine-induced acute renal fallure in unilaterally nephrectomized dogs.

J Lab Clin Med 96: 616-632, 1980.

Talman WT, Alonso DR and Reis DJ: Chronic lability of arterial pressure in the rat does not evolve into hypentension.

Clin Sci 59: 405s-407s, 1980.

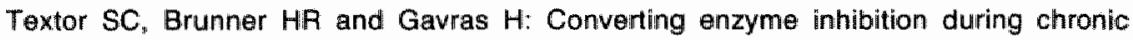
angiotensin II infusion in rats.

Hypertension 3: 269-276, 1981. 
Thames MD and DiBona GF: Renal nerves modulate the secretion of renin mediated by nonneural mechanisms.

Circ Res 44: 645-652, 1979 .

Thibautt G, Garcia $\mathrm{R}$, Cantin $\mathrm{M}$ and Genest $\mathrm{J}$ : Atral natriuretic factor. Characterization and partial purification.

Hypertension 5 (suppl 1): 75-80, 1983 .

Thorén $P$ and Ricksten SE: Recordings of renal and splanchnic sympathetic nervous activity in normotensive and spontaneously hypertensive rats.

Clin Sci 57: 197s-199s, 1979.

Thurau K: Intrarenal action of angiotensin.

In: Handbook of experimental pharmacology, wol 37 (eds: Page $1 \mathrm{H}$ and Bumpas FM). Springer Verlag, Berlin-Heidelberg-New York, 1974, pp 475-489.

Timmermans PBMWM and VanZwieten PA: Alpha2-adrenoceptors: classification. localization, mechanism, and targets for drugs.

$\checkmark$ Med Chem 25: 1389-1401, 1982.

Tobian L and O'Donmell M: Renal prostaglandirs in relation to sodium regulation and thypertension.

Fed Proc 35: 2388-2392, 1976.

Tomomatsu $E$ and Nishi $K$ : Increased activity of carotid sinus baroreceptors by sympathetic stimulation and norepinephrine.

Am \& Physiol 240: H650-H658, $198 \%$.

Torretti $\mathrm{J}$ : Sympathetic control of renin release.

Ann Rev Pharmacol Toxicol 22: 167-192, 1982.

Trippodo NC, MacPhee AA and Cole FE: Partially purified human and rat atrial natriuretic factor.

Hypertension 5 (suppl 1): 81-88, 1983.

Vandongen $R$, Tunney $A$ and Martinez P: Effect of the converting enzyme inhibitor $S Q 14$ 225 (captopril) in early one-kidney, one-clip hypertension in rat.

Clin Scil 60: 387-392, 1981.

Vane JR: The release and fate of vasoactive hormones in the circulation.

Br J Pharmacol 35: 209-242, 1969.

Villamil MF. Amorena $C$. Ponce-Hornos J, Müiler A and Taquini AC: Role of extracellular volume expansion in the development of DOC-salt hypertension in the rat.

Hypertension 4: 620-624, 1982.

Wlachakis ND: Blood pressure response to norepinephrine infusion in relationship to plasma catecholamines and renin activity in man.

J Clin Pharmacol October 654-661, 1979.

Wallin BG, Sundlof G, Eriksson BM, Dominiak P. Grobecker H and Lindblad LE: Plasma noradrenaline correlates to sympathetic muscle nerve activity in normotensive man.

Acta Physiol Scand. 111: 69-73, 1981.

Watson RD, Stallard TJ, Flinn RG and Littler WA: Factors determining direct arterial pressure and its variability in hypertensive man.

Hypertension 2: 333-341, 1980.

Weinberger MH, Aoi W and Henry DP: Direct effect of beta-adrenergic stimulation on renin release by the rat kidney slice in vitro.

Circ Res 37: 318-324, 1975. 
Whitby $L G$, Axelrod J, Weil-Malherbe $H$ : The fate of H3-norepinephrine in animals. J Pharmacol Exp Ther 132: 193-201, 1961.

Willis LR, Lappe AW, Henry DP, Ewan AP and Terzian AR: Urinary excretion of radiolabelled norepinephrine after release from renal sympathetic nerves.

Life Scil 27: $2541-2546,1980$.

Winternitz SR, Katholi AE and Oparil S: Decrease in hypothalamic norepinephrine conitent following renal denervation in the one-kidney, one-clip Goldblatt hypertensive rat. Hypertension 4: 369-373, 1982.

Wintermitz SR and Oparil S: limportance of the renal neves in the pathogenesis of experimental hypertension.

Hypertension 4 (suppil III): 108-115, 1982.

Yamaguchi I and Kopin IJ: Plasma catecholamine and blood pressure responses to sympathetic stimulation in pithed rats.

Am J Physiol 237: H305 H310, 1979.

Yamori $Y$, Tarazi $\mathrm{RC}$ and Ooshima A: Effect of beta-receptor blocking agents on cardiovascular structural changes in spontaneous and noradrenaline-induced hypertension in rats.

Clin Sci 59: $457 \mathrm{~s}-460 \mathrm{~s}, 1980$.

Yao $T$ and Thoren P: Adrenergic and pressure-induced modulation of carotid sinus baroreceptors in rabbit.

Acta Physiol Scand 117: 9-17, 1983.

Young DB and McCaa RE: Role of the renin-angiotensin system in potassium control. Am J Physiol 238: R359-R363, 1980.

Young DB, Murray $\mathrm{AH}$, Bengis $\mathrm{AG}$ and Markov AK: Experimental angiotensin II hypertension.

Am J Physiol 239: H39ע-H398, 1980.

Young III WS and Kuhar MJ: Alpha2-adrenergic receptors are associated with renal proximal tubules.

Eur J Pharmacol 67: 493-495, 1980.

Youngberg SP. Marchand GR, Spielman WS, Osswald $H$ and Knox FG: Filtration dynamics in dogs: glomerular capillary pressure.

Fed Proc 36: 2609-2613, 1977.

Yu $A$ and Dickinson $C J$ : The progressive pressor response to angiotensin in the rabbit. The role of the sympathetic nervous system.

Arch Int Pharmacodyn 191: 24-36, 1971.

Zambraski EJ, DiBona GF and Kaloyanides GJ: Effect of sympathetic blocking agents on the antinatriuresis of reflex renal nerve stimulation.

J Pharmacol Exp Ther 198: 464-472, 1976.

Zambraski EJ and DiBona GF: Interaction of adrenergic stimulli, prostaglandins and angiotensin Ill in the dog kidney.

Proc Soc Exp Biol Med 162: 105-111, 1979.

Zanchetti A and Stella A: Neural control of renin release.

Clin Sci Mol Med 48: 215s-223s, 1975.

Zanchetti A, Stella A, Leonetti $G$, Morganti A and Terzoli $\mathbb{L}_{\text {: }}$ Control of renin release: a review of experimental evidence and clinical implications.

Am J Cardio 37: 675-691, 1976. 
Zerbe GO: Randomization analysis of the completely randomized design extended to growth and response curves.

J Am Statis Assoc 74: 215-221, 1979.

Zimmerman $B G$ : Actions of angiotensin on adrenergic merve endings.

Fed Proc 37: 199-202, 1978. 

J.C.S. Kleinjans werd geboren op 2 september 1954 te Sittard (Limburg). Vanaf 1966 bezocht hij het St. Michiel Lyceum in Geleen, alwaar hij in 1972 het einddiploma Gymnasium $\beta$ behaalde. Vervolgens studeerde hij biologie aan de Katholieke Universiteit van Nijmegen. Het kandidaatsexamen $81 \mathrm{G}$ werd afgelegd in februari 1976. De doktoraal fase bestond uit de bijuakken Vergelijkende en Fysiologische Psychologie onder begeleiding van prof. dr. J. Vossen, Psychofarmakologie met als begeleider prof. dr. J. van Rossum alsmede Neuro-anatomie onder begeleiding van prof. dr. R. Nieuwenhuys en uit het hoofdvak Chemische Cytologie onder supervisie van prof. dr. G. BorstPauwels en prof. dr. Ch. Kuyper. Het doktoraal examen werd behaald op 4 september 1979 .

Sinds 1 augustus 1979 is hij in dienst van de Rijksuniversiteit Limburg. Gedurende vier jaar was hij werkzaam als wetenschappelijk medewerker van de kapaciteitsgroep Farmakologie waar dit proefschrift tot stand kwam onder leiding van prof. dr. H.A.J. Struyker Boudier.

Vanaf 1 augustus 1983 is hij aangesteld als sekretaris van de kommissie Biologische Gezondheidkunde en gedetacheerd bij de kapaciteitsgroep Humane Biologie..

\section{Publikaties}

Kleinjans J, Kasbergen $C$ en Vervoort-Peters L: Labile hypertension following chronic noradrenaline infusion in conscious rats.

Naun Schmied Arch Pharmacol 316 (suppl): 163, 1981.

Kleinjans $\mathrm{J}$, Kasbergen C, Vervoort-Peters $\mathrm{L}_{\text {, }}$ Smits $\mathrm{J}$ en Struyker Boudier HAJ: Chronic intravenous infusion of noradrenaline produces labile hypertension in consciaus rats. Life Sci 29: 509-514, 1981.

Struyker Boudlier HAJ, Smits JFM en Kleinjans JCS: Drug delivery from implants: experimental and therapeutic uses.

In: Proc int Conl on New Concepts in Drug and Nutrition Delivery Systems (ed RS First). New York, 1981, pp 1-15.

Struyker Boudier HAJ, Kieinjans JCS en Smits JFM: Labile hypertension following chronic intravenous noradrenaline infusion in conscious rats.

In: 8th Int Congress of Pharmacology, Tokyo, 1891, 1981.

Struyker Boudier HAJ, Smits JFM, Evenwel RT en Kleinjans JCS: Alphamethyldopa und das sympathische Nervensystem bei der Hypenonie.

In: Alpha-methyldopa (eds H Kaufman en H Kroneberg), Georg Thieme Veriag, Stuttgart, 1981, pp 35-45. 
Kleinjans J, Smits d en Struyker Boudier $H$ : Chronic intrarenal infusion of low doses of noradrenaline causes hypertension in conscious rats.

hin: Hypertensive mechanisms. The spontaneously hypertensive rat as a model to study human hypertension (eds. Rascher WM, Clough D and Ganten DJ). Stuttgant, 1982, pp 490-494.

Kleinjans $\mathrm{J}$ and Van Essen H.: Eftects of chronic intrarenal noradrenaline infusion on renall function in conscious normotensive rats.

Naun Schmied Arch Pharmacol 319 (suppl): 201, 1982.

Kleinjans JC, Smits JF, Van Essen, H en Struyker Boudier HA: Hemodynamic effects of intrarenal noradrenaline infusion in conscious rats.

Fed Proc 41: 8126, 1982.

Kleinjans $J_{i}$ Kasbergen $C$, Vervoort L en Struyker Boudier $H$ : Effects of chronic captopril application on intrarenally noradrenaline-induced hypertension in conscious rats.

Pharmacol Weekbl Sci Ed 41: 163, 1982.

Smits JF, Kleinjans JC, Kasbergen CM en Struyker Boudier HA: Method for chronic drug administration into the renal artery of the consious unrestrained rat.

Fed Proc 41: 8171, 1982.

Kleinjans JCS, Smits JFM, Kasbergen CM, Vervoort-Peters HTM en Struyker Boudier HAJ: Blood pressure response to chronic low-dose intrarenal noradrenaline infusion in conscious rats.

Clin Sci 65: 111-116, 1983.

Kleinjans JCS, Smits JFM, Vervoort-Peters HTM en Struyker Boudier HAJ: Plasma. norepinephrine levels in relation to chronic intrarenal norepinephrine infusion in conscious rats: effects of captopril.

Prog Neuro-Psychopharmacol Biol Psychol (suppl): 267, 1983.

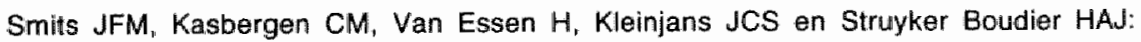
Chronic local infusion into the renal artery of unrestrained rats.

Am J Physiol 244: H304-H307, 1983.

Struyker Boulder HAJ, Smits JFM, Kleinijans JCS en Van Essen H: Hemodynamic actions of diurotic agents.

Clin Exp Hypert A5 (2): 209-223, 1983.

Kleinjans JCS, Smits JFM, Kasbergen CM, Van Essen H en Struyker Boudiler HA.J: Evaluation of renal function during long-term intrarenal norepinephrine infusion in conscious rats.

Fienal Physiol, in press, 1983.

Kleinjans $\mathrm{J}$ en Struyker Boudier $H$ : Variability in anterial pressure and baroreflex sensitivity in noradrenaline-induced hypertension in rats.

Automedica, in press, 1983.

Kleinjans J, Muytjens A en Struyker Boudier H: Variability in blood pressure during noradrenaline-induced hypertension in rats.

Arch Int Physiol Biochem, in press, 1983.

Kleinjans JCS, Smits, JFM, Kasbergen CM en Struyker Boudier HAJ: Body fluid and salt homeostasis during hypertension caused by chronic intrarenal norepinephrine infusion in conscious raits.

J Hypertension, in press, 1983. 